GERSON DOS SANTOS

ESTUDO DE DISPOSITIVOS ORGÂNICOS EMISSORES DE LUZ EMPREGANDO COMPLEXOS DE TERRAS RARAS E DE METAIS DE TRANSIÇÃO 
GERSON DOS SANTOS

\title{
ESTUDO DE DISPOSITIVOS ORGÂNICOS EMISSORES DE LUZ EMPREGANDO COMPLEXOS DE TERRAS RARAS E DE METAIS DE TRANSIÇÃO
}

\begin{abstract}
Tese de Doutorado apresentada à Escola Politécnica da Universidade de São Paulo para obtenção do Título de Doutor em Engenharia Elétrica.
\end{abstract}

São Paulo 
GERSON DOS SANTOS

\title{
ESTUDO DE DISPOSITIVOS ORGÂNICOS EMISSORES DE LUZ EMPREGANDO COMPLEXOS DE TERRAS RARAS E DE METAIS DE TRANSIÇÃO
}

\begin{abstract}
Tese de Doutorado apresentada à Escola Politécnica da Universidade de São Paulo para obtenção do Título de Doutor em Engenharia Elétrica.
\end{abstract}

Área de concentração:

Engenharia Elétrica

Orientador:

Fernando Josepetti Fonseca

São Paulo

2008 
Este exemplar foi revisado e alterado em relação à versão original, sob responsabilidade única do autor e com anuência de seu orientador.

São Paulo, de Setembro de 2008

Assinatura do autor:

Assinatura do orientador:

FICHA CATALOGRÁFICA

Santos, Gerson dos

Estudo de dispositivos orgânicos emissores de luz empregando complexos de terras raras e de metais de transição / G. Santos. -- ed.rev. -- São Paulo, 2008.

$141 \mathrm{p}$.

Tese (Doutorado) - Escola Politécnica da Universidade de São Paulo. Departamento de Engenharia de Sistemas Eletrônicos.

1. Dispositivos Orgânicos Emissores de Luz (OLEDs)

2. Complexos de Terras Raras 3. Complexos de Metais de

Transição 4. Células Eletroquímicas Emissoras de Luz

5. Caracterização eletro-óptica I.Universidade de São Paulo. Escola Politécnica. Departamento de Engenharia de Sistemas Eletrônicos II.t. 
Dedico este trabalho à minha companheira, Marta; aos meus pais, José

e Vera, è minha irmã Paula. 
"Quando olhamos para trás, só nos lembramos das épocas dificeis de nossa vida, nunca dos periodos de tranqüilidade. Os primeiros são luta e, portanto, vida." G. I. Gurdjieff 


\section{AGRADECIMENTOS}

Ao orientador e amigo prof. Fernando Josepetti Fonseca, pela oportunidade, discussões, confiança, transmissão de conhecimento e cooperação, que culminaram na possibilidade de desenvolvimento, com todas as potencialidades, deste trabalho tanto no Brasil como no exterior.

Ao amigo e orientador não oficial prof. Luiz Fernando Ribeiro Pereira pelas incontáveis discussões sobre trabalho e assuntos diversos, atenção e transmissão de conhecimento, hospitalidade em Portugal sem igual e oportunidade de desenvolvimento do trabalho na Universidade de Aveiro - Departamento de Física, que contribuíram de forma fundamental na minha formação profissional e pessoal.

Aos professores Adnei M. Andrade e Ely Dirani pela confiança, incentivo, direcionamento global do grupo GEM e interposições assertivas nos momentos adequados e por suas posições em prol da ciência. Agradecimento redobrado ao prof. Adnei por possibilitar a infra-estrutura necessária à pesquisa de dispositivos eletroluminescentes.

Às professoras Neyde Iha e Leni Ackcelrud pela colaboração científica, discussões, disponibilização de materiais sintetizados nos laboratórios de Química da USP e Federal do Paraná, sem os quais não seria possível a concretização do presente trabalho.

Aos amigos do IQUSP Otávio Patrocínio e Sérgio Mizoguchi por disponibilizar os complexos de Rutênio. Também aos colegas André Polo e Karina pelo complexo de Rênio. Meus agradecimentos aos colegas da química pela confiança, dinamismo e parceria para produção de LECs, que culminaram em ótimas publicações.

Ao amigo Vitor Deichmann da UFPR pela confiança, dinamismo, vontade científica e por ser um grande colaborador através do IMMP desde o início do meu trabalho 
para produção de OLEDs com complexos de Terras Raras. Faço extensão dos meus agradecimentos aos colegas, também da UFPR, Jeferson Jesus, Isabel Grova e Bruno pelos polímeros disponibilizados e que foram frutos de ótimas publicações.

Às colaboradoras do laboratório CICECO de Portugal Profa. Isabel Gonçalves, Susana Braga e Catarina Coelho por confiar no trabalho desenvolvido no Departamento de Física da Universidade de Aveiro e disponibilizar materiais sintetizados.

Ao prof. Roberto Onmori pela transmissão de conhecimento nos primeiros passos na técnica de evaporação térmica de metais na glovebox da Escola Politécnica.

Aos colegas do grupo GEM Emerson Roberto (grande amigo e companheiro de sala e de todos os anos de Doutorado), Helena Gimaiel (sempre dinâmica e com ótimas idéias), Alex Frazatti (Lekinho), Roberto Cavallari (o viajante e conhecedor de muitas línguas), Sérgio Ozaki, John Paul Lima (sempre disposto a ajudar e com muitas idéias), João Cláudio de Brito Santos (grande colaborador e amigo), Alexandre Mantovani Nardes (apesar da distância sempre presente no grupo GEM), Guilherme Braga (Mergulhão), Leonardo Paterno (grande amigo e colaborador), Vitor Zaia, Tunísia (Tutu), Nadja Karolina Leonel Wiziack (Winzip), José Antônio, Camila, Diego Aparecido, Alex Chen e Daniela Diodato pelo companheirismo, discussões e colaboração no trabalho científico do dia-a-dia.

Ao amigo Wilson Simões, pela imensa colaboração, companheirismo, visão científica e prática, além da transmissão de conhecimento e paciência durante meu primeiro período em Aveiro.

Aos alunos da UA, Antônio José (Tozé), Filipe e Tiago (direto da Letônia) pelo auxílio no trabalho científico durante meu segundo período em Aveiro. 
À Marta R. Pinheiro por ser uma verdadeira companheira do dia-a-dia, em quem confio plenamente, pela paciência, atenção, colaboração e dedicação em todos os momentos na minha vida desde que a conheci.

À Valéria R. Pinheiro por sua amizade, pelas diversas conversas, por sua visão inigualável de mundo e paciência.

Aos meus Pais José Manoel e Vera Lúcia e também a minha irmã Paula pela paciência, atenção, ajuda, direcionamento e confiança, que contribuíram de forma fundamental no meu modo de proceder na vida.

Aos técnicos da sala limpa do LME Teresa, Marco, Rita, Cristina, João, Mário e Carlos pelo apoio nas atividades experimentais relacionadas com o Doutorado.

Ao Conselho Nacional de Desenvolvimento Científico e Tecnológico (CNPq) pelo apoio financeiro. (Processo 142164/2004-6)

À Fundação de Apoio a Pesquisa de São Paulo (FAPESP) pela verba para insumos e a possibilidade de implementar a glovebox da EPUSP.

Ao Ministério de Ciência e Tecnologia (MCT) e ao Instituto Multidisciplinar de Materiais Poliméricos (IMMP) por financiar viagens aos congressos e estadias, que são fundamentais aos pesquisadores e também ao progresso científico do país.

Ao Banco Santander e a Fundação da Ciência e Tecnologia (FCT) de Portugal pela complementação financeira durante os períodos em Aveiro.

A todos que contribuíram direta ou indiretamente para a concretização do presente trabalho de Doutorado. 


\section{RESUMO}

Neste trabalho foram projetados, fabricados e caracterizados funcionalmente dispositivos eletroluminescentes empregando complexos de Terras Raras (TR) e de Metais de Transição (MT) tanto como em filmes finos termicamente evaporados quanto formados através da técnica de spin-coating. O estudo foi iniciado com os complexos de TRs (especificamente o complexo de Európio e de Térbio) com filmes termicamente evaporados, com vistas à análise da eficiência externa dos dispositivos em função do ligante principal (CL). Desta análise observou-se que a particular estrutura química do CL resulta em diferenças perceptíveis ao nível da caracterização eletro-óptica (de $0,73 \times 10^{-3}[\mathrm{BTA}]$ para $\left.1,05 \times 10^{-3}[\mathrm{DBM}]\right)$. Dando seqüência à análise de dispositivo com camada emissiva termicamente evaporada, foi realizada a análise do complexo de Térbio com dois tipos de ligante neutro (NL). Com base nos resultados obtidos, neste foco do estudo, observou-se que a configuração estrutural do NL implica em diferenças na eficiência externa (de $0,8 \times 10^{-3}$ [PHEN] para 4,1 $\times 10^{-}$ ${ }^{3}$ [BIPY]) e no comprimento de onda dominante emitido (de $542 \mathrm{~nm}$ [BIPY] para 563 [PHEN]). Ainda explorando os complexos de TRs, foram estudados dispositivos empregando estes dispersos em um polímero com função de matriz, neste caso o polivinilcarbazol (PVK), em filmes formados por spin-coating, os quais apresentaram maior eficiência (de $0,72 \times 10^{-3}$ [evaporado] para $1,24 \times 10^{-3}$ [spincoating]) externa em comparação aos termicamente evaporados. Ainda nesta linha de estudo foi explorada uma nova estrutura de dispositivo empregando filmes automontados, cujos resultados apresentaram uma melhor eficiência externa para três bicamadas de PAni/PEDOT:PSS. Na seqüência, foram empregados os complexos de MT, especificamente de Rutênio e de Rênio, em filmes finos formados por spincoating. Com o primeiro destes, foi avaliada a conseqüência da variação do seu ligante, seus processos de transporte de portadores de carga e os fenômenos relacionados com sua luminescência. Já com o segundo, que foi disperso em PVK em diversas concentrações, foi feita a análise da eficiência externa com a mesma idéia adotada com o complexo de Európio, cujo estudo revelou uma eficiente transferência de energia, descrita pelo mecanismo de Transferência de Carga MetalLigante $\left({ }^{3} \mathrm{MLCT}\right)$. 


\section{ABSTRACT}

This work presents the study of the Rare Earth (RE) and Transition Metals (TM) complexes, as emissive layers of Organic Light-Emitting Devices (OLEDs) designed, built and electro-optically characterized. The thin films were thermally evaporated or spin-coated. This research started with the study of Europium complex changing its central ligand (CL), which showed that its electrical response exhibits external efficiency differences (from $0.73 \times 10^{-3}$ [BTA] to $1.05 \times 10^{-3}$ [DBM]). It was observed that the particular chemical structure of the CL results in significant differences as seen in the electro-optical characterization. Giving continuity to the thermally evaporated device characterization, an analysis was done with the Terbium complexes with two different neutral ligands (NL). It was noticed, in this work, that an NL change in Terbium complex imply in changes in external efficiency (from $0.8 \times 10^{-3}[\mathrm{PHEN}]$ to $4.1 \times 10^{-3}$ [BIPY]) and in the emitted dominant wavelength (from $542 \mathrm{~nm}$ [BIPY] to $563 \mathrm{~nm}$ [PHEN]). Following the study using RE complex, we used it as a dye dispersed in polyvinylcarbazole (PVK) matrix, in a spin-coated deposited thin-film, which results showed a better external efficiency in comparison with thermally evaporated thin-films (from $0.72 \times 10^{-3}$ [thermal evaporation] to $1.24 \times 10^{-3}$ [spin-coating]). Besides, it was studied a new structure of electroluminescent device with thin-film Self-Assembled deposition, which results showed a better external efficiency for three bilayers of PAni/PEDOT:PSS. In the sequence, TM complexes, namely Ruthenium and Rhenium, were studied using spincoated thin-films. With the first of them, the implications of different ligands (bipyridyne and phenanthroline) were evaluated aiming the charge carrier transport and the luminescence related phenomena. The Rhenium complex was dispersed as a dye in the PVK, using the same approach as that used to study the Europium complex showing a very efficient energy transfer process, described in literature as the Metal-Ligand Charge Transfer $\left({ }^{3}\right.$ MLCT) mechanism. 


\section{Lista de Figuras}

FIGURA 1 - NíVEIS DE ENERGIA DO ÍON $\mathrm{EU}^{3+}$ E DO TB $^{3+}$, CUJAS TRANSIÇÕES SÃO AS OBSERVADAS NO ESPECTRO A PARTIR DOS ÍONS TR NO ESTADO TRIVALENTE

FIGURA 2 - DIAGRAMA DE JABLONSKY SIMPLIFICADO INDICANDO A ABSORÇÃO DE ENERGIA NA MATRIZ POLIMÉRICA OU ORGÂNICA E AS POSSIBILIDADES DE RELAXAÇÃO POR MEIO DA FOSFORESCÊNCIA, E A EMISSÃO LUMINOSA DO ÍON TERRA RARA TRIVALENTE. O GRÁFICO AINDA APRESENTA O CRUZAMENTO INTERSISTEMAS (CIS) E A TRANSFERÊNCIA DE ENERGIA (TE). AS SETAS COM LINHAS CHEIAS REPRESENTAM DECAIMENTOS NÃO RADIATIVOS. A ABSORÇÃO DE ENERGIA PODER OCORRER POR MEIO DE FÓTONS DE ALTA ENERGIA OU PELA APLICAÇÃO DE UM POTENCIAL ELÉTRICO. 12

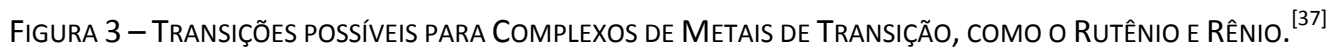
16

FIGURA 4 - DIAGRAMA ESQUEMÁTICO DOS PROCESSOS DE LUMINESCÊNCIA ORIUNDOS DOS ESTADOS ${ }^{3}$ MLCT NO COMPLEXO DE RUTÊNIO. ${ }^{[37]}$ 18

FIGURA 5 - ESTRUTURA QUÍMICA DO TRANS-POLIACETILENO. ${ }^{[48]}$

FiguRA 6 - ESQUEMAS DE A) DUPLA LIGAÇÃO DE ÁTOMOS DE CARBONO SP2 HIBRIDIZADA, QUE CONSISTE EM UMA LIGAÇÃO $\Sigma$ E OUTRA $\Pi$, E B) SISTEMA $\Pi$ DELOCALIZADO EM UMA MOLÉCULA DE BENZENo (PARA ILUSTRAÇÃO)..... 23

FIGURA 7 - DIAGRAMA DE ENERGIA PARA AS ESTRUTURAS DE FILMES FINOS EM DISPOSITIVOS ORGÂNICOS EMISSORES DE LUZ, SENDO A) UMA EMISSÃO CONTROLADA PELA DIFERENÇA HOMO-LUMO DO POLÍMERO ELETROLUMINESCENTE (PLED) E B) POR UM COMPLEXO DE TR DISPERSO EM UMA MATRIZ POLIMÉRICA (OLED).

FIGURA 8 - FUnÇÃO RESPOSTA FOTÓPICA (V[ $\lambda]$ ) COM BASE NO PADRÃO CIE 1924 COM PRECISÃO DE $\quad 1$ NM. ..... 36

FIGURA 9 - ESPALHAMENTO CIRCULAR REPRESENTATIVO DO ESPALHAMENTO DA LUZ. 37

FIgURA 10 - DiagRAMA DE CROMATICIDADE PADRÃO CIE 1931 TíPICO COM A IDENTIFICAÇÃO DOS COMPRIMENTOS E

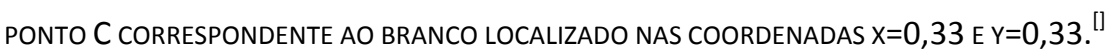

FIGURA 11 - OBTENÇÃO DO PARÂMETRO COMPRIMENTO DE ONDA DOMINANTE E PUREZA DE COR. ${ }^{[]}$.....

FIGURA 12 - LEIAUTE DAS MÁSCARAS UTILIZADAS PARA FABRICAÇÃO DOS DISPOSITIVOS COM BASE NA INFRA-ESTRUTURA DA EPUSP, SENDO A MÁSCARA AZUL PARA A FORMAÇÃO DO CATOdO (EVAPORAÇÃO DO METAL), VERMELHA PARA 
A DEFINIÇÃO DO TCO E A SOBREPOSIÇÃO DE MÁSCARAS PARA VISUALIZAÇÃO PARA ÁREA GEOMÉTRICA ATIVA DE CADA DISPOSITIVO FORMADO. O TRAÇO VERDE QUE IDENTIFICA O DIMENSIONAMENTO DO ENCAPSULAMENTO. . 45

FIGURA 13 - LEIAUTE DAS MÁSCARAS UTILIZADAS PARA A FABRICAÇÃO DE DISPOSITIVOS ELETROLUMINESCENTES NA INFRA-ESTRUTURA DA UA, SENDO A MÁSCARA AZUL PARA A FORMAÇÃO DO CATODO (EVAPORAÇÃO DO METAL), VERMELHA PARA A DEFINIÇÃO DO TCO E A SOBREPOSIÇÃO DE MÁSCARAS PARA VISUALIZAÇÃO PARA ÁREA GEOMÉTRICA ATIVA DE CADA DISPOSITIVO FORMADO. O TRAÇO VERDE QUE IDENTIFICA O DIMENSIONAMENTO DO ENCAPSULAMENTO

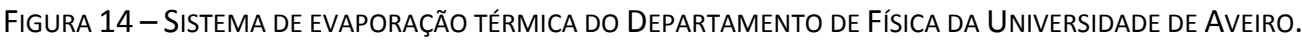
48

Figura 15 - Sistema GloveBox da Escola PolitéCnica da Universidade de SÃo Paulo. 49

FIGURA 16 - DIAGRAMA ESQUEMÁTICO DO EQUIPAMENTO SPIN COATER UTILIZADO PARA FORMAÇÃO DOS FILMES FINOS

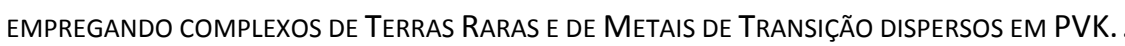
50

FIGURA 17 - DiagRAMA REPRESENTATIVO DO CICLO PARA FORMAÇÃO DE CADA BICAMADA NO PROCESSO DE AUTOMONTAGEM

FIGURA 18 - ESBOÇO DE FUNCIONAMENTO DA TÉCNICA DE PERFILOMETRIA. 53

FIGURA 19 - DIAGRAMA ESQUEMÁTICO DO DISPOSITIVO ELETROLUMINESCENTE COM SEUS FILMES FINOS E A CONEXÃO COM O VIDRO DE ENCAPSULAMENTO FEITO COM EPÓXI.

FIGURA 20 - DIAGRAMA ESQUEMÁTICO DA MONTAGEM CARACTERIZAÇÃO ELETRO-ÓPTICA DOS DISPOSITIVOS ELETROLUMINESCENTES, COM BASE NA INFRA-ESTRUTURA A) EPUSP E B) DF-UA. 55

FIGURA 21 - DIAGRAMA ESQUEMÁTICO DA ESTRUTURA UTILIZADA PARA O ESTUDO DO COMPLEXO DE EURÓPIO COM DIFERENTES LIGANTES PRINCIPAIS COM INDICAÇÃO DA ESTRUTURA QUÍMICA DOS ORGÂNICOS EMPREGADOS PARA TRANSPORTE DE LACUNAS E ELÉTRONS.

FIGURA 22 - DETALHE DA CÂMARA DE EVAPORAÇÃO DA UA COM OS DIFERENTES TIPOS DE CADINHOS EMPREGADOS PARA A FABRICAÇÃO DOS DISPOSITIVOS ELETROLUMINESCENTES...... 59

FIGURA 23 - DiAgRAMA ESQUEMÁTICO DA ESTRUTURA UTILIZADA PARA O ESTUDO DO COMPLEXO DE TÉRBIO VARIANDOSE O LIGANTE NEUTRAL COM INDICAÇÃO DA ESTRUTURA QUÍMICA DOS ORGÂNICOS EMPREGADOS PARA TRANSPORTE DE LACUNAS E ELÉTRONS. 62

FIGURA 24 - DIAGRAMA ESQUEMÁTICO DA ESTRUTURA EMPREGADA PARA ESTUDO DO COMPLEXO DE EURÓPIO DISPERSO EM PVK. 64 
FIGURA 25 - DIAGRAMA ESQUEMÁTICO DA ESTRUTURA EMPREGADA PARA ESTUDO DO COMPLEXO DE TÉRBIO DISPERSO EM PVK. 66

FIGURA 26 - DiAGRAMA ESQUEMÁTICO DA ESTRUTURA PARA AVALIAR O DESEMPENHO DO COMPLEXO DE EURÓPIO COM VARIAÇÃO DO NÚMERO DE BICAMADAS PANI/PEDOT:PSS E AS ESTRUTURAS QUÍMICAS DOS ORGÂNICOS EMPREGADOS. 68

FIGURA 27 - DIAGRAMA ESQUEMÁTICO DA ESTRUTURA SINGLE LAYER EMPREGADA PARA O ESTUDO DO COMPLEXO DE RutêNIO VARIANDO-SE O LIGANTE, SENDO A ESTRUTURA QUímICA A) PolimeTILMETACRILÁTO, B) COMPLEXo $\left.\mathrm{RU}(\mathrm{BPY})_{3}\left(\mathrm{PF}_{6}\right)_{2} \mathrm{EC}\right)$ COMPLEXO RU $\left(\mathrm{PH}_{2} \mathrm{PHEN}\right)_{3}\left(\mathrm{PF}_{6}\right)_{2}$. 70

FIGURA 28 - DIAGRAMA ESQUEMÁTICO DA ESTRUTURA EMPREGADA PARA O ESTUDO DA VARIAÇÃO DA CONCENTRAÇÃO DE COMPLEXO DE RÊNIO DISPERSO NO PVK

FIGURA 29 - ESPECTRO DE FOTOLUMINESCÊNCIA PARA O COMPLEXO EU(TTA) ${ }_{3}$ BIPY E SUAS RESPECTIVAS TRANSIÇÕES EM $300 \mathrm{~K}$. 74

FIGURA 30 - CURVA J-V PARA OS DISPOSITIVOS EMPREGANDO COMPLEXO DE EURÓPIO COM DIFERENTES LIGANTES PRINCIPAIS, COM ESTRUTURA ITO/TPD/EU(CL) ${ }_{3}$ BIPY/ALQ3/AL

FIGURA 31 - ESPECTRO DE ELETROLUMINESCÊNCIA PARA ODISPOSITIVO EMPREGANDO O COMPLEXO EU(TTA) ${ }_{3}$ BIPY COM A APLICAÇÃO DE 25 VOLTS. 76

FIGURA 32 - DIAGRAMA DE CROMATICIDADE COM AS COORDENADAS RELATIVAS AO DISPOSITIVO EMPREGANDO O COMPLEXO EU(TTA) ${ }_{3}$ BIPY.

FIGURA 33 - DIAGRAMA DE ENERGIA PARA AS ESTRUTURAS FABRICADAS, PARA AVALIAR DIFERENTES LIGANTES PRINCIPAIS NO COMPLEXO DE EURÓPIO, CUJOS VALORES REPRESENTAM PARA O FILME EMISSIVO A FAIXA DE VALORES TíPICOS.

FIGURA 34 - REGISTRO FOTOGRÁFICO DOS DISPOSITIVOS ELETROLUMINESCENTES FABRICADOS EMPREGANDO OS COMPLEXOS DE EURÓPIO: A) Eu(DBM) ${ }_{3}$ BIPY, B) Eu(TTA $)_{3}$ BIPY, C) EU(BTA $)_{3}$ BIPY E D) Eu(NTA $)_{3}$ BIPY. 80

FIGURA 35 - ESPECTRO DE FOTOLUMINESCÊNCIA PARA O COMPLEXO TB(ACAC) 3 BIPY.

FIGURA 36 - CURVAS J-V PARA O COMPLEXO DE TÉRBIO EMPREGANDO OS LIGANTES NEUTROS BIPIRIDINA E FENANTROLINA.

FIGURA 37 - POTÊNCIA ÓPTICA PARA O COMPLEXO DE TÉRBIO EMPREGANDO OS LIGANTES NEUTROS BIPIRIDINA E FENANTROLINA 
FIGURA 38 - ESPECTRO DE ELETROLUMINESCÊNCIA NORMALIZADO COM AS RESPOSTAS DOS DISPOSITIVOS EMPREGANDO COMPLEXO DE TÉRBIO COM OS LIGANTES BIPIRIDINA E FENANTROLINA.

FIGURA 39 - COORDENADAS DE CROMATICIDADE PARA OS DISPOSITIVOS EMPREGANDO COMPLEXO DE TÉRBIO COM DIFERENTES LIGANTES NEUTROS

FIGURA 40 - DIAGRAMA DE ENERGIA PARA AS ESTRUTURAS FABRICADAS PARA AVALIAR DIFERENTES LIGANTES NEUTROS NO COMPLEXO DE TÉRBIO. 86

FIGURA 41 - REGISTRO FOTOGRÁFICO DOS DISPOSITIVOS ELETROLUMINESCENTES FABRICADOS EMPREGANDO OS COMPLEXOS DE TÉRBIO: A) TB(ACAC $)_{3}$ BIPY E B) TB(ACAC $)_{3}$ PHEN. 88

FIGURA 42 - ESPECTROS DE ABSORÇÃO E EMISSÃO PARA O COMPLEXO DE EURÓPIO [EU(TTA) ${ }_{3}$ BIPY] E PVK, RESPECTIVAMENTE. MATERIAIS E SOLUÇÃO DE CLOROFÓRMIO PARA AS MEDIÇÕES.

FIGURA 43 - CURVA DENSIDADE DE CORRENTE E POTÊNCIA ÓPTICA EM FUNÇÃO DA TENSÃO APLICADA. 90

Figura 44 - CURVA LOG J VS. LOG V COM BASE NOS DAdOS DA FIGURA 43 PARA EXTRAÇÃO DO FATOR $M$. 91

FIGURA 45 - ESPECTRO DE ELETROLUMINESCÊNCIA DA AMOSTRA EMPREGANDO 5\% DO COMPLEXO EU(TTA) ${ }_{3}$ BIPY DISPERSO EM PVK, INSERIDO NA ESTRUTURA ITO/PEDOT:PSS/PVK:5\% EU(TTA) 3 BIPY/B-PBD/ALUMÍNIO. INSERIDO NA CURVA CONSTA A CONTRIBUIÇÃO DA BANDA DO PVK NA RESPOSTA DO DISPOSITIVO.

FIGURA 46 - DIAGRAMA DE CROMATICIDADE COM AS COORDENADAS RELATIVAS AO DISPOSITIVO EMPREGANDO O COMPLEXO EU(TTA) ${ }_{3}$ BIPY DISPERSO EM PVK.

FIgURA 47 - DiAgRAMA DE ENERGIA PARA A ESTRUTURA FABRICADA PARA ANÁLISE DO COMPLEXO DE EURÓPIO -

EU(TTA $)_{3}$ BIPY - DISPERSO NO PVK. 94

FIGURA 48 - REGISTRO FOTOGRÁFICO DA AMOSTRA A) EMPREGANDO 5\% DO COMPLEXO EU(TTA) ${ }_{3}$ BIPY DISPERSO EM PVK E B) SOMENTE FILME DO PVK SEM COMPLEXO DE EURÓPIO. 95

FIGURA 49 - ESPECTROS DE ELETROLUMINESCÊNCIA DA ESTRUTURA

ITO/PEDOT:PSS/PVK+5\%TB(ACAC)3BIPY/ETL/ALUMÍNIO, NA QUAL VARIOU-SE O ETL UTILIZANDO-SE O $\mathrm{ALQ}_{3}$ E B-PBD, RESPECTIVAMENTE. AdICIONALMENTE NESTE GRÁFICO FOI ADICIONADO O ESPECTRO DE ELETROLUMINESCÊNCIA DE UMA ESTRUTURA, CUJA EMISSÃO PERTENCE PREFERENCIALMENTE AO PVK PARA FINS DE COMPARAÇÃO. 97 
FIGURA 50 - COORDENADAS DE CROMATICIDADE COM OS INDICATIVOS NO DIAGRAMA DAS ESTRUTURAS EMPREGANDO O COMPLEXO DE TÉRBIO DISPERSO EM PVK EMPREGANDO COMO ETLS OS MATERIAIS ORGÂNICOS B-PBD E ALQ3, RESPECTIVAMENTE.

FIGURA 51 - REGISTRO FOTOGRÁFICO DAS AMOSTRAS EMPREGANDO COMPLEXO DE TÉRBIO [TB(ACAC) ${ }_{3}$ BIPY] DISPERSO EM PVK EMPREGANDO COMO ETL A) BUTIL-PBD E B) ALQ 99

FIGURA 52 - ESPECTROS DE EXCITAÇÃO E EMISSÃO FOTOLUMINESCENTE DO TB(ACAC)3PHEN E DA FOTOLUMINESCÊNCIA DO PVK. 100

FIGURA 53 - CURVA J-V PARA OS DISPOSITIVOS FABRICADOS EMPREGANDO O COMPLEXO DE EURÓPIO, EM CUJA ARQUITETURA VARIOU-SE O NÚMERO DE BICAMADAS PANI/PEDOT:PSS E TENDO-SE POR REFERÊNCIA A ESTRUTURA COM FILME DE PEDOT:PSS POR SPIN-COATING.

FIGURA 54 - ESPECTRO DE ELETROLUMINESCÊNCIA PARA OS DISPOSITIVOS EMPREGANDO PEDOT:PSS FORMADO POR SPIN-COATING, SEM HTL E COM AS BICAMADAS AUTOMONTADAS PANI/PEDOT:PSS 105

FIGURA 55 - DIAGRAMA DE CROMATICIDADE COM AS COORDENADAS OBTIDAS PARA A AMOSTRA SEM HTL, COM FILME DE PEDOT:PSS E COM BICAMADAS AUTOMONTADAS PANI/PEDOT:PSS. 106

FIGURA 56 - DiAgRAMA DE ENERGIA PARA A ESTRUTURA FABRICADA PARA ANÁLISE DO COMPLEXO DE EURÓPIO -

EU(TTA $)_{3}$ BIPY - DISPERSO NO PVK VARIANDO-SE O NÚMERO DE BICAMADAS. 107

FIGURA 57 - REGISTRO FOTOGRÁFICO A-C) AMOSTRA PSC COM 18, 22 E 28 VOLTS; D) AMOSTRA COM 3 BICAMADAS.

FIGURA 58 - ESPECTROS DE FOTOLUMINESCÊNCIA DOS COMPLEXOS $\left[\mathrm{RU}(\mathrm{BPY})_{3}\right]^{2+}$ E $\left[\mathrm{RU}\left(\mathrm{PH}_{2} \mathrm{PHEN}\right)_{3}\right]^{2+}$ EM PMMA.. 110

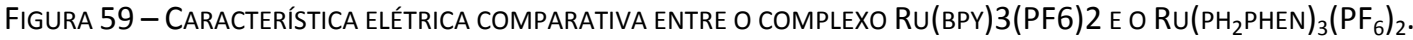

FIGURA 60 - ESPECTROS DE ELETROLUMINESCÊNCIA DOS DISPOSITIVOS EMPREGANDO OS COMPLEXOS $\left[R U(B P Y)_{3}\left(P_{6}\right)_{2}\right]$ E $\left[\mathrm{RU}\left(\mathrm{PH}_{2} \mathrm{PHEN}\right)_{3}\left(\mathrm{PF}_{6}\right)_{2}\right]$ EM CONJUNTO COM O PMMA INSERIDOS NA ESTRUTURA ITO/COMPLEXO DE RUTÊNIO/ALUMÍNIO.

FIGURA 61 - DIAGRAMA DE CROMATICIDADE COM AS COORDENADAS RELATIVAS AO DISPOSITIVO EMPREGANDO O COMPLEXO DE RUTÊNIO.

FIGURA 62 - DIAGRAMA DE ENERGIA PARA A ESTRUTURA EMPREGANDO O COMPLEXO DE RUTÊNIO VARIANDO-SE O LIGANTE. 
FIGURA 63 - FOTOS DOS DISPOSITIVOS ELETROLUMINESCENTES FABRICADOS EMPREGANDO O COMPLEXO DE RUTÊNIO COM A) LIGANTE BIPIRIDINA E B) DIFENILFENANTROLINA

FIGURA 64 - DENSIDADE DE CORRENTE EM FUNÇÃO DA TENSÃO PARA DIVERSAS CONCENTRAÇÕES DO COMPLEXO DE RÊNIO DISPERSO NO POLÍMERO PVK NA ESTRUTURA ITO/PEDOT:PSS/X\% COMPLEXO DE RÊNIO/B-PBD/AL. O GRÁFICO ANEXO APRESENTA O DETALHE DOS DADOS PARA AS CONCENTRAÇÕES DE 0, 3 E 5\% DE COMPLEXO DE RÊNIO, QUE POR SUA VEZ TAMBÉM APRESENTAM COMPORTAMENTO RETIFICADOR.

FIGURA 65 - VARIAÇÃO DA LUMINÂNCIA DOS DISPOSITIVOS FABRICADOS EM FUNÇÃO DA CONCENTRAÇÃO DO COMPLEXO DE RÊNIO.

FIGURA 66 - ESPECTROS DE ELETROLUMINESCÊNCIA DOS DISPOSITIVOS FABRICADOS VARIANDO-SE A CONCENTRAÇÃO DO COMPLEXO DE RÊNIO

FIGURA 67 - DIAGRAMA DE CROMATICIDADE COM AS INDICAÇÕES DAS COORDENADAS DE COR PARA OS DISPOSITIVOS FABRICADOS VARIANDO-SE A CONCENTRAÇÃO DE COMPLEXO DE RÊNIO.

FIGURA 68 - DIAGRAMA DE ENERGIA PARA A ESTRUTURA EMPREGANDO O COMPLEXO DE RÊNIO DISPERSO EM PVK EM DIVERSAS CONCENTRAÇÕES.

FIGURA 69 - REGISTRO FOTOGRÁFICO DAS AMOSTRAS FABRICADAS VARIANDO-SE O COMPLEXO DE RÊNIO, PARTINDO-SE DO AZUL (SOMENTE PVK) (A), PASSANDO PELA REGIÃo DE EMISSÃo BRANCA (B - E) (MISTURA DO AMARELO dO COMPLEXO DE RÊNIO E A BANDA DE EMISSÃO DO PVK NO AZUL) E, POR FIM, EMISSÃO AMARELA CARACTERÍSTICA DO COMPLEXO DE RÊNIO (F). 


\section{Lista de Tabelas}

TABELA 1 - FóRMULAS ESTRUTURAIS, NOMENCLATURA, ABREVIAÇÃO DO NOME E ESTADO TRIPLETO DE ALGUNS $\beta$ -

DICETONATOS.

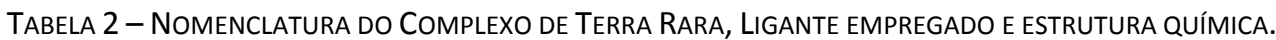
57

TABELA 3 - Nomenclatura do CompleXo de TERRA RARA, LigANTE EMPREgAdo E ESTRUTURA QuímicA.

TABELA 4 - CORRELAÇÃO ENTRE O DISPOSITIVO FABRICADO E O NÚMERO DE BICAMADAS. 67

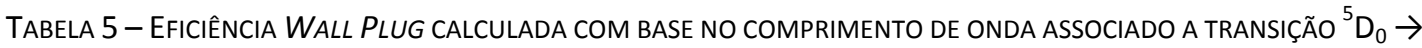
${ }^{7} F_{2}$ 78

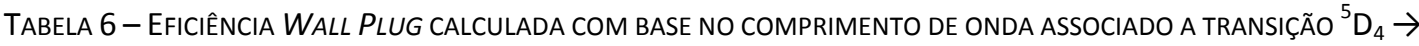

${ }^{7} F_{5}$. 86

TABELA 7 - FATOR M, LUMINÂNCIA E EFICÁCIA LUMINOSA PARA DISPOSITIVOS EMPREGANDO COMPLEXO DE EURÓPIO COM VARIAÇÃO DO NÚMERO DE BICAMADAS PANI/PEDOT:PSS.

TABELA 8 - COORDENADAS DE CROMATICIDADE, COMPRIMENTO DE ONDA DOMINANTE, PUREZA DE COR E EFICIÊNCIA QUÂNTICA EXTERNA PARA OS DISPOSITIVOS EMPREGANDO COMPLEXO DE RÊNIO EM DIVERSAS CONCENTRAÇÕES DISPERSO EM PVK.

TABELA 9 - FATOR M PARA OS DISPOSITIVOS EMPREGANDO COMPLEXO DE RÊNIO EM DIVERSAS CONCENTRAÇÕES DISPERSO EM PVK.

TABELA 10 - RAZÃO ENTRE AS ÁREAS INTEGRADAS DAS BANDAS DE EMISSÃO DO PVK E DO COMPLEXO DE RÊNIO. 


\section{Lista de Abreviaturas}

$A$ - área geométrica

$A^{* *}$ - Constante de Richardson

ACAC - Acetilacetonato

$\mathrm{Alq}_{3}-\operatorname{tris}(8$-hidroxiquinolina alumínio)

bipy - Bipiridina

b-PBD - 2-(4-bifenil)-5-(4-tert-butilfenil)-1,3,4 Oxadiazol

BPP - bicamadas PAni/PEDOT:PSS automontadas

BTA - Benzoiltrifluoroacetonato

$c$ - Velocidade da luz

CIS - Cruzamento intersistemas

CIE - Commission internacionale de L'écrairage - Comissão Internacional de

Iluminação

$\mathrm{CL}$ - Central ligand - Ligante principal

DBM - Dibelzoilmetanato

DFUA - Departamento de Física da Universidade de Aveiro

$E$ - Campo elétrico

EL - Eletroluminescência

EML - Emissive Layer - camada emissiva

EPUSP - Escola Politécnica da Universidade de São Paulo

EQE - Eficiência quântica Externa

ETL - Electron Transport Layer - camada transportadora de elétrons

FWHM - Full Width at Half Maximum - Largura a meia-altura 
$h$ - Constante de Planck

HOMO - Highest Occupied Molecular Orbital - Mais alto orbital molecular ocupado

HTL - Hole Transport Layer - camada transportadora de lacunas

$I$ - Corrente elétrica

$i$ - Intensidade luminosa

ITO - Indium Tin Oxide - Óxido de Indio-Estanho

$J$ - Densidade de corrente elétrica

$L$ - Luminância

LEC - Light Electrochemical Cell - Célula Eletroquímica emissora de Luz

LEP - Light emitting polymer - Polímero emissor de luz

LUMO - Lowest Unoccupied Molecular Orbital - Mais baixo orbital molecular

MEH-PPV - Poli[2-metóxi, 5-(2etil-hexiloxi)-p-fenilenovinileno]

MLCT - Metal-Ligand Charge Tranfer - Transferência de portadores de Carga Metal-Ligante

MT - Metal de Transição

$\mathrm{N}_{\mathrm{c}}$ - Densidade de portadores de carga

$\mathrm{N}_{\mathrm{F}}-$ Número de fótons gerados

NL - Neutral ligand - Ligante neutro

$\mathrm{N}_{\mathrm{PC}}$ - Número de portadores de carga na unidade de tempo

NTA - Naftalotrifluoroacetonato

OLED - Organic Light-Emitting Device - Dispositivo orgânico emissor de luz PAni - Polianilina 
PEDOT:PSS - Polietilenodioxitiofeno dopado com poliestireno sulfonado

$\mathrm{PF}_{6}-$ Hexafluorofosfato

ph2phen - Difenilfenantrolina

PL - Fotoluminescência

PLED - Polimeric Light-Emitting Device - Dispositivo polimérico emissor de luz PMMA - Polimetilmetacrilato

PPV - Poli(p-fenilenovinileno)

PSC - Filme de PEDOT:PSS por spin-coating

PVK - Polivinilcarbazol

$R_{S}-$ Resistência série

SCLC - Space charge limited current - Limitação de corrente por carga espacial

SHTL - Amostra sem HTL

$T$ - Temperatura em Kelvin

TCL - Trapped limited current - Limitação de corrente por armadilhamento de portadores de carga

TCO - Transparent Conductor Oxide - Óxido Transparente Condutor

TE - Transferência de energia

TPD - N,N'-bis(3-metilfenil)-N,N'-difenilbenzidina

TR - Terra Rara

TTA - Tenoiltrifluoroacetonato

$V$ - Potencial elétrico

$V(\lambda)$ - Função resposta fotópica

$V_{o n}$ - Tensão de operação 


\section{Lista de Símbolos}

$d \Omega$ - Valor infinitesimal da variação do ângulo de emissão

$\varepsilon$ - Permissividade

$\phi_{B}-$ Altura da barreira

$\Phi_{\text {tot }}-$ Fluxo total luminosa

$\eta$ - Fator de idealidade

$\eta_{L}-$ Eficácia luminosa

$\eta_{P}-$ Eficiência de potência luminosa

$\eta_{W / W}-$ Eficiência de potência ou Wall Plug

$\varphi$ - Ângulo azimutal relativo a emissão Lambertiana

$\kappa$ - Constante de Boltzmann

$\lambda$ - Comprimento de onda

$\lambda_{D}$ - Comprimento de onda dominante

$\mu_{\mathrm{eff}}-$ Mobilidade efetiva

$v$ - Freqüência

$\theta$ - Ângulo polar relativo a emissão Lambertiana 


\section{RESUMO}

ABSTRACT

Lista de Figuras

Lista de Tabelas

Lista de Abreviaturas

Lista de Símbolos

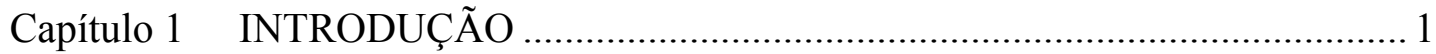

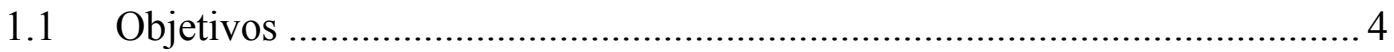

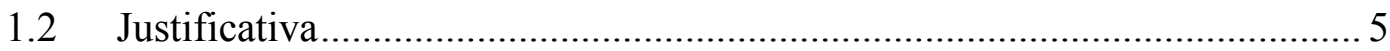

Capítulo 2 FUNDAMENTOS TEÓRICOS …................................................. 7

2.1 Fundamentos teóricos sobre complexos de Terras Raras (TR) ................... 7

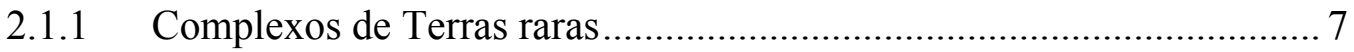

2.1.2 Mecanismos de transferência de energia Föster e Dexter...................... 9

2.1.3 Principais ligantes e o Efeito Antena ................................................ 9

2.1.4 Estado da arte - OLEDs com Complexos de Terras Raras .................. 14

2.2 Fundamentos teóricos sobre complexos de Metais de Transição (MT) ...... 15

2.2.1 Mecanismo de Transferência de Carga Metal-Ligante (MLCT) ......... 15

2.2.2 Propriedades ópticas para os complexos de Rênio e de Rutênio ......... 16

2.2.3 Estado da arte - Dispositivos eletroluminescentes com Metais de

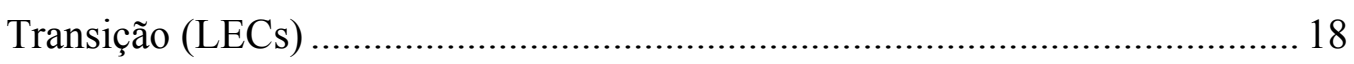


2.3.1 Processos de injeção e transporte de portadores de carga em materiais orgânicos semicondutores

2.4 Eficiência externa para dispositivos eletroluminescentes (definições gerais) 33

2.4.1 Eficiência de Potência ou Wall Plug $\left(\eta_{W W}\right)$

2.4.2 Eficiência de Potência Luminosa $\left(\eta_{P}\right)$ 35

2.4.3 Eficácia luminosa $\left(\eta_{L}\right)$ 37

2.4.4 Eficiência Quântica Externa $\left(\eta_{E Q E}\right)$ 39

2.5 Coordenadas de cromaticidade. 40

Capítulo 3 MATERIAIS E MÉTODOS

3.1.1 Leiaute das máscaras para definição do ITO e do Alumínio . 44

3.1.2 Limpeza superficial do TCO

3.1.3 Processo de formação de filmes finos

3.1.4 Medições de espessuras de filmes depositados por Spin-coating e crescidos por evaporação térmica (Profilômetria) .52

3.1.5 Encapsulamento 54

3.1.6 Caracterização funcional elétrica e óptica. 55

3.1.7 Metodologia empregada para a fabricação dos dispositivos eletroluminescentes. 56 
4.1 Dispositivos com complexos de Terras Raras

4.1.1 Complexo de Európio termicamente evaporado com variação do Ligante principal

4.1.2 Complexo de Térbio com variação do ligante neutro .81

4.1.3 Complexo de Európio disperso em PVK .88

4.1.4 Complexo de Térbio disperso em PVK 96

4.1.5 Complexo de Európio disperso em PVK variando-se o número de bicamadas formadas por automontagem (PAni/PEDOT:PSS) 101

4.2 Dispositivos com complexos de Metais de Transição 110

4.2.1 Complexo de Rutênio com variação do ligante 110

4.2.2 Complexo de Rênio em diversas concentrações disperso em PVK... 117

Capítulo 5 CONCLUSÕES E PERSPECTIVAS 129

APÊNDICE A: LISTA DE PUBLICAÇÕES EM PERIÓDICOS 133

APÊNDICE B: LISTA DE PUBLICAÇÕES EM ANAIS DE CONFERÊNCIAS INTERNACIONAIS 


\section{Capítulo 1 INTRODUÇÃO}

A partir da descoberta de uma classe de polímeros conjugados na década de $90 \mathrm{com}$ comportamento semicondutor (com condutividade na ordem de $10^{-5}{\mathrm{~S} . \mathrm{cm}^{-1}}^{[1,2]} \mathrm{e}$ com possibilidade de fotoluminescência (PL) e eletroluminescência (EL), houve enorme interesse por parte da comunidade científica e industrial para aplicação de tais materiais para a obtenção de dispositivos eletroluminescentes em diversas aplicações, entre elas para mostradores de informação (Displays) ${ }^{* \dagger}$ em telas com espessuras reduzidas ${ }^{\dagger}$ de grandes dimensões ou mesmo em celulares, dispositivos opto-eletrônicos e também iluminação ambiente. Nestes materiais orgânicos, o comportamento equivalente a um semicondutor está associado ao orbital molecular $\pi$ delocalizado ao longo da cadeia. Desta forma, quando o material é submetido a um dado potencial elétrico os portadores de carga ocasionam estados excitados, através dos quais pode haver decaimento radiativo, seguido da emissão de um comprimento de onda dentro da região do visível ou fora dela, podendo abranger o ultravioleta ou mesmo o infravermelho, conforme os níveis HOMO (maior orbital molecular ocupado) e LUMO (menor orbital molecular desocupado) do material. A pesquisa em dispositivos emissores de luz orgânicos e poliméricos (Organic/Polimeric LightEmitting Devices - OLEDs e PLEDs) foi iniciada no inicio dos anos 90 por um grupo

* http://www.universaldisplay.com/

${ }^{\dagger}$ http://www.cdtltd.co.uk/

${ }^{\ddagger}$ http://www.samsungsdi.co.kr/contents/en/product/oled/oled.html 
de Cambridge ${ }^{[3,4]} \mathrm{O}$ desenvolvimento da tecnologia de OLEDs é alternativa a dos Cristais líquidos (Liquid Crystal Displays - LCDs), ${ }^{[5]}$ porém possui vantagens como maior ângulo de visão, elevada luminância, possibilidade de flexibilidade e não necessita de retroiluminação. ${ }^{[6]}$

Os primeiros polímeros luminescentes despertaram grande interesse voltado às aplicações comerciais, porém através da regra de spin demonstrou-se que estes possuem limitação teórica na eficiência quântica interna de $25 \%{ }^{\left[{ }^{[7]}\right.}$ Com base neste fato, a partir de 1998 pesquisadores passaram a empregar em arquiteturas de dispositivos, além de polímeros luminescentes (LEPs) também corantes (dyes) dentro de matrizes poliméricas (host) ou mesmo formação de filmes de complexos de Terras Raras (Rare Earth - TR) e Metais de transição (MT). ${ }^{[8]}$ Tanto na forma de filmes finos, termicamente evaporados, como através destes materiais dispersos dentro de uma matriz polimérica; estes complexos ultrapassam o limite teórico devido ao fato de utilizarem os estados excitados singletos e tripletos, podendo alcançar valores de eficiência quântica interna próximo de $100 \%{ }^{[7]}$

A pesquisa de OLEDs, especificamente dispositivos que empregam complexos de TR (elementos da série dos Lantanídeos, bloco $f$ ), ${ }^{[9]}$ é de grande interesse em aplicações comerciais, pois sua resposta de luminescência apresenta espectros com largura a meia-altura (Full Width at Half Maximum - FWHM $)^{[10]}$ de unidades ou mesmo dezenas de nanômetros, cuja precisão no comprimento de onda é relacionado na literatura como "pureza de cor". ${ }^{[1]}$ Dentre os íons mais estudados, com emissão 
no visível, destacam-se o Európio (vermelho) ${ }^{[12]}$ e o Térbio (verde). ${ }^{[13]}$ Para a aplicação em dispositivos eletroluminescentes são feitas sínteses químicas, cujo material resultante é o complexo de TR com o íon propriamente dito em conjunto com ligantes orgânicos. Os ligantes têm por função de transferir a energia para os centros emissores (íons terras raras). Apesar dos complexos de TR apresentarem elevada eficiência quântica interna ${ }^{[7]}$ estes dependem fortemente da arquitetura do dispositivo na qual estão inseridos, quando no estado sólido; razão pela qual existem diversos centros de pesquisa com atenções voltadas tanto para o desenvolvimento de novos materiais (síntese química) como na metodologia e desenvolvimento na formação de filmes finos no campo da nanotecnologia (Fabricação de dispositivos) com fins de elevar a resposta em luminância $\left(\mathrm{cd} / \mathrm{m}^{2}\right)$, o tempo de vida, pureza de cor e eficiência externa. ${ }^{[14]}$

Dentro do estudo dos OLEDs existe uma classe de dispositivos, fabricados a partir de complexos de MT (bloco $d$ da tabela periódica), conhecidos como Células Eletroquímicas Emissoras de Luz (LECs - Light Electrochemical Cell). ${ }^{[15]}$ Nesta classe de dispositivos são empregados prioritariamente complexos com íons de Rênio, ${ }^{[16]}$ Rutênio $^{[17]}$ e também Irídio, ${ }^{[18]}$ entre outros. Dispositivos empregando complexo de Rutênio apresentam elevada eletroluminescência integrada (acima de $1000 \mathrm{~cd} / \mathrm{m}^{2}$ ), porém com tempo de resposta lento (cerca de 120 segundos em estruturas single layer), o que justifica o estudo de arquiteturas diferenciadas ou mesmo diferentes procedimentos de fabricação além da compreensão dos mecanismos físicos envolvidos na eletroluminescência, para manter o elevado brilho 
associado a um tempo de resposta cada vez menor. Além do Rutênio, nesta classe de dispositivos, destaca-se também complexo de Rênio, cujo mecanismo para emissão de luz aproxima-se mais do OLED (transporte de carga). ${ }^{[19]}$

$\mathrm{Na}$ presente tese os capítulos estão divididos da seguinte forma: Capítulo 2 trata dos fundamentos teóricos dos complexos de Terras Raras (TR), dos complexos de Metais de Transição (MT) e polímeros semicondutores. Além disso, são abordados os aspectos teóricos sobre os mecanismos de transporte de portadores de carga e os métodos para extração da eficiência externa dos dispositivos eletroluminescentes fabricados. No capítulo 3 são apresentados os materiais e métodos empregados na fabricação dos dispositivos eletroluminescentes bem como os respectivos equipamentos utilizados para as medições de espessura e caracterização eletroóptica. No Capítulo 4 são apresentados os resultados em conjunto com as respectivas discussões e, por fim, o Capítulo 5 relata os pontos mais enfáticos e de destaque do trabalho na conclusão incluindo as perspectivas futuras.

\subsection{Objetivos}

Este trabalho teve como objetivo o estudo de arquiteturas de dispositivos eletroluminescentes empregando tanto complexos de terras raras como de metais de transição. Para os TRs foram analisadas as diferentes respostas consoantes à variação de ligantes principais e neutros em filmes depositados por evaporação térmica. Este 
estudo permitiu a evolução para o emprego dos complexos de TR dispersos em matriz polimérica (polímero PVK), cujos filmes foram formados por meio da técnica de spin-coating com o propósito de se implementar novas estruturas de dispositivos e checar sua implicação na eficiência externa. Ainda empregando esta técnica foram estudados também os complexos de MTs, especificamente os complexos de Rutênio e de Rênio. Com o complexo de Rutênio estudou-se a variação do ligante e os mecanismos de transporte de carga no material. Para o complexo de Rênio o objetivo do estudo foi à análise deste material disperso em uma matriz polimérica (polímero PVK) em diversas concentrações e o respectivo reflexo desta variação na eficiência externa.

\subsection{Justificativa}

A formação de filmes finos emissivos, empregando complexos de TRs dispositivos eletroluminescentes, por via úmida com o propósito que maior eficiência externa, constitui um desafio. Para tanto, utilizou-se a técnica de spin-coating, que tem a vantagem de ser simples de operação, de baixo custo e também por não depender da volatilidade (sob temperatura e alto vácuo) dos materiais. Esta última vantagem é importante já que em alguns casos pode ocorrer a degradação dos complexos no estado sólido antes da formação do filme fino sobre o substrato (levando-se em consideração a técnica de evaporação térmica). ${ }^{[20]}$ 
Adicionalmente, constata-se, com base na literatura, que os complexos de MTs constituem uma nova classe de materiais luminescentes promissores para aplicação tanto em OLEDs como em LECs. Assim, empregando tanto o complexo de Rutênio quanto o de Rênio, em conjunto com uma matriz polimérica, avançou-se num estudo pioneiro na aplicação destes materiais em dispositivos eletroluminescentes. 


\section{Capítulo 2 FUNDAMENTOS TEÓRICOS}

\subsection{Fundamentos teóricos sobre complexos de Terras Raras (TR)}

\subsubsection{Complexos de Terras raras}

No campo da pesquisa de materiais luminescentes os íons Terras Raras geralmente encontram-se na forma de complexos, ${ }^{[21]}$ nos quais usualmente o íon metálico trivalente está conectado a um ligante orgânico; isto porque os lantanídeos possuem maior estabilidade no estado de oxidação trivalente. Além disso, os lantanídeos têm maior probabilidade de realizar ligações com átomos como flúor, oxigênio, nitrogênio e enxofre, seguindo esta ordem de eletronegatividade. Outra característica dos lantanídeos, conforme já citado, e de grande interesse para aplicação prática é o fato de apresentarem bandas de emissão extremamente definidas, ${ }^{[22]}$ isto ocorre devido aos elétrons $4 f$. Desta forma, o espectro é produzido com base nas transições $f-f$ de um estado $J$ de configuração $f^{n}$ para outro estado de mesma configuração. ${ }^{[22]}$

Os complexos de TR apresentam vantagem, pois nos polímeros fluorescentes ocorrem decaimentos não-radiativos nos estados tripletos. ${ }^{[22]}$ Assim, a eficiência quântica externa nestes materiais é limitada em 25\%. Por outro lado, utilizando-se corantes (complexos de Terras Raras) com ligantes $\pi$-conjugados, como os $\beta$ dicetonatos, é possível excitar os estados tripletos do ligante via transferência 
intersistemas, que por sua vez transfere energia ao centro emissor, cujo processo é denominado Efeito Antena e será abordado no item 2.1.3. Na Figura 1 são apresentadas as transições típicas para os íons Európio e Térbio.

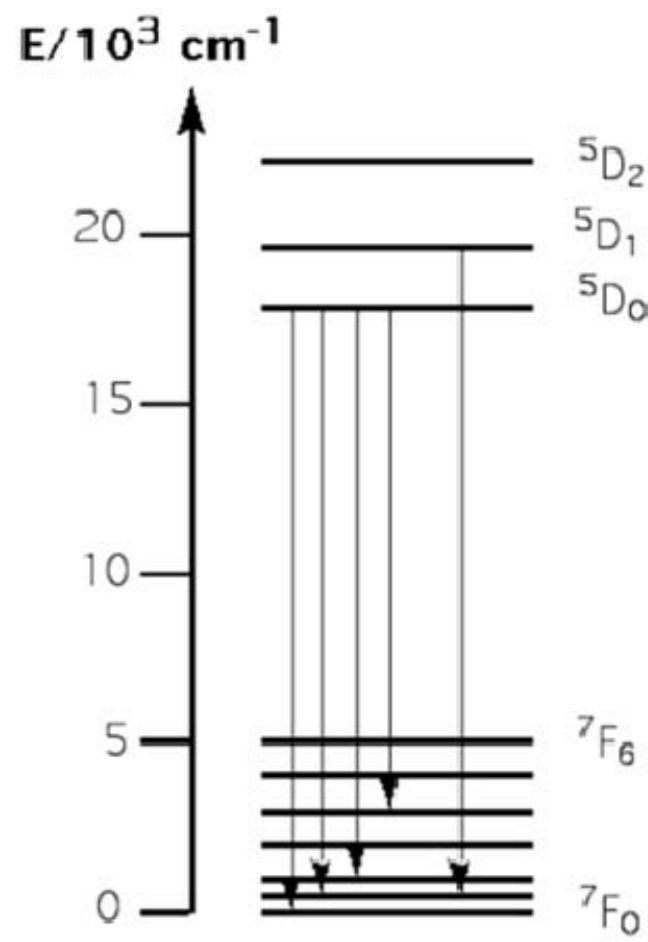

$\mathrm{Eu}(\mathrm{III})$

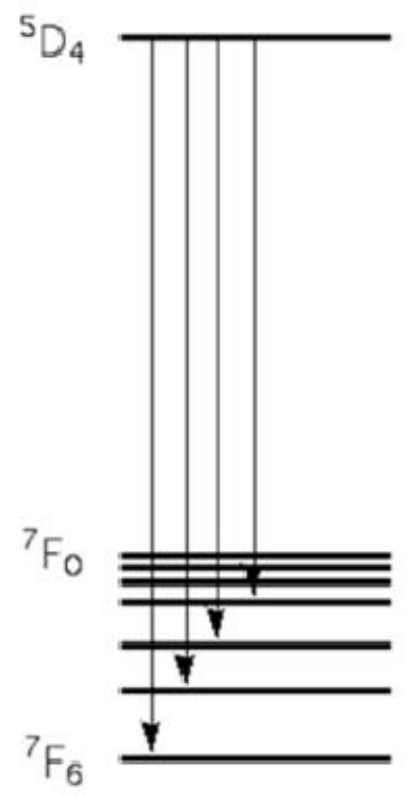

$\mathrm{Tb}(\mathrm{III})$

Figura 1 - Níveis de energia do íon $\mathrm{Eu}^{3+}$ e do $\mathrm{Tb}^{3+}$, cujas transições são as observadas no espectro a partir dos íons TR no estado trivalente. ${ }^{[23]}$

O estado fundamental e seus desdobramentos, bem como os excitados são relacionados a identificadores denominados termos espectroscópicos genericamente identificados como ${ }^{2 S+1} L_{J}$, onde $S$ é o momento angular total do spin, $L$ momento 
angular total do orbital e $J$ momento angular quântico. A expressão $2 s+1$ é definida como multiplicidade de spin.

\subsubsection{Mecanismos de transferência de energia Föster e Dexter}

O mecanismo de transferência de energia em materiais orgânicos é associado a interação dipolar ou mesmo multipolar entre o polímero semicondutor e o íon lantanídeo ou metálico de transição pela interposição do ligante, cujo fenômeno é

denominado mecanismo de transferência Föster ${ }^{[24]}$ e, conforme reportado, ocorre para distâncias elevadas; levando-se em consideração a escala molecular. Por outro lado, para distâncias ínfimas (menores que 10Å), segundo a literatura, o mecanismo predominante é o de transferência Dexter. ${ }^{[25]}$ Assim, a principal diferença entre os dois mecanismos reside no fato de que a transferência Föster depender fortemente da sobreposição do espectro de emissão do material polimérico ou orgânico e da absorção do complexo. ${ }^{[26]}$

\subsubsection{Principais ligantes e o Efeito Antena}

Para que haja transferência de energia significativa do ligante para o centro emissor (íon Terra Rara) é necessário que haja compatibilidade entre os níveis de energia do polímero, do ligante orgânico e do íon. Os ligantes apresentados na literatura são entre outros, nitrogênios e oxigênios coordenantes. Os oxigênios coordenantes são os mais estudados de acordo com a literatura. ${ }^{[22]}$ 
Entre os ligantes que utilizam oxigênios coordenantes destacam-se as $\beta$-dicetonas, que, por sua vez, são excelentes quelatos para íons Terras Raras. ${ }^{[27]}$ Os complexos que fazem uso dos $\beta$-dicetonatos foram estudados primeiramente por URBAIN et al., ${ }^{[28]}$ sendo posteriormente estudado com maior precisão para determinar a estabilidade destes complexos em solução. A Tabela 1 apresenta alguns ligantes apresentados na literatura. ${ }^{[29]}$

Tabela 1 - Fórmulas estruturais, nomenclatura, abreviação do nome e estado tripleto de alguns $\beta$-dicetonatos.

\begin{tabular}{|l|l|l|l|}
\hline & Nomenclatura & Abreviação & Estado \\
Tripleto (eV)
\end{tabular}

Em se tratando de dispositivos empregando uma matriz polimérica ou orgânica, na qual é disperso o complexo de TR existe a possibilidade de transferência de energia 
com uma seqüência do tipo: matriz polimérica ou orgânica $\rightarrow$ ligante $\rightarrow$ íon terra rara proporcionando a geração de fótons. Por outro lado, o complexo de TR pode ser empregado como filme emissivo sem a presença do polímero. Assim, o processo de luminescência (Eletroluminescência e Fotoluminescência) depende unicamente da localização dos níveis de energia tanto do ligante principal quanto do íon. Este processo de transferência de energia, implicando em decaimento radiativo, é denominado Efeito Antena. ${ }^{[22,27]}$ Este processo de sensibilização ainda não é completamente conhecido partindo-se do ponto de vista do material aplicado na forma de filmes finos em dispositivo eletroluminescentes, por este motivo, existem muitas linhas de pesquisa na área de química orgânica-inorgânica, física aplicada e engenharia de superfície ${ }^{[24]}$ com o intuito de compreender e melhorar a eficiência de transferência de energia. Através do diagrama de Jablonsky simplificado (ver Figura 2) observa-se que a partir da absorção da energia fornecida, por meio de fótons de alta energia ou potencial elétrico, ao material ocorrem as seguintes possibilidades:

Decaimento radiativo na própria matriz polimérica (se houver na arquitetura fabricada), ocasionando a fluorescência;

Conversão de energia do estado singleto da matriz polimérica ou orgânica para o estado tripleto do ligante por meio de cruzamento intersistemas (CIS). Este mecanismo de transferência de energia é conhecido como mecanismo Föster, ${ }^{[24]}$ podendo ocasionar a fosforescência ou mesmo um decaimento não radiativo; 
Transferência de energia do estado tripleto do ligante para os níveis de energia pertencentes ao íon Terra Rara. Este tipo de transferência de energia é conhecido como mecanismo Dexter, ${ }^{[31]}$ implicando em uma primeira possibilidade que é o decaimento radiativo (emissão característica do íon) ou mesmo um decaimento não radiativo.

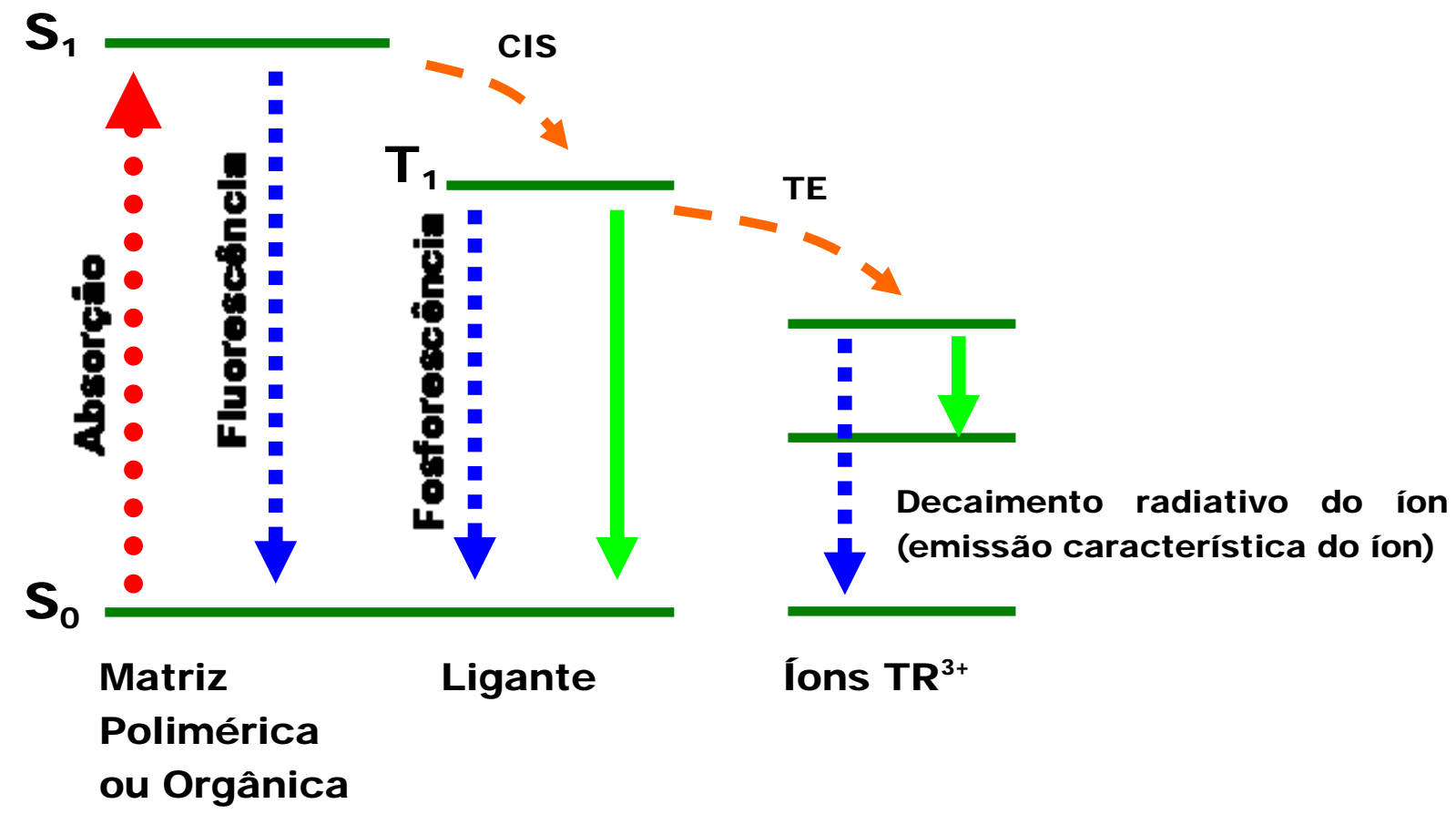

Figura 2 - Diagrama de Jablonsky simplificado indicando a absorção de energia na matriz polimérica ou orgânica e as possibilidades de relaxação por meio da fosforescência, e a emissão luminosa do íon terra rara trivalente. $O$ gráfico ainda apresenta o cruzamento intersistemas (CIS) e a transferência de energia (TE). As setas com linhas cheias representam decaimentos não radiativos. A Absorção de energia poder ocorrer por meio de fótons de alta energia ou pela aplicação de um potencial elétrico.

G. Santos - Escola Politécnica da Universidade de São Paulo - OLEDs, PLEDs e LECs 
Normalmente os processos de fluorescência são extremamente rápidos (da ordem dos nanosegundo ou menos) e que ocorrem em função da transição entre estados de energia com mesma multiplicidade de spin, isto é, singleto $\rightarrow$ singleto; já a fosforescência caracteriza-se como um processo mais lento (da ordem de micro a milisegundos ou mesmo maior) por estar relacionado a transições "proibidas" por spin (baixa probabilidade de transição) apenas visível por efeito do campo local que torna a transição permitida. No caso dos íons de TRs ocorre uma transição entre spins de diferentes multiplicidades (Tripleto $\rightarrow$ Singleto), no entanto, com probabilidade de transição intermediária. Assim o tempo de decaimento é da ordem dos microsegundos, em geral, e dessa forma, as transições são comumente classificadas como de fosforescência rápida (fast phosphorescence). ${ }^{[14]}$

Além disso, devido a regra de spins, a eficiência quântica interna dos TRs pode alcançar praticamente $100 \%{ }^{[32]}$ ao contrário dos $25 \%$ dos polímeros conjugados. ${ }^{[33]}$ Desta forma, toda a energia transferida ao TR (ver Figura 2) para seus respectivos níveis excitados ocasionam elevada probabilidade de luminescência. Observando os processos de luminescência é possível identificar que um dos principais desafios envolvendo os TRs e polímeros, isto é, a otimização destes processos tanto no desenvolvimento de novos materiais na área de síntese química como na fabricação de dispositivos, sob o ponto de vista físico e tecnológico, ajustando-se devidamente os níveis de energia do complexo de TR em relação aos filmes adjacentes para transporte de lacunas e elétrons. 


\subsubsection{Estado da arte - OLEDs com Complexos de Terras Raras}

O primeiro registro na literatura de um dispositivo empregando complexos de terras raras foi reportado por KIDO et al. em 1990, com a estrutura ITO/TPD/Térbio(ACAC) 3 /Al, sendo o complexo constituído pelo íon Térbio em conjunto com o ligante acetilacetonato. A resposta deste dispositivo apresentou bandas com largura à meia altura entre 10 e $20 \mathrm{~nm}$ com transições provenientes do Térbio ${ }^{5} \mathrm{D}_{4} \rightarrow{ }^{7} \mathrm{~F}_{6}(490 \mathrm{~nm}),{ }^{5} \mathrm{D}_{4} \rightarrow{ }^{7} \mathrm{~F}_{5}(545 \mathrm{~nm}),{ }^{5} \mathrm{D}_{4} \rightarrow{ }^{7} \mathrm{~F}_{4}(585 \mathrm{~nm})$ e ${ }^{5} \mathrm{D}_{4} \rightarrow{ }^{7} \mathrm{~F}_{3}$ $(620 \mathrm{~nm}) .^{[34]}$

$\mathrm{Na}$ literatura encontra-se dispositivos desta classe que apresentam elevados valores de luminância e eficiência externa conjugando diferentes arquiteturas, materiais e processabilidade. Como, por exemplo, em 2006, FANG et al. ${ }^{[35]}$ que reportou a eficiência luminosa e luminância de $0,47 \mathrm{~cd} / \mathrm{A}$ e $160 \mathrm{~cd} / \mathrm{m}^{2}$, respectivamente, para dispositivos empregando complexo de Európio disperso em PVK.

Com base na literatura, observa-se que o desenvolvimento científico envolvendo complexos de Terras Raras, Metais de Transição em conjunto com polímeros luminescentes, ainda pouco explorado na literatura, avançou de modo a buscar melhorias tanto na síntese de novos materiais bem como arquiteturas de dispositivos. ${ }^{[14]} \mathrm{O}$ termo arquitetura de dispositivos empregada no presente trabalho relaciona-se com o melhor dimensionamento da área ativa, das espessuras dos filmes finos empregados e seleção de materiais, formas de processamento e técnicas a serem 
utilizadas para a formação de filmes finos e, dependendo da finalidade e foco pontual dentro do estudo global, também abrange projeto de encapsulamento para testes de tempo de vida ou mesmo para simples proteção mecânica durante a caracterização funcional eletro-óptica. Ambos os enfoques são igualmente necessários, fundamentalmente importantes e complementares no desenvolvimento de OLEDs.

\subsection{Fundamentos teóricos sobre complexos de Metais de Transição (MT)}

\subsubsection{Mecanismo de Transferência de Carga Metal-Ligante (MLCT)}

Os elementos do bloco $d$ da tabela periódica em conjunto com os ligantes chamados polipiridinas possuem orbitais $\sigma$ doadores localizados em átomos de nitrogênio em conjunto com orbitais $\pi$ e $\pi^{*}$ aceitadores, que por sua vez são delocalizados nos anéis aromáticos. Assim, com base na teoria da descrição para um elétron, em um estado excitado, ocorre uma transição do orbital $\pi_{M}$ do metal para o $\pi_{L}{ }^{*}$ do ligante, cujo mecanismo é denominado Transferência de Carga Metal-Ligante - Metal Ligand Charge Transfer - $\left({ }^{3} \mathrm{MLCT}\right)$. Por outro lado, se a transição ocorre do orbital $\pi_{M}$ para

o $\sigma_{M}{ }^{*}$ tem-se o mecanismo Metal Centrado - Metal Centered - (MC); já a transição 
do orbital $\pi_{L}$ para o $\pi_{L}{ }^{*}$ chama-se Ligante Centrado - Ligand Centered - (LC), conforme mostra diagrama da Figura 3 extraído da literatura. ${ }^{[36]}$

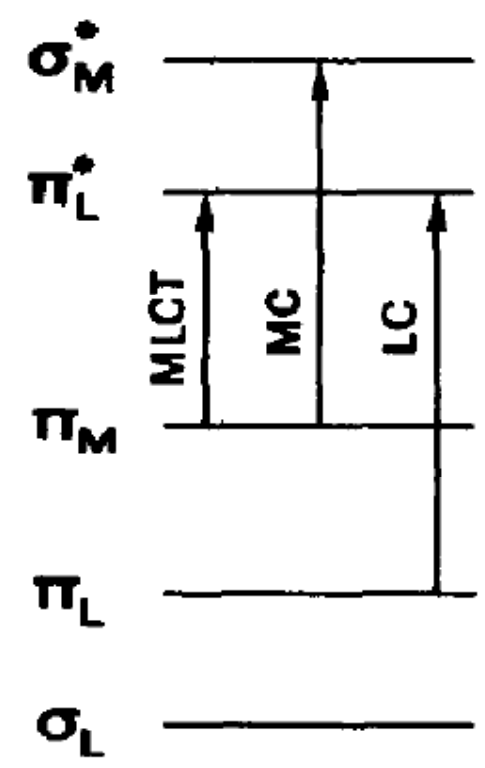

Figura 3 - Transições possíveis para Complexos de Metais de Transição, como o Rutênio e Rênio. $^{[36]}$

\subsubsection{Propriedades ópticas para os complexos de Rênio e de Rutênio}

No complexo de Rênio o comprimento de onda predominante espectral abrange o laranja-amarelo, cujo mecanismo é regido pelo mecanismo ${ }^{3} \mathrm{MLCT} .{ }^{[37]}$ Nestes complexos forma-se um gap entre os orbitais $d$ do metal e $\pi^{*}$ do ligante. Estes 
materiais são muito interessantes e promissores na tecnologia de dispositivos eletroluminescentes devido ao fato de serem estáveis térmica e quimicamente. ${ }^{[38]}$

Por outro lado, o complexo de Rutênio destaca-se por ser um complexo extensivamente estudado (últimos 50 anos) ${ }^{[36]}$ Sua fosforescência é detectada com facilidade em temperatura ambiente e esta é atribuída ao estado de menor ${ }^{3} \mathrm{MLCT},{ }^{[36]}$ sendo sua emissão espectral entre laranja-vermelho. O processo de emissão pode ser melhor compreendido com base no seguinte equacionamento $a-d$, que por sua vez descreve a reação nas proximidades dos eletrodos, a formação do estados excitados e, por fim, a emissão luminosa e retorno ao estado estável da espécie, sendo Rutênio $(\mathrm{Ru})$ e o ligante (L). ${ }^{[36]}$

a) $\mathrm{Ru}(\mathrm{L})_{3}{ }^{2+}+\mathrm{e}-\rightarrow \mathrm{Ru}(\mathrm{L})_{3}{ }^{+}$(fenômeno próximo ao catodo)

b) $\mathrm{Ru}(\mathrm{L}) 3^{2+} \rightarrow \mathrm{Ru}(\mathrm{L}) 3^{3+}+$ e- (fenômeno próximo ao anodo)

c) $\mathrm{Ru}(\mathrm{L})_{3}{ }^{+}+\mathrm{Ru}(\mathrm{L})_{3}{ }^{3+} \rightarrow \mathrm{Ru}(\mathrm{L})_{2}{ }^{2+}+\mathrm{Ru}(\mathrm{L})_{2}{ }^{2+*}$ (estados excitados)

d) $\mathrm{Ru}(\mathrm{L})_{2}{ }^{2+*} \rightarrow \operatorname{Ru}(\mathrm{L})_{2}{ }^{2+}+\mathrm{h} v$ (emissão na região visível e retorno ao estado estável da espécie)

$\mathrm{O}$ equacionamento descrito pode ser melhor visualizado por meio do diagrama da Figura 4. 


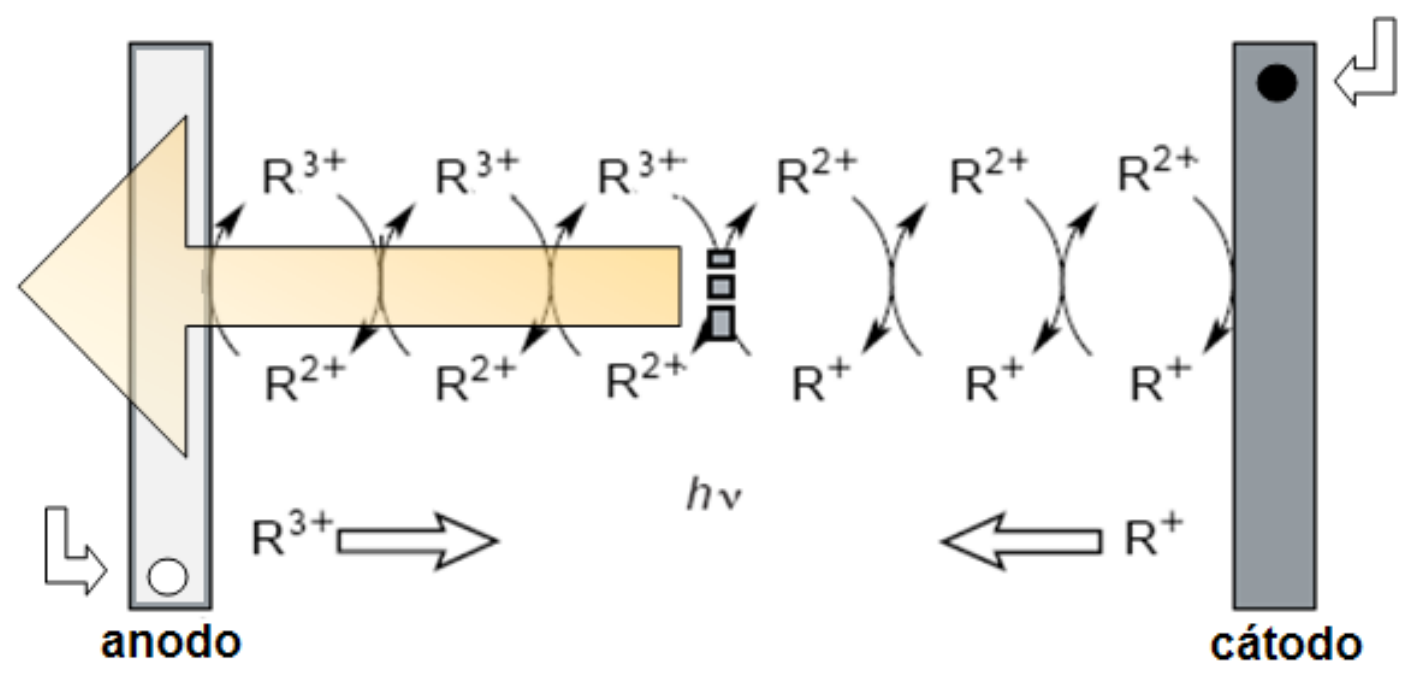

Figura 4 - Diagrama esquemático dos processos de luminescência oriundos dos estados ${ }^{3}$ MLCT no complexo de Rutênio. ${ }^{[36]}$

\subsubsection{Estado da arte - Dispositivos eletroluminescentes com Metais de Transição (LECs)}

O principal elemento, que diferencia os LECs dos OLEDs, propriamente ditos, é o fato do filme emissivo ser tanto condutor eletrônico como iônico. Segundo modelos apresentados na literatura, em um primeiro momento, levando-se em consideração o complexo de Rutênio na forma de filme fino no estado sólido e entre dois eletrodos, quando se aplica um potencial elétrico, existe uma redistribuição de cargas iônicas, as quais proporcionam a formação de campo elétrico nos eletrodos de forma que esses apresentem um comportamento ôhmico. ${ }^{[39]}$ A mesma diferença de potencial aplicada ao longo do tempo favorece a formação de ânions e cátions tornando a 
estrutura polarizada semelhante a um diodo inorgânico de junção $\mathrm{PN}$, sendo o equivalente ao material tipo $p$ próximo ao anodo e o tipo $n$ ao cátodo. ${ }^{[40]}$ Devido ao fato da mobilidade dos contra-íons não existe necessidade de eletrólito e estes possuem função essencial no mecanismo de luminescência do complexo de MT quando este se na forma de filme fino no estado sólido. ${ }^{[1]}$ Alem disso, esses materiais são muito promissores, pois possuem emissão proveniente de estados tripletos implicando em probabilidade de elevada eficiência quântica externa. ${ }^{[42]}$ Por outro lado, essa redistribuição de cargas, isto é, oxidação do metal e a redução do ligante, em conjunto com as próprias características polímero empregado implicam em um tempo de resposta prolongado para que haja emissão de luz. ${ }^{[43]}$

Pesquisas recentes envolvendo complexos de MT, especificamente complexos de Rutênio e Rênio apontam para a resolução dos seguintes desafios:

Complexo de Rutênio:

Estudo tempo de resposta;

Estudo de diferentes ligantes;

Estudo de diferentes contra-íons;

Estudos de diferentes polímeros em conjunto com o complexo. 
Complexo de Rênio:

Análise do complexo em diferentes estruturas e dispositivos;

Estudo de diferentes ligantes;

Estudo aprofundado nos mecanismos de transporte envolvendo o complexo.

\subsection{Polímeros semicondutores luminescentes}

Os polímeros semicondutores luminescentes devem necessariamente possuir estrutura conjugada, que significa possuir alternância entre ligações simples e duplas. Exemplos de polímeros conjugados extensamente explorados e reportados são: transpoliacetileno, politiofeno, poli[2-metóxi, 5-(2etil-hexiloxi)-p-fenilenovinileno] $(\mathrm{MEH}-\mathrm{PPV}),{ }^{[44]}$ o poli(p-fenilenovinileno $)(\mathrm{PPV}),{ }^{[33]}$ a polianilina, ${ }^{[45]}$ entre outros.

Nos polímeros semicondutores ocorre a sobreposição de orbitais $p_{z}$ devido a hibridação $s p^{2}+p_{z}$ dos átomos de carbono. Assim tem-se ligações $\sigma$ formadas a partir da sobreposição de orbitais híbridos $s p^{2}$ que atua unindo os átomos da cadeia principal e, por outro lado, as ligações $\pi$ que ocorrem devido a sobreposição dos orbitais $p_{z}$ e por sua vez proporcionam os orbitais ocupados $\pi$ e vazios $\pi^{*}$ que se separam conforme predito na teoria descrita como instabilidade de Peierls, a qual esta relacionada às ligações carbono-carbono, sendo ligações simples mais longas

que as duplas. Com base no teorema da instabilidade de Peierls ${ }^{[46]}$ é possível 
descrever a formação de orbitais moleculares equivalentes às bandas de valência e condução em semicondutores inorgânicos, como o silício. A diferença de energia entre os orbitais HOMO e LUMO encontra-se na faixa entre 1,5 e 4 eV, a modulação deste valor é fonte de investigação científica, pois implica em variações tanto nas propriedades ópticas quanto elétricas do material.

Em polímeros como o trans-poliacetileno (Figura 5) é possível realizar-se a introdução de defeitos, os quais são denominados sóliton, que é neutro e possui spin 1/2. Esta entidade pode existir também em dois estados, dependo do tipo de dopagem realizada

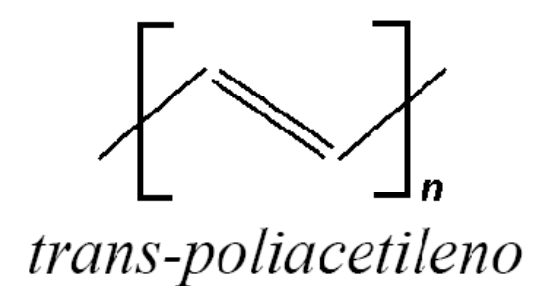

Figura 5 - Estrutura química do trans-poliacetileno. ${ }^{[4]}$

Com base na teoria, o sóliton, ${ }^{[47]}$ como entidade, pode ser constatado no polímero trans-poliacetileno, que caracteriza-se como o único polímero a apresentar degenerescência de estados. Em outros polímeros, as cadeias separadas por um defeito possuem energias diferentes. Assim, a cada defeito na cadeia polimérica ocorre o aparecimento de um anti-defeito, denominado anti-sóliton, para que se mantenha a condição de equilíbrio no material. No caso destes defeitos possuírem carga elétrica nula estes podem decair rapidamente, no entanto, se possuírem carga 
elétrica se estabelecem e, neste caso, são denominados pólarons, que por sua vez estão intrinsecamente relacionados com a formação de estados ligantes $(\pi)$ e antiligantes $\left(\pi^{*}\right)$ ou ao gap do polímero. Os pólarons quando carregados positivamente são denominados pólarons positivos e na condição contrária pólarons negativos. $\mathrm{Na}$ condição de um pólaron positivo encontrar um negativo, estes recombinam e ocasionam a formação de uma entidade denominada éxciton singleto e, posteriormente, ocorre a emissão de luz. Por outro lado, quando ocorre o encontro entre o sóliton e anti-sóliton forma-se a entidade chamada bipolaron, que por sua vez também pode encontra-se positiva ou negativamente carregado.

Como regra geral atribui-se aos éxcitons a emissão de fótons por parte desta classe de polímeros semicondutores, isto é, ocorre a transição de elétrons do estado fundamental para o excitado, cuja relaxação pode ocasionar emissão de luz. Este processo pode ocorrer por meio de excitação do material com fótons com alta energia (luz ultravioleta), denominado como fotoluminescência ou pela injeção de portadores de carga aplicando-se um potencial elétrico, conhecido como eletroluminescência. Por outro lado, o éxciton pode decair não-radiativamente em um estado tripleto ou mesmo ser aprisionado em defeitos na cadeia polimérica.

Além disso, é importante realçar a forma como os materiais orgânicos eletroluminescentes podem ser projetados e sintetizados para emitirem luz em um dado comprimento de onda. Em verdade estes materiais poliméricos de uma forma simples são idealizados com base na diferença entre os seus respectivos níveis 
HOMO e LUMO, os quais determinaram, em última análise, a cor emitida. Por outro lado, a diferença de energia está relacionada com o grau de conjugação das cadeias poliméricas. As ligações $\pi$ na molécula interatuam entre si livremente dando lugar a um sistema $\pi$ delocalizado com a formação de novos orbitais moleculares. Esses orbitais moleculares, os quais podem se estender por toda a molécula. A Figura 6 ilustra o sistema para uma molécula de benzeno, como exemplo.

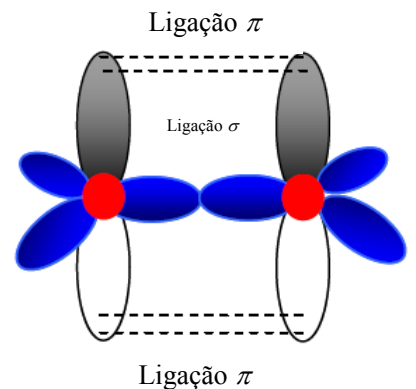

(a)

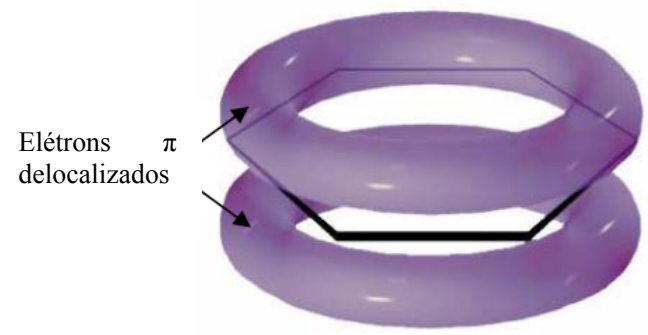

(b)

Figura 6 - Esquemas de a) dupla ligação de átomos de carbono sp2 hibridizada, que consiste em uma ligação $\sigma$ e outra $\pi$, e b) sistema $\pi$ delocalizado em uma molécula de benzeno (para ilustração).

Genericamente, os níveis HOMO e LUMO nos semicondutores orgânicos são orbitais $\pi$. Assim, o nível HOMO corresponde ás orbitais ligantes $\pi$ e o nível LUMO a orbitais anti-ligantes $\pi^{*}$. Quando se formam filmes finos, as moléculas são sobrepostas umas as outras com seus respectivos orbitais $\pi$ estendidos. Como resultado, desta sobreposição de orbitais entre moléculas vizinhas, pode ocorrer troca molecular eletrônica nos níveis HOMO ou LUMO. Contudo, devido à fraca sobreposição das orbitais $\pi$ entre as moléculas, nas quais se tem ligações fracas de 
van der Waals, a qual é tão fraca que os elétrons possuem maior probabilidade de localização em moléculas individuais.

Fazendo-se analogia entre polímeros luminescentes e complexos de TRs e de MTs, cujos materiais processados para dispositivos é foco nesta Tese, tem-se que nos complexos de TRs a cor é obtida a partir dos níveis de energia do íon e não da componente orgânica do complexo, conforme descrito anteriormente no Efeito Antena. Embora alguns ligantes também apresentem luminescência. Analogamente ocorre com os complexos de MTs, nos quais a emissão é proveniente das espécies formadas envolvendo o centro metálico em conjunto com a componente orgânica, descrito pelo mecanismo ${ }^{3}$ MLCT. A Figura 7 apresenta os processos descritos me termos de níveis de energia, que são fundamentais no projeto de PLEDs e OLEDs.

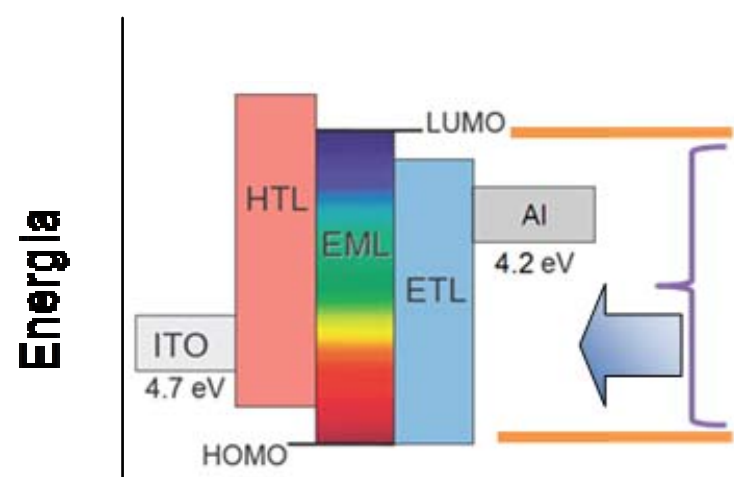

(a)

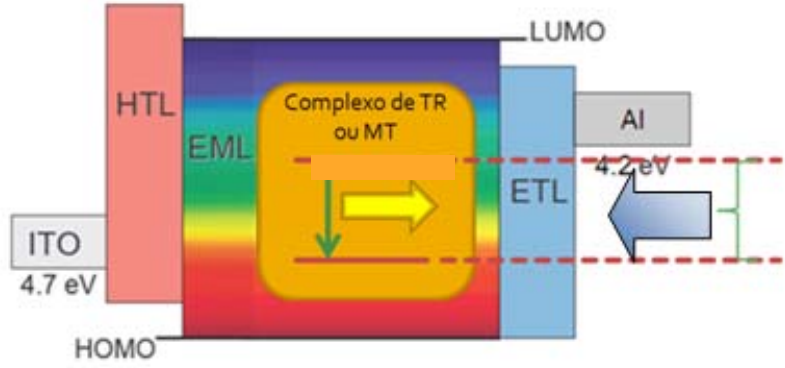

(b)

Figura 7 - Diagrama de energia para as estruturas de filmes finos em dispositivos orgânicos emissores de luz, sendo a) uma emissão controlada pela diferença HOMO-LUMO do polímero eletroluminescente (PLED) e b) por um complexo de TR disperso em uma matriz polimérica (OLED). 


\subsubsection{Processos de injeção e transporte de portadores de carga em materiais orgânicos semicondutores}

Os materiais orgânicos e poliméricos possuem como característica sua estrutura desordenada, o qual em geral é descrito por meio do mecanismo hopping. ${ }^{[48]}$ Sua estrutura desordenada conduz intrinsecamente a uma elevada probabilidade de defeitos e, com isso, a mobilidades na faixa entre $10^{-7}$ a $10^{-3} \mathrm{~cm}^{2} \mathrm{~V}^{-1} \mathrm{~s}^{-1}(300 \mathrm{~K})$, a qual varia com a temperatura, assim como os semicondutores inorgânicos.

$\mathrm{Na}$ literatura são reportados modelos de injeção de carga em semicondutores orgânicos como o de Fowler-Nordheim ou mesmo emissão termiônica do tipo Schottky. ${ }^{[49]}$ No caso da emissão termiônica pode-se descrever a corrente elétrica em função do potencial elétrico aplicado, genericamente conforme Eq. [1].

$$
I(V)=A A^{* *} T^{2}\left(e^{-\frac{\phi_{B}}{k T}}\right)\left(e^{\frac{q V_{a}-I R_{s}}{\eta k T}}\right)\left(1-e^{\frac{-q\left(V_{a}-I R_{s}\right)}{k T}}\right),
$$

sendo $A$ a área geométrica do contato elétrico do dispositivo, $A^{* *}$ a constante de Richardson, $T$ a temperatura, $q$ a carga do elétron, $R_{S}$ a resistência série, $k$ a constante de Boltzmann, $\phi_{B}$ a altura da barreira de potencial, $\eta$ o fator de idealidade e $V_{a}$ o potencial elétrico aplicado. 
Em condições ideais para semicondutores inorgânicos, na faixa entre 75 e $150 \mathrm{mV}$, tem-se um comportamento exponencial, em cuja condição $R_{S}$ é desprezível e o fator de idealidade equivale a unidade. Dessa forma, a Eq. [1] é reduzida de forma a descrever o comportamento da corrente de difusão devido à emissão termiônica na interface entre o metal e o semicondutor.

Com base no equacionamento tradicional Schottky tem-se uma variante denominada emissão termiônica Richardson - Schottky, a qual define a redução da barreira de potencial na interface entre metal semicondutor com o campo elétrico aplicado, que depende do potencial elétrico e da área $(E=V / A)$. Assim tem-se a densidade de corrente associada a este modelo, conforme Eq. [2].

$$
J=A^{* *} T^{2} e^{\frac{-\phi_{B}-\beta \sqrt{E}}{k T}}
$$

sendo as constantes $A^{* *}$ e $\beta$ definidos como $\frac{4 \pi q m^{*} k^{2}}{h^{3}}$ e $\sqrt{\frac{q^{3}}{4 \pi \epsilon_{r} \epsilon_{0}}}$, respectivamente. Neste caso, $h$ é a constante de Planck, $\varepsilon_{0}$ e $\varepsilon_{\mathrm{r}}$ são as permissividades do vácuo e elétrica, respectivamente e $m^{*}$ é a massa efetiva do elétron.

O mecanismo Fowler-Nordheim consiste em um modelo que desconsidera o efeito da interação eletrostática (apenas tunelamento através da barreira) e é regido segundo a Eq. [3]. 
$J=\frac{A^{* *} q^{2} E^{2}}{\phi_{B}\left(\frac{4 \pi \sqrt{2 m^{2}}}{h}\right)^{2} k^{2}} e^{-\frac{2\left(\frac{4 \pi \sqrt{2 m^{2}}}{h}\right) \phi^{3 / 2}}{3 q E}}$

Em ambos os modelos, associados a adequações, são muito apropriados para semicondutores inorgânicos, porém significativamente limitados para os orgânicos, que por sua vez conta com estrutura amorfa, com densidade de defeitos significativamente elevada.

Em se tratando de condução elétrica em semicondutores existem modelos que considera a limitação de corrente por carga espacial (SCLC), a qual foi proposta por ROSE e LAMPERT et al. ${ }^{[49]}$ que demonstraram experimentalmente como a lei de potência é dependente da corrente oriunda da aplicação de um potencial elétrico. Nesta teoria é anexado o efeito de armadilhamento de portadores de carga, isto é, considera-se um regime no qual existe limitação de corrente devido aos portadores de carga armadilhados (Trapped Charge Limited - TCL) por defeitos ou mesmo impurezas, onde as propriedades de transporte eletrônico são determinadas principalmente pelo bulk. Com o aumento do potencial elétrico cresce a densidade de portadores de carga injetados, que por sua vez são armadilhados. Ao longo do tempo, com a redução do processo de armadilhamento de portadores de carga a mobilidade efetiva é incrementada e, com isso, tem-se a corrente regida pela relação $I \alpha V^{m}$. Assim, para potenciais suficientemente altos o mecanismo TCL torna-se SCLC. Este 
mecanismo é detectado, segundo a literatura, em polímeros extensamente estudados como o PPV..$^{[49]}$

Assim, em estruturas de dispositivos orgânicos eletroluminescentes, levando-se em conta baixos potenciais elétricos, genericamente, a expectativa é de que haja baixa mobilidade, regida por um comportamento ôhmico, no qual existe linearidade entre potencial elétrico aplicado e a corrente no sistema, que ocorre via geração térmica. Assim a densidade de corrente pode ser descrita conforme Eq. [4].

$J=\frac{q \mu \eta_{0} V}{d}$

onde $\mu$ é a mobilidade, $n_{0}$ a densidade de portadores de carga termicamente gerados e $d$ a espessura do filme fino empregado na estrutura com função de transporte de elétrons. Para o caso de $n_{0}$ ser negligenciável em relação aos portares de carga elétrica injetados tem-se a predominância do mecanismo SCLC, conforme Eq. [5].

$J=\frac{9}{8} \frac{\mu \varepsilon V^{2}}{d^{3}}$

Nesta dependência da relação com potencial elétrico aplicado constata-se também que existe comportamento ôhmico para baixos valores de potencial elétrico e também para filmes muito espessos. Este regime tem sua importância, pois trata da máxima corrente unipolar que um dado dispositivo pode manter para uma dada 
variação de potencial elétrico aplicado. Para que seja possível superar esta limitação de corrente é necessário que haja dupla injeção de portadores de carga, cuja condição permite a compensação de parte da carga espacial gerada.

Quando a densidade de armadilhas é elevada, a corrente é ínfima e, neste caso, a dependência quadrática só é mantida se houver armadilhamento de portadores de carga em níveis discretos de energia. Nesta condição a Eq. [5] é modificada, conforme apresentado na Eq. [6].

$J=\frac{9}{8} \theta \varepsilon_{r} \varepsilon_{0} \mu \frac{V^{2}}{d^{3}}$

onde $\theta=n /\left(n+n_{t}\right)$ e representa a razão entre os portadores livres $(n)$ e o número total de portadores $\left(n_{t}\right)$. A mobilidade efetiva é definida como $\mu_{\mathrm{eff}}=\theta \times \mu$. Além disso, se armadilhas possuem distribuição em energia, estas serão gradualmente preenchidas com o incremento do campo elétrico, isto é, $\theta$ é dependente do campo elétrico e a corrente elétrica aumentará em uma dependência superior à quadrática até que todas as armadilhas estejam preenchidas. Dessa forma, ocorre uma distribuição exponencial de armadilhas. Além disso, tem-se por definição, em semicondutores orgânicos, a distribuição exponencial de armadilhas, denotada como $\mathrm{N}_{\mathrm{t}}$. Nesta condição tem-se o Trap-charge limited current (TCL), cujo equacionamento é apresentado na Eq. [7]. 
$J=N_{C} \mu q\left(\frac{\varepsilon_{r} \varepsilon_{0} m}{N_{t} q(m+1)}\right)^{m}\left(\frac{2 m+1}{m+1}\right)^{m+1} \frac{V^{m+1}}{d^{2 m+1}}$

sendo o parâmetro $m=E_{t} / k_{B} T$ e $N_{c}$ a densidade de portadores de carga. ${ }^{[50,51]}$

Assumindo-se que não é possível considerar a mobilidade independente do campo elétrico, existe uma solução analítica, que leva em consideração uma dependência arbitrária desta, cujo modelo insere ainda a ausência de armadilhas. Contudo, a densidade de corrente só pode ser definida de forma paramétrica. ${ }^{[52]}$ Uma aproximação analítica foi obtida por MURGATROYSD et al. ${ }^{[53]}$ e é conhecida pela dependência da mobilidade definida na literatura como campo de Poole-Frenkel $(P F)$, como indicado na Eq. [8].

$\mu(E)=\mu_{0} \exp (\beta \sqrt{E})$

que por sua vez é freqüentemente observada em materiais moleculares desordenados, polímeros dopados e na maioria dos polímeros conjugados. ${ }^{[54]}$ A densidade de corrente, neste caso, enquadra-se no modelo SCLC livre de armadilhamento de portadores de carga multiplicado pela mobilidade de $\mathrm{PF}^{[53]}$, conforme Eq. [9]. 
$J \approx \frac{9}{8} \varepsilon_{r} \varepsilon_{0} \mu_{0} \frac{V^{2}}{d^{3}} \exp \left(0,89 \beta \sqrt{\frac{V}{d}}\right)$

Com base nos modelos apresentados e considerando-se os dispositivos orgânicos e sua resposta elétrica é necessário definir a corrente elétrica é limitada por injeção de portadores de carga ou por carga espacial. Assim, tem-se duas hipóteses, isto é, se ocorre TCL com uma distribuição exponencial de armadilhas ou se existe uma mobilidade dependente do campo elétrico e da temperatura, como comportamento dominante.

Muito embora a distribuição de armadilhas de portadores de carga seja mais complexa do que as aproximações apresentadas pelos modelos adotados atualmente, tem-se boa aproximação e, dessa forma, é possível interpretar alguns fenômenos constatados experimentalmente.

Ainda que o modelo SCLC seja válido integralmente para semicondutor com transporte de portadores de carga unipolar (que não é o caso dos materiais emissivos) observa-se que a emissão de luz ocorre apenas quando o transporte de portadores de carga no dispositivo entra em regime supra linear $\left(J \propto V^{n}, n \geq 2\right)$ sendo o valor de $n$ mais elevado para um maior confinamento de carga. Desta forma, observa-se que os dispositivos orgânicos e poliméricos seguem o modelo SCLC, no qual os níveis de energia das armadilhas propiciam impacto fundamental para que este ocorra. Não se descarta a possibilidade de que existam estruturas de filmes finos em que haja 
limitação de portadores de carga pelo eletrodo ou mesmo outro casos em que a limitação seja predominante bulk. Contudo, ainda neste caso, o comportamento descrito anteriormente possui validade.

De acordo com as equações descritas, a dependência funcional da corrente elétrica com a espessuras do filme fino inseridos na estrutura do dispositivo podem levar às seguintes conclusões:

i) Em um comportamento com predominância por parte do injetor de portadores de carga, a corrente para um campo elétrico constante não tem uma dependência direta na espessura, assim tem-se $J=J(E)$;

ii) Para um comportamento SCLC livre de armadilhas com (ou sem) uma mobilidade dependente do campo elétrico, a corrente para um campo constante tem dependência do inverso da espessura do filme fino, produzindo a relação: $J=J^{\prime}(E) / d$;

iii) Para sistemas com comportamento TCL com uma distribuição exponencial de armadilhas e mobilidade independente do campo elétrico, a corrente elétrica depende da espessura do filme fino de acordo a lei de potências e leva ao equacionamento: $J=J^{\prime \prime}(E) / d^{l}$ para $l>1$.

Assim, com base nestes modelos, em uma primeira análise, é possível definir algumas tendências importantes acerca dos processos dominantes na injeção e /ou transporte de portadores de carga em dispositivos orgânicos. A sua correlação com as 
figuras de mérito como a tensão de operação $\left(V_{o n}\right)$, eficiência externa e potencial limite - threshold são parâmetros que colaboram de forma essencial no projeto e planejamento futuro de OLEDs. Destacando o fato de que nos dispositivos estudados neste trabalho o modelo mais apropriado foi o TCL com uma distribuição exponencial de armadilhas com mobilidade independente do campo elétrico, em um primeiro momento, seguido pelo modelo SCLC. Assim, atribuiu-se este modelo, com todas as ressalvas e limitações deste, anteriormente citadas, e, sendo que a respectiva análise foi centrada apenas na verificação do comportamento macroscópico dos dispositivos.

\subsection{Eficiência externa para dispositivos eletroluminescentes (definições gerais)}

Considerando o espectro do ângulo integrado de eletroluminescência (Potência Óptica) $\left(\mathrm{P}_{\mathrm{OLED}}[\lambda]\right)$ de um OLED, PLED ou LEC, cuja emissão ocorre em função de um dado comprimento de onda $(\lambda)$ tem-se o número de fótons gerados na unidade de tempo $\left(N_{F}\right)$, conforme Eq. [10].

$$
N_{F}=\int_{0}^{\infty} \frac{P_{O L E D}(\lambda)}{h c} \lambda d \lambda,
$$


sendo $c$ a velocidade da luz e $h$ a constante de Planck. Sob uma corrente $(I)$ o número de portadores de carga que atravessam o dispositivo na unidade de tempo é dado por $N_{\mathrm{PC}}=I /$ e. Assim, a Eficiência Quântica Externa $(E Q E)$ é justamente a relação entre o número de fótons obtidos e a quantidade de portadores de carga, conforme apresentado na Eq. [11].

$$
\frac{N_{F}}{N_{P C}}=\frac{e}{h c I} \int_{0}^{\infty} \frac{P_{O L E D}(\lambda)}{h c} \lambda d \lambda
$$

\subsubsection{Eficiência de Potência ou Wall Plug $\left(\eta_{w w}\right)$}

Para o cálculo da Eficiência de Potência $\left(\eta_{W W}\right)$, também denominada na literatura de

Eficiência Wall Plug, ${ }^{[55]}$ é preciso levar-se em consideração a potência óptica, dada na Eq. [12],

$$
L=\int_{0}^{\infty} P_{O L E D}(\lambda) d \lambda \quad[\mathrm{W}]
$$

e a potência elétrica, $P_{\text {ele }}=V I$.

Assim, tem-se a Eficiência de Potência ou Wall Plug, conforme a Eq. [13]. 
$\eta_{W W}=\frac{L}{I V}=\frac{\int_{0}^{\infty} P_{O L E D}(\lambda) d \lambda}{I V} \quad$ [adimensional]

\subsubsection{Eficiência de Potência Luminosa $\left(\eta_{P}\right)$}

Para aplicações em mostradores de informações (Displays) ou mesmo iluminação ambiente, leva-se em consideração a percepção de luz com base na sensibilidade do olho humano. Assim tem-se, para o fluxo luminoso total $\left(\Phi_{\text {tot }}\right)$ a Eq.[14].

$\Phi_{t o t}=\int_{0}^{\infty} K(\lambda) P_{O L E D}(\lambda) d \lambda \quad[\operatorname{lm}]$

Sendo $K(\lambda)=683 V(\lambda) \mathrm{lm} / \mathrm{W}$, onde $V(\lambda)$ é a função resposta fotópica, que por sua vez é adimensional e está relacionada com a sensibilidade do olho humano. A Figura 8 apresenta o padrão Comissão Internacional de Iluminação - Commission internacionale de l'Éclairage (CIE) de 1924 para a função $V(\lambda)$, cujo ponto de máximo $(V(\lambda)=1)$ ocorre para o comprimento de onda de 555,17 $\mathrm{nm}$ (amarelo-verde). 


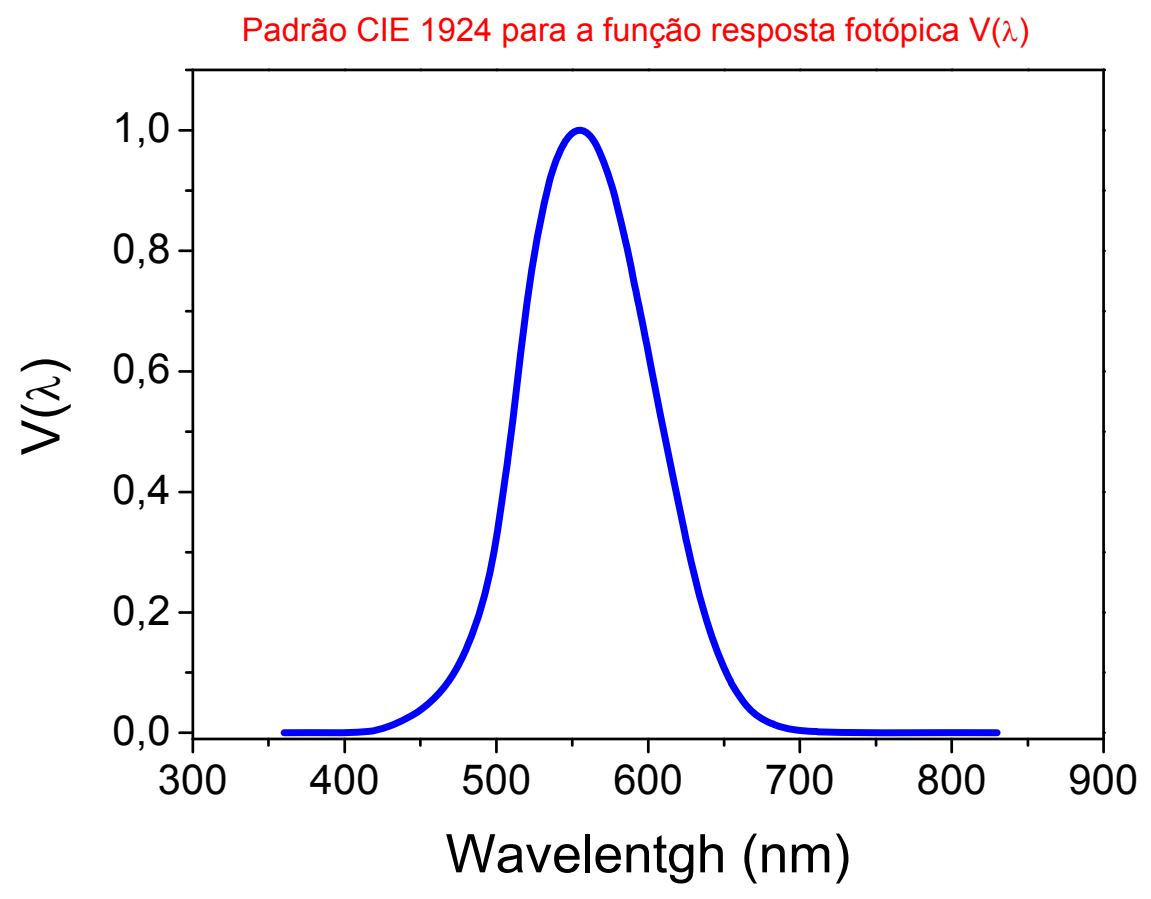

Figura 8 - Função resposta fotópica (V[ $\lambda]$ ) com base no padrão CIE 1924 com precisão de $1 \mathrm{~nm} . \$$

Com isso, a definição para a Eficiência de Potência Luminosa é dada pela relação entre o fluxo luminoso e a potência elétrica, conforme Eq. [15].

$\eta_{P}=\frac{\Phi_{t o t}}{I V}=\frac{\int_{0}^{\infty} K(\lambda) P_{O L E D}(\lambda) d \lambda}{I V} \quad[1 \mathrm{~m} / \mathrm{W}]$

\footnotetext{
${ }^{\S}$ http://www.cvrl.org/cie.htm
} 


\subsubsection{Eficácia luminosa $\left(\eta_{L}\right)$}

Considerando um fluxo de luz circular com raio ( $r$ ) de uma área infinitesimal proveniente de um OLED, conforme ilustra a Figura 9, é possível atribuir, para distâncias (d) sendo d $>>$ r, efetivamente a consideração de que existe uma fonte de luz pontual.

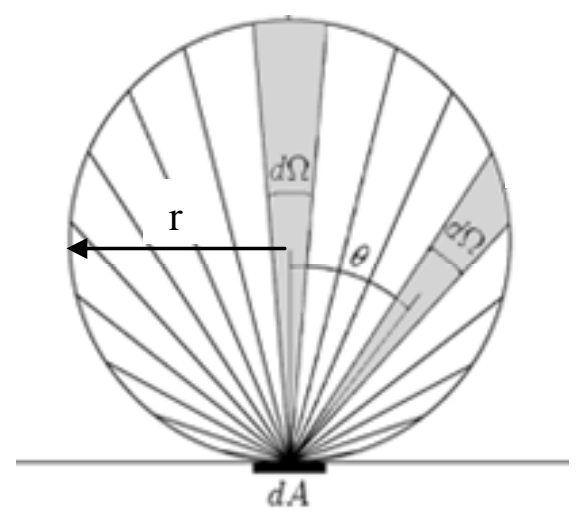

Figura 9 - Espalhamento circular representativo do espalhamento da luz.

A detecção deste sinal (fluxo de fótons por estéreo-radiano) é definida como intensidade luminosa $(i)$, sendo esta grandeza função dos ângulos polar $(\theta)$ e azimutal $(\varphi)$, respectivamente; $d \Omega$ é a variação infinitesimal do ângulo de emissão. Dessa forma, o fluxo luminoso total emitido é definido conforme a Eq. [16].

$\Phi_{t o t}=\int_{0}^{2 \pi} \int_{0}^{\theta / 2} i(\theta, \varphi) \operatorname{sen} \theta d \varphi d \theta$ 
Para fins de simplificação, usualmente considera-se o fluxo de fótons somente em função de $\theta$, no entanto, em alguns estudos, mais específicos, leva-se em consideração o ângulo azimutal para compreender melhor o alinhamento em cadeias poliméricas em filmes formados através da técnica de spin-coating. Levando-se em consideração apenas $\theta$, cujo referencial é de $90^{\circ}$ em relação à superfície, tem-se a aproximação de uma superfície Lambertiana ${ }^{[56]}$ e, com isso, a intensidade possui a seguinte forma $i(\theta)=i_{0} \cos (\theta)$. Assim, o fluxo luminoso total é definido conforme Eq. [17].

$$
\Phi_{\text {tot }}=2 \pi \int_{0}^{\pi / 2} i_{0} \cos \theta \operatorname{sen} \theta d \theta
$$

A Eq. [17] tem por solução $\pi i_{0}$, isto é, para uma superfície Lambertiana a intensidade de 1 Candela (cd) na direção normal equivale a um fluxo luminoso total de $\pi$ Lúmen $(\operatorname{lm})$.

De modo prático a medição óptica de um OLED inicia-se obtendo-se a Luminância (L). Para tanto, é preciso levar em consideração intensidade luminosa $[i(\theta=0)]$ bem como a área emissiva (A). A Luminância é definida na Eq. [18].

$$
L=\frac{i(\theta=0)}{A}\left[\mathrm{~cd} / \mathrm{m}^{2}\right]
$$


Com a medição da corrente elétrica $(I)$ do OLED e sua área emissiva é possível obter a densidade de corrente $(J)$. Assim a eficácia luminosa $\left(\eta_{L}\right)$ pode ser definida como a razão entre a Luminância e a densidade de corrente, como apresentado na Eq. [19].

$\eta_{L}=\frac{L}{J}[\mathrm{~cd} / \mathrm{A}]$

Assumindo-se a emissão do dispositivo eletroluminescente como um emissor Lambertiano é possível obter a eficiência de potência luminosa a partir da $\eta_{L \text {, }}$ conforme apresentado na Eq. [20].

$\eta_{P}=\frac{\pi}{V} \eta_{L}[\operatorname{lm} / \mathrm{W}]$

\subsubsection{Eficiência Quântica Externa ( $\left.\eta_{E Q E}\right)$}

Para o cálculo da Eficiência Quântica Externa $\left(\eta_{E Q E}\right)$ leva-se em consideração a função resposta fotópica e a $\eta_{L}$, conforme Eq. [21].

$\eta_{E Q E}=\frac{\pi e}{K(\lambda) h \nu} \eta_{L}$ [adimensional] 
A Eq. [21] pode ser aproximada a Eq. [22], na qual observamos que a $\eta_{E Q E}$ tem dependência em relação ao comprimento de onda dominante $\left(\lambda_{D}\right)$, a função resposta fotópica $[V(\lambda)]$ e também $\eta_{L}$.

$\eta_{E Q E}=\frac{3,7 \times 10^{3} \lambda_{D}}{V(\lambda)} \eta_{L}$

No presente trabalho para a análise dos dispositivos eletroluminescentes fabricados fez-se uso da eficiência de Potência ou Wall Plug e Eficiência Quântica Externa para as amostras obtidas com base na infra-estrutura do DFUA e EPUSP, respectivamente. Sendo as análises destas eficiências citadas não comparáveis entre si. Em alguns casos, devido à limitação de parâmetros obtidos, a análise foi realizada utilizando-se apenas a $\eta_{L}$. Além disso, as medições de luminância foram efetuadas de segundo a direção normal (adotando-se emissão Lambertiana) e nas de potência óptica ajustou-se no equipamento o comprimento de onda máximo de emissão discreto.

\subsection{Coordenadas de cromaticidade}

As coordenadas de cromaticidade estão relacionadas à teoria de colorimetria, que por sua vez é designada como o estudo das percepções humanas da cor descrevendo e quantificando tais fenômenos. A sistematização das cores tem por base o padrão da 
CIE. No presente trabalho foi utilizado o padrão de 1931, denominado padrão dois graus. Este padrão possui os iluminantes A, B e C bem como as expressões para cálculo dos valores triestímulos $(X Y Z)$ e também as coordenadas de cromaticidade $(x y)$, sendo o iluminante A relativo à emissão de um corpo negro com temperatura de 2856K; o B representa a luz do sol e possui temperatura de cor de aproximadamente 4900K e, por fim, o C representa a luz média do dia e sua temperatura de cor é de $6800 \mathrm{~K}$.

O triestímulo $X Y Z$ da CIE consiste em um sistema aditivo para descrição das cores primárias virtuais. Neste sistema as cores podem ser expressas segundo a Eq. [23].

$\mathrm{xX}+\mathrm{yY}+\mathrm{zZ}$,

sendo x, y e z as quantidades padrão para determinação espectral das cores. As cores normalizadas com base nestas quantidades podem ser expressas segundo as Eqs. [24a, b e c].

$$
x=\frac{X}{X+Y+Z}(\mathrm{a}) ; \quad y=\frac{Y}{Z+Y+Z}(\mathrm{~b}) ; \quad z=\frac{Z}{X+Y+Z}(\mathrm{c}),
$$

sendo verdadeira a afirmativa de que $\mathrm{x}+\mathrm{y}+\mathrm{z}=1$, onde $\mathrm{x}$ e y são associados ao matiz e a saturação, respectivamente. O matiz é considerado a variação da cor acrescido de outra; já a saturação refere-se a proporção do valor atribuído a uma dada cor em 
relação a luminosidade, isto é, ocorre maior saturação quando houver menor quantidade da cor cinza existir na composição da cor.

Com base nas coordenadas de cromaticidade é possível identificar todas as cores possíveis em um gráfico bidimensional, conforme Figura 10.

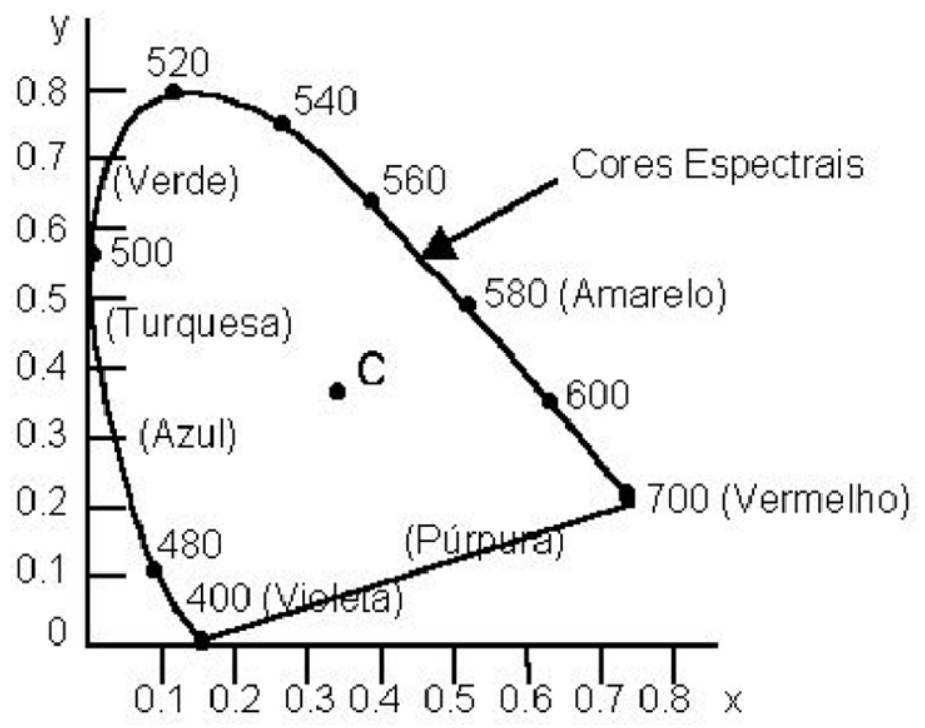

Figura 10 - Diagrama de cromaticidade padrão CIE 1931 típico com a identificação dos comprimentos e ponto $C$ correspondente ao branco localizado nas coordenadas $x=0,33$ e $\mathbf{y}=\mathbf{0 , 3 3}{ }^{[57]}$

Com base neste diagrama neste diagrama é possível extrair parâmetros como o comprimento de onda dominante $\left(\lambda_{D}\right)$, utilizado no cálculo da $E Q E$ (ver Eq. [22]), bem como a pureza de cor. O parâmetro $\lambda_{D}$ é obtido por meio da extrapolação entre o ponto central do diagrama - branco $(x=0,33$ e $y=0,33)$ - e o ponto proveniente da medição, como mostrado na Figura 11. Nesta figura é apresentado um exemplo no 
qual o ponto mensurado foi de $x=0,28$ e $y=0,69$, proporcionando um $\lambda_{D}$ de $547 \mathrm{~nm}$ (verde). No mesmo gráfico têm-se as condições para a extração da pureza de cor, que é designada pela razão entre as dimensões $a$ e $b$ apresentadas no gráfico, no caso apresentado tem-se os valores $a=0,36$ e $b=0,38$, implicando em um pureza de cor de 0,97, indicando verde de alta pureza.

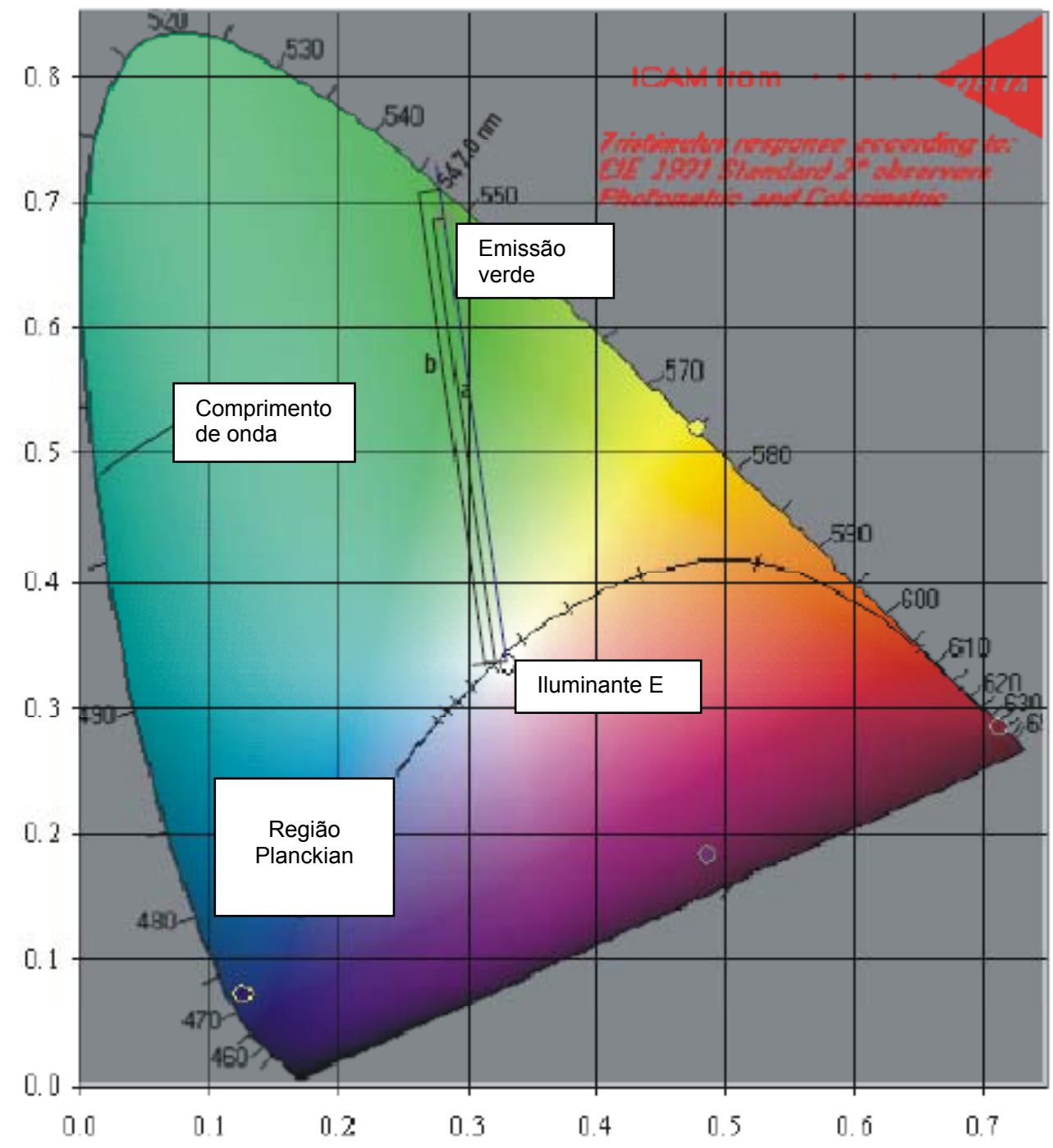

Figura 11 - Obtenção do parâmetro comprimento de onda dominante e pureza de cor. ${ }^{[58]}$ 


\section{Capítulo 3 MATERIAIS E MÉTODOS}

\subsubsection{Leiaute das máscaras para definição do ITO e do Alumínio}

Antes do processo de fabricação dos dispositivos eletroluminescentes, é necessário que tenha sido feito o projeto das máscaras que definem as geometrias do anodo, da área de deposição de polímeros ou orgânicos e do catodo. A área geométrica emissiva dos dispositivos é definida com base neste dimensionamento. No presente trabalho projetaram-se as máscaras apresentadas na Figura 12, nas quais têm-se a definição para o anodo (TCO) e o catodo (metal). Neste caso a área geométrica emissiva é de $9 \mathrm{~mm}^{2}$ com formação de quatro dispositivos em cada amostra. Neste projeto levou-se em consideração a área mínima para medições de luminância, que por sua vez é da ordem de $7 \mathrm{~mm}^{2}$, justamente em respeito a área mínima de medição de luminância, cuja área do ângulo sólido do equipamento é desta ordem, bem como a interdependência entre os dispositivos formados na mesma amostra para evitar o fluxo de corrente para um pixel vizinho. Em todas as amostras fabricadas, no presente trabalho, empregou-se o óxido de índio-estanho (ITO) da Delta Technologies, inc. ${ }^{* *}$ com resistência de folha de $30-60$ ohms/ $\square$.

** http://www.delta-technologies.com/ 
Sobreposição das máscaras
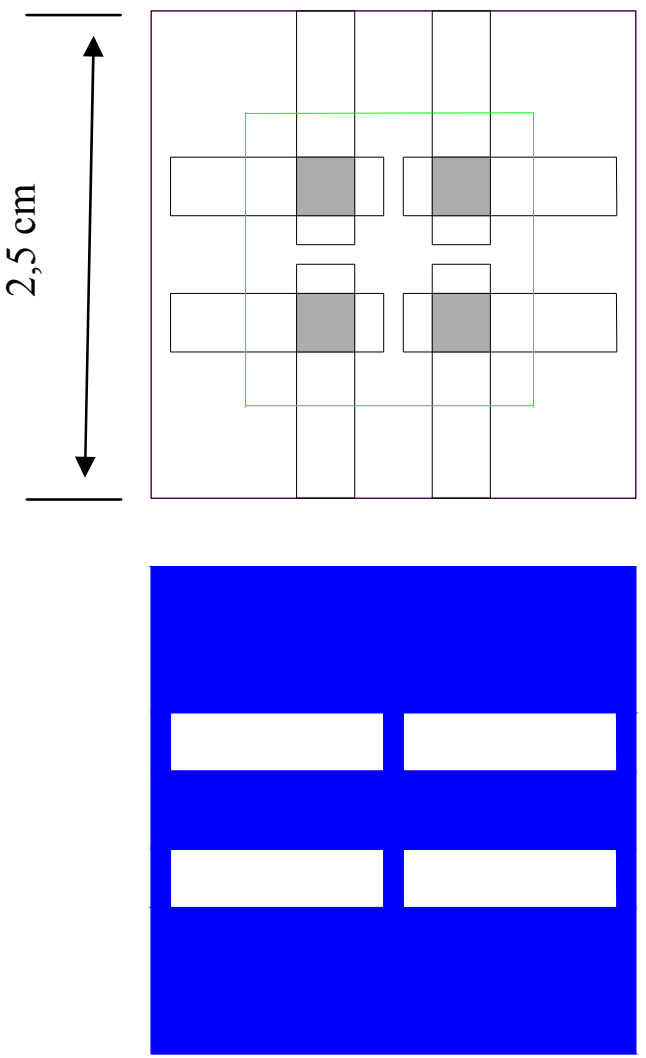

Máscara mecânica para evaporação do metal
Máscara TCO

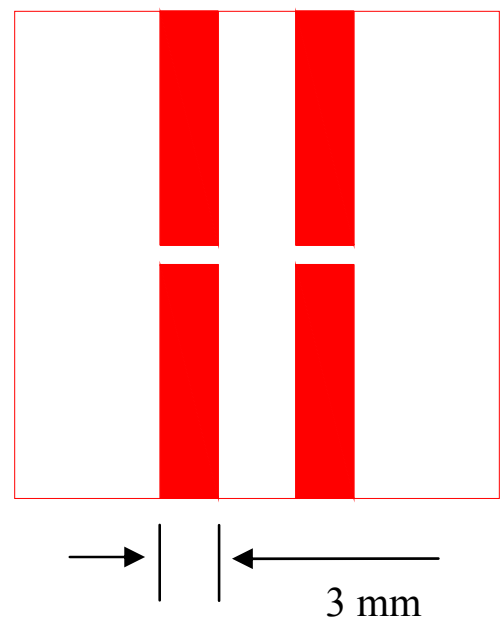

Figura 12 - Leiaute das máscaras utilizadas para fabricação dos dispositivos com base na infraestrutura da EPUSP, sendo a máscara azul para a formação do catodo (evaporação do metal), vermelha para a definição do TCO e a sobreposição de máscaras para visualização para área geométrica ativa de cada dispositivo formado. $O$ traço verde que identifica o dimensionamento do encapsulamento.

Além das máscaras projetadas (Figura 12) utilizaram-se também as máscaras da Figura 13 para fabricação de dispositivos no Departamento de Física da Universidade de Aveiro, cuja infra-estrutura permite a fabricação de dispositivos com área 
geométrica emissiva de $25 \mathrm{~mm}^{2}$ com formação também de quatro dispositivos na mesma amostra.

Máscara TCO

Sobre posição de máscaras

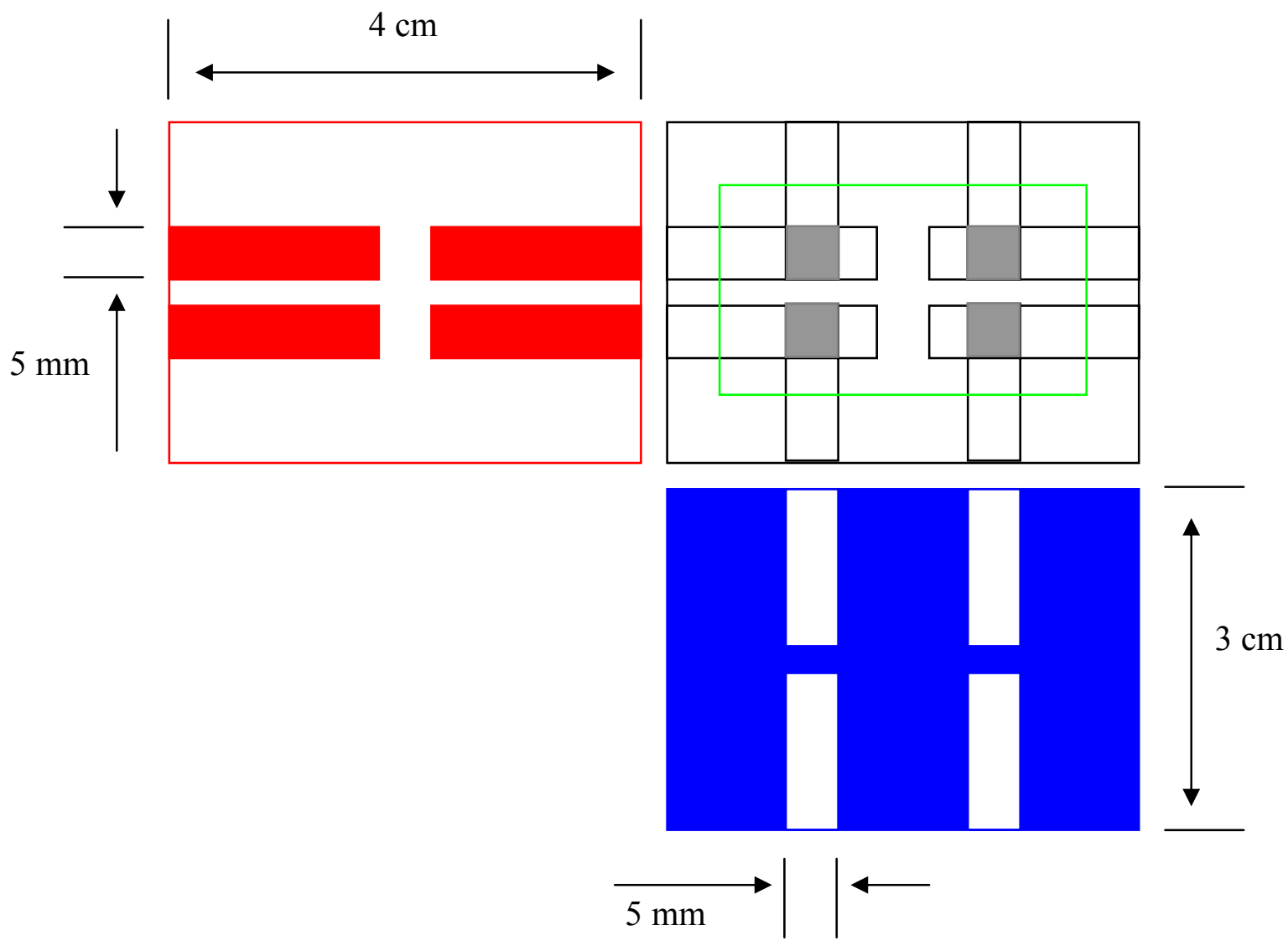

Máscara mecânica para a evaporação do metal

Figura 13 - Leiaute das máscaras utilizadas para a fabricação de dispositivos eletroluminescentes na infra-estrutura da UA, sendo a máscara azul para a formação do catodo (evaporação do metal), vermelha para a definição do TCO e a sobreposição de máscaras para visualização para área geométrica ativa de cada dispositivo formado. $O$ traço verde que identifica o dimensionamento do encapsulamento.

G. Santos - Escola Politécnica da Universidade de São Paulo - OLEDs, PLEDs e LECs 


\subsubsection{Limpeza superficial do TCO}

Após a definição da geometria a ser empregada a placa de vidro com o ITO é submetida a um processo de limpeza superficial que tem por objetivo remover contaminantes orgânicos. Para tanto, são adotados os seguintes procedimentos:

- Banho de ultra-som com acetona por 20 minutos;

- Remoção de traços de acetona com água destilada/DI ou Ultra-Pura por 1 minuto;

- Banho de ultra-som com isopropanol para remoção de traços de água por 10 minutos.

Após a o banho de ultra-som, empregando isopropanol, a placa é seca com fluxo de nitrogênio. Seguidamente a limpeza, esta é imediatamente encaminhada para a deposição dos filmes finos para formação do dispositivo eletroluminescente.

\subsubsection{Processo de formação de filmes finos}

\subsubsection{Evaporação térmica}

A evaporação térmica consiste na formação de filmes finos empregando materiais orgânicos (moléculas pequenas) e aquecimento sob alto vácuo. $\mathrm{O}$ composto orgânico, dependendo de suas características, é acondicionado em um cadinho 
apropriado, e este pode ser constituído por um material cerâmico, ou mesmo metálico como molibdênio e tungstênio. Para materiais que sublimam costuma-se empregar cadinhos cerâmicos; já para materiais que fundem são utilizados os metálicos. No presente trabalho foram utilizadas tanto a evaporadora do Departamento de Física da Universidade de Aveiro quanto a da Escola Politécnica da Universidade de São Paulo, que se encontra embutida no sistema GloveBox, ambas são apresentadas nas Figura 14 e Figura 15.

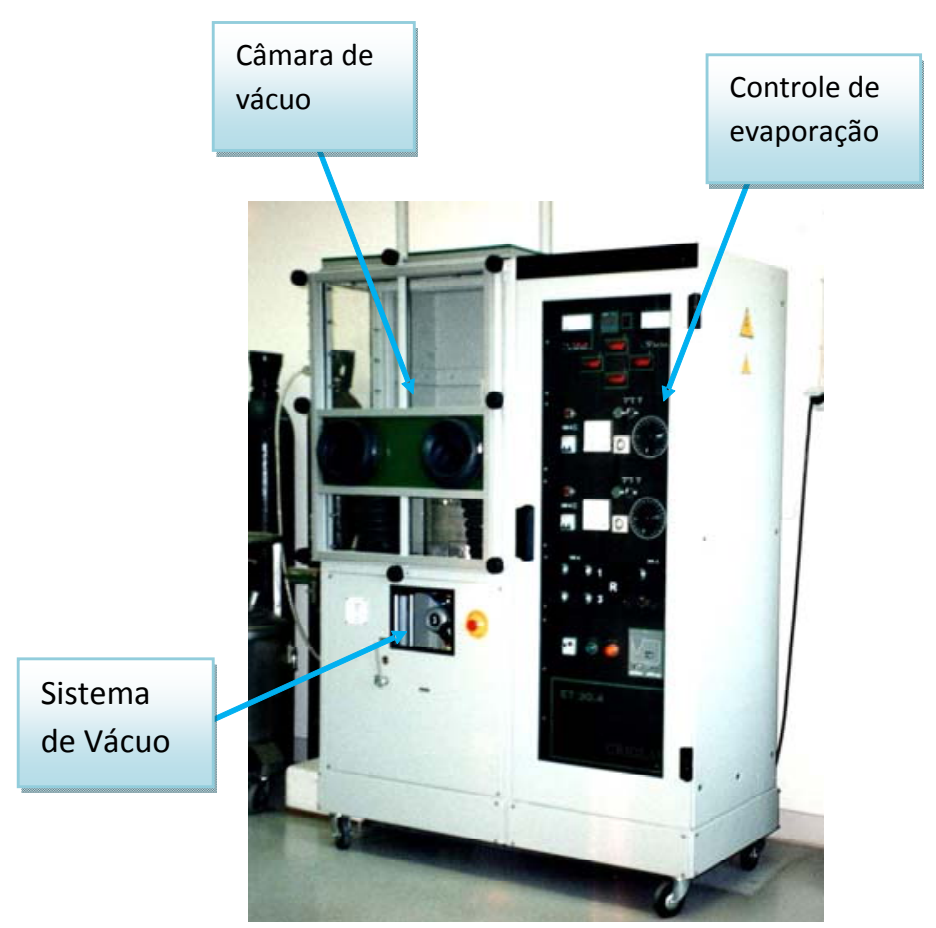

Figura 14 - Sistema de evaporação térmica do Departamento de Física da Universidade de Aveiro. 


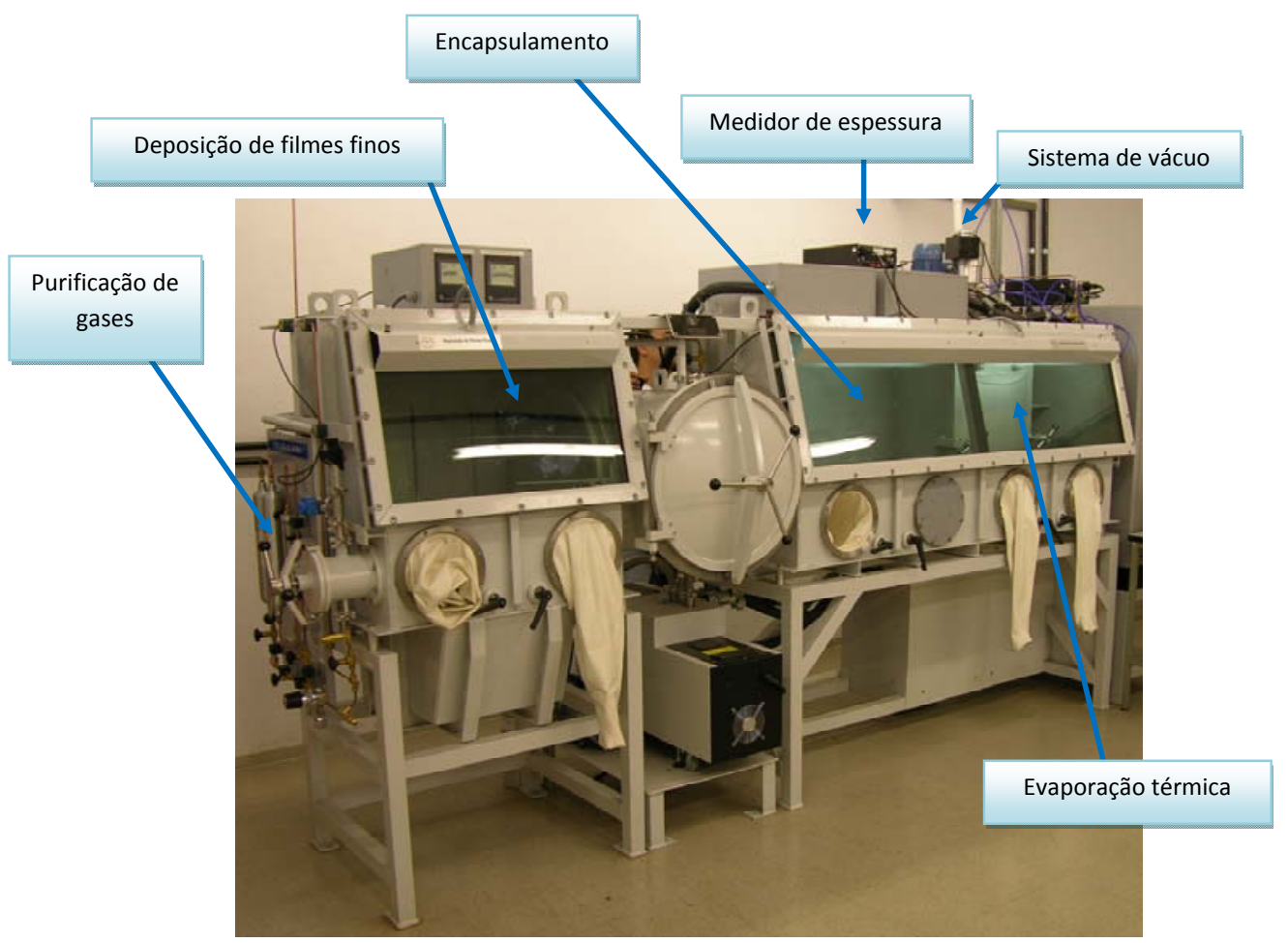

Figura 15 - Sistema GloveBox da Escola Politécnica da Universidade de São Paulo.

\subsubsection{Spin-coating}

Para formação dos filmes finos utilizando-se a técnica de spin-coating foi empregado o equipamento SPIN COATER modelo P-6000 da Specialty Coating Systems, Inc, cujo processo é realizado por meio do ajuste da rotação e tempo, definidos em rotação por minuto (RPM) e segundos, respectivamente. Assim os filmes, formados no presente trabalho, contaram previamente com estudo de cada material, em específico, para se obter uma espessura compatível com dispositivos deste tipo, levando-se em consideração que para filmes muito finos (abaixo de $10 \mathrm{~nm}$ ) existe elevada probabilidade de curto-circuito, enquanto que filmes espessos (acima de 
$500 \mathrm{~nm}$ ) existe a probabilidade de elevada resistência no dispositivo acoplada com menor chance de recombinação de portadores de carga e, com isso, nestes casos extremos, perde-se a função estipulada para o filme fino formado. A Figura 16 apresenta o diagrama esquemático do spin coater utilizado no presente trabalho.

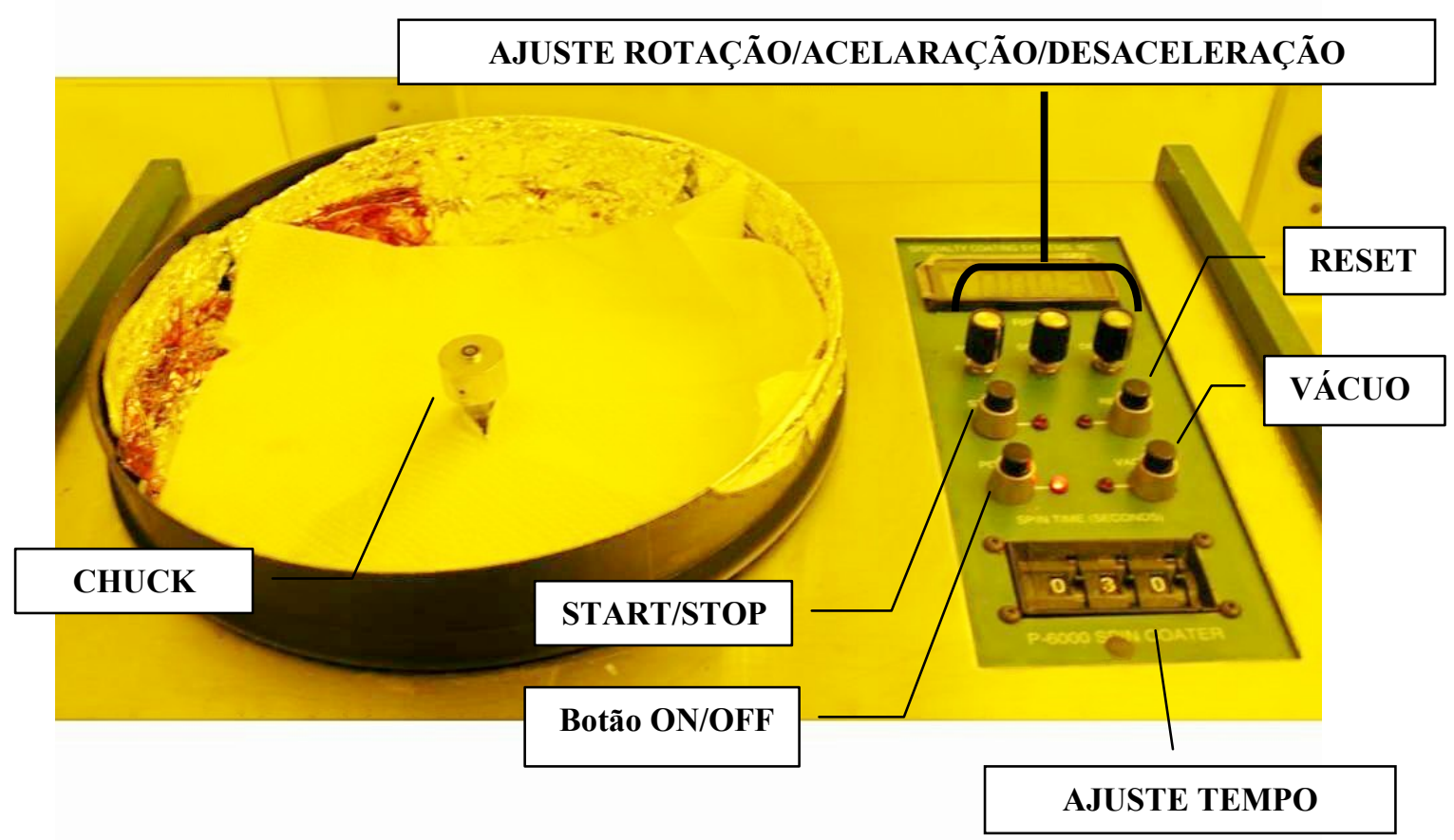

Figura 16 - Diagrama esquemático do equipamento Spin coater utilizado para formação dos filmes finos empregando complexos de Terras Raras e de Metais de Transição dispersos em PVK. 


\subsubsection{Automontagem (Self-Assembly)}

Tradicionalmente os filmes finos utilizados para a fabricação de dispositivos eletroluminescentes são formados através da técnica de spin-coating ou mesmo por evaporação térmica. A técnica de automontagem ou Layer-by-Layer é uma técnica alternativa ao spin-coating bem como o spin-casting e que tem por característica a formação de filmes ultra-finos (da ordem de $2 \mathrm{~nm}$ cada bicamada) com elevada homogeneidade e também condutividade, cujo pioneiro foi DECHER et al. ${ }^{[59]}$ Além disso, esta técnica é simples e de baixo custo. Adicionalmente, os filmes formados nesta técnica possuem compatibilidade de uso de polímeros não solúveis em água.

Apesar de possuir processamento fácil envolvendo uma solução catiônica, água e outra aniônica, os filmes são formados manualmente o que implica na introdução de pequenas variações ao longo da formação das bicamadas. Recentemente, algumas instituições de pesquisa têm investido em opções de automação com o intuito de que os filmes formados sejam mais reprodutíveis e viáveis para deposições acima de vinte bicamadas. ${ }^{[60]}$

Seguindo a forma manual ou automática, o processo desenvolve-se segundo o diagrama apresentado na Figura 17. No presente trabalho os filmes automontados foram produzidos manualmente. 


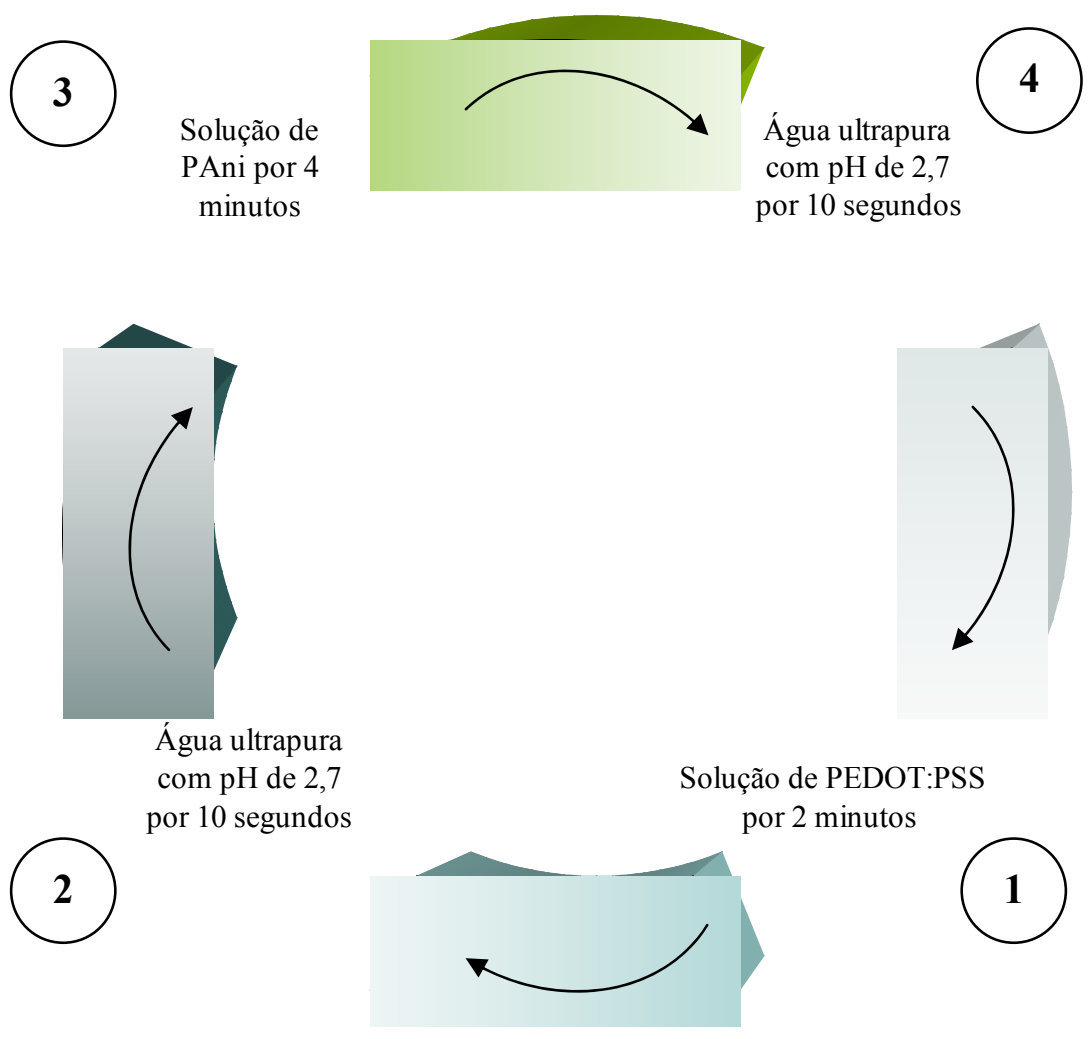

Figura 17 - Diagrama representativo do ciclo para formação de cada bicamada no processo de automontagem.

\subsubsection{Medições de espessuras de filmes depositados por Spin- coating e crescidos por evaporação térmica (Profilômetria)}

Para a avaliação da espessura dos filmes finos formados, tanto através da técnica de spin-coating como evaporação térmica, utilizou a técnica de profilômetria, que consiste em uma microponta que faz varredura na superfície do filme fino até a interface de um degrau, previamente definido.

G. Santos - Escola Politécnica da Universidade de São Paulo - OLEDs, PLEDs e LECs 
Para a obtenção destas medições utilizou-se o equipamento da TENCOR modelo ALPHA STEP 500 surface profiler. A Figura 18 apresenta o esboço de funcionamento desta técnica.

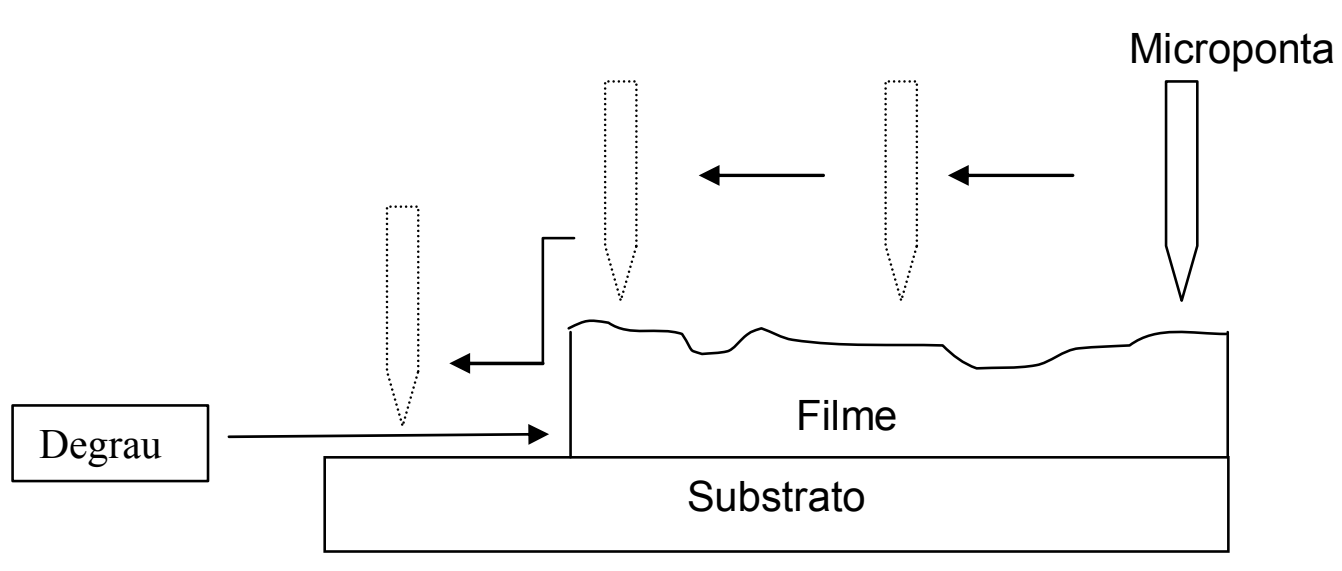

Figura 18 - Esboço de funcionamento da técnica de perfilometria.

Neste trabalho alguns filmes finos não tiveram suas respectivas espessuras inferidas, através desta técnica, pelo fato do filme ser muito fino (abaixo da espessura mínima do equipamento de perfilometria). Além disso, alguns filmes, termicamente evaporados, são de densidade conhecida e, desta forma, ajustou-se o medidor de quartzo (localizado dentro da câmara de evaporação), que por sua vez apresenta os valores da taxa de deposição em $[\AA / s]$ bem como o valor final do filme evaporado $\mathrm{em}[\AA]$. 


\subsubsection{Encapsulamento}

Os dispositivos eletroluminescentes, fabricados na Escola Politécnica da Universidade de São Paulo, foram encapsulados utilizando-se vidro e epóxi em ambiente inerte, com gás argônio. O propósito do encapsulamento não foi a verificação do tempo de vida, pois não fazia parte do escopo do presente trabalho, mas facilitar o manuseio e caracterização eletro-óptica bem como minimizar a chance de danificação ou mesmo contato involuntário com a região ativa do dispositivo. A Figura 19 apresenta o diagrama da estrutura do dispositivo eletroluminescente incluindo o encapsulamento.

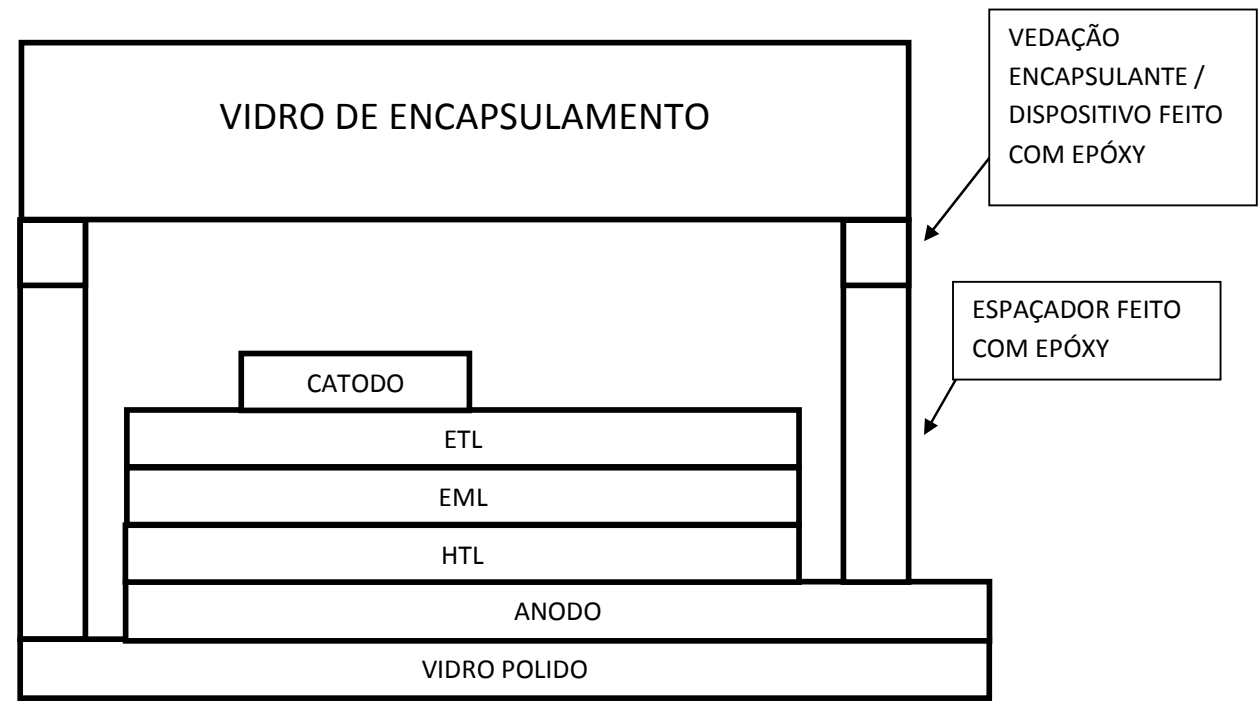

Figura 19 - Diagrama esquemático do dispositivo eletroluminescente com seus filmes finos e a conexão com o vidro de encapsulamento feito com epóxi. 


\subsubsection{Caracterização funcional elétrica e óptica}

A caracterização funcional elétrica foi realizada utilizando-se o equipamento Keithley Sourcemeter modelo 2410C (EPUSP) e 6410 (DFUA) em conjunto com o colorímetro da Konica Minolta, modelo CS100A, o espectrofotômetro Ocean Optics, modelo HR2000+, e o medidor de potência óptica OPHIR, modelo PD300-SH. Esses equipamentos permitem a obtenção das curvas J-V-L, sendo L a luminância ou potência óptica. Os diagramas esquemáticos das montagens elaboradas para a caracterização eletro-óptica na EPUSP e no DFUA são apresenta nas Figura 20a e b, respectivamente. Ressalta-se que todas as medições de PL foram realizadas a temperatura ambiente.

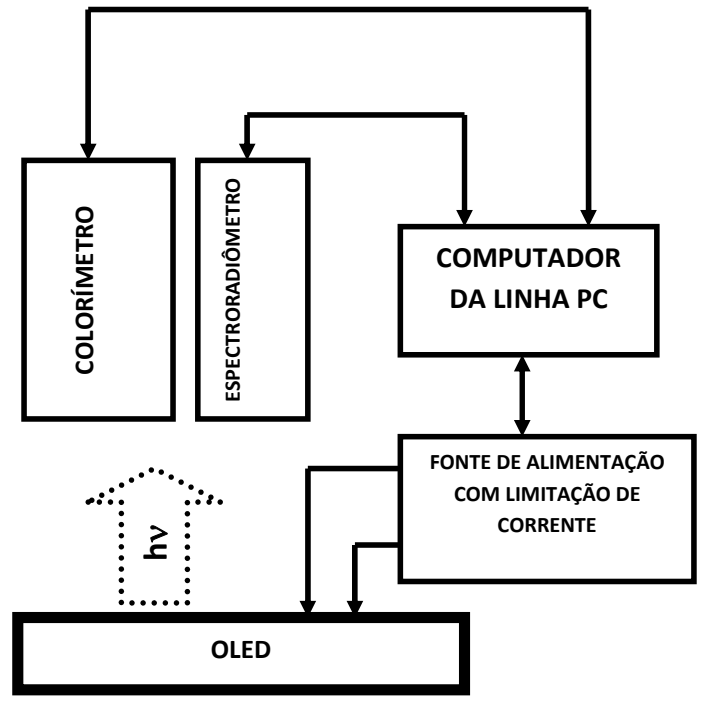

(a)

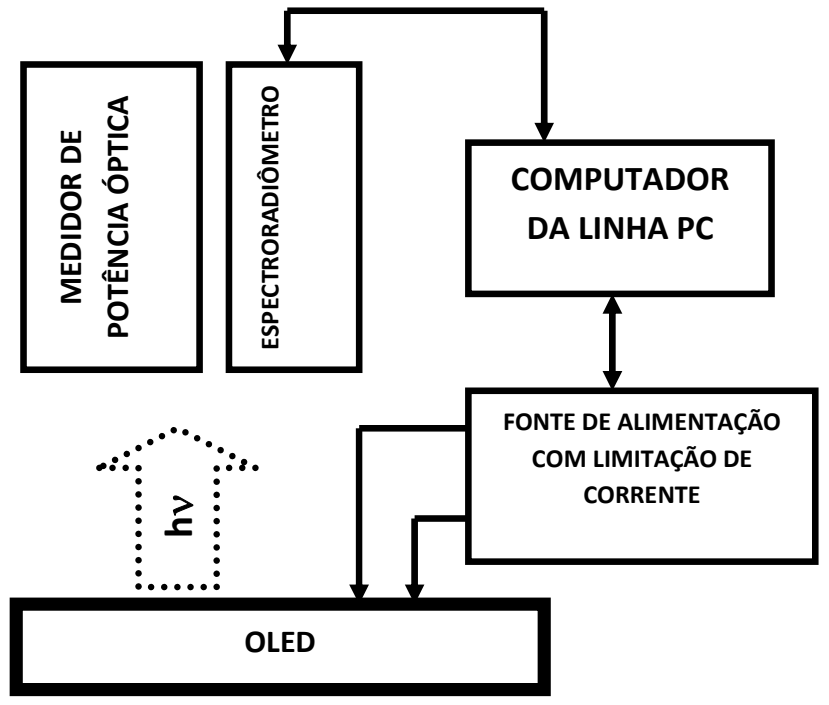

(b)

Figura 20 - Diagrama esquemático da montagem caracterização eletro-óptica dos dispositivos eletroluminescentes, com base na infra-estrutura a) EPUSP e b) DF-UA. 
Com a caracterização funcional elétrica, acoplada a óptica, é possível obter as eficiências externas dos dispositivos eletroluminescentes como a eficácia luminosa $\left(\eta_{L}\right)$ dada em $c d / A$, eficiência de potência luminosa $\left(\eta_{P}\right)$ dada em $\mathrm{lm} / W$, de potência ou Wall Plug $\left(\eta_{W W}\right)$ - adimensional e quântica externa $\left(\eta_{E Q E}\right)$ também adimensional, cuja teoria foi descrita no tópico 2.4 .

\subsubsection{Metodologia empregada para a fabricação dos dispositivos eletroluminescentes}

\subsubsection{OLEDs empregando complexo de Európio com a variação do ligante principal (evaporação térmica)}

Neste caso, foram fabricadas estruturas do tipo ITO/ N,N'-bis(3-metilfenil)-N,N'-

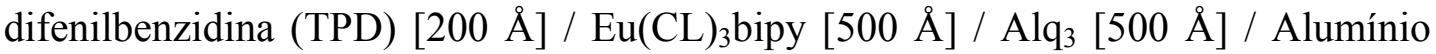
$\left[\begin{array}{ll}1000 & \AA\end{array}\right]$ (Figura 21) para o estudo, do ponto de vista físico e tecnológico, do complexo de Európio com estrutura química $\mathrm{Eu}(\mathrm{CL})_{3}$ bpy, sendo CL o ligante principal, como filme emissivo. As máscaras utilizadas para a formação destes dispositivos possuem $25 \mathrm{~mm}^{2}$ de área emissiva (máscaras da Figura 13).

Os complexos de Európio com os diferentes ligantes principais e suas respectivas estruturas químicas empregados no presente trabalho são apresentados na Tabela 2. 
Tabela 2 - Nomenclatura do Complexo de Terra Rara, Ligante empregado e estrutura química.

\begin{tabular}{|c|c|c|}
\hline $\begin{array}{l}\text { Nomenclatura do } \\
\text { complexo }\end{array}$ & Ligante Principal & Estrutura Química \\
\hline $\mathrm{Eu}(\mathrm{DBM})_{3}$ bipy & Dibenzoilmetanato & Eu(DBM)3bipy \\
\hline $\mathrm{Eu}(\mathrm{TTA})_{3}$ bipy & Tenoiltrifluoroacetonato & {$\left[_{\text {Eu(TTA)3bipy }}\right]_{3}$} \\
\hline $\mathrm{Eu}(\mathrm{NTA})_{3}$ bipy & Naftalotrifluoroacetonato & Eu(NTA)3bipy \\
\hline $\mathrm{Eu}(\mathrm{BTA})_{3}$ bipy & Benzoiltrifluoroacetonato & $\begin{array}{l}\langle\Delta\rangle]_{3} \\
\text { Eu(BTA)3bipy }\end{array}$ \\
\hline
\end{tabular}


O diagrama esquemático da estrutura dos dispositivos fabricados é apresentado na Figura 21 em conjunto com a estrutura química dos orgânicos empregados com função de transporte de lacunas (TPD) e elétrons $\left(\mathrm{Alq}_{3}\right)$, respectivamente.

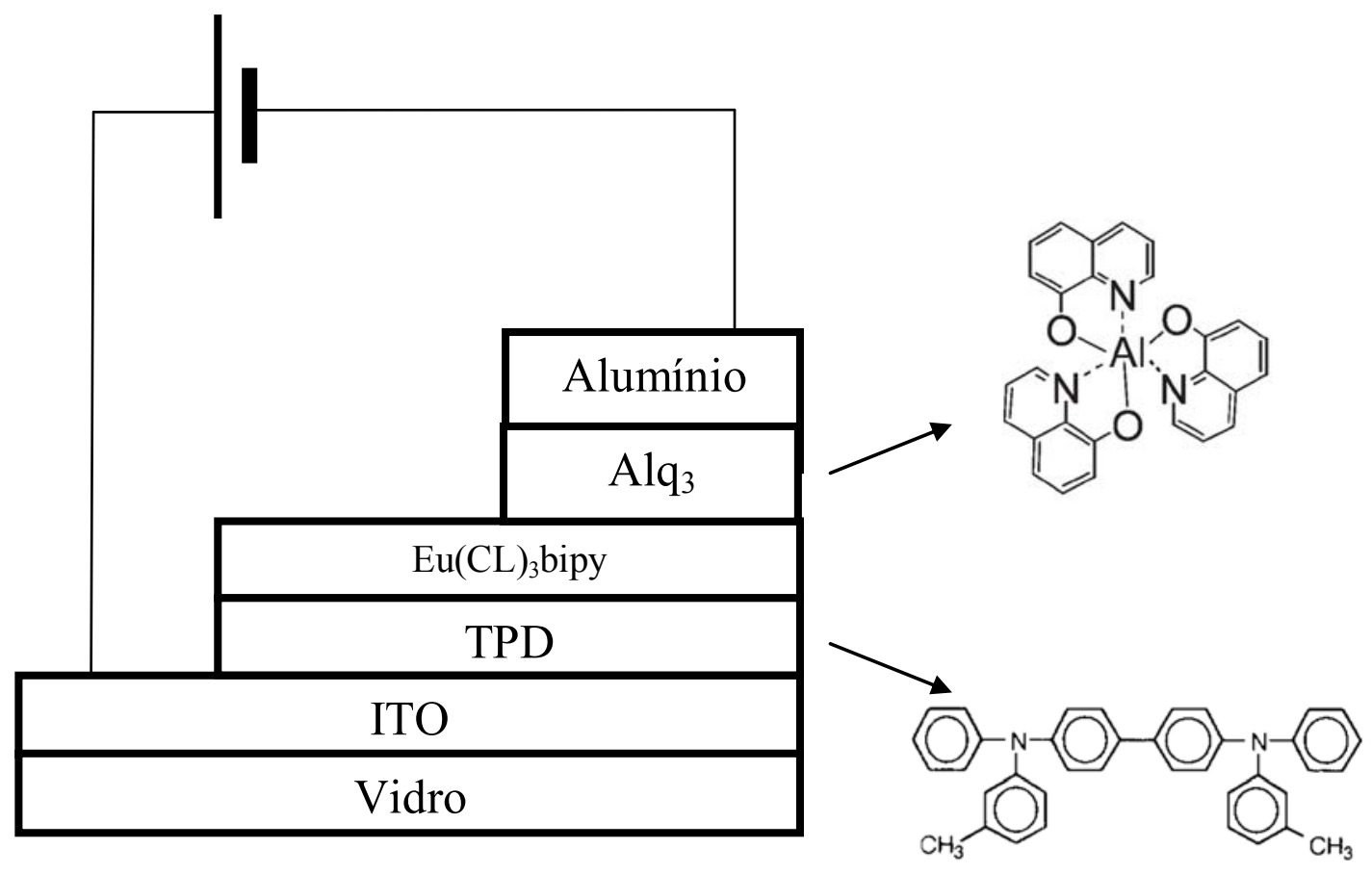

Figura 21 - Diagrama esquemático da estrutura utilizada para o estudo do complexo de Európio com diferentes ligantes principais com indicação da estrutura química dos orgânicos empregados para transporte de lacunas e elétrons. ${ }^{[61]}$

A Figura 22 apresenta o detalhe para evaporação do complexo de TR (cadinho de molibdênio) e também do material orgânico com função de transportador de elétrons (ETL) Alq3 (cadinho cerâmico suportado por um filamento de tungstênio). 


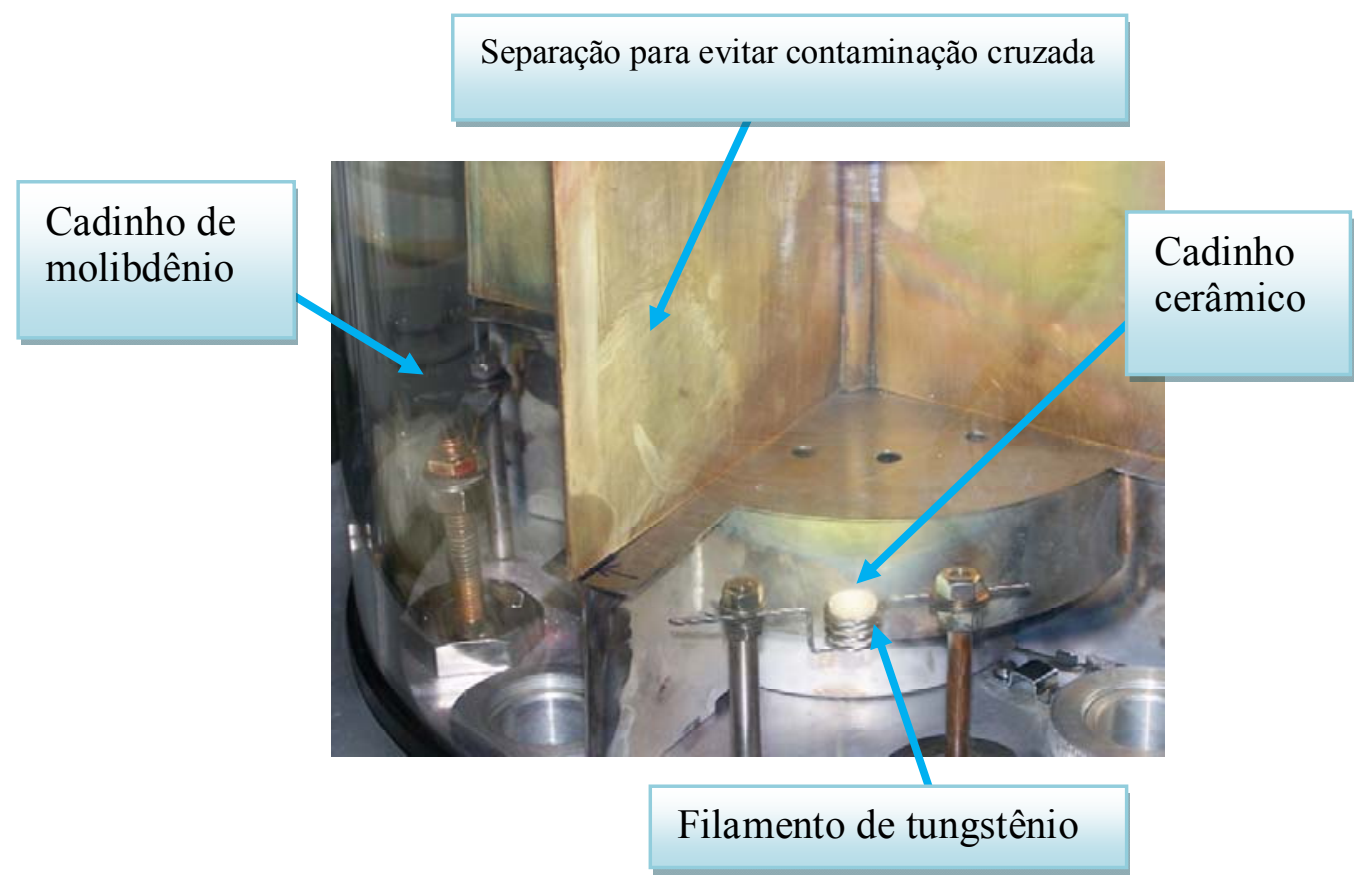

Figura 22 - Detalhe da câmara de evaporação da UA com os diferentes tipos de cadinhos empregados para a fabricação dos dispositivos eletroluminescentes.

Os complexos de Terras Raras, utilizados neste trabalho, foram sintetizados no Laboratório de Polímeros Paula Scarpa (LaPPS) da Universidade Federal do Paraná $(\mathrm{UFPR})^{[62]}$ e também no Centro de Investigação em Materiais Cerâmicos e Compósitos (CICECO) da Universidade de Aveiro (UA). ${ }^{[63]}$ Os compostos orgânicos comerciais $(N, N$-difenil- $N, N$-bis (3-metilfenil)-1,1'-bifenil-4,4'-diamina [TPD], 2-(4bifenil)-5-(4-tert-butilfenil)-1,3,4 Oxadiazol [b-PBD] e tris(8-hidroxiquinolina alumínio) $\left[\mathrm{Alq}_{3}\right]$ foram obtidos da Sigma-Aldrich. ${ }^{\dagger \dagger}$

\footnotetext{
${ }^{\#}$ http://www.sigmaaldrich.com
} 


\subsubsection{OLEDs empregando complexo de Térbio variando-se o ligante neutro (evaporação térmica)}

Ainda em se tratando de dispositivos com filmes termicamente evaporados (tópico 3.1.3.1) empregou-se o complexo de Térbio variando-se NL, o qual possui por função, segundo a hipótese mais aceitável, manter a estabilidade química e térmica no complexo. No presente trabalho buscou-se investigar comparativamente a variação do ligante neutro na eficiência externa dos dispositivos fabricados. Neste caso, manteve-se fixo o ligante principal (CL), o acetilacetonato (ACAC), e variouse o ligante neutro (NL), cujas estruturas são apresentadas na Tabela 3. 
Tabela 3 - Nomenclatura do Complexo de Terra Rara, Ligante empregado e estrutura química.

\begin{tabular}{|c|c|c|}
\hline $\begin{array}{c}\text { Nomenclatura do } \\
\text { complexo }\end{array}$ & Ligante Neutro & Estrutura Química do \\
\hline $\mathrm{Tb}(\mathrm{ACAC})_{3}$ bipy & Bipiridina & complexo \\
\hline $\mathrm{Tb}(\mathrm{ACAC})_{3}$ phen & Fenantrolina
\end{tabular}

Com base nesta variação do complexo de Térbio fabricou-se a estrutura do tipo ITO/TPD $\left[\begin{array}{ll}200 & \AA\end{array}\right] / \operatorname{Tb}(\mathrm{ACAC})_{3}(\mathrm{NL}) \quad\left[\begin{array}{ll}500 & \AA\end{array}\right] / \mathrm{Alq}_{3}\left[\begin{array}{ll}500 & \AA\end{array}\right] /$ Alumínio $\left[\begin{array}{lll}1000 & \AA\end{array}\right]$, conforme diagrama esquemático do dispositivo apresentado na Figura 23. Neste caso, todos os filmes finos formados foram termicamente evaporados. 


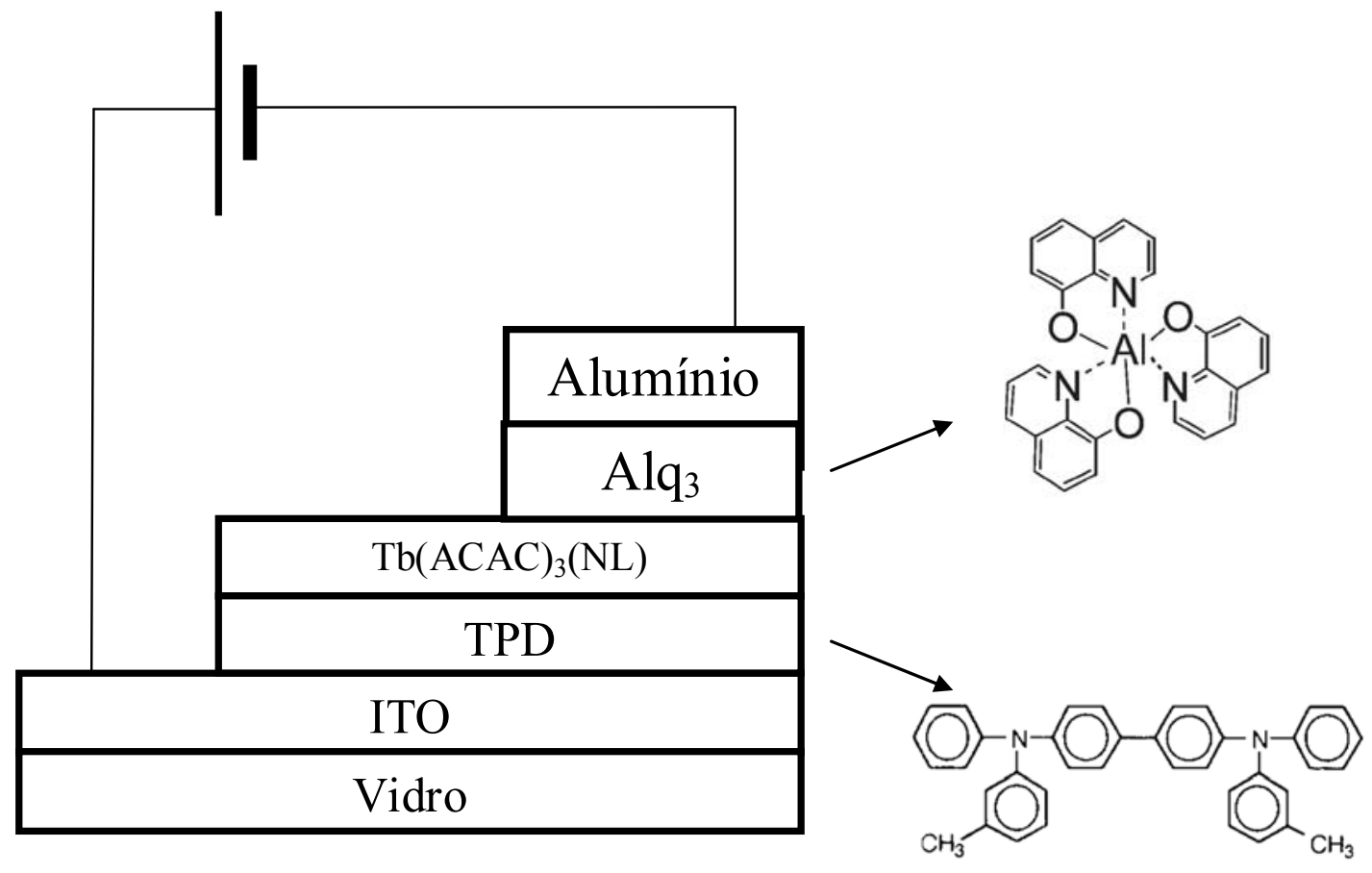

Figura 23 - Diagrama esquemático da estrutura utilizada para o estudo do complexo de Térbio variando-se o ligante neutral com indicação da estrutura química dos orgânicos empregados para transporte de lacunas e elétrons.

\subsubsection{OLEDs empregando complexo de Európio disperso em PVK (spin-coating)}

\subsection{Complexo de Európio disperso em PVK}

A partir dos ensaios empregando o complexo de Európio termicamente evaporado, formando, o próprio complexo, o filme emissivo, partiu-se para a alternativa de 
empregar o complexo como um corante disperso em uma matriz polimérica com a perspectiva de se ter maior eficiência externa, com base nas vantagens descritas no tópico 2.1.4 e também no fato de que o polivinilcarbazol (PVK) possuir uma emissão, cuja banda intercepta a de absorção do complexo de Európio $^{[64]}$ proporcionando, deste modo, transferência de energia adequada, segundo o fenômeno do Efeito Antena (ver tópico 2.1.3).

Neste foco do estudo foi selecionado o complexo $\operatorname{Eu}(\mathrm{TTA})_{3}$ bipy, o qual foi inserido na estrutura ITO/polietilenodioxitiofeno dopado com poliestireno sulfonado

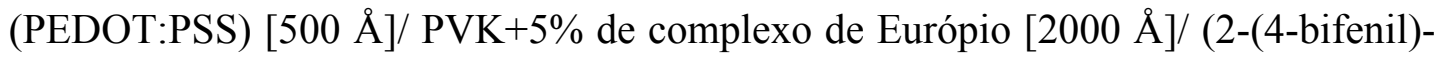
5-(4-tert-butilfenil)-1,3,4 oxidiazol (b-PBD) [100 A]/Alumínio [1000 Å], conforme estrutura apresentada na Figura 24, a qual inclui também as estruturas químicas dos orgânicos utilizados. Neste caso, o HTL e o EML foram depositados por meio da técnica de spin-coating (ver tópico 3.1.3.2), enquanto o ETL e catodo por evaporação térmica (ver tópico 3.1.3.1). 


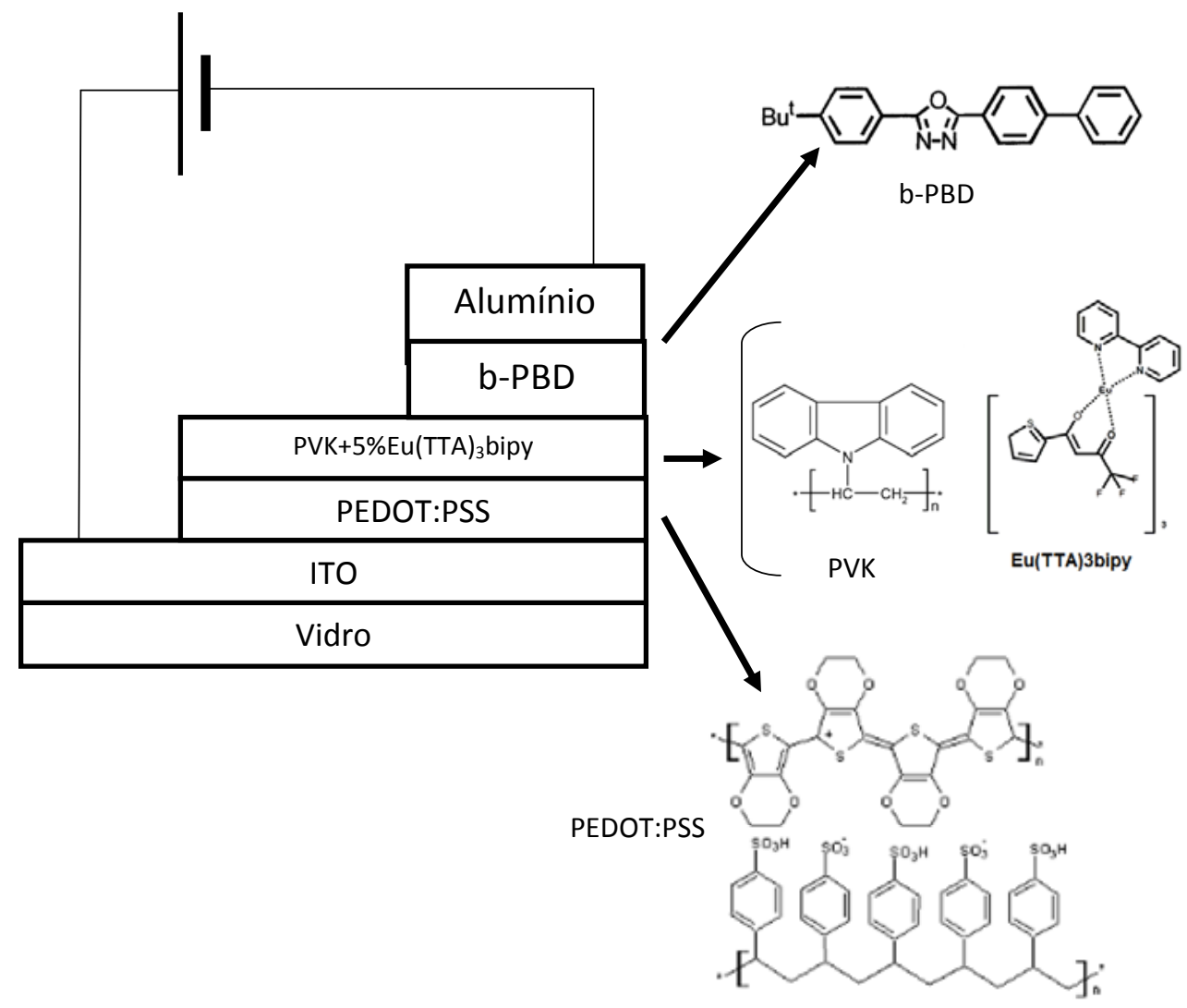

Figura 24 - Diagrama esquemático da estrutura empregada para estudo do complexo de Európio disperso em PVK.

\subsubsection{OLED empregando complexo de Térbio disperso em PVK (spin-coating)}

A partir dos ensaios empregando o complexo de Térbio termicamente evaporado, e seguindo a idéia já referida para os complexos de Európio, foram igualmente testados dispositivos utilizando-se um filme emissivo obtido pela dispersão do complexo de Térbio [Tb(ACAC $)_{3}$ bipy] em PVK. Apesar do PVK possuir uma emissão, cuja banda 
intercepta pouco a de absorção do complexo de Térbio (apresentada na secção de resultados experimentais respectiva) não devendo proporcionar, em princípio, uma transferência de energia adequada, segundo o fenômeno do Efeito Antena, existe, reportado na literatura, resultados promissores (embora com um ligante orgânico diferente mas que, em uma primeira análise tende a obedecer às mesmas condições energéticas para popular o estado ${ }^{5} \mathrm{D}_{4}$ do íon Térbio). ${ }^{[65]}$

Neste foco do estudo foi selecionado o complexo $\mathrm{Tb}(\mathrm{ACAC})_{3}$ bipy, o qual foi inserido na estrutura ITO/ PEDOT:PSS $[500 \AA] / \mathrm{PVK}+5 \%$ de complexo de Térbio

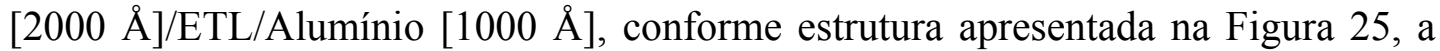
qual inclui também as estruturas químicas dos orgânicos utilizados. Como ETL empregou-se tanto o butil-PBD quanto o $\mathrm{Alq}_{3}$ comparativamente, para avaliar se a influência deste filme poderia atenuar possibilidade de emissão por parte do complexo de Térbio. Neste caso, o HTL e o EML foram depositados por meio da técnica de spin-coating (ver tópico 3.1.3.2), enquanto o ETL e catodo por evaporação térmica (ver tópico 3.1.3.1). 


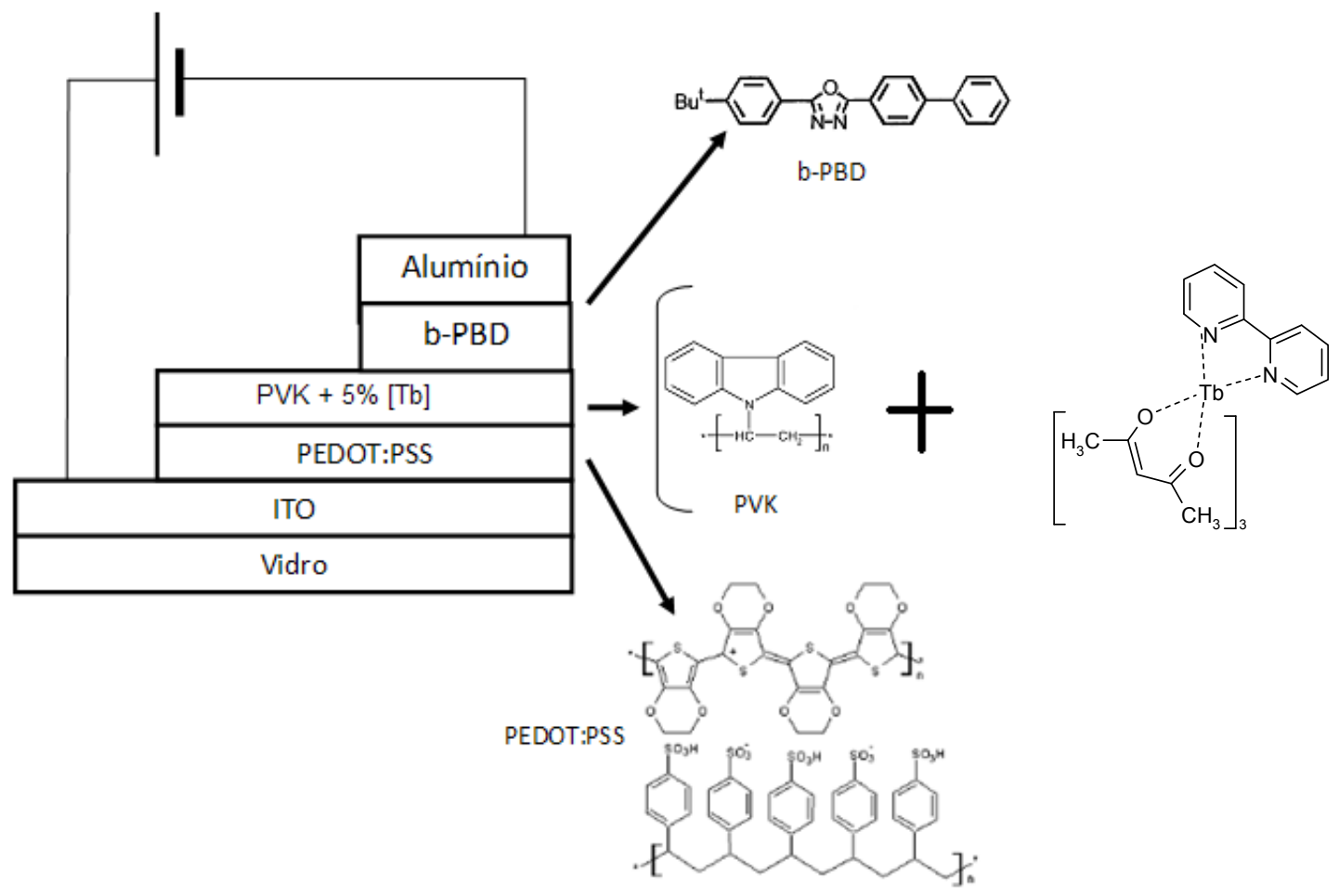

Figura 25 - Diagrama esquemático da estrutura empregada para estudo do complexo de Térbio disperso em PVK.

\subsubsection{OLEDs empregando complexo de Európio disperso em PVK (EML) e bicamadas PAni/PEDOT:PSS (HTL) comparativamente ao filme de PEDOT:PSS por spin-coating}

Com base na experiência bem sucedida da utilização do complexo de Európio disperso na matriz polimérica, composta, neste caso, pelo polivinilcarbazol (PVK), projetou-se uma nova arquitetura alterando-se o transportador típico de lacunas PEDOT:PSS por bicamadas de polianilina (PAni) e PEDOT:PSS automontadas. 
Adicionalmente avaliou-se o desempenho da arquitetura sem HTL, isto é, sem formação de bicamadas nem filme de PEDOT:PSS por spin-coating. A finalidade deste estudo foi avaliar o desempenho do dispositivo eletroluminescente empregando-se filmes ultra-finos depositados por meio da técnica de automontagem (ver tópico 3.1.3.3). Neste caso, fez-se um estudo comparativo para avaliar o desempenho entre dispositivos variando-se o número de bicamadas PAni/PEDOT:PSS, conforme Tabela 4, sendo que cada bicamada possui aproximadamente $2 \mathrm{~nm}$ de espessura. Essa estimativa decorre do fato da adesão das moléculas por atração eletrostática de modo que cada bicamada seja comparável a escala atômica. ${ }^{[66]}$ Os materiais para fabricação dos dispositivos e para o processo de automontagem foram sintetizados na UFPR, IQUSP e EPUSP, os quais foram utilizados como preparado. ${ }^{[67]}$

Tabela 4 - Correlação entre o dispositivo fabricado e o número de bicamadas.

\begin{tabular}{|c|c|}
\hline $\mathbf{n}^{\mathbf{0}}$ do dispositivo & $\mathbf{n}^{\mathbf{0}}$ de bicamadas \\
\hline 1 & Sem bicamadas \\
\hline 2 & 1 \\
\hline 3 & 3 \\
\hline 4 & 5 \\
\hline 5 & 10 \\
\hline
\end{tabular}

Para deposição da EML utilizou-se a técnica de spin-coating descrita no tópico 3.1.3.2, com aproximadamente $200 \mathrm{~nm}$. Como ETL utilizou-se o orgânico butil-PBD com $100 \AA$ Å. Por fim, evaporou-se alumínio para a formação do anodo. O ETL e 
catodo foram termicamente evaporados (ver tópico 3.1.3.1), cujo diagrama esquemático do dispositivo fabricado é apresentado na Figura 26.

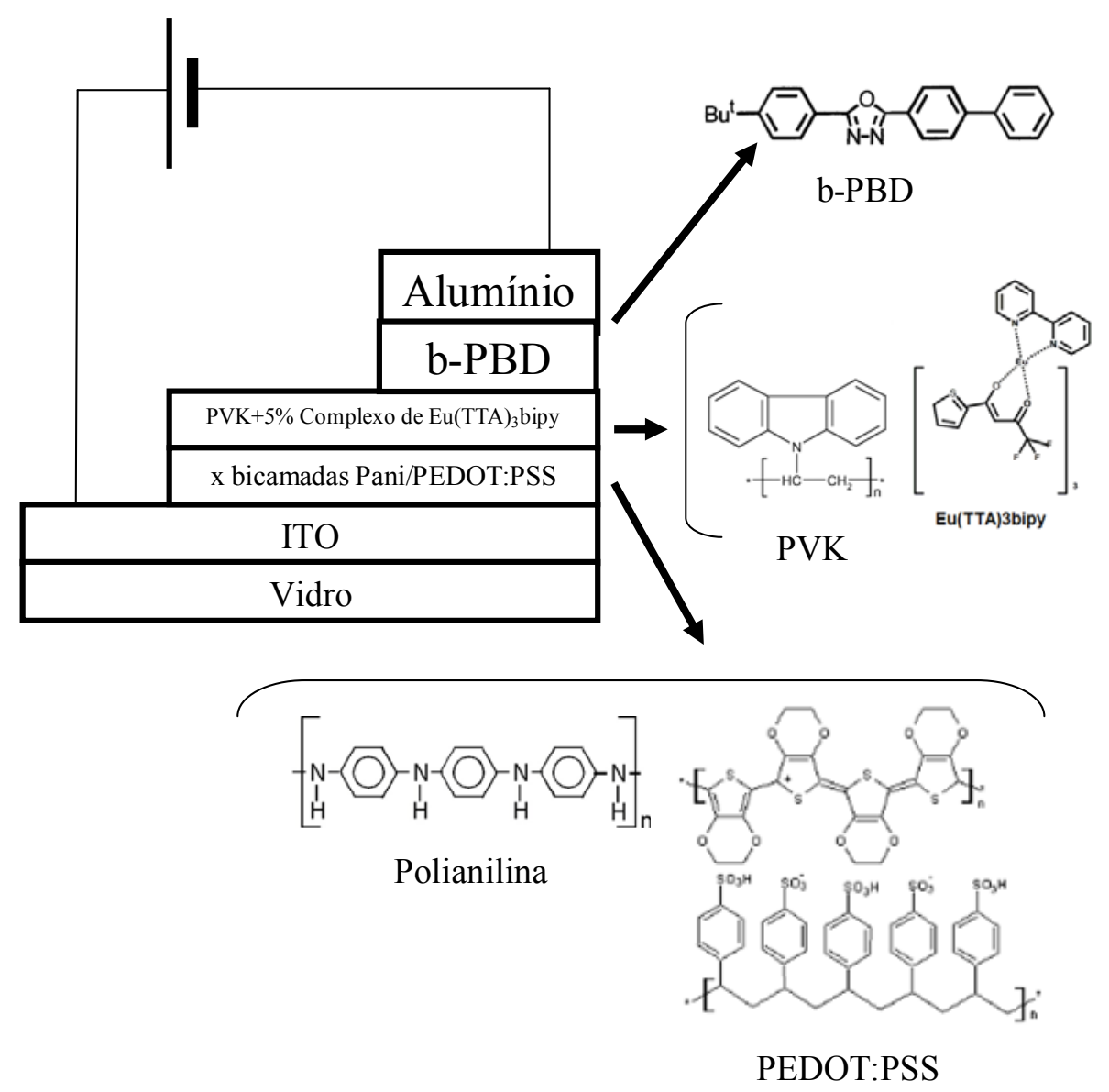

Figura 26 - Diagrama esquemático da estrutura para avaliar o desempenho do complexo de Európio com variação do número de bicamadas PAni/PEDOT:PSS e as estruturas químicas dos orgânicos empregados. 


\subsubsection{LECs empregando complexo de Rutênio variando-se o ligante (spin-coating)}

As LECs preparadas neste estudo possuem a estrutura single layer constituída apenas de dois eletrodos e o filme emissivo entre eles, isto é, empregou-se a estrutura do tipo ITO/Ru( $(L)_{3}\left(P F_{6}\right)_{2} /$ Alumínio, sendo $L$ o ligante do complexo. Com base nessa estrutura foram analisados dois ligantes e manteve-se fixo o contra-íon, o hexafluorofosfáto $\left(\mathrm{PF}_{6}\right)_{2}$. Os ligantes empregados, neste estudo, foram: 1) bipiridina (bipy) e 2) difenilfenantrolina ( $p h_{2}$ phen). Em ambos os casos os filmes finos emissivos foram depositados utilizando-se a técnica de spin-coating, descrita no tópico 3.1.3.2.

Para formação dos dispositivos preparou-se duas soluções, sendo uma o próprio complexo de Rutênio com concentração de $40 \mathrm{mg} / \mathrm{ml}$ e outra com o polimetilmetacrilato (PMMA) com concentração de $20 \mathrm{mg} / \mathrm{ml}$, as quais foram misturadas na proporção de 3:1, respectivamente. A solução preparada foi depositada sobre ITO pré-limpo e com padrão definido conforme descrição do tópico 3.1.1. No processo de spin-coating utilizou-se como parâmetros de deposição a rotação de $1500 \mathrm{RPM}$ seguida de um processo térmico a $55^{\circ} \mathrm{C}$, que por sua vez proporcionou espessuras na faixa entre 200 e $400 \mathrm{~nm}$, para ambos complexos. Por fim, efetuou-se uma evaporação térmica de com alumínio para formação do catodo do dispositivo. 


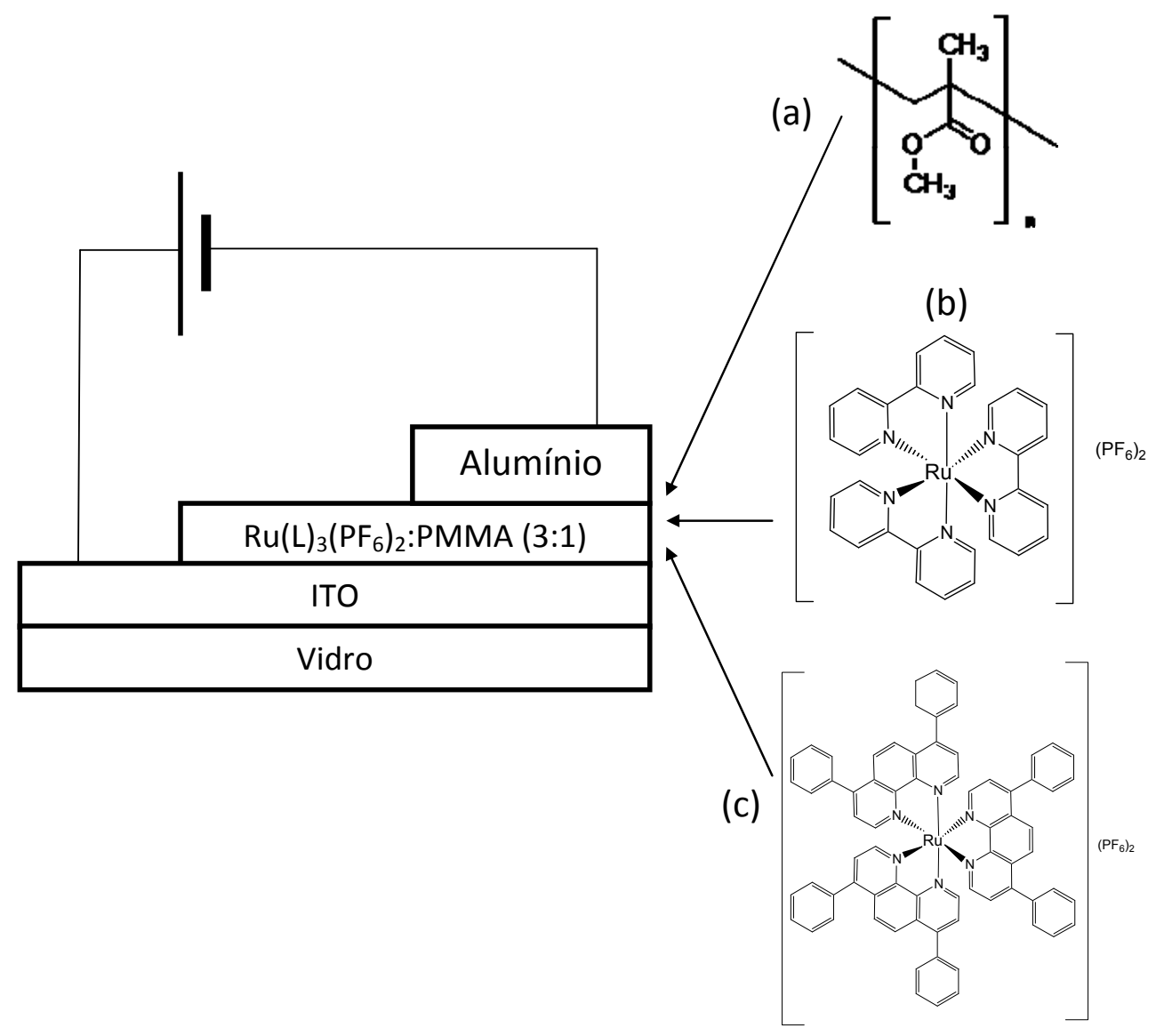

Figura 27 - Diagrama esquemático da estrutura single layer empregada para o estudo do complexo de Rutênio variando-se o ligante, sendo a estrutura química a) Polimetilmetacriláto, b) complexo $R u(b p y)_{3}\left(P F_{6}\right)_{2}$ e c) complexo $R u\left(p_{2} p h e n\right)_{3}\left(P F_{6}\right)_{2}$.

Todos os complexos de MTs processados neste trabalho foram sintetizados no Departamento de Química Fundamental do Instituto de Química da Universidade de São Paulo. ${ }^{[68]}$ 


\subsubsection{OLEDs empregando complexo de Rênio disperso em PVK em diversas concentrações (spin-coating)}

Com base no trabalho desenvolvido com os complexos de Európio e Térbio e dada as características do complexo de Rênio de ser um complexo de características adequadas a ser utilizado como um corante inserido em uma matriz, segundo o que

relata a literatura, ${ }^{[69]}$ e atendendo a condição de sobre posição entre a banda de emissão do PVK e a de absorção do complexo de Rênio. Para tanto, no presente trabalho foram efetuados ensaios aplicando este material em PVK nas concentrações $0,3,5,10,20$ e 40\%, conforme estrutura apresentada na Figura 28. 


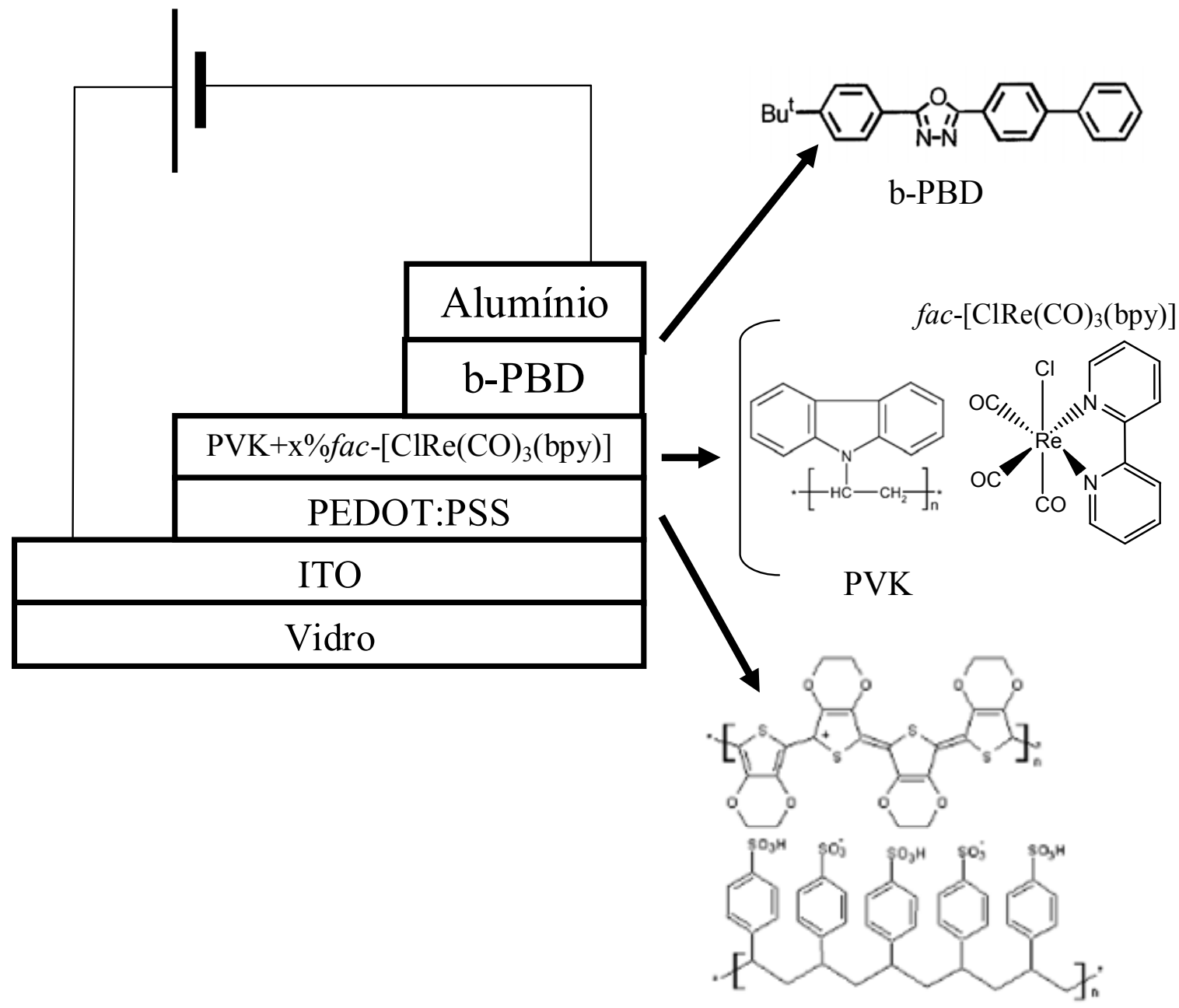

Figura 28 - Diagrama esquemático da estrutura empregada para o estudo da variação da concentração de complexo de Rênio disperso no PVK.

Neste caso, no ITO definiu-se o padrão apresentado na Figura 12 e este foi previamente limpo com a limpeza padrão (tópico 3.1.2). Em seguida o filme com função HTL (PEDOT:PSS), com espessura de $\sim 50 \mathrm{~nm}$, foi formado via spin-coating (tópico 3.1.3.2), bem como o EML ( $f a c-\left[\mathrm{ClRe}(\mathrm{CO})_{3}(\mathrm{bpy})\right]$ ), com espessura de 200 nm; já o ETL e catodo foram termicamente evaporados (tópico 3.1.3.1), com espessuras de $10 \mathrm{~nm}$ e $80 \mathrm{~nm}$, respectivamente. 


\section{Capítulo 4 RESULTADOS E DISCUSSÕES}

\subsection{Dispositivos com complexos de Terras Raras}

\subsubsection{Complexo de Európio termicamente evaporado com variação do Ligante principal}

Este primeiro ensaio iniciou o estudo dos complexos de terras raras, em específico o complexo de Európio com diferentes CL mantendo-se fixo o NL, conforme metodologia descrita no tópico 3.1.7.1.

A PL de todos os complexos testados apresentou espectro relativo às transições $f-f$, com emissões semelhantes. Com base nas mesmas condições experimentais, observou-se que o $\mathrm{Eu}(\mathrm{TTA})_{3}$ bipy e o $\mathrm{Eu}(\mathrm{DBM})_{3}$ bipy apresentam respostas em PL mais intensas enquanto que o $\mathrm{Eu}(\mathrm{BTA})_{3}$ bipy conta com a menor, comparativamente entre os complexos testados. A Figura 29 apresenta o espectro de PL normalizado para o complexo Eu(TTA) $)_{3}$ bipy, no qual observa-se claramente as transições ${ }^{5} \mathrm{D}_{0} \rightarrow$ ${ }^{7} \mathrm{~F}_{0,1,2,3,4}$, sendo a transição ${ }^{5} \mathrm{D}_{0} \rightarrow{ }^{7} \mathrm{~F}_{2}$ claramente a mais intensa. 


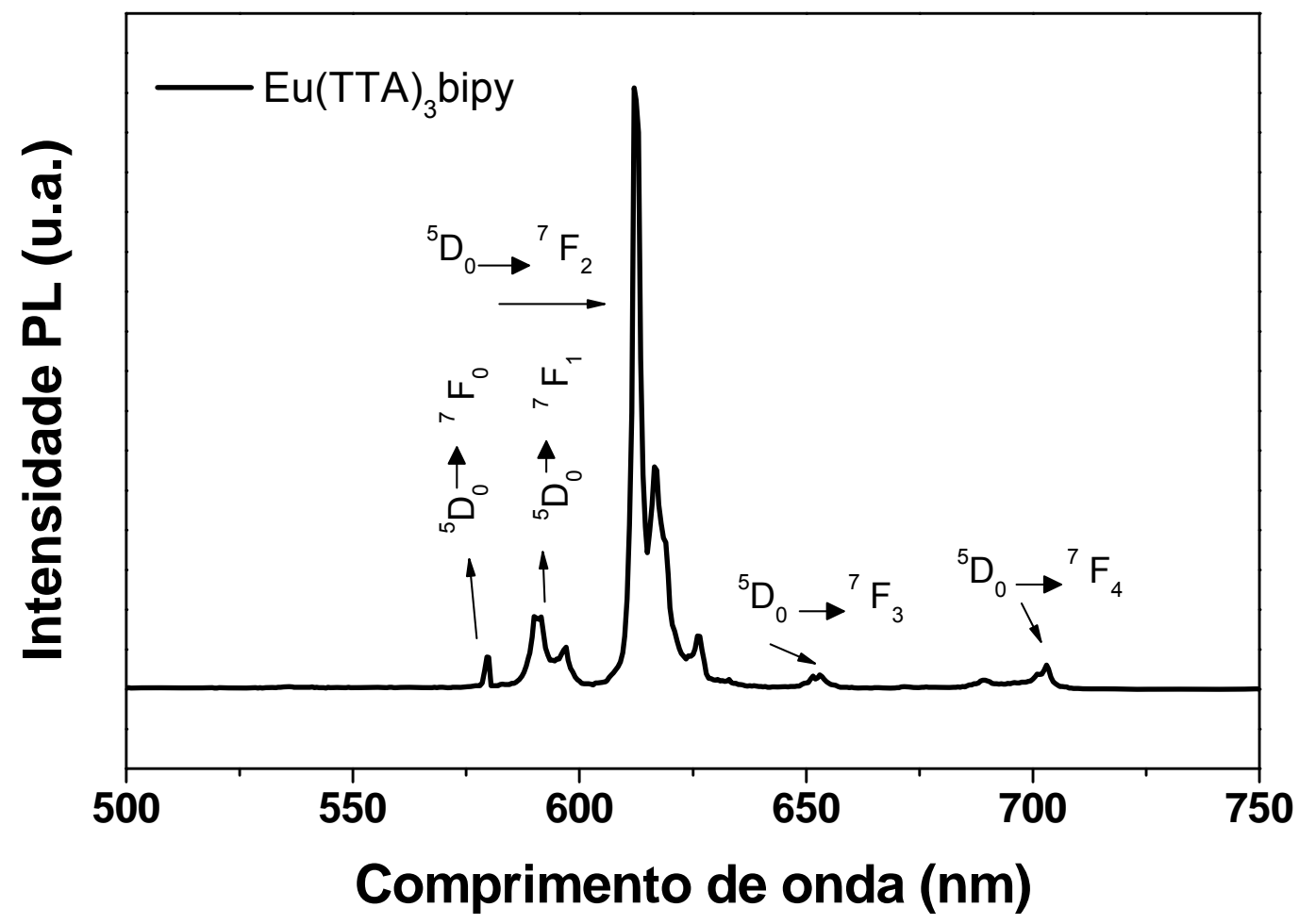

Figura 29 - Espectro de Fotoluminescência para o complexo Eu(TTA) $)_{3}$ bipy e suas respectivas transições (medições realizadas à 300K).

A Figura 30 apresenta o comportamento da densidade de corrente obtida em função da tensão aplicada $(J-V)$ para os dispositivos empregando os complexos de Európio analisados, cuja tensão de operação $\left(V_{O N}\right)$ extraída localiza-se no intervalo entre 14 e 16 volts. Entre os complexos analisados evidenciou-se que o $\mathrm{Eu}(\mathrm{BTA})_{3}$ bipy apresenta-se como o mais condutivo e também mais instável para valores de tensão próximos de 20 volts. ${ }^{[63]}$ Esta instabilidade conduz a hipótese de que a barreira de potencial formada entre o transportador de lacunas ou o de elétrons é significativamente mais elevada em comparação com os outros complexos. Dessa forma, proporciona-se maior acumulação de portadores de carga, que por sua vez 
levam a ruptura irreversível do dispositivo para potenciais elétricos próximos de 20 volts. Por outro lado, o $\mathrm{Eu}(\mathrm{NTA})_{3}$ bipy apresenta um comportamento mais resistivo com base em sua densidade de corrente para um dado potencial elétrico, comparativamente aos outros ligantes principais. ${ }^{[61]}$

Ainda com base na Figura 30 observa-se que todos os complexos de Európio com diferentes ligantes principais, nesta estrutura elaborada, operam em uma corrente muito próxima, que por sua vez esta na faixa entre 0,2 a $0,4 \mathrm{~mA}$ para uma tensão de 18 volts.

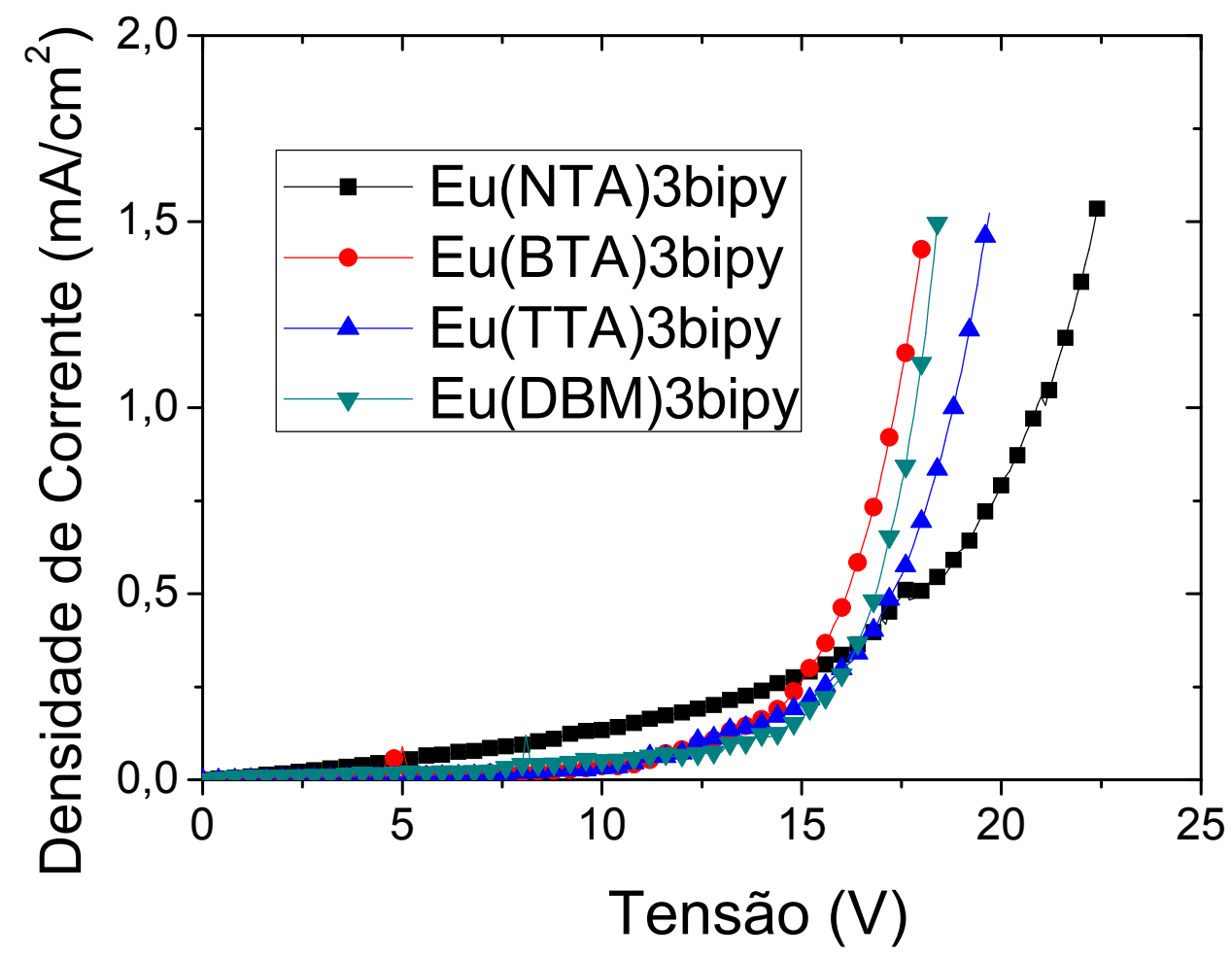

Figura 30 - Curva J-V para os dispositivos empregando complexo de Európio com diferentes ligantes principais, com estrutura ITO/TPD/EU(CL) $)_{3}$ BIPY/ALQ3/AL.

G. Santos - Escola Politécnica da Universidade de São Paulo - OLEDs, PLEDs e LECs 
Os espectros de eletroluminescência (EL), para todos os ligantes principais analisados, apresentam também comportamento semelhante (ver Figura 31), nos quais é evidenciada a transição ${ }^{5} \mathrm{D}_{0} \rightarrow{ }^{7} \mathrm{~F}_{2}$; reproduzindo, dessa forma, a resposta em PL, cujo pico em comprimento de onda associado, neste caso, é de $612 \mathrm{~nm}$, que por sua vez tem como coordenadas de cromaticidade os valores $x=0,56$ e $y=0,34$. A Figura 31 especificamente apresenta o espectro de eletroluminescência associado ao complexo $\operatorname{Eu(TTA})_{3}$ bipy.

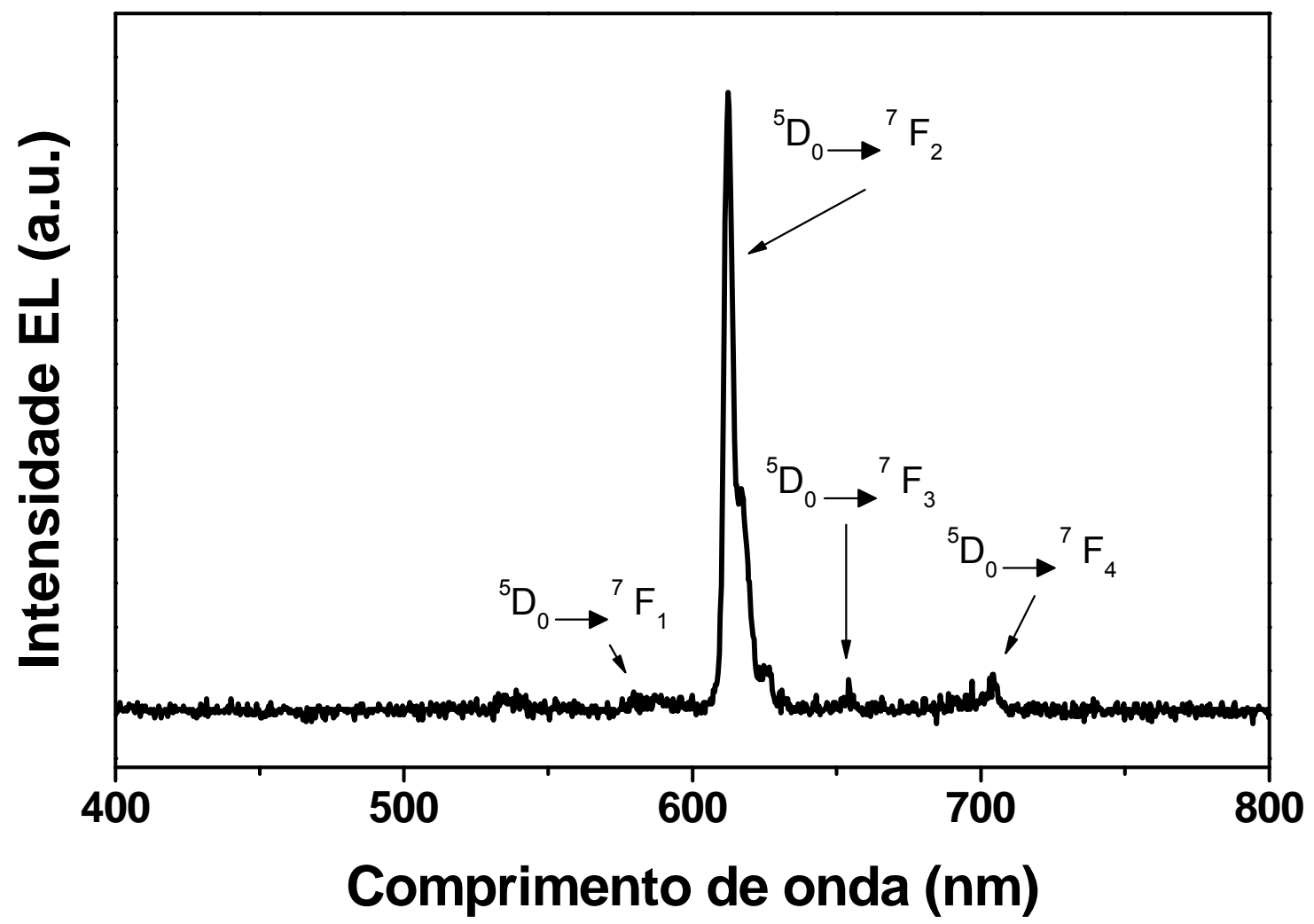

Figura 31 - Espectro de Eletroluminescência para odispositivo empregando o complexo Eu(TTA) $)_{3}$ bipy com a aplicação de 25 volts. 
Com base no espectro da Figura 31, obtiveram-se as coordenadas de cromaticidade, que por sua vez são representadas no diagrama da Figura 32, na qual é possível identificar a cor vermelha proveniente do complexo de Európio.

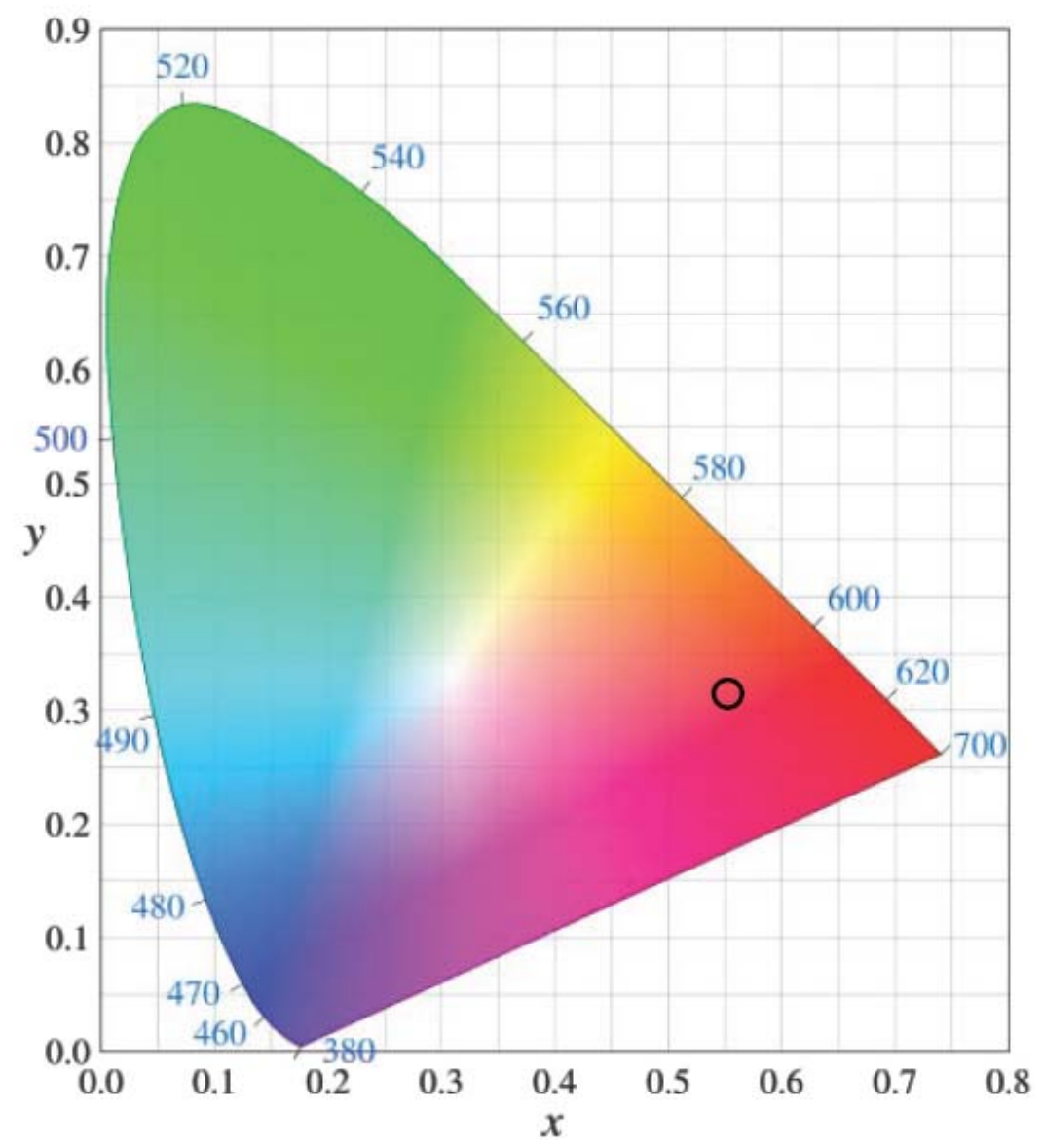

Figura 32 - Diagrama de cromaticidade com as coordenadas relativas ao dispositivo empregando o complexo Eu(TTA) $)_{3}$ bipy.

A Tabela 5 apresenta os valores calculados para a Eficiência Wall Plug dos dispositivos eletroluminescentes fabricados com os diversos complexos. Nessa tabela observa-se a eficiência externa, cujo significado está relacionado ao percentual de potência elétrica convertida em óptica, proveniente da emissão monocromática da 
transição ${ }^{5} \mathrm{D}_{0} \rightarrow{ }^{7} \mathrm{~F}_{2}$. A partir dos dados evidencia-se o complexo $\mathrm{Eu}(\mathrm{DBM})_{3}$ bipy como o mais eficiente e, por outro lado, o Eu(NTA) $)_{3}$ bipy como o menos eficiente.

Tabela 5 - Eficiência Wall Plug calculada com base no comprimento de onda associado a transição ${ }^{5} \mathbf{D}_{0} \rightarrow{ }^{7} \mathbf{F}_{2}$.

\begin{tabular}{|c|c|c|c|}
\hline $\begin{array}{c}\text { Complexo de } \\
\text { Európio }\end{array}$ & $\begin{array}{c}\text { Coordenadas de } \\
\text { cromaticidade (x e y) }\end{array}$ & $\begin{array}{c}\text { Pureza de } \\
\text { cor }\end{array}$ & $\begin{array}{c}\text { Eficiência Wall Plug } \\
\left(\eta_{w w}\right)\left(\times 10^{-3} \%\right) @ 612 \\
\mathbf{n m}\end{array}$ \\
\hline Eu(DBM) $)_{3}$ bipy & $(0,56 ; 0,34) @ 20 \mathrm{~V}$ & 70,3 & 1,05 \\
\hline Eu(TTA) $)_{3}$ bipy & $(0,55 ; 0,35) @ 20 \mathrm{~V}$ & 69,7 & 0,72 \\
\hline Eu(NTA) $)_{3}$ bipy & $(0,53 ; 0,35) @ 20 \mathrm{~V}$ & 64,1 & 0,35 \\
\hline Eu(BTA $)_{3}$ bipy & $(0,55 ; 0,34) @ 18 \mathrm{~V}$ & 61,0 & 0,73 \\
\hline
\end{tabular}

De maneira global constatou-se que o CL influencia a eficiência externa do OLED; essa premissa indica que as diferenças observadas, entre os complexos de Európio analisados, são fortemente afetadas pela ocorrência de decaimentos não-radiativos, cujo efeito implica em variações significativas na eficiência externa do OLED. Além disso, a ausência de outras bandas no espectro de EL reforça o fato de que existe um confinamento adequado de cargas no filme emissivo formado com os complexos de Európio inseridos na estrutura empregada neste foco particular do presente trabalho.

Com base na literatura ${ }^{[63,61,70,71,72]}$ elaborou-se o diagrama de níveis de energia da Figura 33 considerando-se todos os filmes finos da arquitetura fabricada. Neste diagrama é possível visualizar melhor as prováveis variações dos níveis HOMO e LUMO do complexo de Európio de acordo com os ligantes empregados. 


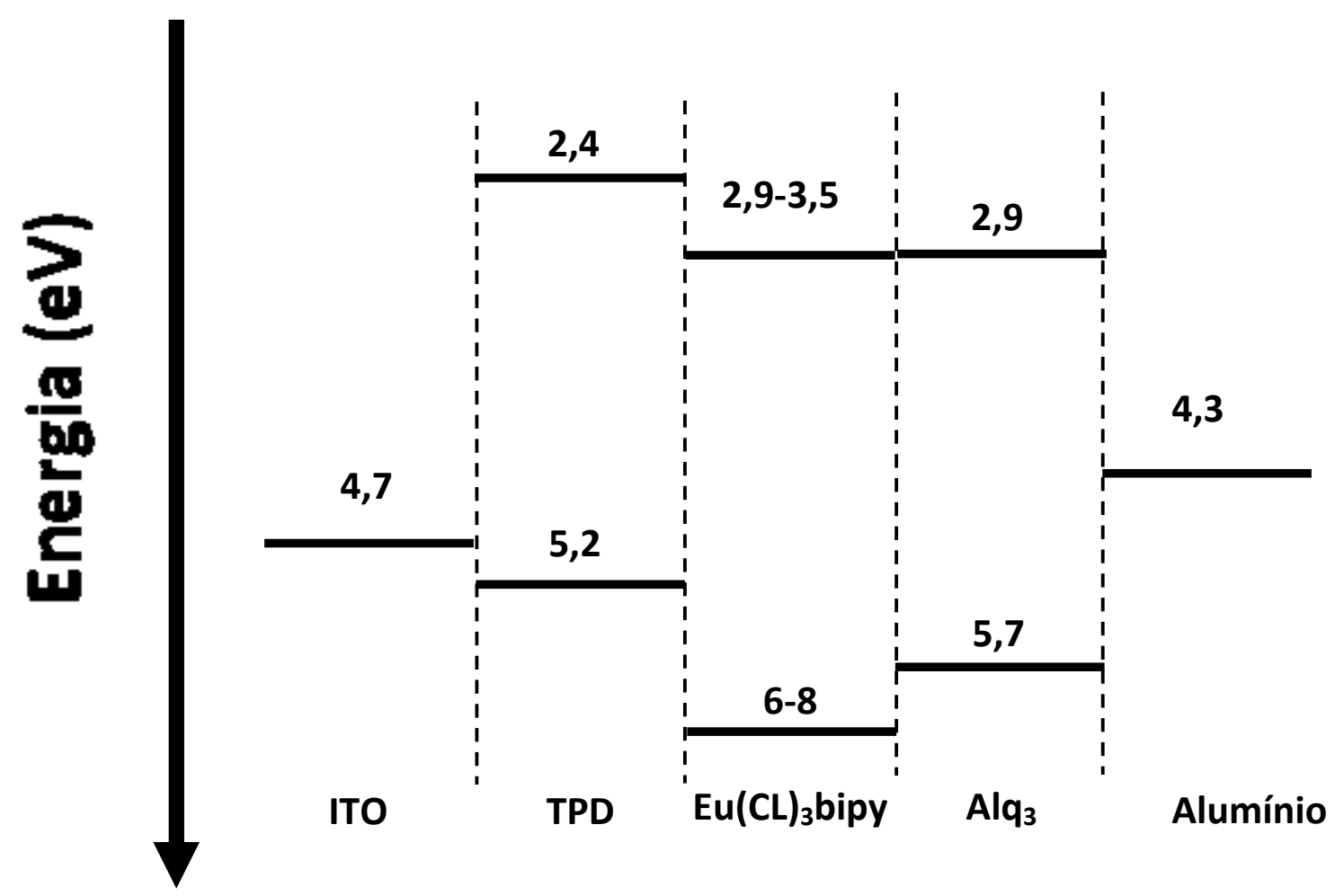

Figura 33 - Diagrama de energia para as estruturas fabricadas, para avaliar diferentes ligantes principais no complexo de Európio, cujos valores representam para o filme emissivo a faixa de valores típicos.

Com base no diagrama da Figura 33, nota-se que o TPD, empregando como HTL, favorece a redução de barreira entre anodo e o filme emissivo devido ao seu nível de energia HOMO. Além disso, seu nível de energia LUMO bloqueia elétrons. Ainda neste diagrama constata-se que o $\mathrm{Alq}_{3}$ efetua um trabalho semelhante ao TPD para com os elétrons de forma que a estrutura empregada para este foco de estudo em termos de níveis de energia propicia significativo confinamento de portadores de carga. 
A Figura 34 apresenta o registro fotográfico dos OLEDs fabricados empregando os complexos de Európio analisados.

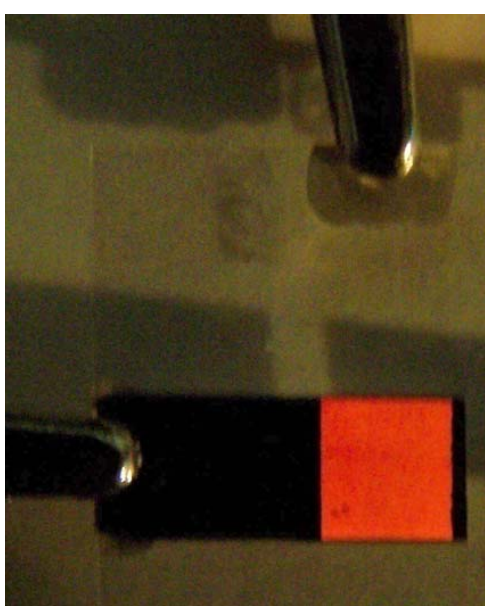

(a) $\mathrm{Eu}(\mathrm{DBM})_{3}$ bipy

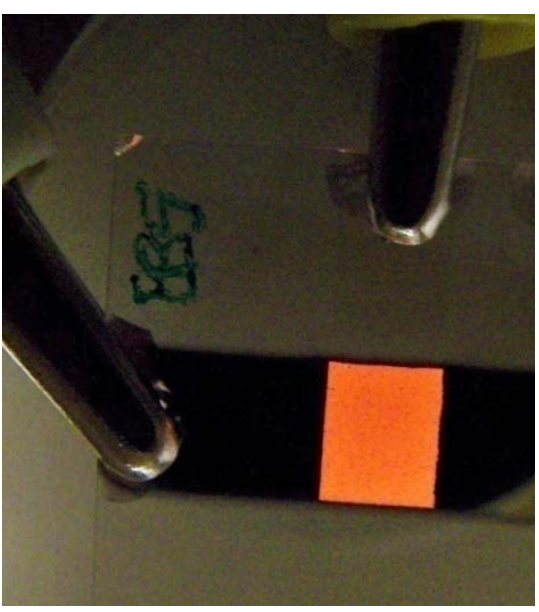

(c) $\operatorname{Eu}(\mathrm{BTA})_{3}$ bipy

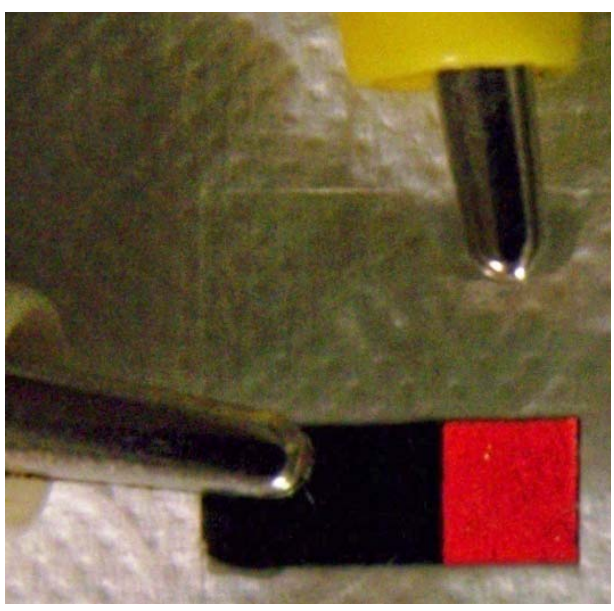

(b) $\operatorname{Eu}(\mathrm{TTA})_{3}$ bipy

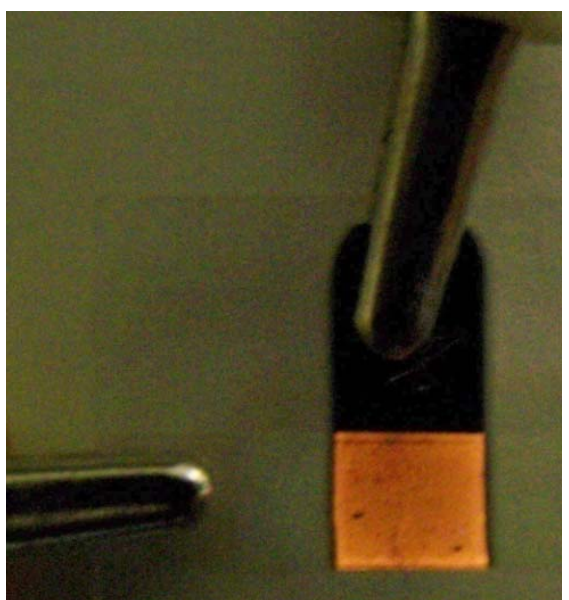

(d) Eu(NTA) $)_{3}$ bipy

Figura 34 - Registro fotográfico dos dispositivos eletroluminescentes fabricados empregando os

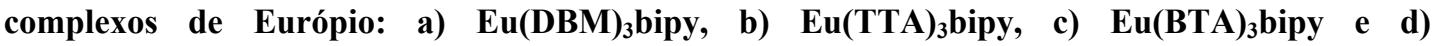
Eu(NTA) $)_{3}$ bipy. 


\subsubsection{Complexo de Térbio com variação do ligante neutro}

Este ensaio teve por finalidade o estudo do complexo de Térbio variando-se o ligante neutro. Os dispositivos deste ensaio que seguem a metodologia apresentada no tópico 3.1.7.2. Na Figura 35 é apresentado o espectro de PL do complexo de Térbio, no qual é possível identificar as transições típicas já bem exploradas na literatura.73

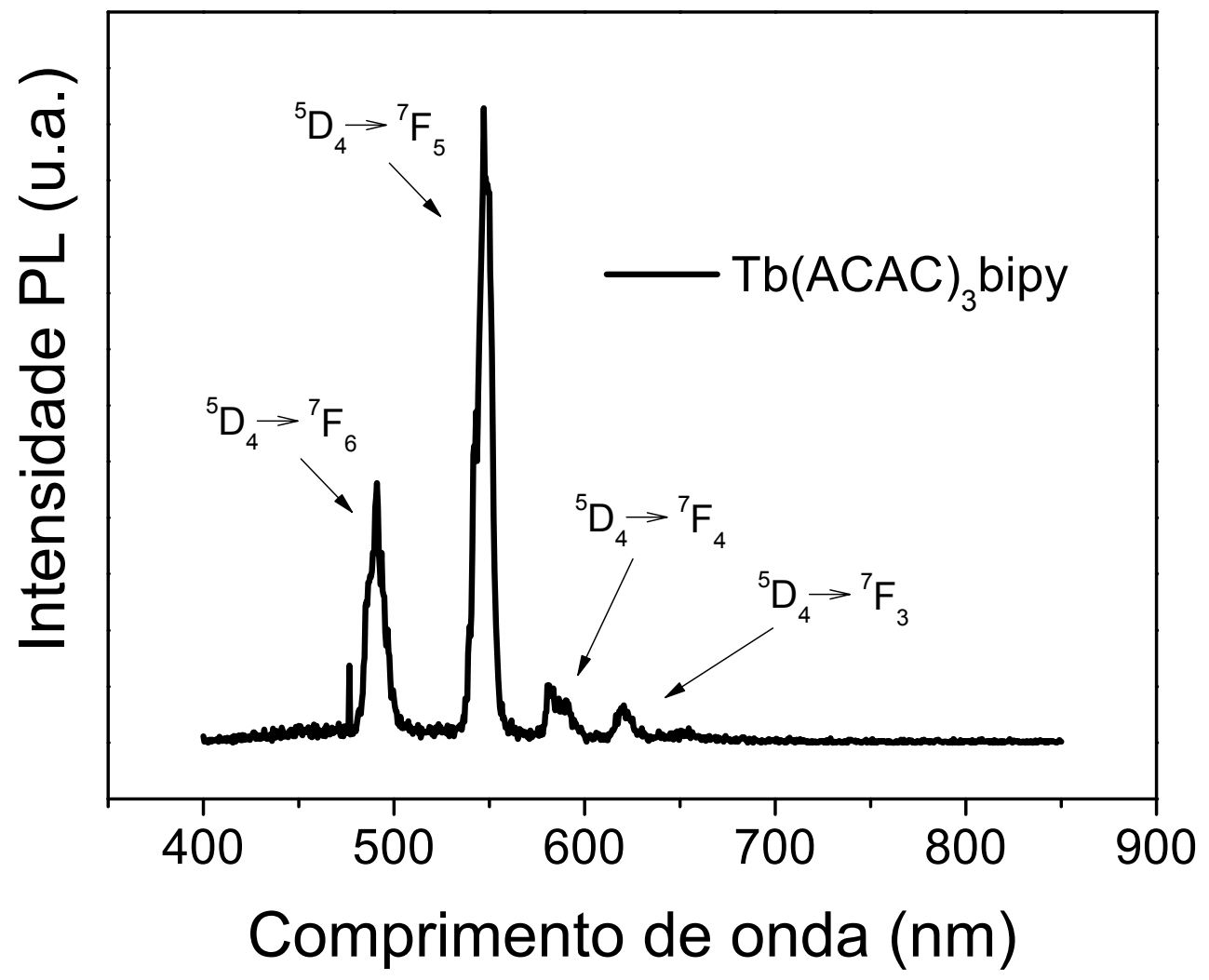

Figura 35 - Espectro de fotoluminescência para o complexo $\operatorname{Tb}(\mathrm{ACAC})_{3}$ bipy.

A resposta elétrica comparativa dos complexos de Térbio empregando dois tipos de ligantes neutros é apresentada na Figura 36. Nesta figura observa-se claramente que 
o ligante fenantrolina proporciona ao dispositivo maior condutividade, se comparado com a bipiridina. Já a Figura 37 apresenta a resposta de Potência óptica em função do potencial elétrico aplicado, cujos dados foram utilizados para o cálculo da eficiência externa.

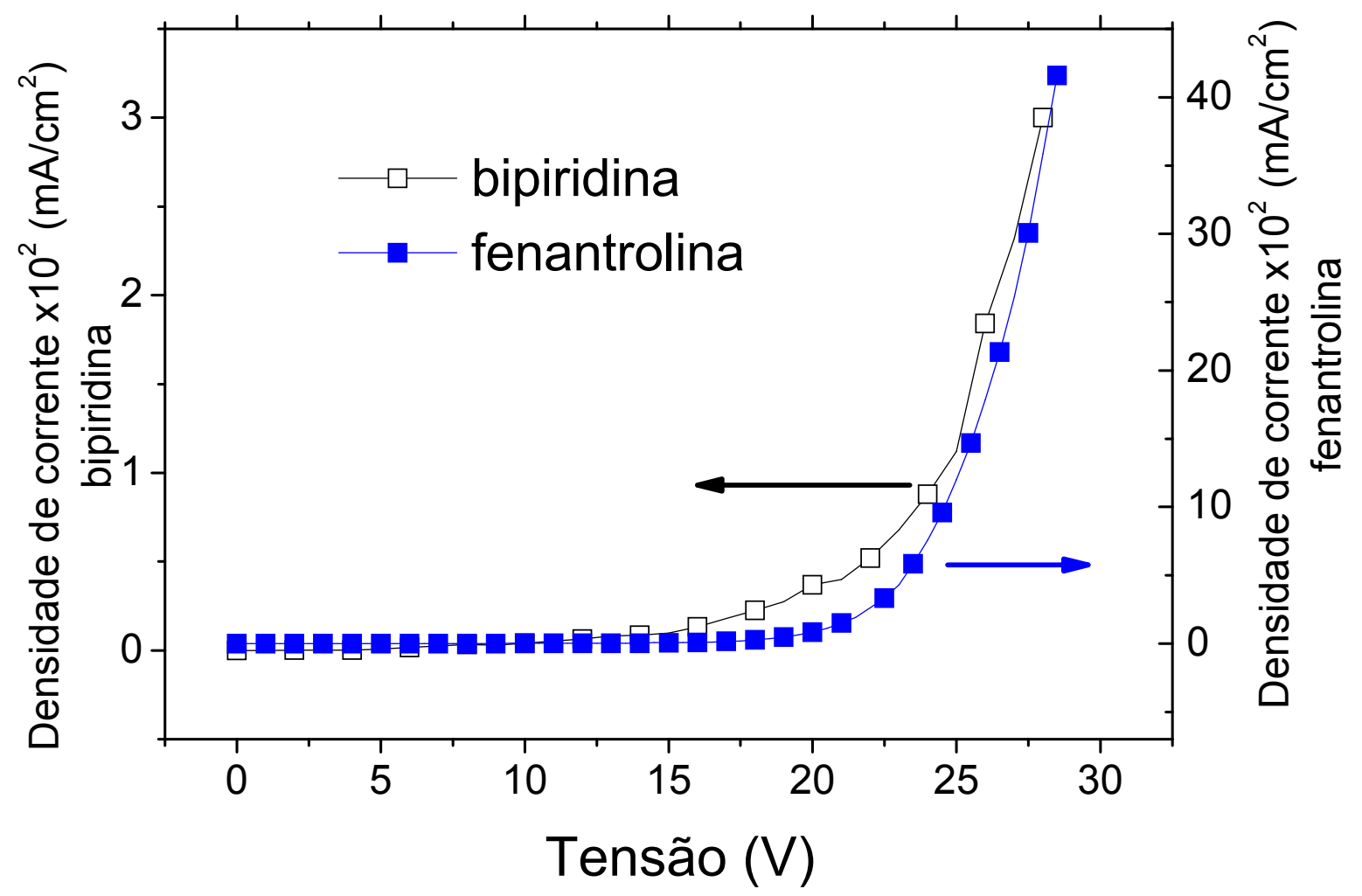

Figura 36 - Curvas J-V para o complexo de Térbio empregando os ligantes neutros bipiridina e fenantrolina. 


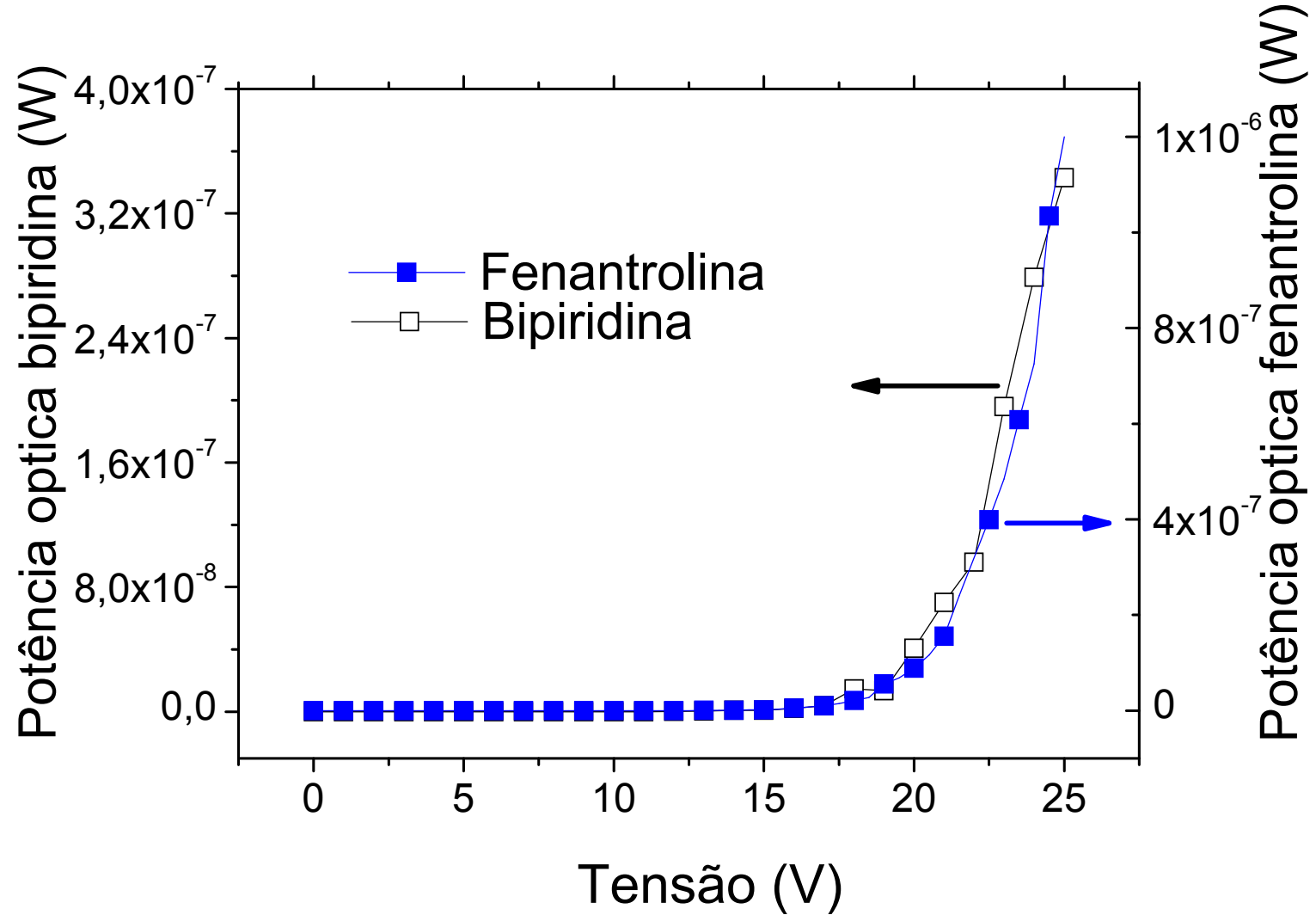

Figura 37 - Potência óptica para o complexo de Térbio empregando os ligantes neutros bipiridina e fenantrolina.

A maior condutividade observada, por parte do ligante fenantrolina, implica em maior probabilidade de recombinação de cargas fora da região ativa. Neste caso, evidencia-se também emissão significativa por parte do transportador de elétrons empregado neste foco do estudo, no caso o $\mathrm{Alq}_{3}$. A Figura 38 apresenta o espectro de EL das amostras empregando tanto a bipiridina quanto a fenantrolina, cujo espectro relativo à resposta do complexo com fenantrolina possui uma banda sobreposta pertencente ao $\mathrm{Alq}_{3}$. 


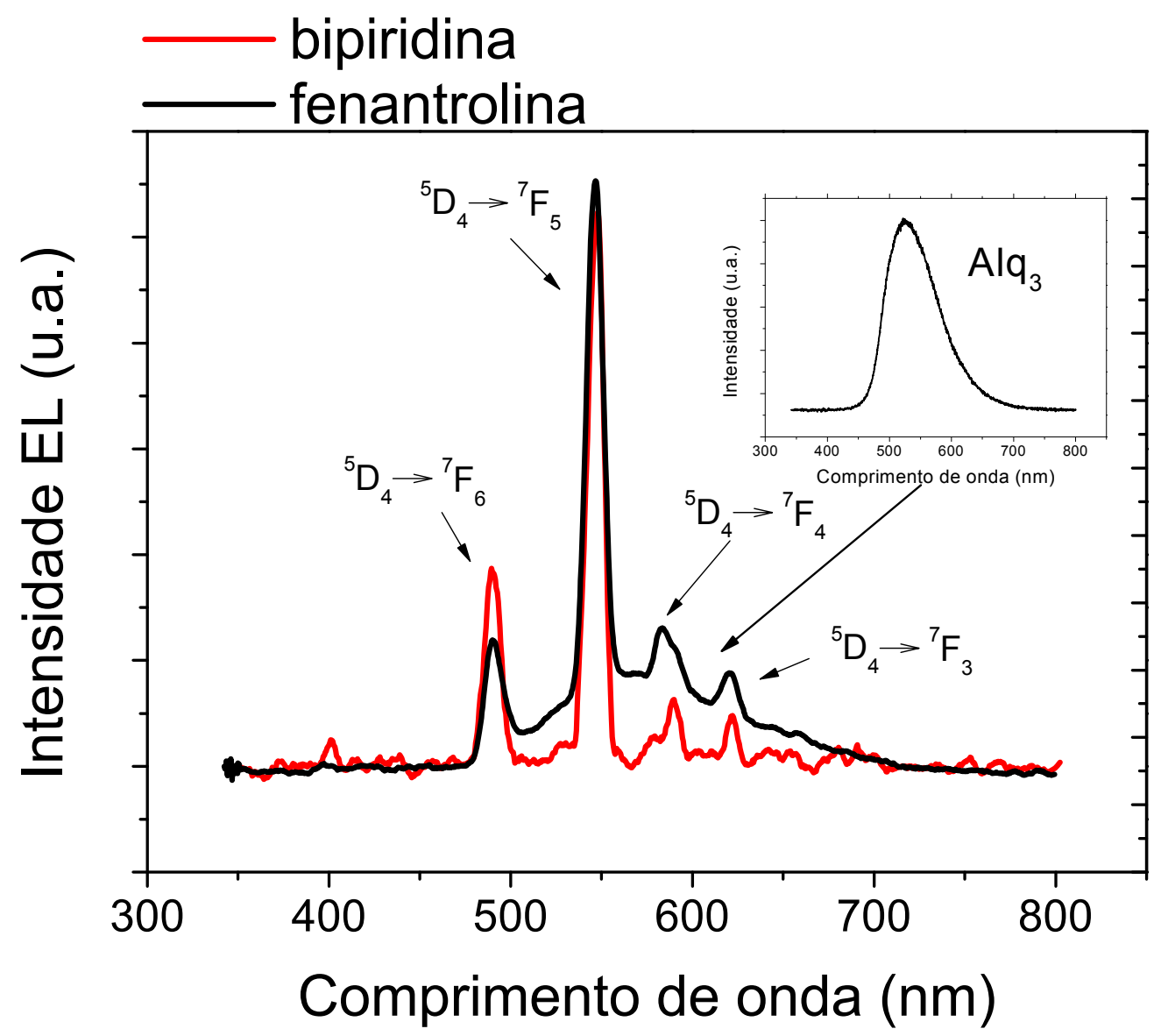

Figura 38 - Espectro de Eletroluminescência normalizado com as respostas dos dispositivos empregando complexo de Térbio com os ligantes bipiridina e fenantrolina.

A influência do $\mathrm{Alq}_{3}$ na resposta do dispositivo implica em variação de cor característica do complexo de Térbio, de modo que o comprimento de onda dominante passa do verde para o verde-amarelado, conforme indicação das coordenadas de cromaticidade apresentadas no diagrama da Figura 39. 


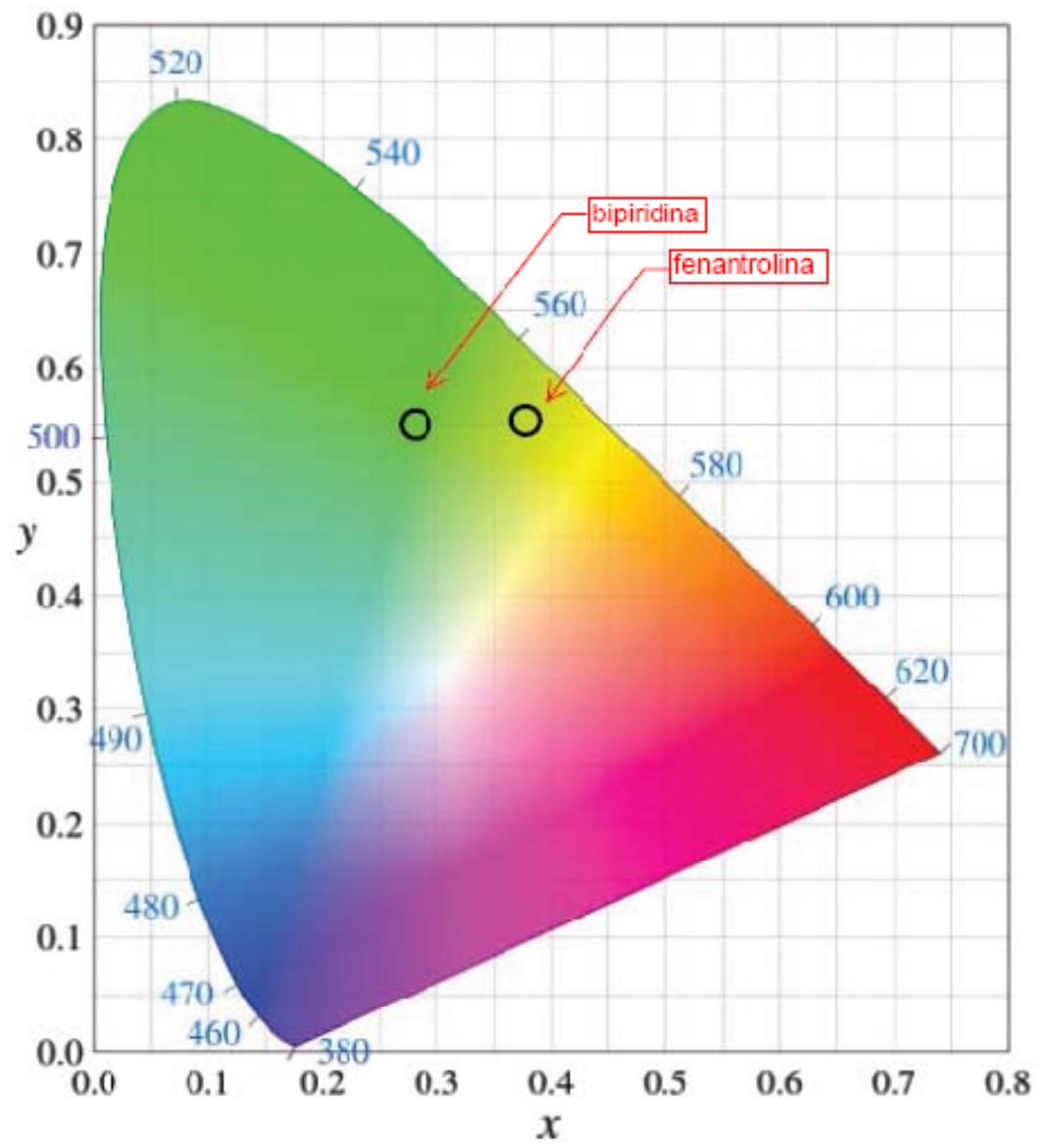

Figura 39 - Coordenadas de cromaticidade para os dispositivos empregando complexo de Térbio com diferentes ligantes neutros.

Além da variação de cor por interferência da emissão de fótons produzidos no filme responsável pelo transporte de elétrons, o pior confinamento e desempenho produzido pelo ligante fenantrolina pode ser constatado por meio do cálculo da eficiência externa Wall Plug indicada na Tabela 6. 
Tabela 6 - Eficiência Wall Plug calculada com base no comprimento de onda associado a transição ${ }^{5} \mathbf{D}_{4} \rightarrow{ }^{7} \mathbf{F}_{5}$.

\begin{tabular}{|c|c|c|}
\hline Complexo de Térbio & $\begin{array}{c}\text { Coordenadas de } \\
\text { cromaticidade (x e y) }\end{array}$ & $\begin{array}{c}\text { Eficiência Wall Plug } \\
\left(\eta_{w w}\right)\left(\times 10^{-3} \%\right) @ \\
\mathbf{5 4 7 n m}\end{array}$ \\
\hline $\mathrm{Tb}(\mathrm{ACAC})_{3}$ bipy & $(0,22 ; 0,55) @ 25 \mathrm{~V}$ & 4,1 \\
\hline $\mathrm{Tb}(\mathrm{ACAC})_{3}$ phen & $(0,39 ; 0,56) @ 25 \mathrm{~V}$ & 0,8 \\
\hline
\end{tabular}

Para avaliar melhor o processo de eletroluminescência elaborou-se com base na literatura $^{[72,74,75,76]}$ o diagrama de níveis de energia da Figura 40, cujos valores apontados na literatura fundamentam a hipótese de variações nos níveis HOMO e LUMO, que por sua vez corroboram as observações constatadas no presente trabalho.

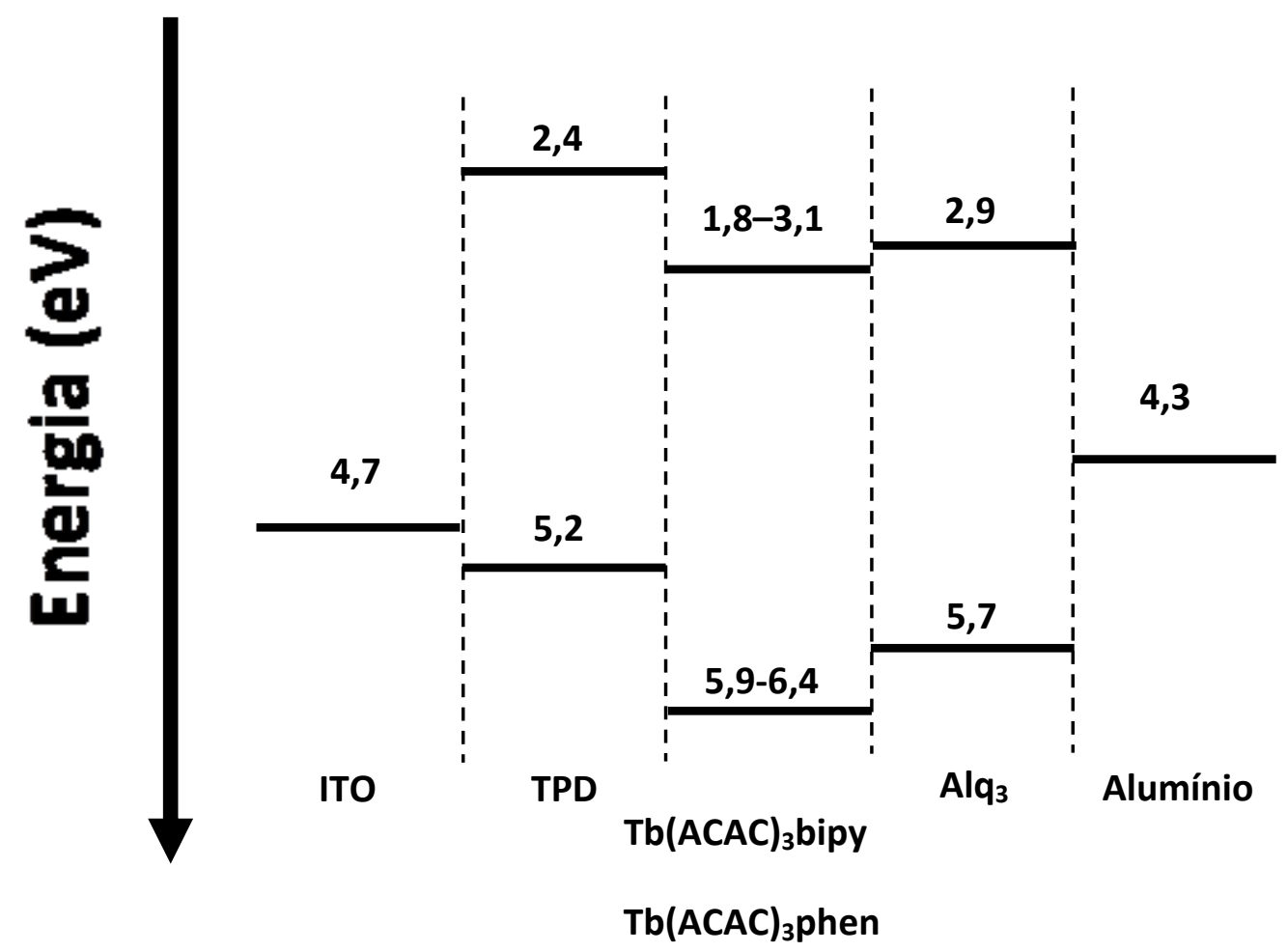

Figura 40 - Diagrama de energia para as estruturas fabricadas para avaliar diferentes ligantes neutros no complexo de Térbio.

G. Santos - Escola Politécnica da Universidade de São Paulo - OLEDs, PLEDs e LECs 
Ainda com base no diagrama da Figura 40, constata-se novamente a correta escolha para utilização do TPD, com função de HTL. No entanto, em relação ao $\mathrm{Alq}_{3}$, observa-se que este material não atua de forma ideal para o transporte de elétrons, mas propicia acumulação de portadores de carga o suficiente para que haja emissão do íon Térbio satisfatória. De forma alternativa testou-se o b-PBD, com função de ETL, neste estudo, no entanto, constatou-se sistematicamente curto-circuito em potenciais elétricos próximos da tensão de operação, tornando o dispositivo instável para medições eletro-ópticas. Este fenômeno é atribuído justamente aos níveis de energia do b-PBD, cujo nível HOMO (6,2 eV) ocasiona elevada acumulação de portadores de carga na interface complexo de ETL.

A Figura 41 apresenta o registro fotográfico dos dispositivos caracterizados funcionalmente. 


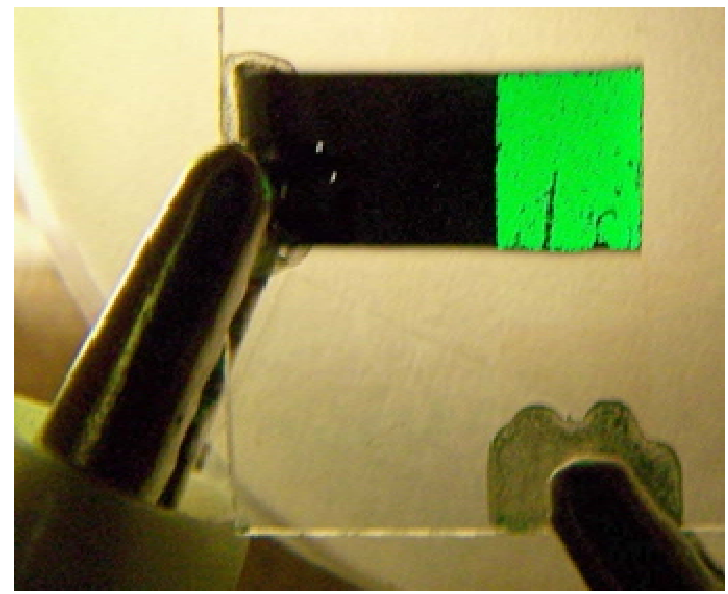

(a) $\mathrm{Tb}(\mathrm{ACAC})_{3}$ bpy

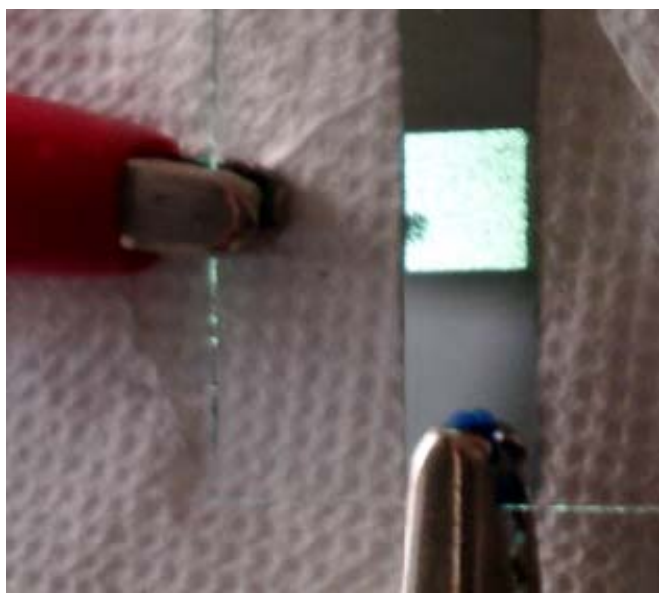

(b) $\mathrm{Tb}(\mathrm{ACAC})_{3}$ phen

Figura 41 - Registro fotográfico dos dispositivos eletroluminescentes fabricados empregando os complexos de Térbio: a) $\mathrm{Tb}(\mathrm{ACAC})_{3}$ bipy e b) $\mathrm{Tb}(\mathrm{ACAC})_{3}$ phen.

\subsubsection{Complexo de Európio disperso em PVK}

Neste primeiro ensaio, para filmes depositados por spin-coating, empregando-se o complexo de Európio selecionado - Eu(TTA) 3 bipy - disperso em PVK desenvolveuse com base no fato de que ocorre transferência de energia do polímero matriz para o complexo de TR, seja por fótons de alta energia (fotoluminescência) ou pela aplicação de um potencial elétrico (eletroluminescência). Para que ocorra a emissão luminosa se pronuncie é necessário que haja sobreposição entre a absorção do complexo de TR (dye) e emissão do polímero (host $)^{[77]}$, o que ocorre de forma satisfatória, conforme mostram os espectros da Figura 42. 


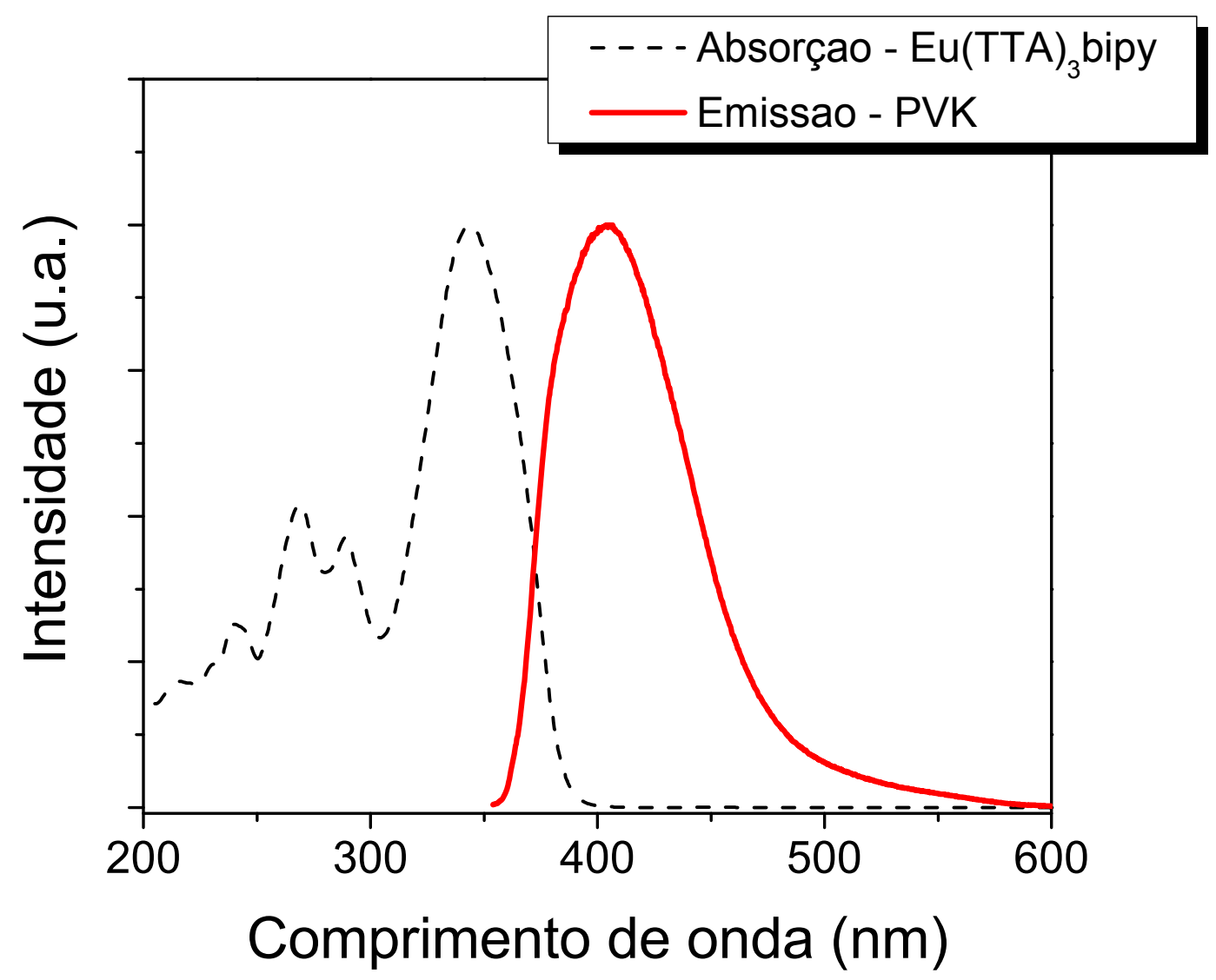

Figura 42 - Espectros de absorção e emissão para o complexo de Európio [Eu(TTA) 3 bipy] e PVK, respectivamente. Materiais e solução de clorofórmio para as medições.

Na Figura 43 nota-se, como esperado, maior condutividade do dispositivo em virtude do uso do polímero PVK, que devido a sua conjugação ${ }^{[47]}$ permite uma maior mobilidade de portadores de carga, comparativamente a um filme formado unicamente pelo complexo. Nesta figura observa-se também o comportamento da Potência óptica em função da tensão aplicada, cujos dados foram utilizados para se obter a eficiência Wall Plug, como descrito no tópico 2.4.1. 


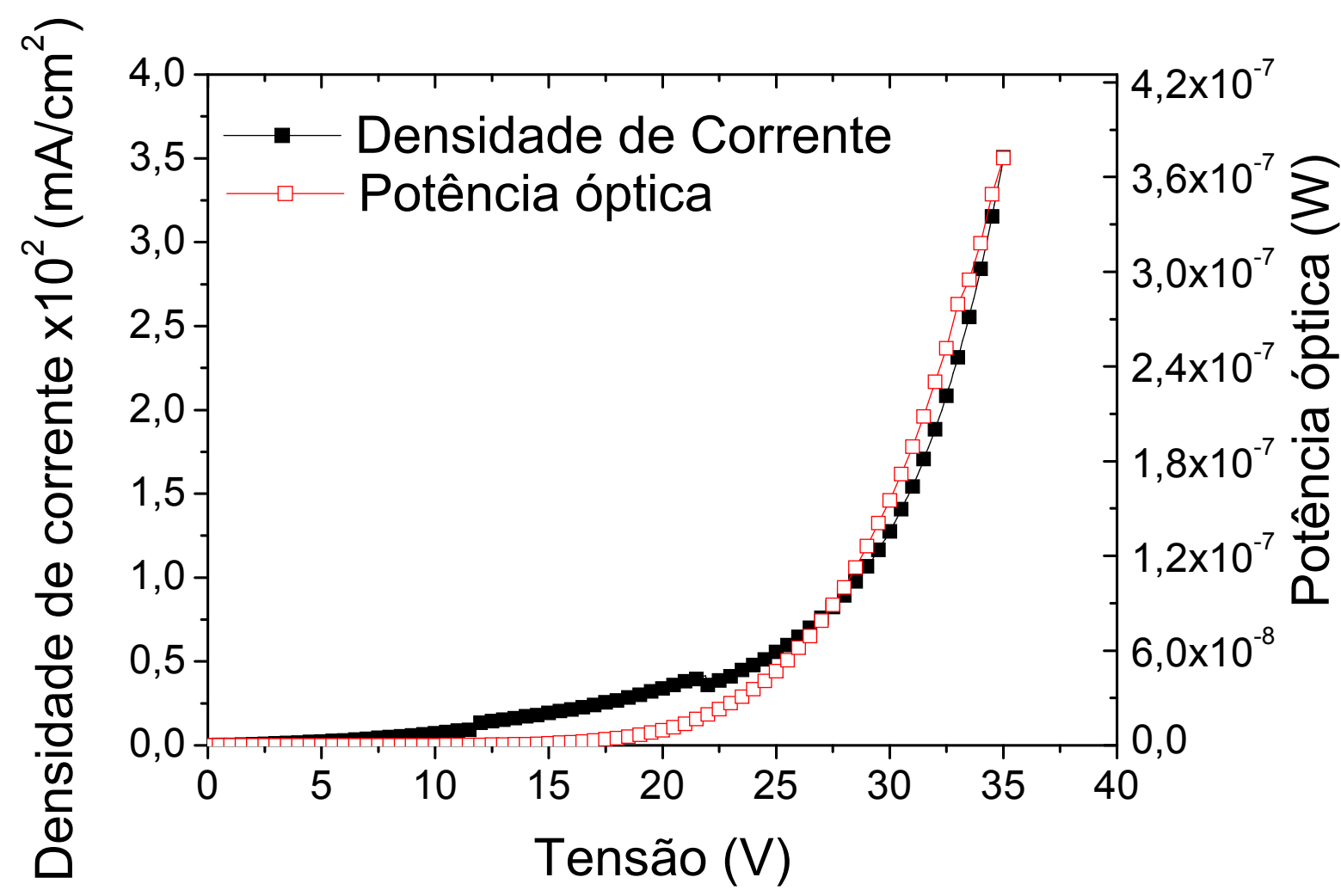

Figura 43 - Curva Densidade de corrente e Potência óptica em função da tensão aplicada.

Com base nos dados obtidos da resposta de Potência óptica obteve-se o valor de $1,24 \times 10^{-3} \%$ para a eficiência Wall Plug. Este valor é superior comparativamente a estrutura empregando o filme formado unicamente pelo complexo. Infelizmente não é possível experimentalmente comparar o complexo de Európio em um filme termicamente evaporado e depositado por spin-coating na mesma estrutura de dispositivo, no entanto, considera-se as características gerais de que ambas as estruturas possuem HTL e ETL (ressaltando-se que foram utilizados materiais diferentes na estrutura do filme termicamente evaporado e depositado por spin- 
coating) e que os eletrodos são os mesmos, é valido apontar a superioridade do complexo inserido em um polímero com função de corante.

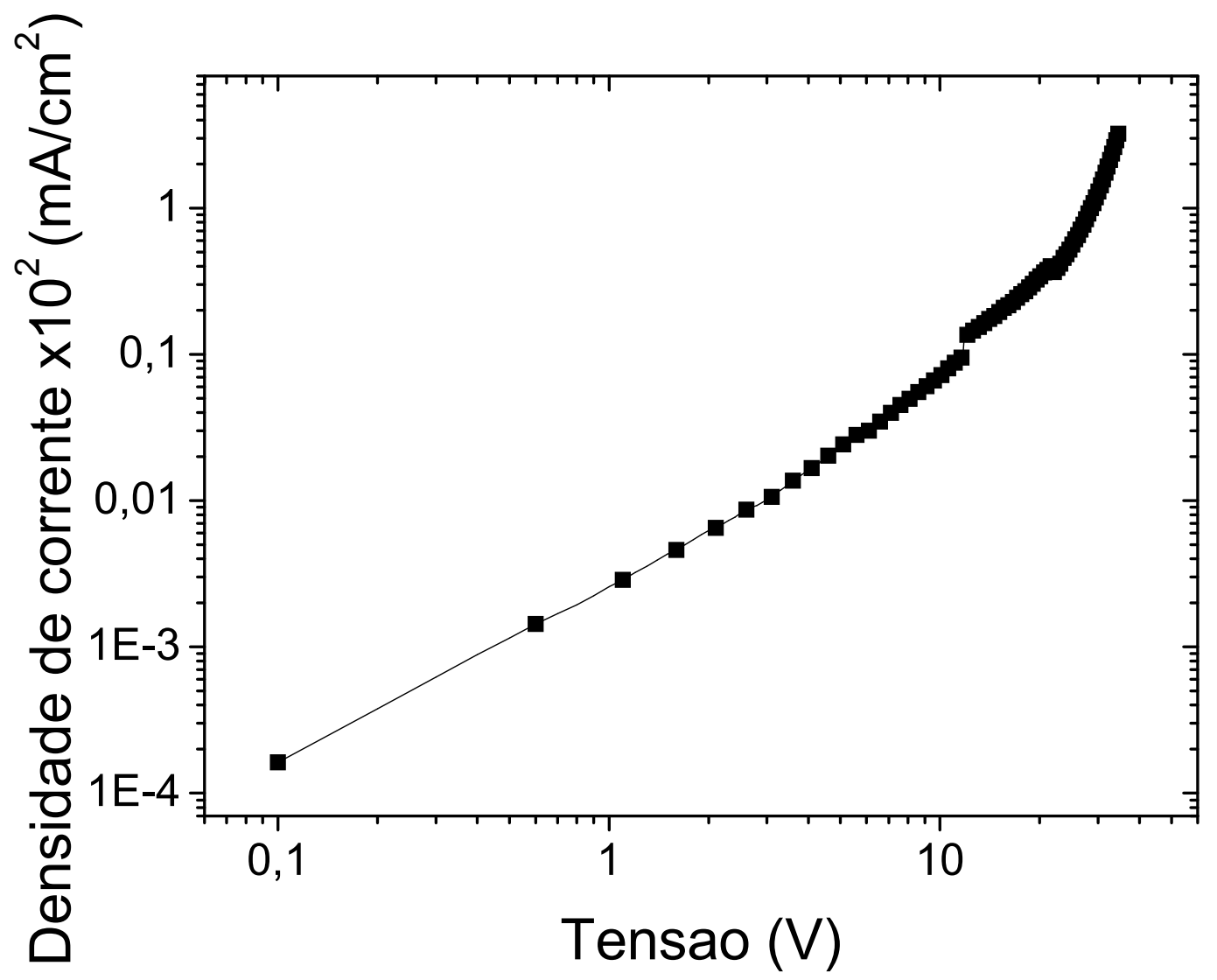

Figura 44 - Curva $\log J$ vs. $\log V$ com base nos dados da Figura 43 para extração do fator $m$.

Com base na resposta elétrica da Figura 44 observa-seque existe um comportamento exponencial condizente com os modelos apresentados na literatura, ${ }^{[49]}$ sendo válida a relação $J \alpha V^{m}$, cujo fator $m$, neste caso, foi de 5,1 , que por sua vez fundamenta o fenômeno de limitação de corrente por carga espacial (SCLC). O mesmo método de 
extração do fator $m$ foi utilizado para as outras estruturas de dispositivos analisadas, sem apresentação de gráficos $\log$-log.

Por outro lado, tem-se a informação, segundo o espectro de EL obtido (Figura 45), de que não há, neste caso, somente a emissão do complexo de Európio típica, na qual se evidencia a transição ${ }^{5} \mathrm{D}_{0} \rightarrow{ }^{7} \mathrm{~F}_{2}$; existe adicionalmente uma pequena contribuição relacionada ao PVK, cujo pico encontra-se em torno de $490 \mathrm{~nm}$.

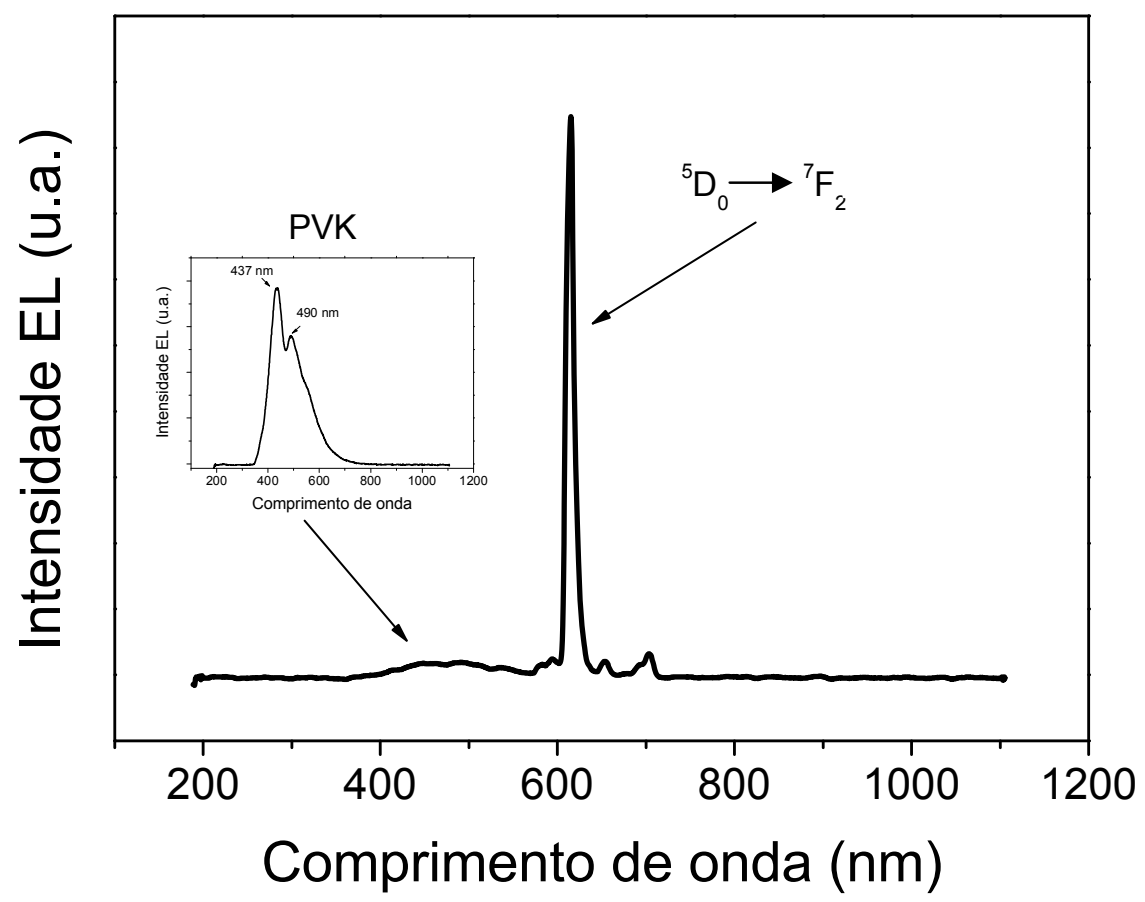

Figura 45 - Espectro de eletroluminescência da amostra empregando 5\% do complexo Eu(TTA) $)_{3}$ bipy disperso em PVK, inserido na estrutura ITO/PEDOT:PSS/PVK:5\% Eu(TTA) $)_{3}$ bipy/b-PBD/Alumínio. Inserido na curva consta a contribuição da banda do PVK na resposta do dispositivo.

Com base no espectro de eletroluminescência obteve-se as coordenadas de cromaticidade $x=0,53$ e $y=0,31$ apresentadas na Figura 46, cuja coordenada $x$ indica 
deslocamento para a esquerda no diagrama de cromaticidade se comparado o complexo de Európio termicamente evaporado e depositado por spin-coating. Essa influência é clara dada a contribuição de cor azul proveniente do PVK.

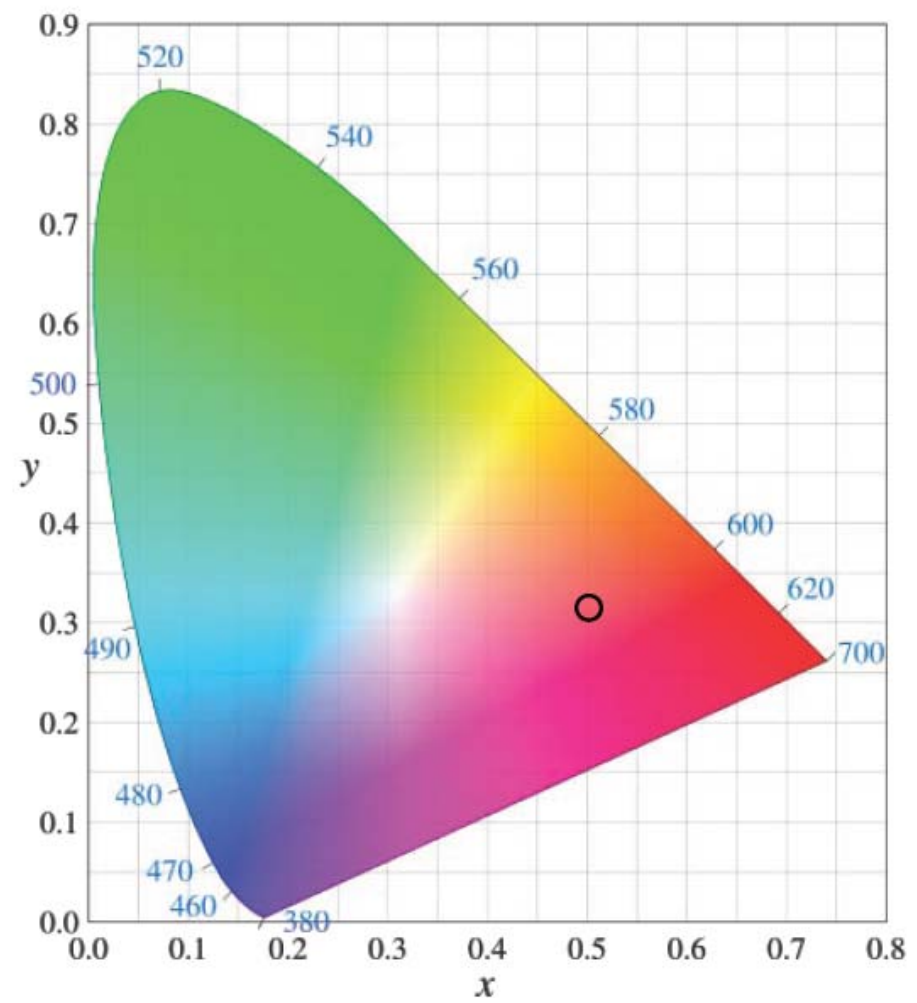

Figura 46 - Diagrama de cromaticidade com as coordenadas relativas ao dispositivo empregando o complexo Eu(TTA) $)_{3}$ bipy disperso em PVK.

A Figura 47 apresenta o diagrama de níveis de energia considerando todos os materiais da estrutura fabricada levando-se em consideração tanto níveis de energia citados na literatura ${ }^{[71,78,79]}$ quanto deduções obtidas a partir dos resultados experimentais obtidos. ${ }^{[61]}$ 


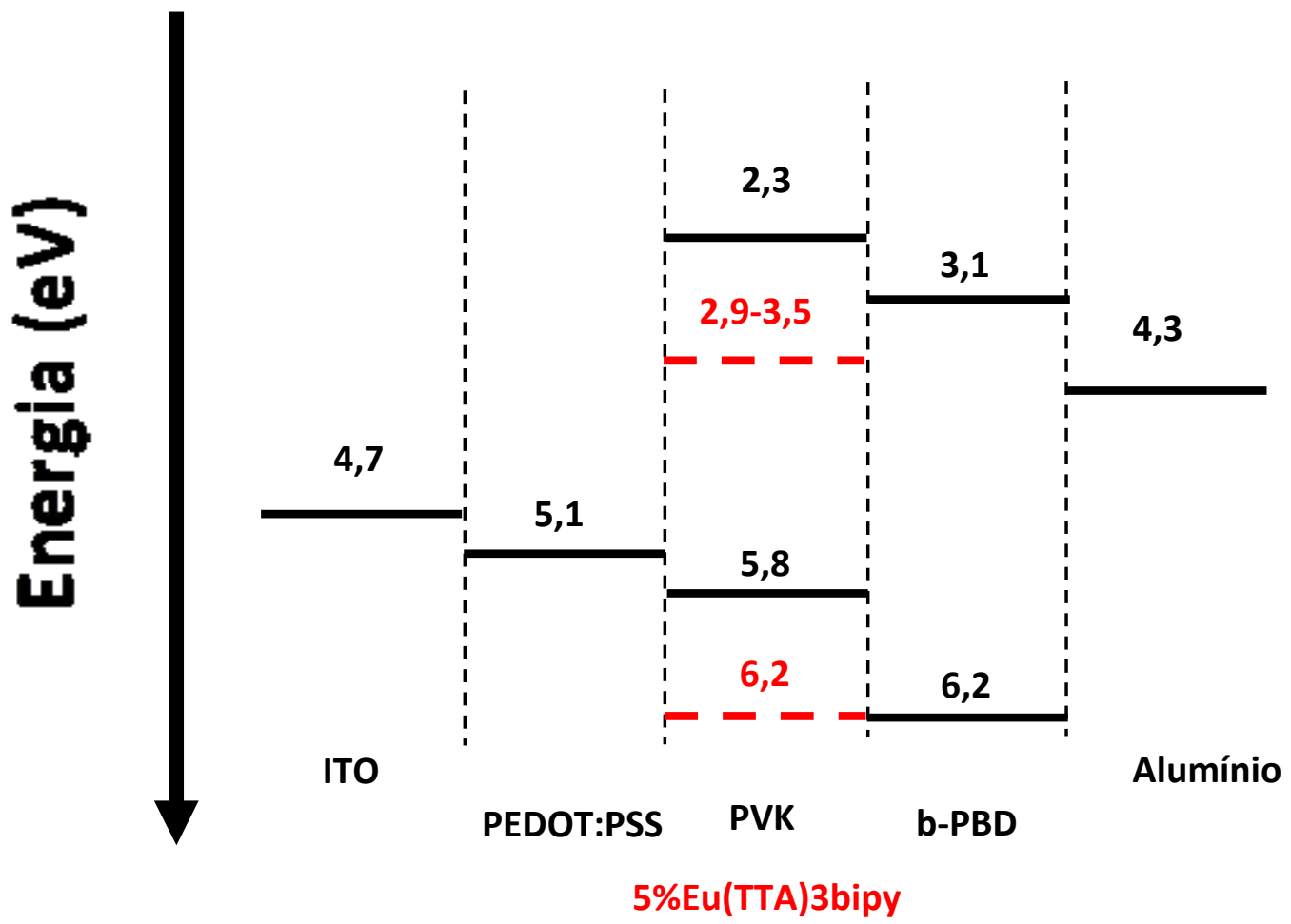

Figura 47 - Diagrama de energia para a estrutura fabricada para análise do Complexo de Európio - Eu(TTA) $)_{3}$ bipy - disperso no PVK.

No diagrama da Figura 47 observa-se que o PEDOT:PSS auxilia significativamente o transporte de lacunas do anodo para o filme emissivo, especificamente para o nível HOMO do PVK. Por outro lado, o b-PBD confere transporte adequado de elétrons ao nível LUMO do PVK e ainda colabora para o bloqueio de lacunas. Neste caso, dados os níveis de energia do polímero o b-PBD não proporciona acumulação de portadores de carga em demasia, como em dispositivos empregando apenas o complexo como filme emissivo. Neste caso, o único evento indesejado é a recombinação de portadores de carga e formação de éxcitons singletos do PVK, isto é, este material não atua simplesmente como uma matriz inerte que transfere energia ao complexo, mas contribui também com alguma emissão, cuja intensidade da banda 
depende da estrutura do dispositivo. Naturalmente que esta contribuição é prejudicial tendo-se por objetivo principal a emissão única do complexo, no entanto, foi demonstrado, neste trabalho, que a maior parte da energia que chega ao PVK é transferida ao complexo e, além disso, a contribuição do PVK não altera a resposta típica do complexo de Európio.

Por fim, a Figura 48 apresenta o registro fotográfico da amostra empregando o complexo de Európio disperso em PVK (Figura 48a) e da amostra com mesma estrutura, porém sem a adição do complexo (Figura 48b).

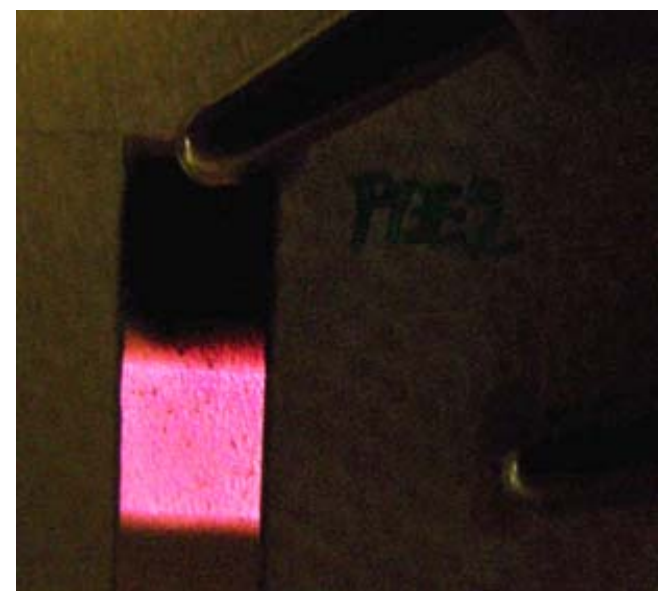

(a)

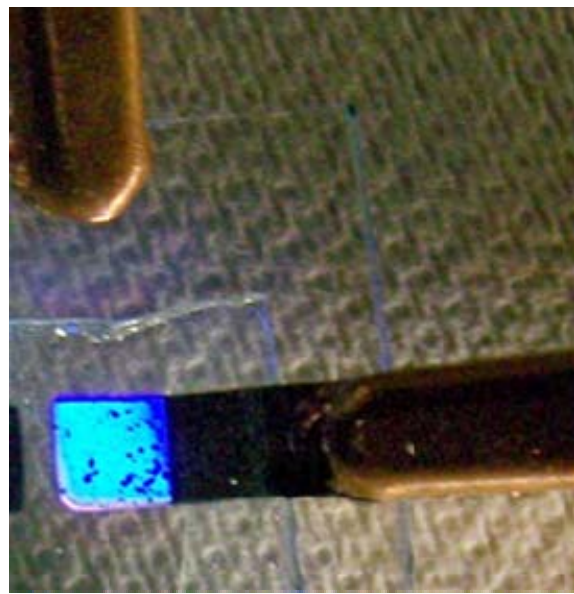

(b)

Figura 48 - Registro fotográfico da amostra a) empregando $5 \%$ do complexo Eu(TTA) 3 bipy disperso em PVK e b) somente filme do PVK sem complexo de Európio. 


\subsubsection{Complexo de Térbio disperso em PVK}

De forma análoga ao estudo efetuado para o complexo de Európio, foi executada tentativas de se obter a resposta por parte do complexo de Térbio disperso em PVK, dados os resultados significativos anteriormente obtidos com o Európio. Reportandose à literatura, ${ }^{[65]}$ e levando-se em consideração as bandas de emissão do PVK e de absorção dos ligantes orgânicos principais terem overlap pouco significativo, tem-se aparentemente possibilidade de se obter emissão do complexo de Térbio. No entanto, os resultados, para filmes depositados por spin-coating, empregando-se o complexo de Térbio selecionado - Tb(ACAC) 3 bipy - disperso em PVK evidencia-se, conforme Figura 49, que só é possível identificar a eletroluminescência praticamente do polímero PVK. Resultados análogos foram obtidos alterando-se o ETL da estrutura, cuja tentativa justificou-se pelo fato da intenção de confinamento de cargas no filme emissivo. 


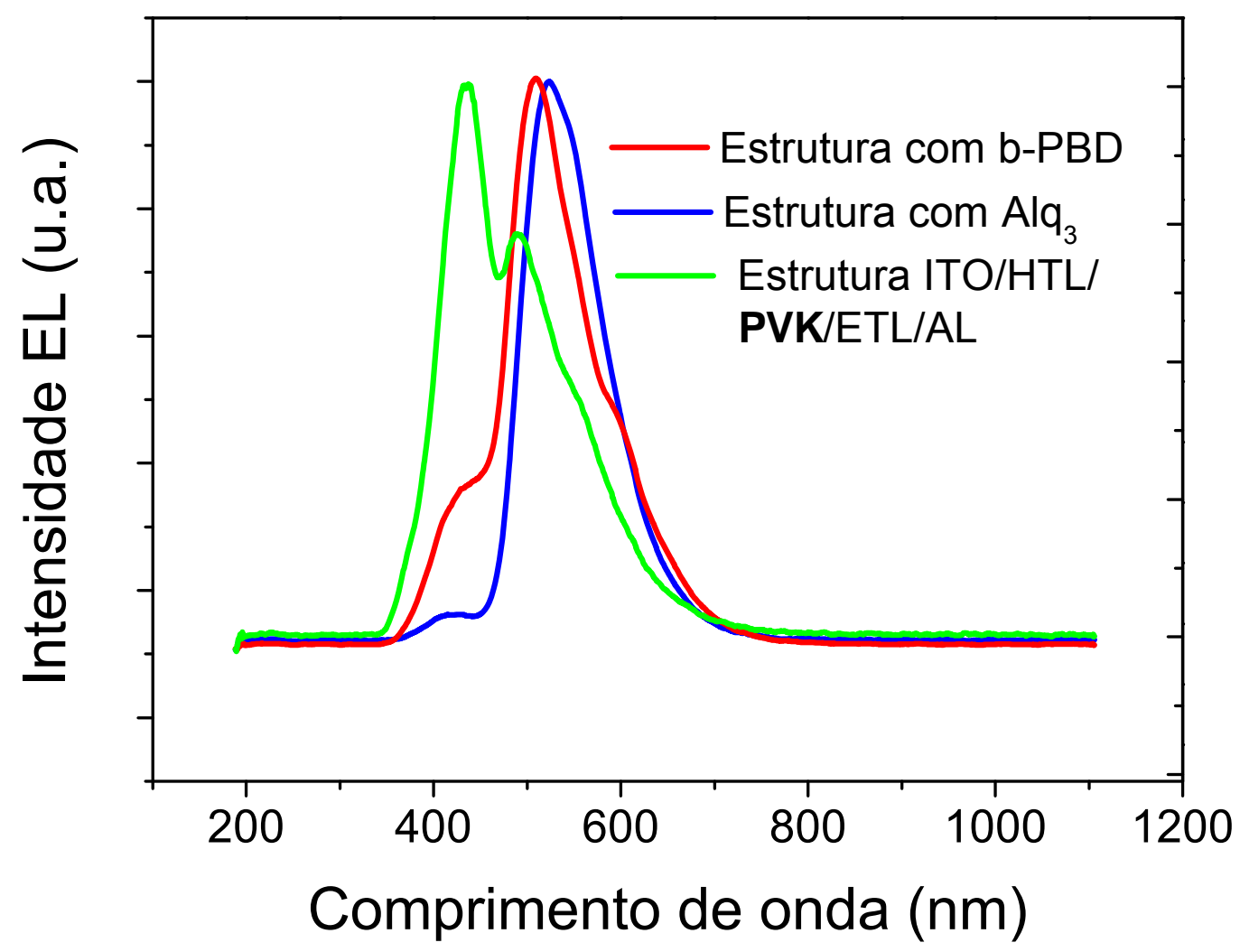

Figura $49 \quad-\quad$ Espectros de eletroluminescência da $\quad$ estrutura ITO/PEDOT:PSS/PVK+5\%Tb(ACAC)3bipy/ETL/Alumínio, na qual variou-se o ETL utilizando-se o $\mathrm{Alq}_{3}$ e b-PBD, respectivamente. Adicionalmente neste gráfico foi adicionado o espectro de eletroluminescência de uma estrutura, cuja emissão pertence preferencialmente ao PVK para fins de comparação.

A Figura 50 apresenta as coordenadas de cromaticidade tanto para a estrutura empregando o b-PBD quanto para a que emprega o $\mathrm{Alq}_{3}$. 


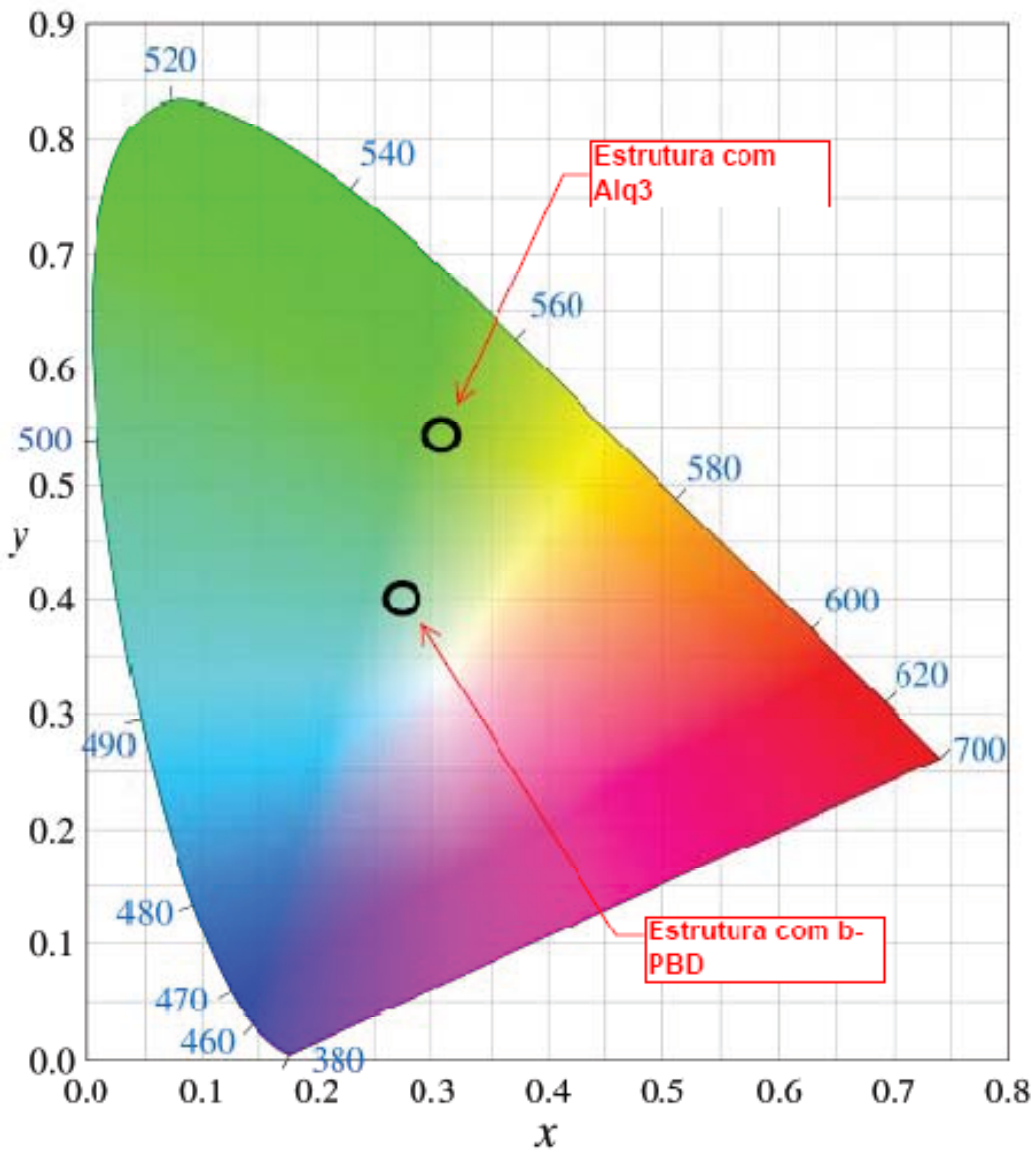

Figura 50 - Coordenadas de cromaticidade com os indicativos no diagrama das estruturas empregando o complexo de Térbio disperso em PVK empregando como ETLs os materiais orgânicos b-PBD e Alq3, respectivamente.

A Figura 51 apresenta o registro fotográfico das amostras produzidas. 


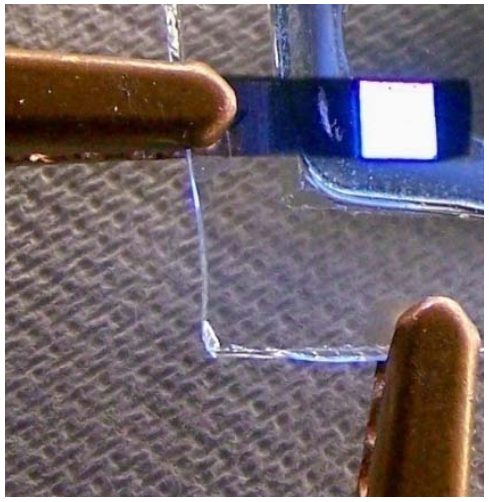

(a)

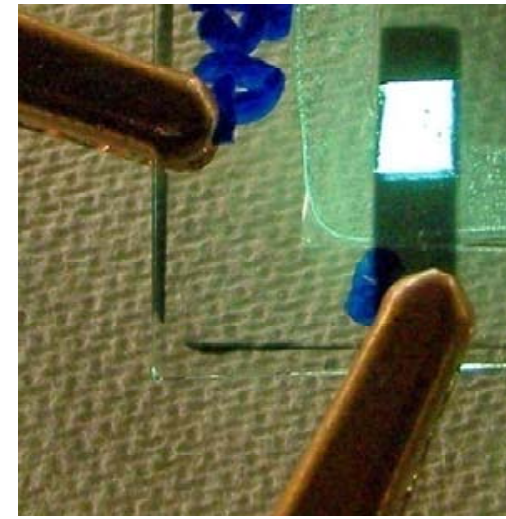

(b)

Figura 51 - registro fotográfico das amostras empregando complexo de Térbio [Tb(ACAC) $)_{3}$ bipy] disperso em PVK empregando como ETL a) butil-PBD e b) Alq .

Um dos mais conhecidos ligantes $\beta$-dicetonato empregado no complexo de Térbio é o Acetilacetonato (ACAC), pois seus níveis de energia permitem transferência de energia adequadamente ao nível ${ }^{5} \mathrm{D}_{4}$ do íon Térbio. Paralelamente existe a aplicação, referenciada na literatura pelo pesquisador CHEN et al. ${ }^{[65]}$, que por sua vez utilizou um complexo de Térbio com um ligante orgânco atípico e que neste caso foi adequado à transferência de energia para que a emissão do complexo de Térbio se pronunciasse. Comparativamente identificou-se que o ligante estudado neste trabalho e do referido pesquisador, em termos energéticos, são semelhantes. Além disso, observa-se, nos espectros de absorção e emissão em PL do Tb(ACAC) ${ }_{3}$ bipy e do PVK, conforme Figura 51, claramente que ocorre sobreposição da absorção do complexo de Térbio com a emissão do PVK pouco significativa, o que implica em baixa probabilidade de transferência de energia do polímero ao íon Térbio. 
Portanto, os dados experimentais obtidos fudamentam a explicação do fenômeno físico observado nos dispositivos eletroluminescentes fabricados no presente trabalho.

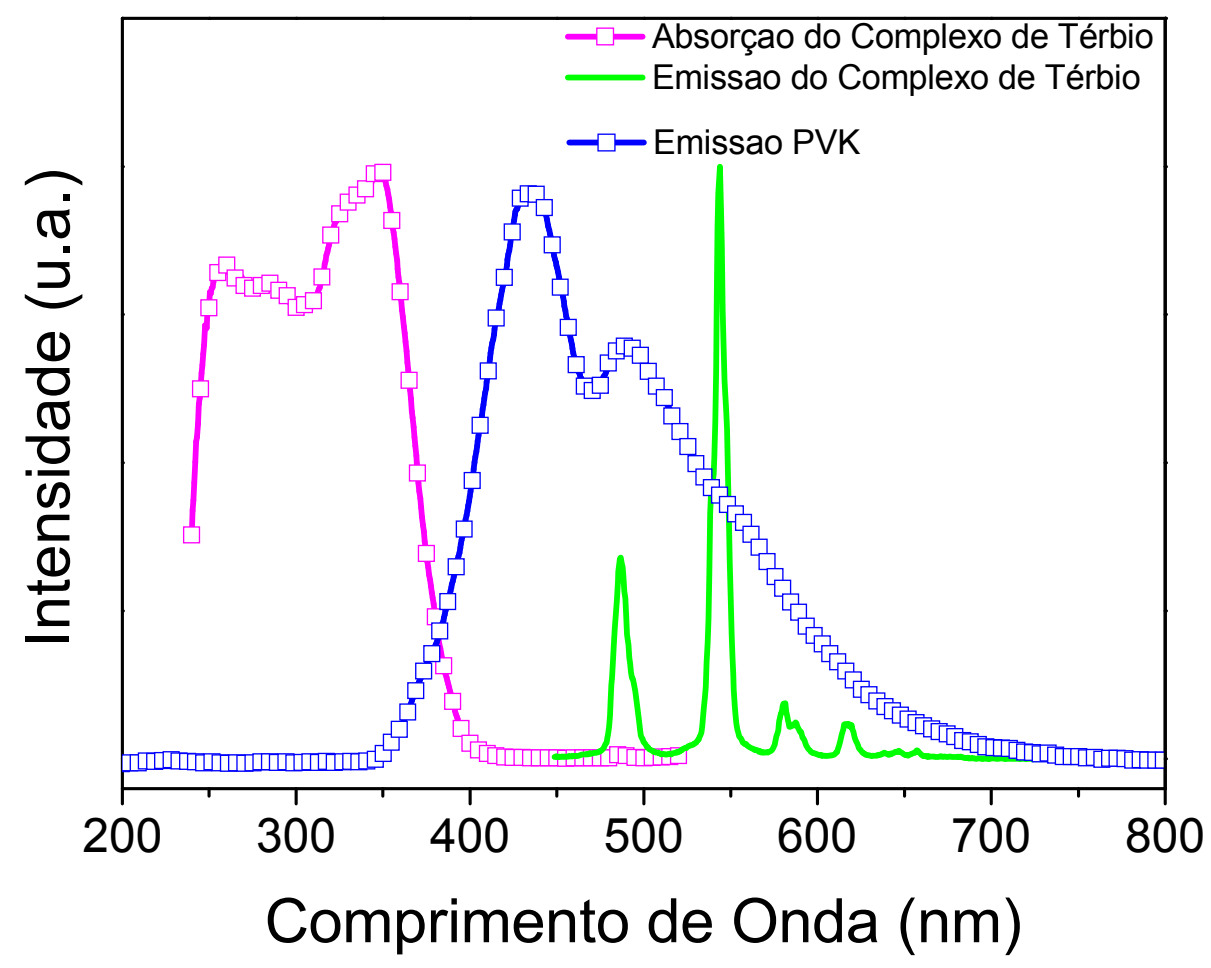

Figura 52 - Espectros de excitação e emissão fotoluminescente do Tb(ACAC)3phen e da fotoluminescência do PVK.

Por outro lado, ZHANG et al. ${ }^{[80]}$ parece reportar resultados muito similar ao do presente trabalho, o qual aponta para uma emissão típica do polímero PVK. Adicionalmente tem-se o fato de que os resultados obtidos por CHEN et al. ${ }^{[65]}$ são únicos e até o momento deste trabalho, não reproduzidos na literatura por outros pesquisadores. Assim, fica em aberto a possibilidade de utilização do PVK como matriz polimérica para complexos de Térbio. 


\subsubsection{Complexo de Európio disperso em PVK variando-se o número de bicamadas formadas por automontagem (PAni/PEDOT:PSS)}

A Figura 53 apresenta as curvas da densidade de corrente em função da tensão aplicada para as amostras com filme de PEDOT:PSS formado por spin-coating (PSC), sem HTL (SHTL) e com bicamadas de PAni/PEDOT:PSS (BPP) automontadas. Com base na resposta elétrica é possível extrair a informação de que ao passo que se aumenta o número de bicamadas a condutividade do dispositivo também é incrementada, partindo-se do referencial da amostra SHTL (ITO/PVK+Complexo de Európio/b-PBD/Alumínio). Este aumento da condutividade explica-se devido ao fato de que cada bicamada contribui com uma quantidade maior de polianilina, que por sua vez é considerada, dentre os polímeros condutores, um dos que possui maior condutividade, alcançando valores tão altos quanto $2 \times 10^{-3}$ S/cm. ${ }^{[81]}$ Além disso, tem-se uma drástica alteração na condutividade ao se chegar em 3 bicamadas; este evento esta correlacionado com a hipótese de que efetivamente forma-se um filme contínuo a partir deste número de bicamadas, onde considera-se, como hipótese também, que isso ocorra para a maior parte dos materiais aplicados para o processo de formação de filmes ultra-finos por automontagem. De forma complementar a esta hipótese é preciso levar em consideração a condição superficial do TCO ou substrato no qual o processo foi executado. 


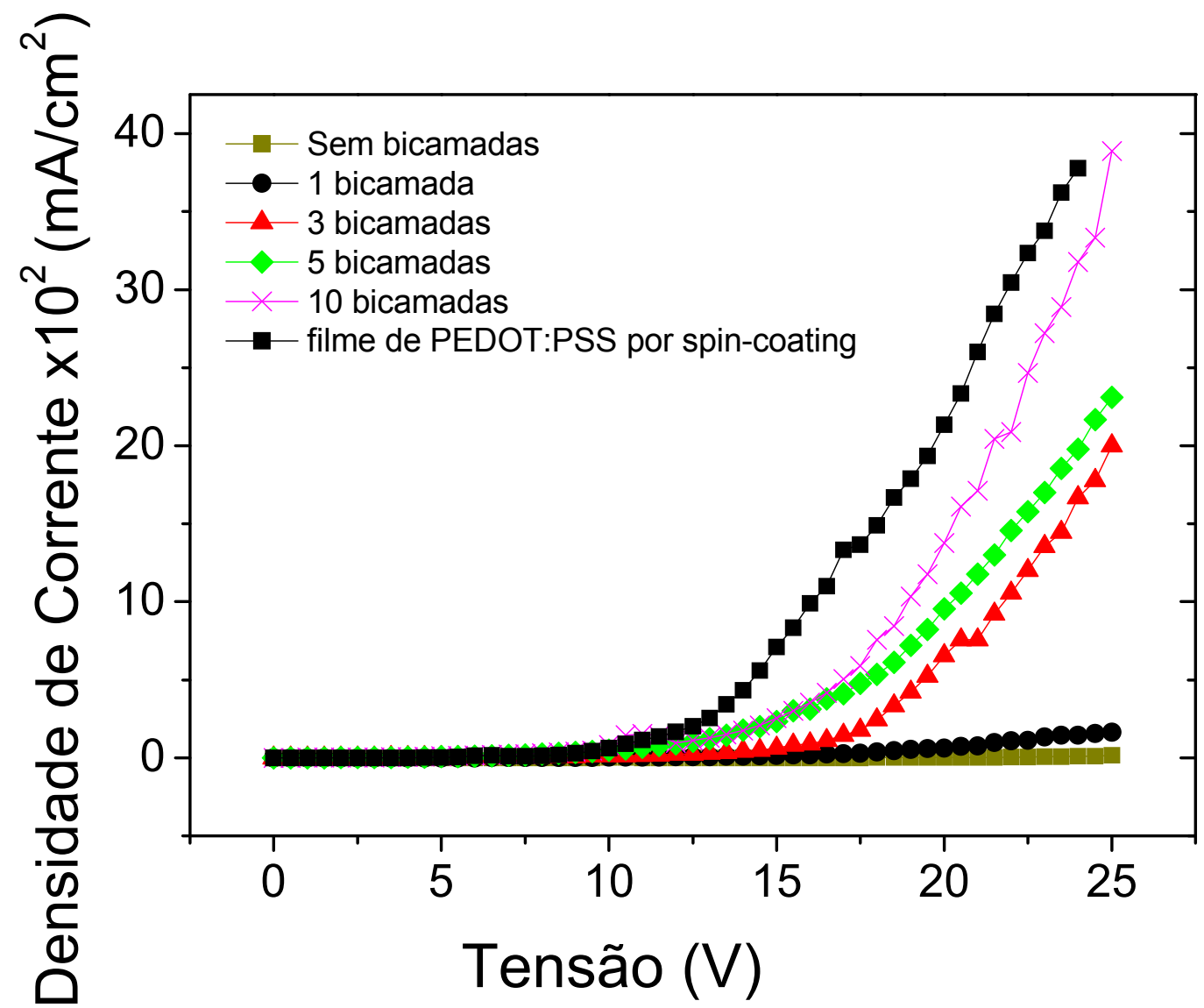

Figura 53 - Curva J-V para os dispositivos fabricados empregando o complexo de Európio, em cuja arquitetura variou-se o número de bicamadas PAni/PEDOT:PSS e tendo-se por referência a estrutura com filme de PEDOT:PSS por spin-coating.

Apesar de se ter um aumento na condutividade proporcional ao número de bicamadas nota-se que o luminância não se comporta do mesmo modo. A Tabela 7 resume os dados obtidos para as amostras fabricadas. Notadamente observa-se que existe um máximo de luminância para 3 bicamadas. Desta forma, foram constatados dois pontos quantitativos importantes, isto é, a maior luminância com 3 bicamadas e maiores eficácias luminosas para uma e três bicamadas. Paralelamente aos valores encontrados na comparação entre as amostras PSC e BPP, tem-se a amostra SHTL, 
que por sua vez apresenta valor elevado para a eficácia luminosa, porém isto não reflete diretamente em melhor desempenho do dispositivo, pois a relação de eficácia luminosa avalia a corrente que circula no dispositivo e a luz gerada. Neste caso, o consumo de corrente por parte do dispositivo SHTL é ínfima, o que implica em elevada eficácia luminosa, mas sem possibilidade de aplicação prática já que a intensidade luminosa deste é muito baixa $\left(<1 \mathrm{~cd} / \mathrm{m}^{2}\right)$ mesmo aplicando-se elevado potencial, o que corrobora com o fenômeno de transporte de portadores de carga deficiente, diferente da estrutura da amostra PSC; essa estrutura apesar de apresentar baixa intensidade luminosa, no mesmo potencial elétrico da comparação feita (25 volts), conta com um sistema mais eficaz de transporte de portadores de carga, devido ao níveis de energia do PEDOT:PSS e, com isso, elevando-se o potencial elétrico é possível obter maiores valores de luminância.

Ainda na Tabela 7 observa-se o fator $m$ que para o caso da estrutura das amostras BPP varia entre 5 e 7. Estes valores relacionam a resposta elétrica ao modelo SCLC descrito no tópico 2.3.1, sendo verdadeira a relação $J \alpha V^{m}$. Este regime identifica a faixa de operação no dispositivo, na qual o potencial elétrico é suficiente para preencher todas as armadilhas e conseqüentemente a corrente torna-se limitada por carga espacial. ${ }^{[49]}$

Por fim, a Tabela 7 evidencia que as bicamadas automontadas colaboram significativamente para o aumento do desempenho do dispositivo eletroluminescente alcançando relações interessantes entre luminância obtida e eficiência externa. 
Tabela 7 - Fator $m$, Luminância e Eficácia luminosa para dispositivos empregando complexo de Európio com variação do número de bicamadas PAni/PEDOT:PSS.

\begin{tabular}{|c|c|c|c|}
\hline $\mathbf{N}^{\mathbf{0}}$ de bicamadas & Fator $\boldsymbol{m}$ & $\begin{array}{c}\text { Luminância } \\
\left(\mathbf{c d} / \mathbf{m}^{\mathbf{2}}\right) \boldsymbol{( a )} \mathbf{2 5} \mathbf{~ V}\end{array}$ & $\begin{array}{c}\text { Eficácia Luminosa } \\
\mathbf{x 1 0} \mathbf{- 3}(\mathbf{c d} / \mathbf{A})\end{array}$ \\
\hline Sem bicamada & 9,4 & 0,4 & 220 \\
\hline $\begin{array}{c}\text { PEDOT:PSS por } \\
\text { spin-coating }\end{array}$ & 3,3 & 1,4 & $2-4$ \\
\hline 1 & 5,1 & 0,7 & 51 \\
\hline 3 & 7,1 & 1,6 & 20 \\
\hline 5 & 4,4 & 1,1 & 10 \\
\hline 10 & 5,8 & 0,6 & 58 \\
\hline
\end{tabular}

$\mathrm{Na}$ Figura 54 é apresentada a resposta em eletroluminescência das amostras fabricadas. Nesta resposta espectral nota-se claramente uma emissão no azul. Relaciona-se a esta banda de emissão a hipótese da atuação do polímero PVK. A este fenômeno atribui-se ao fato do aumento no transporte de lacunas com o número de bicamadas, aumentando, desta forma, a probabilidade de recombinação e gerando uma emissão fluorescente devido aos níveis singletos do polímero PVK. 
@28 volts

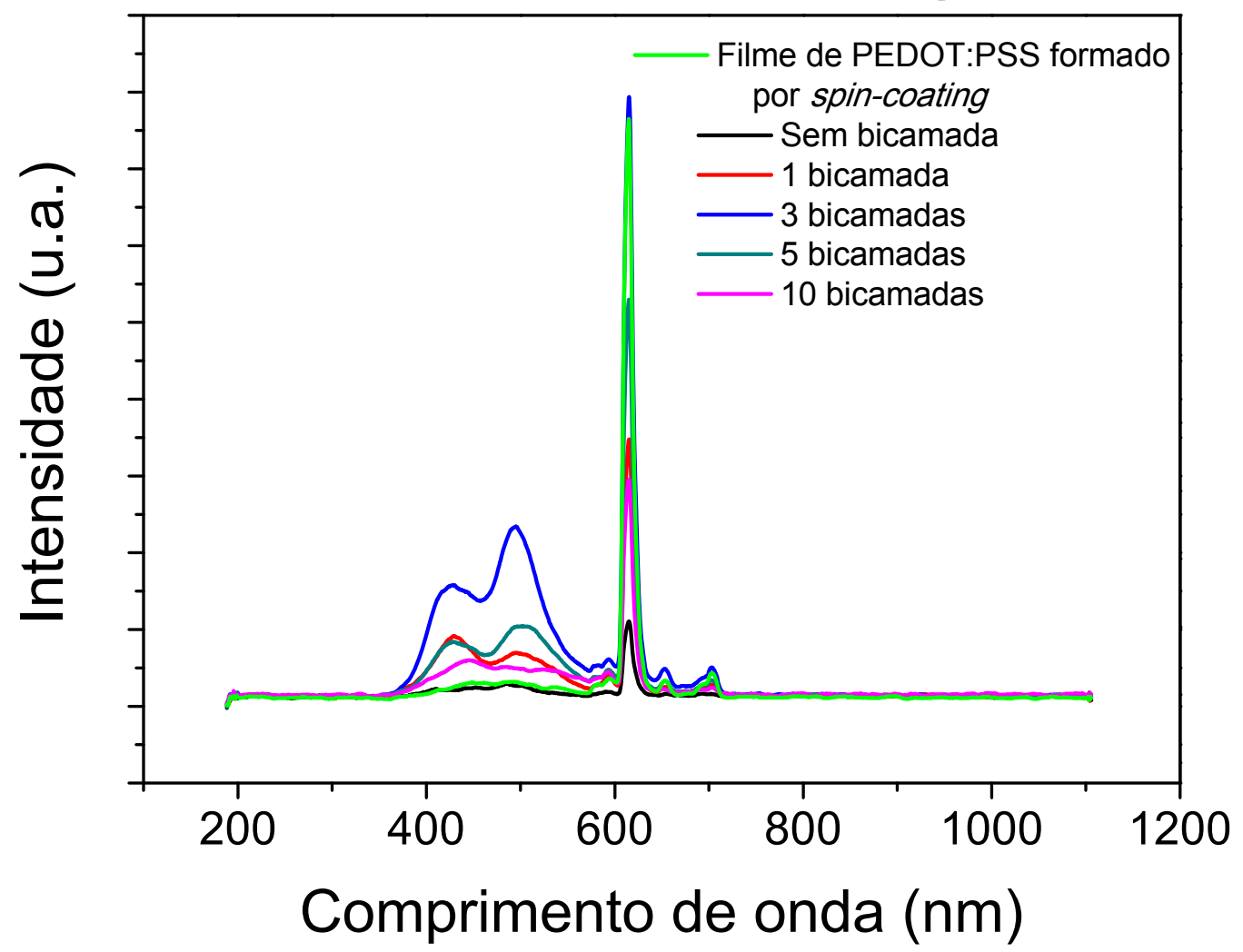

Figura 54 - Espectro de eletroluminescência para os dispositivos empregando PEDOT:PSS formado por spin-coating, sem HTL e com as bicamadas automontadas PAni/PEDOT:PSS.

Ainda com base na resposta espectral (Figura 54) foram extraídas as coordenadas de cromaticidade, as quais são apresentadas na Figura 55 indicando para a amostra PSC o vermelho típico do complexo de Európio; já nas amostras SHTL e BPP têm-se a cor magenta-azulada, caracterizando a influência azul proveniente da banda do PVK em conjunto com o vermelho do complexo de Európio. 


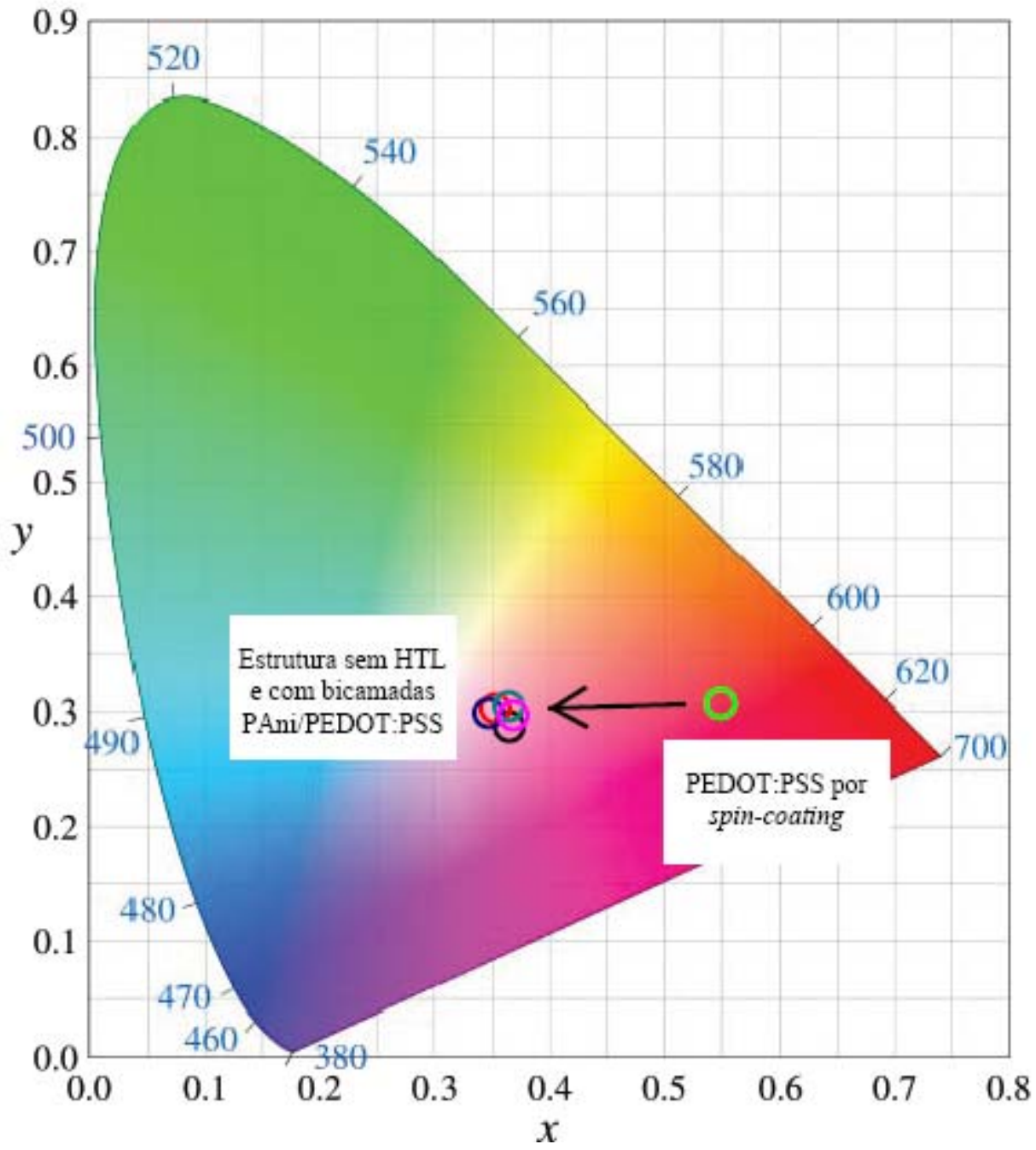

Figura 55 - Diagrama de cromaticidade com as coordenadas obtidas para a amostra sem HTL, com filme de PEDOT:PSS e com bicamadas automontadas PAni/PEDOT:PSS.

Neste caso não foi calculada a eficiência quântica externa $(E Q E)$, pois as coordenadas de cromaticidade obtidas para essa estrutura encontram-se em uma região definida, no diagrama CIE de 1931, como de cores não cromáticas. Com isso, ocorre a impossibilidade de se determinar o comprimento de onda dominante. ${ }^{[82]}$ 
Complementando o diagrama de energia já elaborado para arquitetura empregando complexo de Európio disperso em PVK (ver Figura 47) obteve-se o diagrama da Figura 56, na qual os níveis de energia da PAni e do PEDOT:PSS foram adicionados.

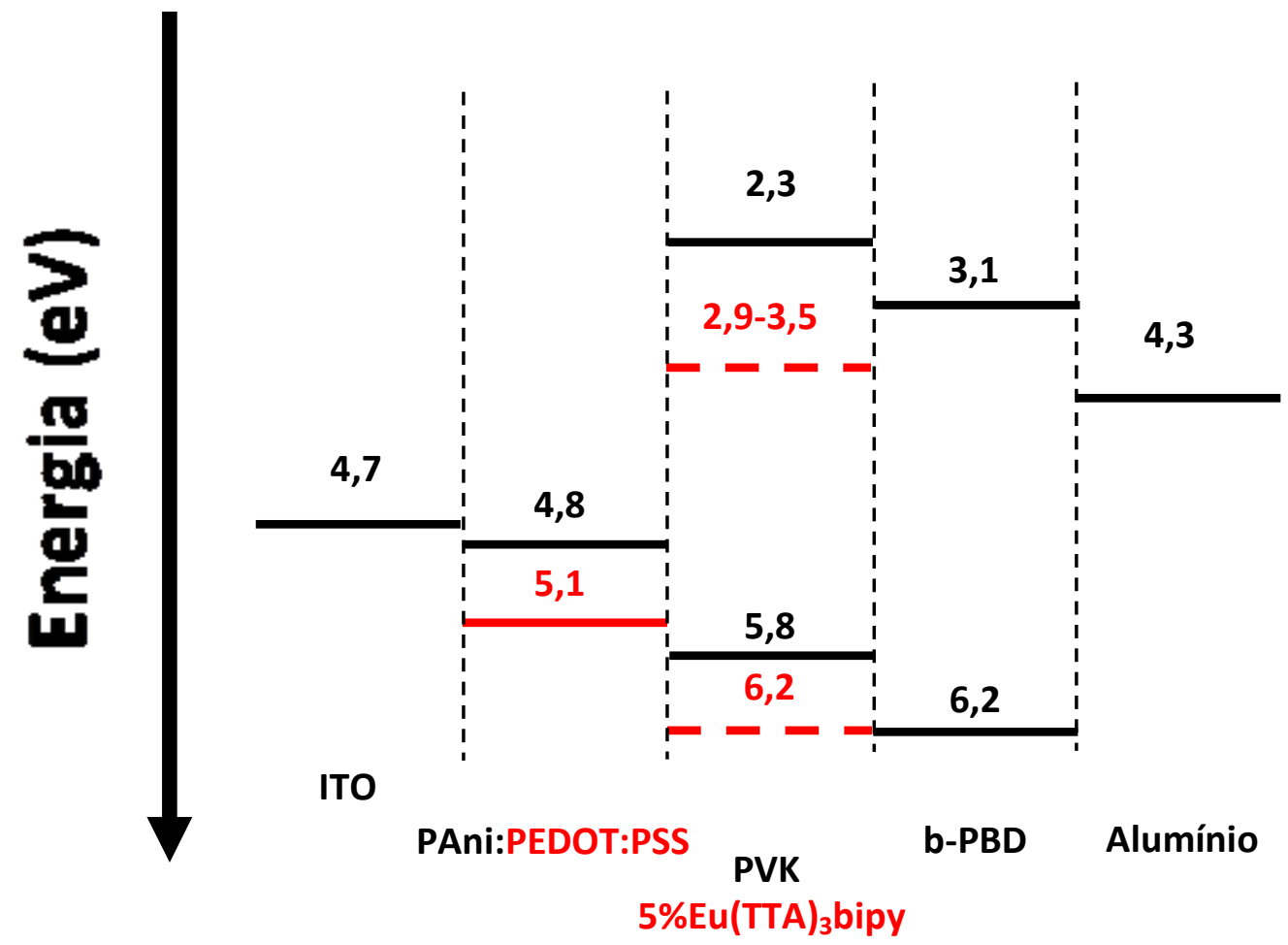

Figura 56 - Diagrama de energia para a estrutura fabricada para análise do Complexo de Európio - Eu(TTA) 3 bipy - disperso no PVK variando-se o número de bicamadas.

Com os resultados obtidos e partido-se da referência de uma estrutura que empregue apenas o PEDOT:PSS, verifica-se que ocorre uma aumento da eficiência em conjunto com maior intensidade da banda do PVK, o que leva a hipótese, com base no diagrama apresentado na Figura 56, que a estrutura que emprega as bicamadas de PAni/PEDOT:PSS automontadas propiciam uma melhor uniformidade em termos de filme fino, no entanto, essa contribuição não colabora para potencializar a 
transferência de energia do polímero para o complexo de Európio. Uma hipótese para este fenômeno é a formação de níveis de energia, cuja localização, dada a interface entre bicamadas automontadas/filme emissivo, proporciona maior probabilidade de recombinação no PVK; outra hipótese é fato do próprio aumento na condutividade propiciar maior quantidade de lacunas, cuja densidade é tão elevada que a probabilidade de recombinação no próprio polímero torna-se mais acentuada que a transferência de energia, que por sua vez ocorre em paralelo. Todavia, o fato da eficiência externa aumentar aloca os filmes automontados aplicados para OLEDs como promissores.

Na Figura 57a-c tem-se o registro fotográfico das amostras PSC e d) amostra BPP. Nota-se que com o aumento do potencial elétrico aplicado é possível identificar o aumento da banda do PVK na amostra PSC, cuja resposta é semelhante a cor produzida pelas amostras BPP. 


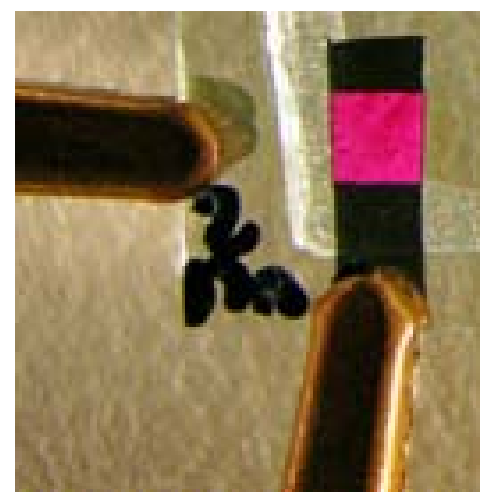

a) Estrutura com PEDOT por spincoating(PSC)@18 V

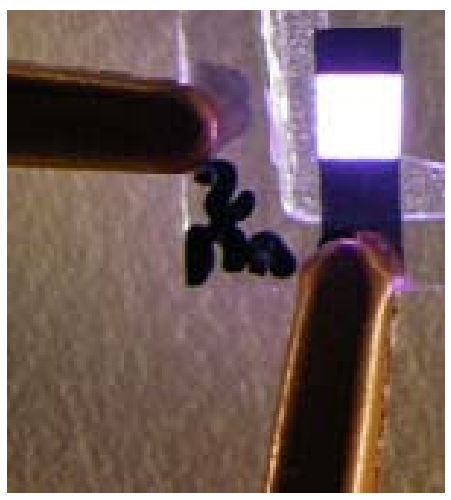

c) Estrutura com PEDOT por spincoating(PSC)@28 V

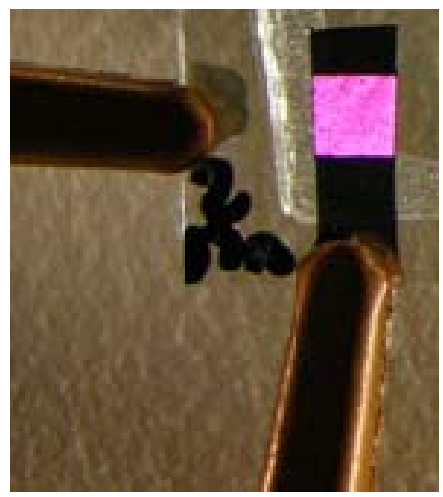

b) Estrutura com PEDOT por spincoating(PSC)@22 V

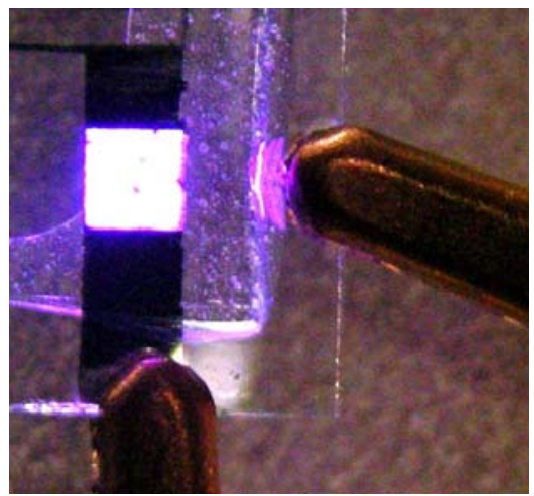

d) Estrutura com 3 bicamadas PAni/PEDOT:PSS (BPP)@28 V

Figura 57 - registro fotográfico a-c) amostra PSC com 18, 22 e 28 volts; d) amostra com 3 bicamadas.

De modo geral, as informações obtidas qualificam, em uma primeira análise, os filmes automontados, como promissores ao estudo mais aprofundado em dispositivos com complexos de Terras Raras como filme emissivo. ${ }^{[83]}$ 


\subsection{Dispositivos com complexos de Metais de Transição}

\subsubsection{Complexo de Rutênio com variação do ligante}

No ensaio empregando os complexos $\mathrm{Ru}(\text { bipy })_{3}\left(\mathrm{PF}_{6}\right)_{2}$ [bipiridina] $\mathrm{e}$ $\mathrm{Ru}\left(\mathrm{ph}_{2} \mathrm{phen}\right)\left(\mathrm{PF}_{6}\right)_{2} \quad$ [difenilfenantrolina], foi analisada a resposta comparativa variando-se o ligante $(L)$ e mantendo-se fixo o contra-íon, que no presente trabalho, foi o hexafluoreto de fósforo. Figura 58 apresenta a resposta de PL comparativa entre os complexos de Rutênio empregando os ligantes bipiridina e difenilfenantrolina.

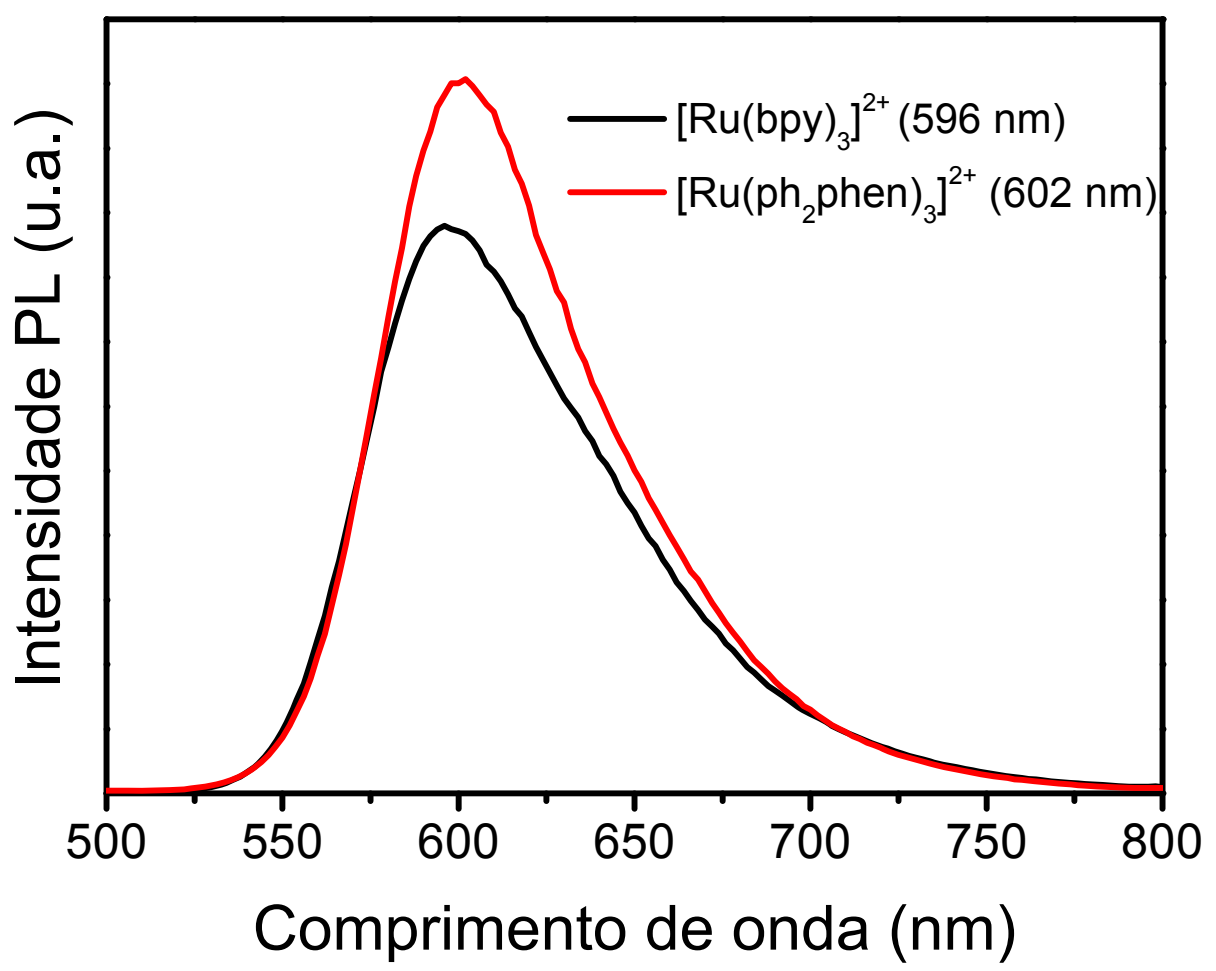

Figura 58 - Espectros de fotoluminescência dos complexos $\left[R u(b p y)_{3}\right]^{2+}$ e $\left[R u\left(p h_{2} p h e n\right)_{3}\right]^{2+}$ em PMMA.

G. Santos - Escola Politécnica da Universidade de São Paulo - OLEDs, PLEDs e LECs 
A Figura 59 apresenta a característica elétrica comparativa do complexo de Rutênio empregando os ligantes bipy e $p h_{2} p h e n$. Com base na resposta elétrica, é possível identificar que embora a concentração de complexo de Rutênio no polímero PMMA e a fabricação das amostras sigam as mesmas condições, nota-se que a corrente elétrica na estrutura empregando o complexo de Rutênio com ligante bipiridina, é muito mais elevada; já no parâmetro tensão de operação constata-se que praticamente não houve variação significativa, e neste caso os valores obtidos foram 2,7 e 4 volts, para o ligante bipiridina e difenilfenantrolina, respectivamente. Com base no fato da proximidade das espessuras dos filmes finos dos complexos de Rutênio com ambos ligantes $(\cong 200 \mathrm{~nm})$, é possível concluir que o ligante difenilfenantrolina incrementa a resistência elétrica na estrutura do LEC. Neste caso, a estrutura química do complexo $\mathrm{Ru}\left(\mathrm{ph}_{2}\right.$ phen) corrobora com esta hipótese, pois do ponto de vista do transporte de portadores de carga, bem como os processos envolvidos no mecanismo de emissão de luz, existe maior oposição aos portadores de carga devido a estrutura química do próprio material. 


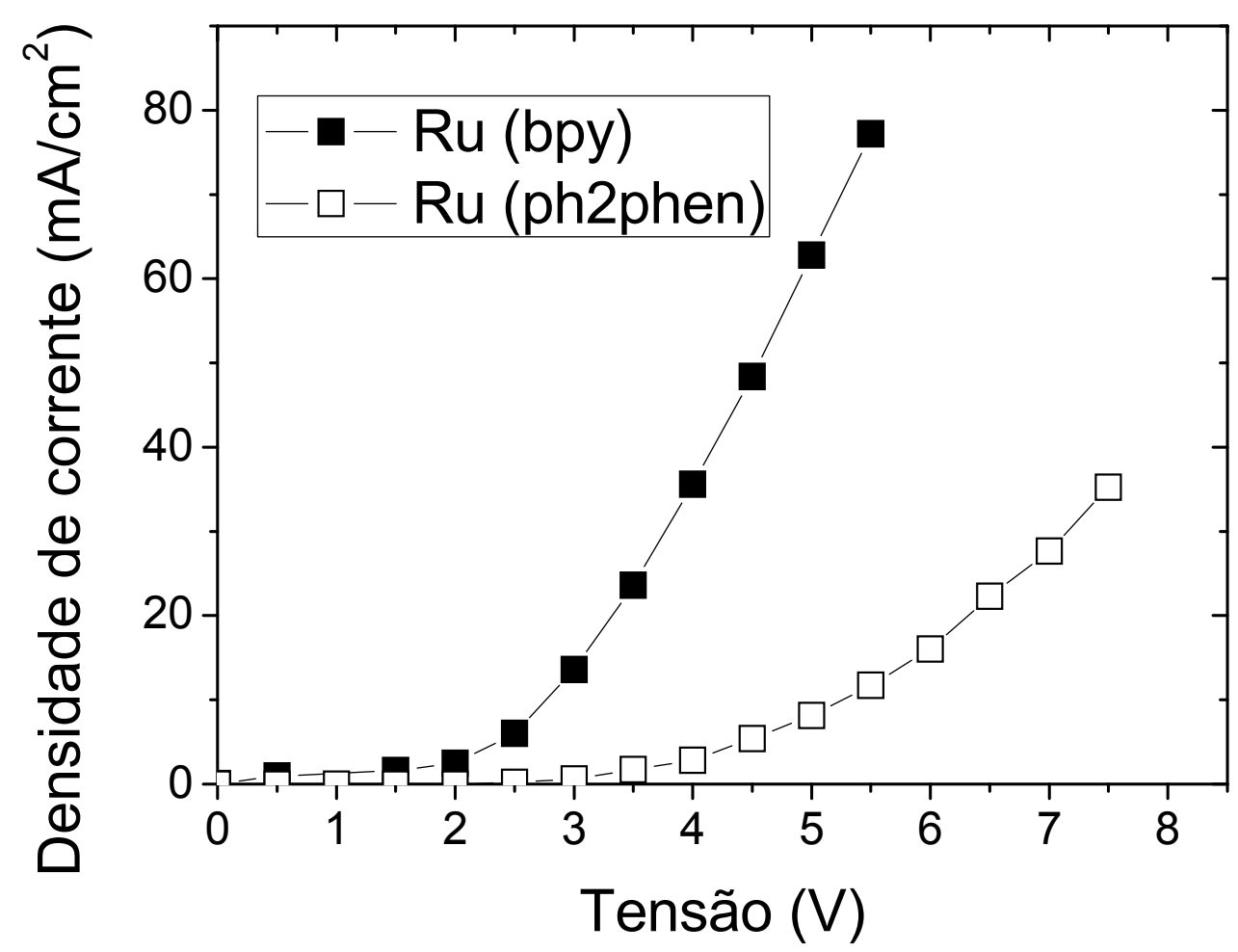

Figura 59 - Característica elétrica comparativa entre o complexo Ru(bpy)3(PF6)2 e o $\operatorname{Ru}\left(\text { ph }_{2} \text { phen }\right)_{3}\left(\mathbf{P F}_{6}\right)_{2}$.

A resposta elétrica apresentada na Figura 59 evidencia elevada densidade de corrente e, com isso, não se pode excluir a existência de injeção de portadores de carga unipolar neste tipo de dispositivo. Para avaliar esse caráter unipolar do dispositivo foi extraída uma curva $J-V$ rápida de modo a impedir o processo típico de redistribuição de portadores de carga, no caso os contra-íons, responsável pela eletroluminescência. Nesta condição, o hopping dos elétrons nas espécies formadas no complexo de Rutênio, durante sua excitação elétrica, é governado por um campo elétrico uniforme através do filme. Dessa forma, a condução elétrica pode ser modulada por uma 
expressão do tipo $J=J_{0}\left[e^{\beta V}-e^{(-\beta V)}\right]$, onde $J_{0}$ é a densidade de corrente de troca entre os locais dos estados nas espécies formadas no complexo de Rutênio e $\beta$ um parâmetro que depende das propriedades físicas do material e também da temperatura. ${ }^{[84]}$ Os melhores ajustes realizados, na região de baixos potenciais elétricos aplicados, indicam valores médios para $J_{0}$ de aproximadamente de 10 $\mathrm{mA} / \mathrm{cm}^{2}$, cujo valor se enquadra nos valores obtidos experimentalmente. Este resultado aponta para a hipótese de que as espécies formadas, durante o processo de excitação elétrica do complexo de Rutênio, na região de cátodo conduzem a uma injeção unipolar de portadores de carga em baixos potenciais elétricos (abaixo da Tensão de operação). Com isso, espera-se com base na definição dada para $J_{0}$, dada a elevada concentração de complexo de Rutênio no filme emissivo, uma elevada densidade de espécies formadas. O fundamento desta análise se justifica, pois essa hipótese pode contribuir para reduzir o tempo de resposta do dispositivo fazendo-se, futuramente, variações no catodo de forma que este elemento na estrutura do dispositivo ajude na modificação da injeção unipolar.

Comparativamente, evidencia-se na resposta elétrica apresentada na Figura 59 o melhor desempenho do complexo com o ligante bipiridina, bem como na resposta de eletroluminescência apresentada na Figura 60. Nesta figura a banda de eletroluminescência apresenta pico máximo em $630 \mathrm{~nm}$, cuja resposta reproduz a resposta em PL em temperatura ambiente, sendo também, neste caso, a emissão atribuída ao mecanismo ${ }^{3}$ MLCT. 


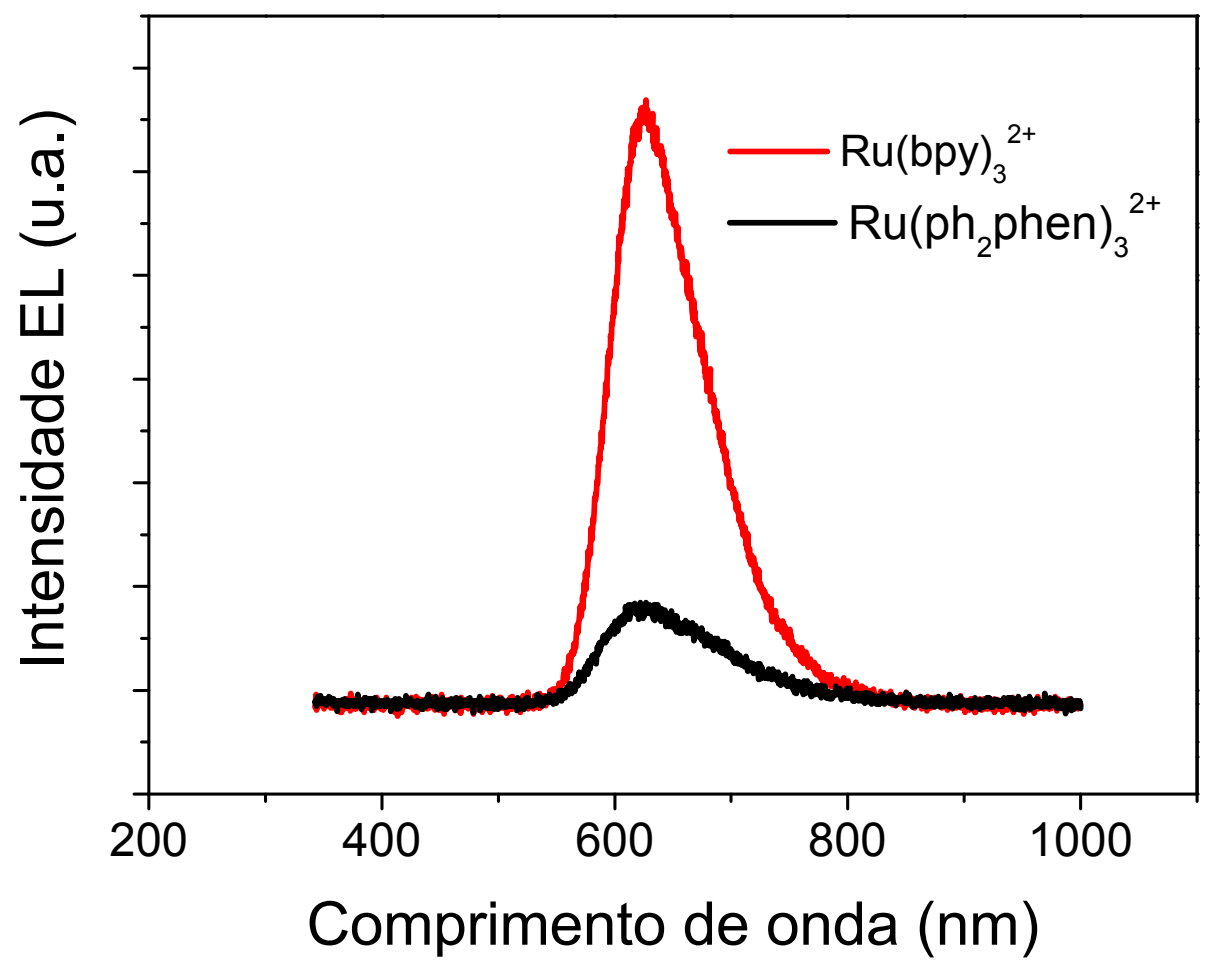

Figura 60 - Espectros de eletroluminescência dos dispositivos empregando os complexos $\left[\mathrm{Ru}(\mathrm{bpy})_{3}\left(\mathrm{PF}_{6}\right)_{2}\right]$ e $\left[\mathrm{Ru}\left(\mathrm{ph}_{2} \text { phen }\right)_{3}\left(\mathrm{PF}_{6}\right)_{2}\right]$ em conjunto com o PMMA inseridos na estrutura ITO/Complexo de Rutênio/Alumínio.

Com base na resposta de EL, as coordenadas de cromaticidade obtidas para os dispositivos empregando complexo de Rutênio com os ligantes bipiridina e difenilfenanatrolina foram de $\mathrm{x}=0,64 ; \mathrm{y}=0,35$ e $\mathrm{x}=0,52 ; \mathrm{y}=0,37$, respectivamente, as quais são apresentadas no diagrama da Figura 61. 


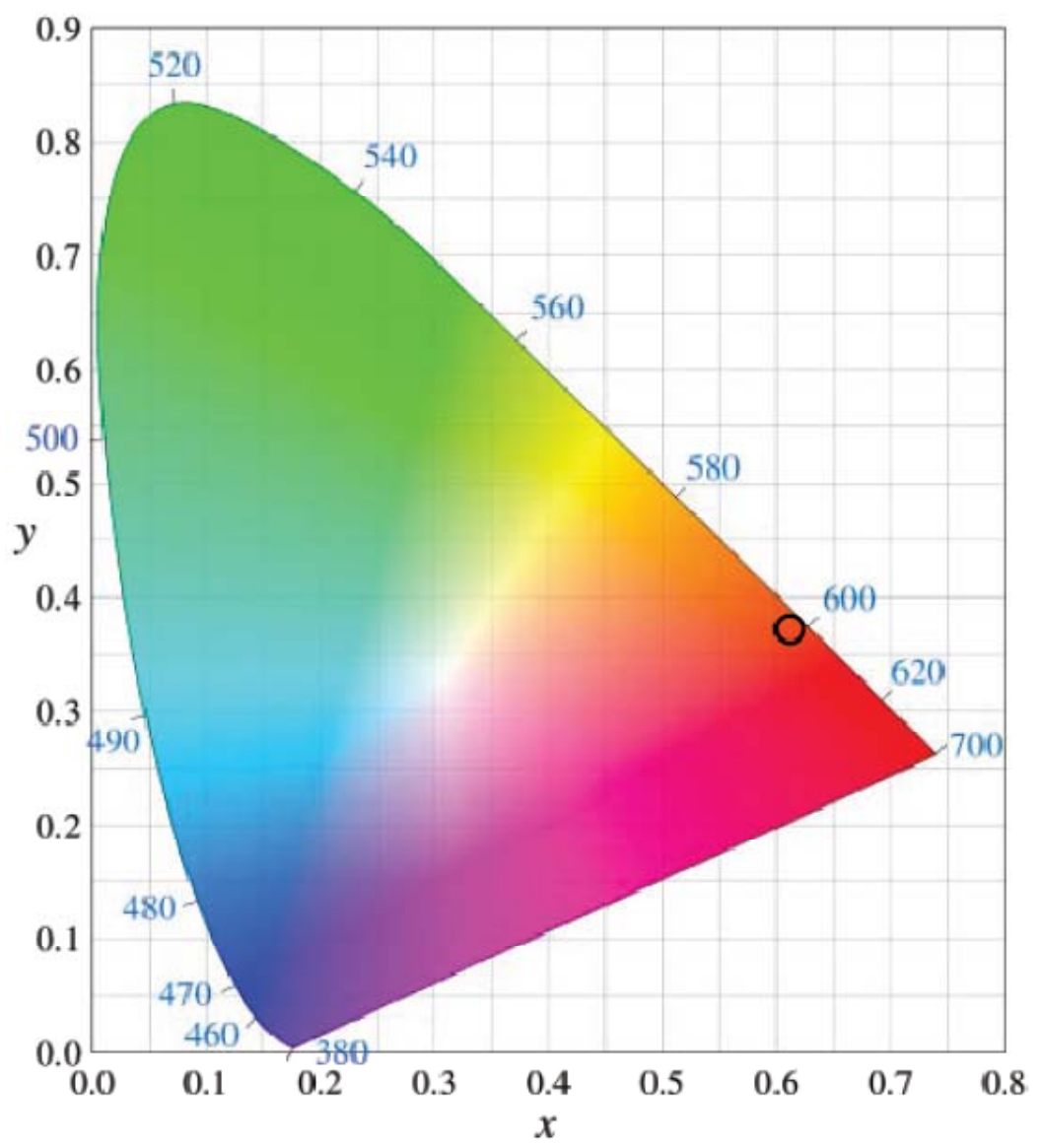

Figura 61 - Diagrama de cromaticidade com as coordenadas relativas ao dispositivo empregando o complexo de Rutênio.

Extraindo-se a eficiência Wall Plug, para esta classe de dispositivos eletroluminescentes, obteve-se a eficiência de $2,6 \times 10^{-2} \%$ para o complexo empregando o ligante bipiridina, enquanto que para o difenilfenantrolina foi de $1 \times 10^{-2} \%$. Apontando para melhor eficiência em EL para o ligante bipiridina, no entanto, em PL o outro ligante sobressai devido a maior possibilidade de formação de estados excitados ${ }^{3}$ MLCT sob luz ultra-violeta. 
A Figura 62 apresenta a proposição do diagrama de níveis de energia com base em dados apontados na literatura, cujos estados excitados são calculados por simulação. ${ }^{[5]}$ Neste diagrama é possível fazer uma analogia dos níveis HOMO e LUMO para com as espécies excitadas formadas durante o processo de eletroluminescência.

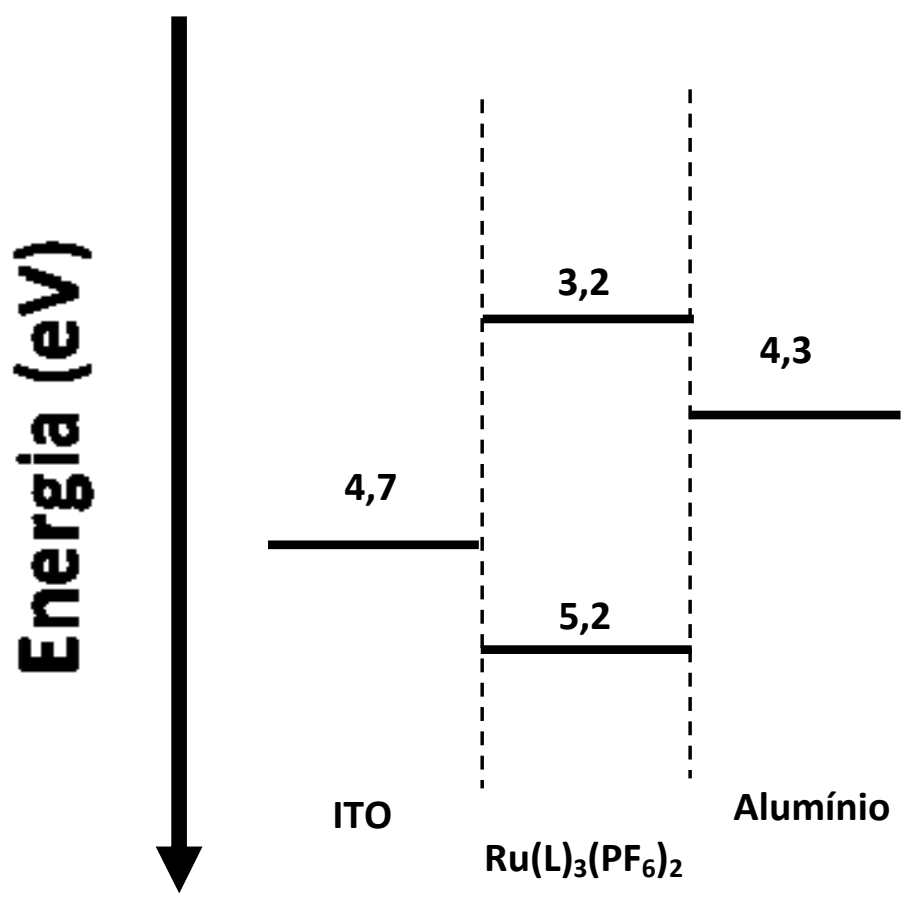

Figura 62 - Diagrama de energia para a estrutura empregando o complexo de Rutênio variando-se o ligante.

Por fim, a Figura 63 mostra os registros fotográficos das amostras empregando o complexo de Rutênio com os ligantes bipiridina e difenilfenantrolina. 


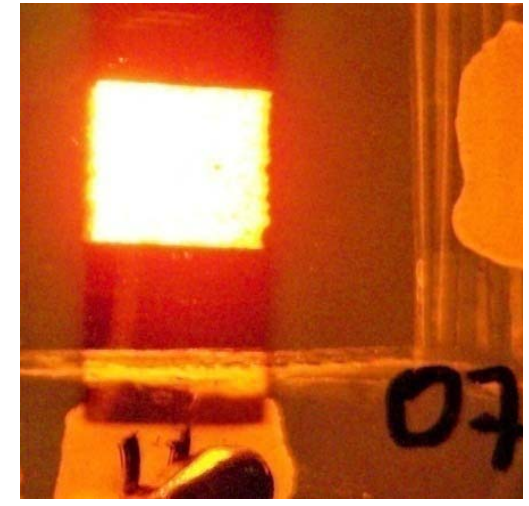

(a)

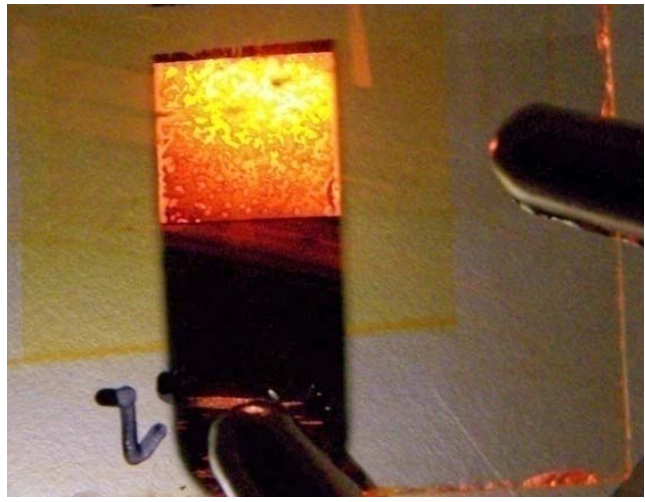

(b)

Figura 63 - Fotos dos dispositivos eletroluminescentes fabricados empregando o complexo de Rutênio com a) ligante bipiridina e b) difenilfenantrolina.

\subsubsection{Complexo de Rênio em diversas concentrações disperso em PVK}

Neste foco do estudo observou-se que ao passo que se aumenta a concentração do complexo de Rênio (função corante) disperso no PVK ocorre drástica variação na condutividade do dispositivo, conforme dados apresentados na Figura 64. 


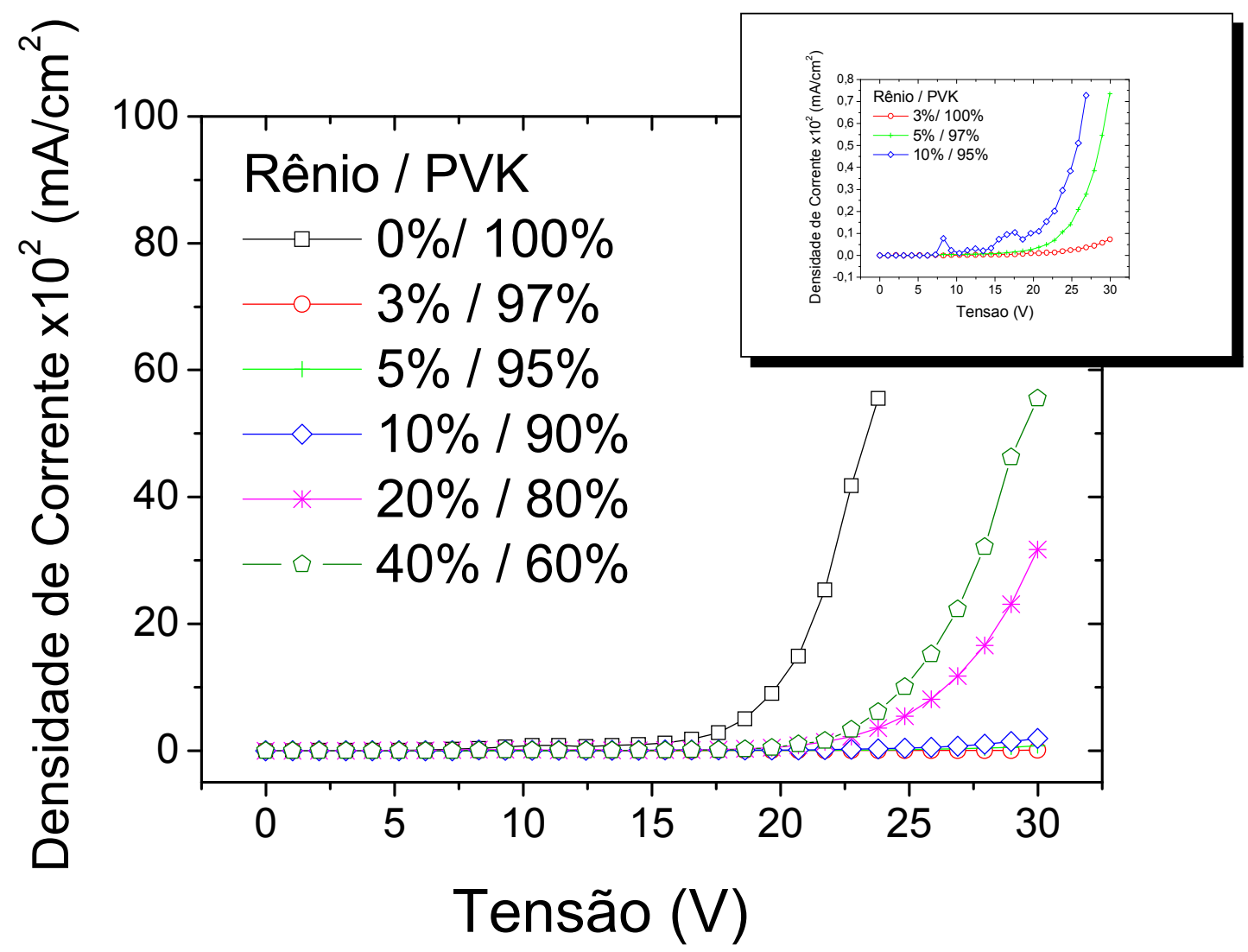

Figura 64 - Densidade de corrente em função da tensão para diversas concentrações do complexo de Rênio disperso no polímero PVK na estrutura ITO/PEDOT:PSS/x\% complexo de Rênio/b-PBD/Al. O gráfico anexo apresenta o detalhe dos dados para as concentrações de 0,3 e $5 \%$ de complexo de Rênio, que por sua vez também apresentam comportamento retificador.

A partir dos dados obtidos (Figura 64) tem-se por hipótese que a adição do complexo de Rênio, na matriz do polímero PVK, leva a uma maior resistência do sistema dado que o ligante do complexo de Rênio possui características de transporte de portadores de carga deficiente. No entanto, a condutividade aumenta com a concentração de complexo dispersa na matriz polimérica e, para isso, tem-se como hipótese a maior concentração localizada de acessos para a passagem de corrente devido ao próprio complexo, porém este fenômeno, mesmo em elevadas 
concentrações, não permite que se alcance o patamar de condutividade do polímero atuando isoladamente.

Paralelamente aos fenômenos associados à condutividade, evidencia-se que com o aumento da concentração em massa do complexo de Rênio, conforme dados apresentados na Figura 65, a luminância aumenta, diferente do que ocorre nos complexos de Terras Raras, nos quais a luminescência é atenuada em concentrações acima de $8 \%$ em massa devido ao fenômeno denominado como na literatura como aniquilação tripleto-tripleto ${ }^{[86]}$ No entanto, quando a concentração aumenta de 20 para 40\% em massa a eletroluminescência cai drasticamente. A esse fenômeno atribuí-se o fato de que em concentrações elevadas existe uma densidade elevada de centros emissores, no entanto, a energia transferida do polímero para o complexo não consegue ser aproveitada adequadamente. A hipótese é que a energia, não convertida em luz, perde-se na rede de forma vibrônica ou mesmo em decaimentos nãoradiativos. Estudos mais aprofundados são necessários para se comprovar esta hipótese, como variação da concentração da solução, diferentes arquiteturas de modo a modular o confinamento de carga e checar sua relação com o filme fino formado. 


\section{(a) 30 volts}

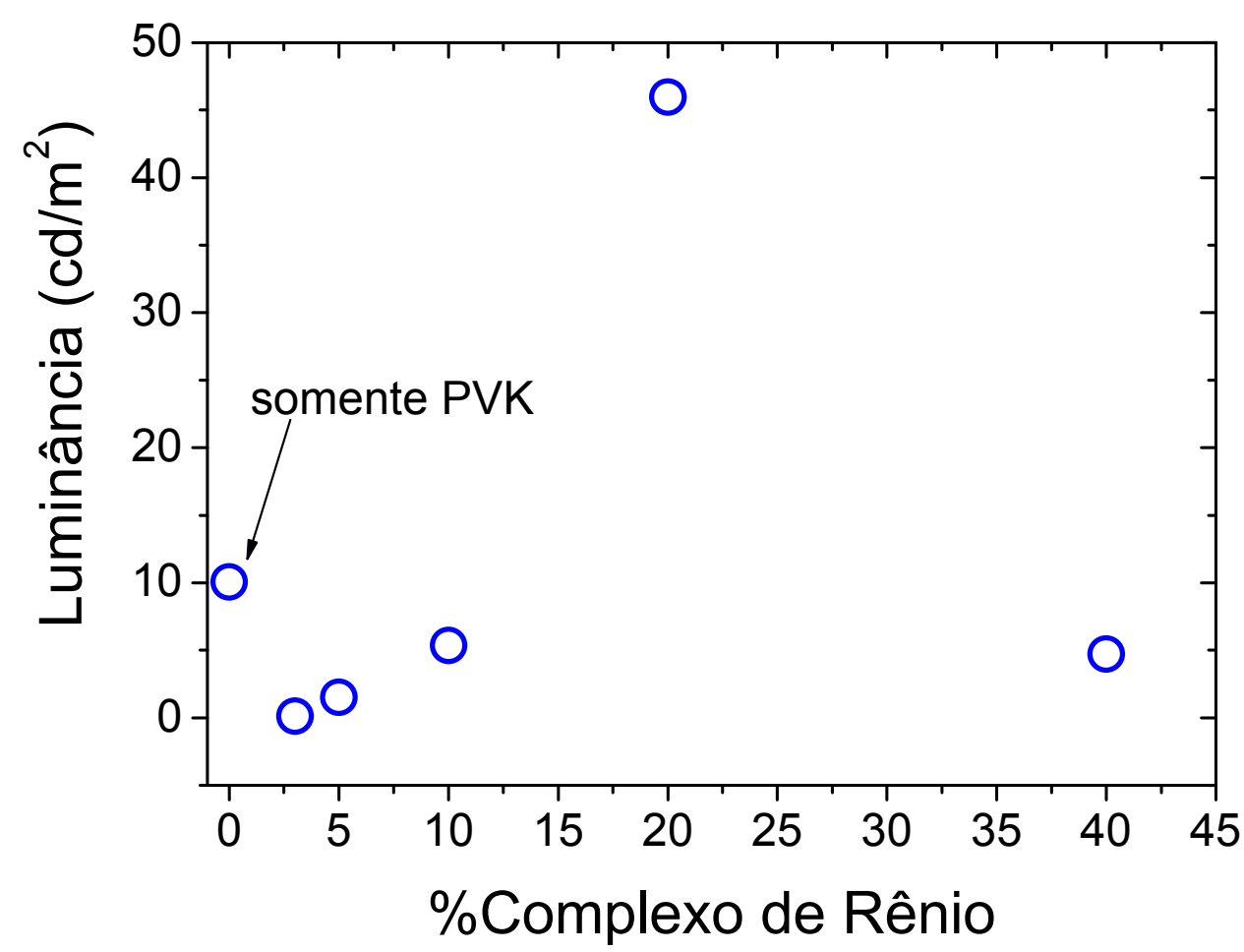

Figura 65 - Variação da luminância dos dispositivos fabricados em função da concentração do complexo de Rênio.

Além das possíveis perdas citadas, quando a quantidade de complexo alcança em massa um ponto equiparado a massa do polímero, responsável pela formação do filme emissor empregando-se a técnica de spin-coating, a qualidade do filme fino formado é empobrecida. Defini-se por qualidade de filme formado a desuniformidade qualitativamente observada pós spin-coating. Existe a possibilidade de se encontrar condições melhores para formação de filmes finos em elevadas concentrações, no entanto, outras perdas, já citadas, podem ainda ocorrer de modo 
que o ponto ótimo, impreterivelmente ocorre em concentrações abaixo de $40 \% \mathrm{em}$ massa.

Na Tabela 8 são apresentados os dados obtidos para as diversas concentrações do complexo de Rênio disperso em PVK. Nessa tabela observa-se ao passo que se aumenta a concentração do complexo de Rênio as coordenadas de cromaticidade partem do azul predominante, com a emissão exclusiva do PVK, para a região amarelo-esverdeada em baixas concentrações do complexo de Rênio para o amarelo (acima de 5\% do complexo de Rênio em massa) com sensação visual de cor branca em elevados potenciais elétricos.

Tabela 8 - Coordenadas de cromaticidade, comprimento de onda dominante, pureza de cor e eficiência quântica externa para os dispositivos empregando complexo de Rênio em diversas concentrações disperso em PVK.

\begin{tabular}{|c|c|c|c|c|}
\hline $\begin{array}{c}\mathbf{x \%} \text { de } \\
\text { complexo de } \\
\text { Rênio } \\
\text { disperso em } \\
\text { PVK }\end{array}$ & $\begin{array}{c}\text { Coordenadas } \\
\text { de } \\
\text { cromaticidade } \\
\text { @ 40 volts }\end{array}$ & $\begin{array}{c}\text { Comprimento } \\
\text { de onda } \\
\text { dominante } \\
(\mathbf{n m})\end{array}$ & Pureza de cor & $\begin{array}{c}\text { Eficiência } \\
\text { Quântica } \\
\text { Externa } \\
\left(\mathbf{x 1 0}^{-3}\right) \text { @ 25 V } \\
\mathbf{( \% )}\end{array}$ \\
\hline $\begin{array}{c}\text { Sem complexo } \\
\text { de Rênio }\end{array}$ & 0,$20 ; 0,17$ & 472 & 61,8 & 29 \\
\hline 3 & 0,$36 ; 0,39$ & 569 & 24,9 & 9 \\
\hline 5 & 0,$43 ; 0,46$ & 575 & 67,2 & 35 \\
\hline 10 & 0,$45 ; 0,47$ & 576 & 76,2 & 54 \\
\hline 20 & 0,$46 ; 0,49$ & 575 & 85,1 & 53 \\
\hline 40 & 0,$46 ; 0,45$ & 579 & 73,2 & 1,86 \\
\hline
\end{tabular}

Ainda com base na Tabela 8 , observa-se que para valores acima de 5\% de complexo de Rênio praticamente não existe variação no comprimento de onda dominante. Por 
outro lado a pureza de cor aumenta na faixa entre 5 a $20 \%$, identificando a banda de emissão predominante do complexo de Rênio.Por outro lado, a $E Q E$ apresenta aumento entre 3 e $10 \%$ e praticamente se mantém constante aumentando-se a concentração de 10 para $20 \%$, no entanto, o aumento de 10 para $20 \%$ justifica-se pelo fato de que ocorre aumento na condutividade do sistema, que por sua vez não compromete a eficiência externa nem a qualidade de formação do filme fino e ainda incrementa a luminância de $\cong 10 \mathrm{~cd} / \mathrm{m}^{2}(\mathrm{em} 10 \%)$ para $\cong 50 \mathrm{~cd} / \mathrm{m}^{2}$ (em $20 \%$ ) fixandose um potencial elétrico de 30 volts.

Nesta classe de dispositivos observou-se, com base na teoria, que após o preenchimento dos defeitos ocorre um rápido aumento na mobilidade efetiva passando da relação de lei de potência (Power-law) da relação $I \alpha V^{2}$ para um regime SCLC em potenciais elétricos suficientemente elevados, ${ }^{[49]}$ no caso das arquiteturas fabricadas acima de 18 volts, conforme mostra o fator $m$ na Tabela 9, para as diversas concentrações. 
Tabela 9 - Fator $m$ para os dispositivos empregando complexo de Rênio em diversas concentrações disperso em PVK.

\begin{tabular}{|c|c|}
\hline $\begin{array}{c}\text { x\% de complexo de Rênio disperso em } \\
\text { PVK }\end{array}$ & Fator $\boldsymbol{m}$ \\
\hline Sem complexo de Rênio & 9,4 \\
\hline 3 & 5,5 \\
\hline 5 & 7,7 \\
\hline 10 & 7,9 \\
\hline 20 & 10,2 \\
\hline 40 & 12,6 \\
\hline
\end{tabular}

Além disso, nota-se também que com o incremento da concentração do complexo de Rênio disperso no PVK tem-se aumento na banda relativa a emissão do próprio Rênio devido a maior probabilidade de decaimento radiativo nos estados excitados das espécies formadas no complexo, regidas pelo mecanismo ${ }^{3} \mathrm{MLCT},{ }^{[69]}$ conforme Figura 66, no entanto, tem-se também um aumento relativo a banda de emissão do PVK. Porém observa-se, segundo dados da Tabela 10, que embora haja aumento da banda de emissão do PVK a razão entre áreas integradas das bandas de emissão do complexo de Rênio e PVK aumenta e, dessa forma, tem-se uma emissão proporcional menor por parte do PVK, o que faz sentido dado o fato de que existe uma maior concentração e emissão luminosa por parte do complexo de Rênio. 


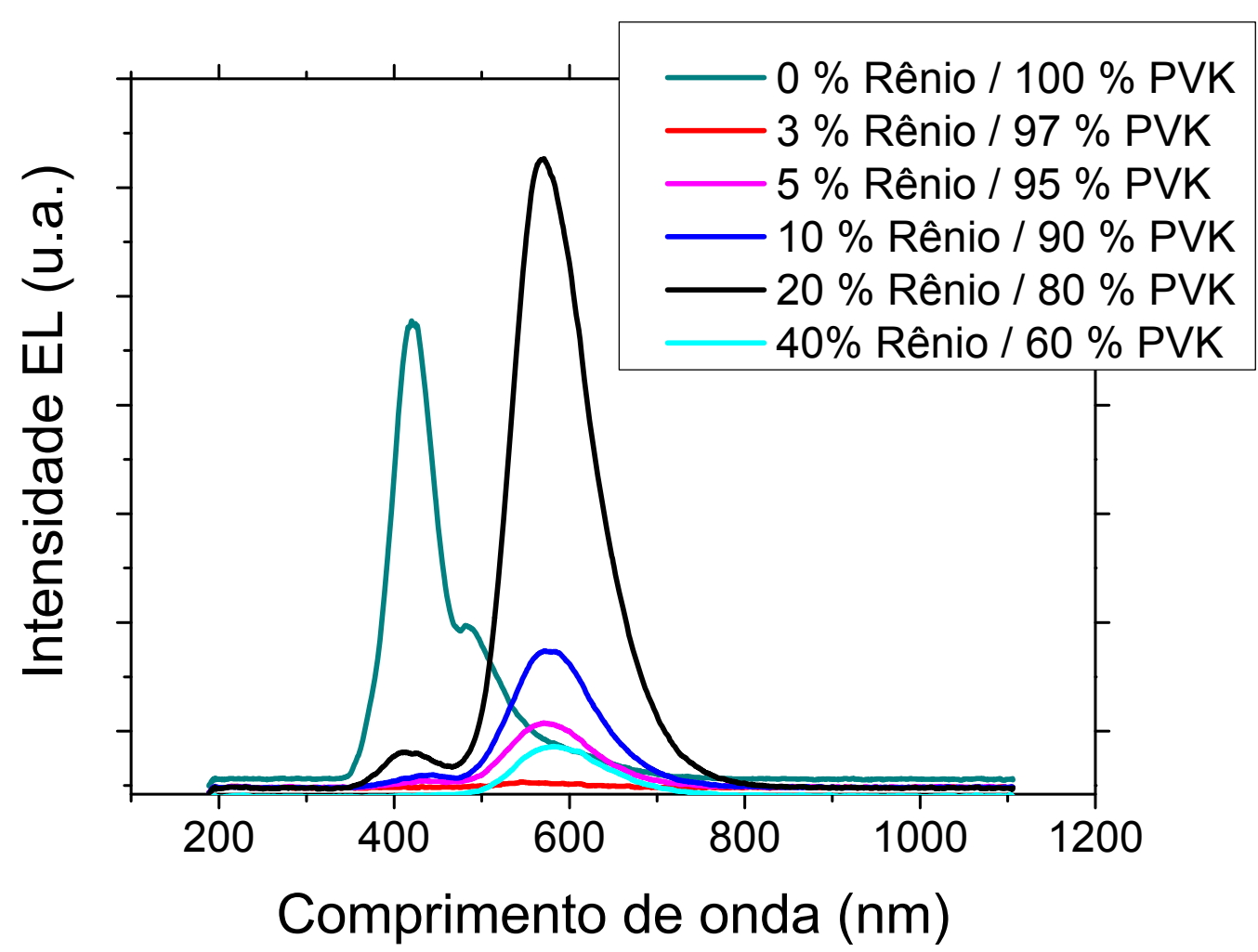

Figura 66 - Espectros de eletroluminescência dos dispositivos fabricados variando-se a concentração do complexo de Rênio.

Tabela 10 - Razão entre as áreas integradas das bandas de emissão do PVK e do complexo de Rênio.

\begin{tabular}{|c|c|c|c|}
\hline $\begin{array}{c}\mathbf{x} \% \text { de complexo de } \\
\text { Rênio no PVK }\end{array}$ & $\begin{array}{c}\text { Área do PVK } \\
\text { (normalizada) }\end{array}$ & $\begin{array}{r}\text { Ârea do complexo de } \\
\text { Rênio (normalizada) }\end{array}$ & Razão \\
\hline Somente PVK & 126,83 & Sem banda & 0 \\
\hline $3 \%$ & sem banda & 202,07 & 0 \\
\hline $\mathbf{5 \%}$ & $\mathbf{9 1 , 4 7}$ & $\mathbf{3 4 9 , 5 7}$ & $\mathbf{3 , 8}$ \\
\hline $\mathbf{1 0 \%}$ & $\mathbf{6 4 , 2 7}$ & $\mathbf{2 5 9 , 1 6}$ & $\mathbf{4 , 0}$ \\
\hline $\mathbf{2 0} \%$ & $\mathbf{2 0 , 5 5}$ & $\mathbf{1 4 9 , 2 7}$ & $\mathbf{7 , 2}$ \\
\hline $40 \%$ & sem banda & 227,78 & 0 \\
\hline
\end{tabular}


A Figura 67 apresenta o deslocamento das coordenadas de cromaticidade em função da variação da concentração do complexo de Rênio disperso no PVK, partindo do azul (somente PVK) até o amarelo (40\% em massa de complexo).

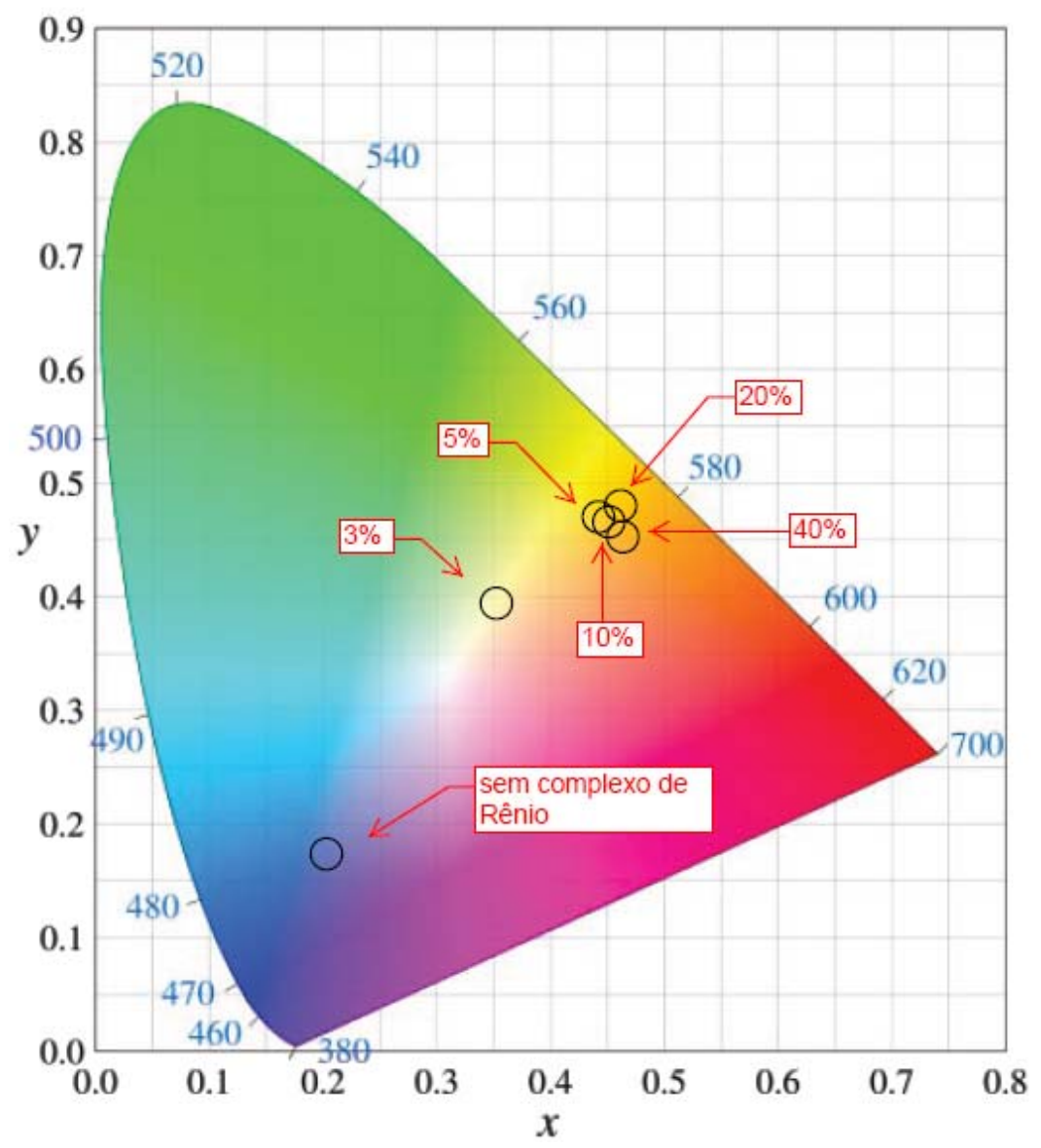

Figura 67 - Diagrama de cromaticidade com as indicações das coordenadas de cor para os dispositivos fabricados variando-se a concentração de complexo de Rênio. 
O diagrama de energia da Figura 68 foi baseado na literatura ${ }^{[69,87]}$ Assim como no caso do complexo de Rutênio é possível fazer uma analogia das espécies excitadas formadas, no processo de eletroluminescência, aos níveis HOMO e LUMO.

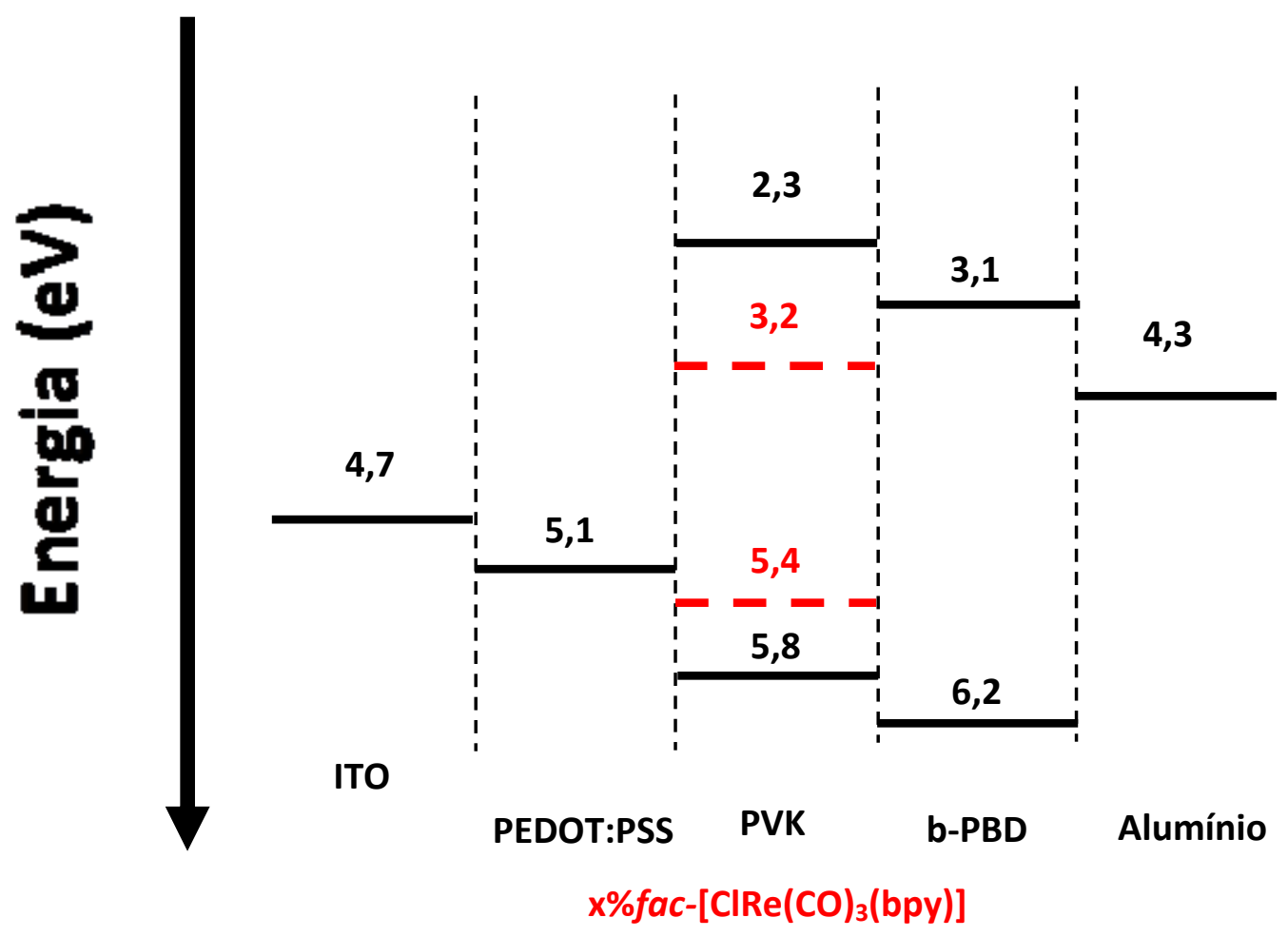

Figura 68 - Diagrama de energia para a estrutura empregando o complexo de Rênio disperso em PVK em diversas concentrações.

No diagrama elaborado e apresentado na Figura 68, observa-se, como em outras estruturas empregando o PVK como polímero matriz, afinidade entre os PEDOT:PSS e o b-PBD em suas respectivas função de transporte de lacunas e elétrons. Além disso, com base em valores dos níveis de energia apresentados na literatura acerca do complexo de Rênio, constata-se adequação satisfatória para transferência de energia 
dos estados excitados do polímero para a espécie excitada do complexo de Rênio, cuja hipótese fundamentam os resultados obtidos experimentalmente.

$\mathrm{Na}$ Figura 69 têm-se os registros fotográficos das amostras fabricadas, sendo a) somente PVK, b) PVK+3\% Rênio, c) PVK+5\% Rênio, d) PVK+10\% Rênio, e) PVK $+20 \%$ Rênio e, por fim, f) PVK+40\% Rênio. 


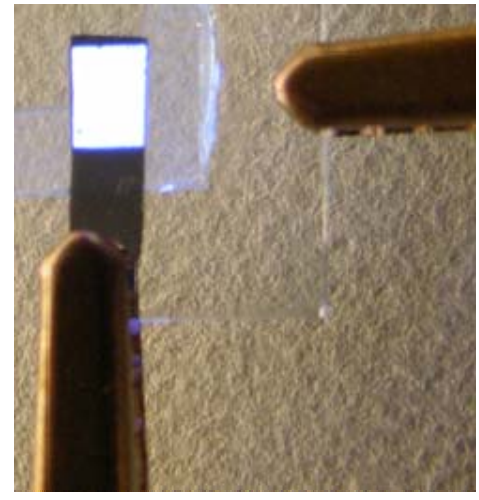

a) Sem complexo de Rênio (resposta PVK)

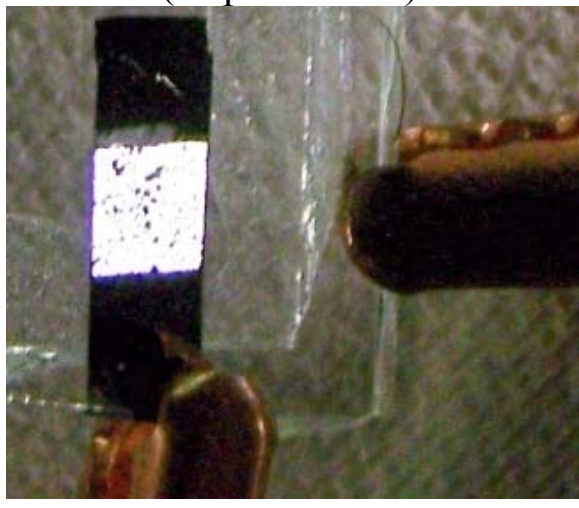

c) $5 \%$ de complexo de Rênio

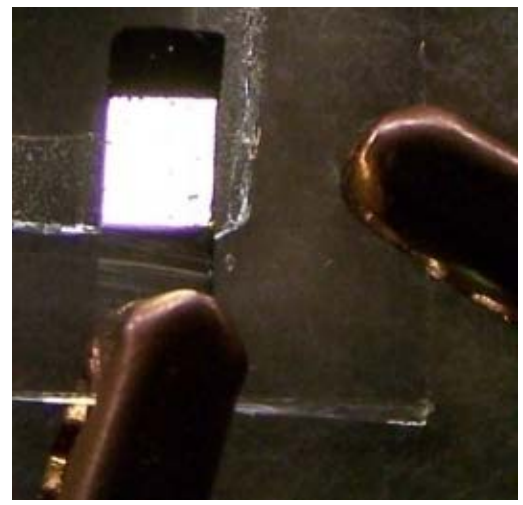

e) $20 \%$ de complexo de Rênio

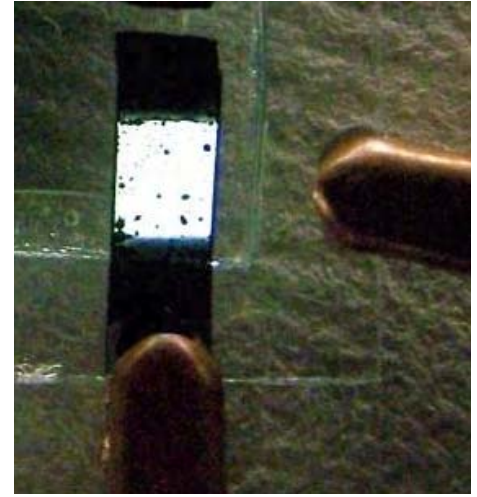

b) 3\% de complexo de Rênio

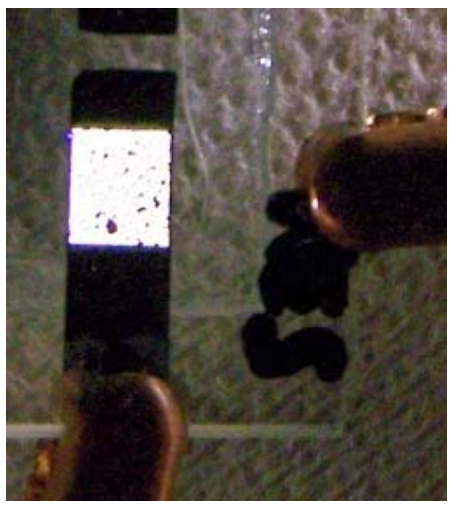

d) $10 \%$ de complexo de Rênio

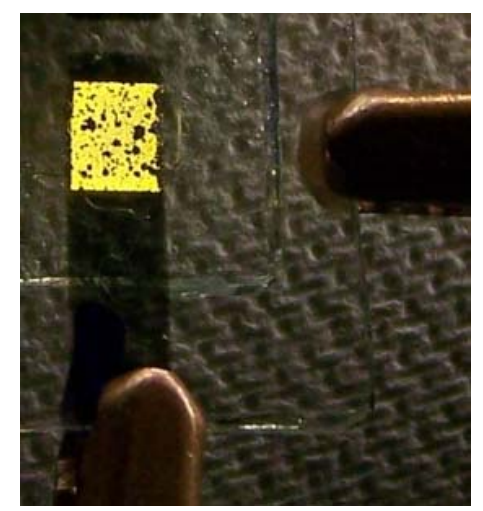

f) $40 \%$ de complexo de Rênio

Figura 69 - Registro fotográfico das amostras fabricadas variando-se o complexo de Rênio, partindo-se do azul (somente PVK) (a), passando pela região de emissão branca (b - e) (mistura do amarelo do complexo de Rênio e a banda de emissão do PVK no azul) e, por fim, emissão amarela característica do complexo de Rênio (f). 


\section{Capítulo 5 CONCLUSÕES E PERSPECTIVAS}

No presente trabalho estudou-se os complexo de terras raras e de metais de transição aplicados em dispositivos orgânicos emissores de luz com vistas à aplicação futura tecnológica destes materiais em dispositivos mostradores de informação (displays) e também com perspectiva para iluminação ambiente. Os resultados do presente trabalho trouxeram a tona alguns aspectos inovadores dessa classe de dispositivos eletroluminescentes.

Nesta tese apresentou-se a análise de dispositivos eletroluminescentes iniciando-se pelos termicamente evaporados até os com filmes emissivos depositados por meio da técnica de spin-coating, cujos pontos principais foram:

- Complexo de Európio com variação do ligante principal: Neste foco observou-se que o ligante principal, mantendo-se fixo o neutro, influencia na eficiência externa do dispositivo, porém não contribui para que haja variação significativa de cor. Adicionalmente, este estudo revelou que o ligante principal proporciona variação na estabilidade elétrica do dispositivo. Ainda neste foco constatou-se que os ligantes principais mais eficientes foram o DBM e o TTA, enquanto que o BTA torna o dispositivo instável em polarizações superiores a 18 volts na arquitetura utilizada.

- Complexo de Térbio com variação do ligante neutro: Esta análise, empregando o complexo de Térbio variando-se o ligante neutro e mantendo- 
se fixo o principal, revelou que a configuração estrutural do ligante neutro contribui para maior condutividade no sistema. Este fato pode implicar em variação do comprimento de onda dominante emitido consoante a arquitetura do dispositivo fabricado.

- Complexo de Európio disperso em PVK: Este ensaio reproduziu resultados já obtidos anteriormente na literatura ${ }^{[62]}$ e serviram de conexão para que o estudo dos complexos de TRs e de MTs dispersos em polímero fossem iniciados. Além disso, serviu também para que o filme de complexo de Európio disperso em uma matriz polimérica fosse empregado em uma arquitetura inovadora empregando como HTL filmes formados através da técnica de Automontagem (Self-Assembly).

- Complexo de Európio disperso em PVK variando-se o número de bicamadas formadas por automontagem: Os resultados inovadores deste foco revelaram que as bicamadas contribuem para melhor desempenho do dispositivo e que pode ser otimizado com base na arquitetura empregada. Com base nos resultados obteve-se melhor desempenho para três bicamadas de PAni/PEDOT:PSS. Este resultado proporcionou maior condutividade no sistema, melhor recombinação e melhor eficácia luminosa em comparação com o filme com função de HTL de PEDOT:PSS formado por spin-coating.

- Complexo de Rutênio variando-se o ligante: Com base nos ensaios com os complexos de TRs, utilizando-se a técnica de spin-coating o estudo foi ampliado aos complexos de Metais de Transição começando pelo complexo de Rutênio. Com a variação do ligante verificou-se que a bipiridina torna o 
dispositivo mais eficiente em comparação à difenilfenantrolina. Paralelamente, com a hipótese de haver injeção unipolar causada pelo catodo em baixos potenciais elétricos, abre-se a possibilidade do estudo da redução do tempo de resposta desta classe de dispositivos.

- Complexo de Rênio em diversas concentrações disperso em PVK: Partindo-se da mesma idéia do complexo de Európio empregou-se o complexo de Rênio disperso em PVK. Nesses ensaios observou-se um eficiente processo de transferência de energia da matriz polimérica para o complexo de Rênio, cuja emissão conjunta (Polímero e complexo) produz emissão luminosa com sensação visual de cor próxima ao branco. Isto abre a possibilidade de aplicação deste tipo de dispositivo para iluminação ambiente.

De forma global, os resultados contribuíram para elucidar alguns fenômenos, relacionados ao estudo de dispositivos eletroluminescentes com filmes finos no estado sólido empregando complexos de terras raras e de metais de transição, ainda não totalmente explorados na literatura, deixando em aberto ainda a perspectiva de diversos pontos a serem aprofundados no futuro, como:

- Novas estruturas empregando complexo de Európio disperso em matriz polimérica para melhor confinamento de portadores de carga e redução da banda de emissão da matriz polimérica e, com isso, potencializar a recombinação e eficiência externa do mesmo. 
- Aplicação de novos materiais em filmes automontados em conjunto com complexos de TR de forma a conjugar a formação de filmes ultrafinos e espectros de elevada pureza de cor com significativa eficiência externa.

- Processamento de novos complexos de Rutênio sintetizados, bem como o estudo de diferentes catodos para potencializar seu tempo de resposta em dispositivos com uma única camada (single layer).

- Estudo mais aprofundado dos mecanismos de luminescência do complexo de Rênio envolvendo modelos para aprimorar e explicar com mais detalhes a formação das espécies excitadas no mecanismo ${ }^{3}$ MLCT. Com isso, melhorar a conjugação do complexo deste complexo com outros materiais com função de injeção e transporte de portadores de carga. 


\section{APÊNDICE A: LISTA DE PUBLICAÇÕES EM PERIÓDICOS}

1) G. Santos, F. J. Fonseca, A. M. Andrade, A. O. T. Patrocínio, S. K. Mizoguchi, N. Y. Murakami Iha, M. Peres, T. Monteiro e L. Pereira.; "Development and characterization of Light-Emitting Diodes (LEDs) based on ruthenium complex single layer for trans-parent displays". Physica Status Solidi A, 1-4, 2008 / DOI 10.1002/pssa.200778925

2) S. S. Braga, A. C. Coelho, I. S. Gonçalves, G. Santos, F. J. Fonseca, A. M. Andrade, M. Peres, W. Simóes, T. Monteiro e L. Pereira; "Luminescence properties of the TRIMEB inclusion compound of a europium tris-beta-diketonate". Journal of Non-Crystalline Solids, v. 354, Ed. 19-25, p. 2736-2739, 2008.

3) G. Santos, F. J. Fonseca, A. M. Andrade, A. O. T. Patrocínio, S. K. Mizoguchi, N. Y. Murakami Iha, M. Peres, W. Simões, T. Monteiro e L. Pereira; "Opto-electrical properties of single layer flexible electroluminescence device with Ruthenium complexes". Journal of Non-Crystalline Solids, .v 354, Ed. 19-25, p. 2571-2574, 2008.

4) G. Santos, F. J. Fonseca, A. M. Andrade, V. Deichmann, L. Ackcelrud, S. S. Braga, A. C. Coelho, I. S. Gonçalves, M. Peres, W. Simões, T. Monteiro e L. Pereira; "Organic light emitting diodes with Europium(III) emissive layers based on $\beta$ diketonate complexes: the influence of the central ligand". Journal of NonCrystalline Solids, v. 354, Ed. 19-25, p. 2897-2900, 2008.

5) G. Santos, F. J. Fonseca, A. M. Andrade, V. Deichmann, L. Ackcelrud, M. Peres, T. Monteiro, W. Simões e L. Pereira; "Electro-optical measurements, stability and physical charge behavior of rare-earth based organic light emitting diode". SPIE digital Library, Proceedings Vol. 6655 V (Organic Light Emitting Materials and Devices XI)/ DOI: 10.1117/12.734901, 2007

6) G. Santos, F. J. Fonseca, A. M. Andrade, M. Peres, T. Monteiro, W. Simões e L. Pereira; "Light emission optimization of europium based complex in multilayer organic light emitting diode". SPIE Digital Library, Proceedings Vol. 6655 U (Organic Light Emitting Materials and Devices XI)/ DOI: 10.1117/12.734818, 2007.

7) G. Santos, F. J. Fonseca, A. M. Andrade, S. S. Braga, A. C. Coelho, I. S. Gonçalves, W. Simões e L. Pereira; "Novel Europium -diketonate Complex in Organic Light Emitting Diode: Eu(BTA)3bipy [tris(1-(2-benzoyl)-3,3,3trifluoroacetone))-bipyridine, Europium(III)]". The Electrochemical Society, ECS Transactions, v. 9, Ed. 1, p. 243-249, 2007. 


\section{APÊNDICE B: LISTA DE PUBLICAÇÕES EM ANAIS DE CONFERÊNCIAS INTERNACIONAIS}

1) G. Santos, F. J. Fonseca, A. M. Andrade, V. Deichmann, L. Ackcelrud, M. Peres, T. Monteiro e L. Pereira; "Luminescence of an organic semiconductor with $\mathrm{Tb}^{3+}$ and its application in OLEDs". International School on Structural characterization of nanostructures (ISSCN), 2007.

2) G. Santos, V. Zaia, S. K. Mizoguchi, A. S. Polo, F. J. Fonseca, A. M. Andrade, N. Y. Murkami Iha e L. Pereira; "Electroluminescence characterization of an OLED based on rhenium(I) complex". VI Encontro SBPMat, 2007.

3) G. Santos, W. Simões, F. J. Fonseca, A. M. Andrade e L. Pereira; "DC and AC electrical characterization of a tris-beta-diketonate Europium complex OLED and the relationship with electroluminescence behavior". VI Encontro SBPMat, 2007.

4) G. Santos, J. F. de Deus, F. J. Fonseca, A. M. Andrade, L. Ackcelrud e L. Pereira; "The search for white Organic Light Emitting Diode using a polymeric conductive blend" Polymer Processing Society $24^{\text {th }}$ Annual Meeting, 2008.

5) G. Santos, V. Deichmann, W. Simões, F. J. Fonseca, A. M. Andrade, L. Ackcelrud e L. Pereira; "Improvement of Europium based Organic Light Emitting structure using a polymeric conductive host”. Polymer Processing Society $24^{\text {th }}$ Annual Meeting, 2008.

6) A. Amaral, G. Lavareda, N. Carvalho, G. Santos, F. J. Fonseca, A. M. Andrade, W. Simões e L. Pereira; "Organic light emitting diode on ultra-thin flexible substrate: target to a new area on plastic electronics". $2^{\text {nd }}$ International Conference on Advanced Nano Materials (ANM), 2008.

7) G. Santos, F. J. Fonseca, A. M. Andrade, I. Grova, L. Ackcelrud, W. Simões, L. Pereira; "A new polymer Light Emitting Diode using PFT - poly $\left(9,9^{\prime}\right.$-n-dihexil2,7fluorenodiilvinileno-alt-2,5tiofeno)". $2^{\text {nd }}$ International Conference on Advanced Nano Materials (ANM), 2008.

8) S. S. Braga, A. C. Coelho, I. Gonçalves, G. Santos, F. J. Fonseca, A. M. Andrade, L. Rino e L. Pereira; "Modifying emissive complexes for Organic Light Emitting Diode by nanoencapsulation of charge molecules ligands: the case of TRIMEB.Eu(BTA)3.2H2O". $2^{\text {nd }}$ International Conference on Advanced Nano Materials (ANM), 2008.

9) L. Rino, W. Simões, G. Santos, F. J. Fonseca, A. M. Andrade, V. A. F. Deichmann, L. Ackcelrud, I. Pereira; "Photo and Electroluminescence behavior of $\mathrm{Tb}(\mathrm{ACAC}) 3$ phen complex used as emissive layer on Organic Light Emitting Diode". $\mathbf{9}^{\text {th }}$ international Workshop on Non-Crystalline Solids, 2008.

G. Santos - Escola Politécnica da Universidade de São Paulo - OLEDs, PLEDs e LECs 


\section{REFERÊNCIAS BIBLIOGRÁFICAS}

[1] Burroughes, J. H. et al. "Light-emitting diodes based on conjugated polymers". Nature, .v 347, p. 539-541, 1990.

[2] Santos, J. C. B.; "Estudo de Camadas Transportadoras de Cargas em Diodos Emissores de Luz Poliméricos". Dissertação de Mestrado, Escola Politécnica da Universidade de São Paulo, 2007.

[3] Burroughes et al.; "Light-emitting diodes based on conjugated polymers", Nature, v. 347, 1990, p. 539.

[4] Brütting, W.; Berleb, S., Mückl, A. G.; "Devices physics of organic light-emitting diodes based on molecular materials". Organic Electronics, .v 2, p. 1-36, 2001.

[5] Hughes, et al.; "Application of amorphous silicon field effect transistor in addressable liquid crystal display panels". Applied Physics A, v, 24, nº 4, p. 357-362, 1981.

[6] Allen, K. J.; "Reel to Real - Prospects for Flexible Displays", Proceedings of the IEEE v. 93, 2005, p. 1394.

[7] Kido, J. And Okamoto, Y.; "Organo Lanthanide Metal Complexes for Electroluminescent Materials", Chemical Reviews v. 102, 2002, p. 2357.

[8] Kido, J. et al.; "Bright red light-emitting organic electroluminescent devices having europium complex as an emitter ".Applied Physics Letters, v. 65, $n^{\circ} 17$, p. 2124-2126, 1994.

[9] Kido et al., "Organic electroluminescent devices using lanthanide complex". Journal of Alloys Compounds, .v 192, p. 30.33, 1993.

[10] "half-width (of a band)". IUPAC Compendium of Chemical Terminology, site: http://www.iupac.org/goldbook/H02723.pdf acesso em: 01/12/2006.

[11] Choy, C. H. W.; Liang, C. J.; "Color tunable organic light-emitting diodes by using europium organometallic complex", Appl. Phys. Lett. v. 89, 2006, p. 251108.

[12] $\mathrm{Li}$ et al.; Improved performance of electroluminescence device based on an europium complex", Appl. Phys. Lett. v. 76, 2000, p. 67.

[13] Huang, C.; "Electroluminescence of a novel terbium complex", Appl. Phys. Lett. v. 72, 1998, p. 2217.

[14] Eliseeva et al.; "Photo and Electroluminescence of Lanthanide(III) Complexes", Russ. Jour. Of Inorg. Chem. v. 51, 2006, 73.

[15] Rubner, M. F.; "Solid-State Light-Emitting Devices Based on the Tris-Chelated Ruthenium(II) Complex 2. Tris (bypiridyl)ruthenium(II) as a High-Brightness Emitter". Journal of the American Chemical Society, .v 121, p. 3525-3528, 1999. 
[16] Liu, S. et al, "Red electrophosphorescence devices based on rhenium complex". Applied Physics Letters, v. 83, n², p. 365-367, 2003.

[17] Malliaras, G. G.; "Solid-state electroluminescence devices based on transitions metal complexes". Chemical Communications, p. 2392-2399, 2003.

[18] Heeger, A. J. et al.; "Electrophosphorescence from a polymer Guest-Host system with an Iridium Complex as Guest: Föster Energy Transfer and Charging Trapping". Advanced Functional Materials, v. 13, p. 439-444, 2003.

[19] Chan et al.; "Trifuctional Light-Emitting Molecules based on Rhenium and Ruthenium bipypidine Complexes, Adv. Mat., v. 10, 1998, p. 1337.

[20] Huang, W. et al., "Synthesis and Luminscence Properties of Novel Eu-Containing Copolymers Consisting of Eu(III)-Acrylate-beta-Diketonate Complex Monomers and Methyl Methacrylate". Chemistry Materials, v. 12, p. 2212-2218, 2000.

[21] Zinner, K. et al., "Luminescence and structure of Europium compounds". Coordination Chemistry Reviews, .v 196, p. 352-382, 2000.

[22] Kido, J.; Okamoto, Y.; "Organo Lanthanide Metal Complexes for Eletroluminescent Materials". Chemical Review, v. 102, p. 2357-2368, 2002.

[23] Aspinall, H. C.; "Chemistry of the f-block elements". Advanced Chemistry Texts, v. 5, Ed. Gordon and Breach, 2001.

[24] Föster, T., "Transfer mechanims of electronic excitation". $10^{\text {th }}$ Spiers Memorial Lecture, p. 7-17, 1959.

[25] Dexter, D. L.; "A Theory of Sensitized Luminescence in Solids". The Journal of Chemical Physics, v. 1, n 5, p. 836-850, 1953.

[26] Hebbink, G.; "Luminescent materials based on Lanthanides lons". PhD. Thesis, University of Twente, Netherlands, 2002.

[27] E. P. S., Teotonio; "Síntese e investigação das propriedades fotoluminescentes de dispositivos moleculares conversores de luz (DMCL) de complexos dicetonatos de terras raras com ligantes amidas". Tese de Doutorado, Universidade de São Paulo, Instituto de Química, 2004.

[28] G., Urbain; Bull. Soc. Chim., vol 15, p. 347, 1896.

[29] W. R., Dawson; J. L., Kropp; M. W., Windsor; J. Chem. Phys., v. 45, p. 2409, 1966.

[30] S., Sato; M., Wada; Bull. Chem. Soc. Jpn., v. 43, p. 1955, 1970.

[31] Dexter, D. L.; "A theoryof sinthetized luminescence in solids". Journal of Chemical Physics, v. 21, p. 836-850, 1953.

[32] Huang, C. H. et al; "Bright red light-emitting electroluminescence devices based on a functionalized europium complex".New Journal of Chemistry, v. 27, p. 1731-1734, 2003. 
[33] Friend, R. H. et al.; "Electroluminescence in conjugated polymers". Nature, v. 397, no 14, p. 121-128, 1999.

[34] Kido, J. et al.; "Electroluminescence in Terbium Complex". Chemistry Letter, v. 19, p. $657-660,1990$.

[35] Fang. et al. "High-efficiency spin-coated prganic light-emitting diodes based on a europium complex". Thin Solid Films, v. 515, p. 2419-2422.

[36] Juris, A; Balzani, V.; Barigelletti, F.; Campagna, S.; Belser, P e Zelewsky, A. Von; "Ru(II) polipiridine complexes: photophysics, photochemistry, electrochemistry and chemiluminescence". Coordination Chemistry Reviews, v. 84, p. 85-277, 1988.

[37] Wrighton, M. e Morse, D. L.; "The Nature of the lowest excited state in tricabonylchrolo-1,10-phrnantrolinerhenium(I) and Related complexes". Journal of the American Chemical Society, v. 96, ed. 4, p. 998-1003, 1974.

[38] Evans, R. C.; Douglas, P.; Winscom, C. J.; "Coordinations complexes exhibiting room-temperature phosphorescence: Evaluation of their suitability as triplet emitters in organic light emitting diodes". Coordination Chemistry Reviews, .v 250, p. 2093-2126, 2006.

[39] Mello De, J. C.; Physics Review B, v. 66, 235210-235211, 2002.

[40] Yang, Y.; Pei, Q.; Apllied Physics Letters, v. 68, p. 2708, 1996.

[41] Rudmann, H.; Shimada, S.; Rubner, M. F.; Journal Apllied Physics, v. 94, p. 115, 2004.

[42] Rudmann, H.; Shimada, S.; Rubner, M. F.; Oblas, D. W.; Whittens, J. E.; Journal of Applied Physics, v. 92, p. 1576, 2002.

[43] Yu, G.; Yang, Y.; Cao, Y.; Pei, Q.; Zhang, C.; Heeger, A. J.; Chemistry Physics Letter; v. 259, p. 465, 1996.

[44] Feng Teng, D. L. et al.; "Influence of capacitance effect on alternating-current organic light-emitting diodes". Solid State Communications, v. 137, p. 391-394, 2006.

[45] Shiratori, S. et al.; "Flexible multilayer electrode films consisted of polyaniline and polyelectrolyte by layer-by-layer self-assembly". Colloids and Surface A, 2007, doi:10.1016/j.colsurfa.2007.05.046.

[46] Peierls, R. E.; "Quantum Theory of solids". Claredon, Oxford, 1955.

[47] Bianchi, R. F.; "Estudo das propriedades eletrônicas e ópticas de filmes e dispositivos poliméricos". Tese de Doutoramento, Universidade de São Paulo, Escola de Engenharia de São Carlos, 2002.

[48] Brütting, W., Berleb, S.; Mülckl, Anton G.; "Device physics of organic light-emitting diodes based on molecular materials". Organic electronics, .v 2, p. 1-36, 2001.

G. Santos - Escola Politécnica da Universidade de São Paulo - OLEDs, PLEDs e LECs 
[49] Burrows, P. E.; Shen, Z.; Bulovic, V.; McCarty, D. M.; Forrest, S. R.; Cronin, J. A.; Thompson, M. E., "Relationship between electroluminescence and current transport in organic heterojunction light-emitting devices". Journal of Applied Physics Letters, v. 79, p. 7991-8006, 1996.

[50] Lampert, M. A.; Mark, P. Current Injection in Solids, Academic Press, New York, 1970.

[51] Kao, K.C.; Hwang, W.; Electrical Transport in Solids, Pergamon Press, Oxford, 1981.

[52] Young, R. H.; Phil. Mag. Lett., v 70, p. 331, 1994

[53] Murgatroyd, P.N.; J. Phys. D: Appl. Phys., v. 3, p. 151, 1970.

[54] Borsemberg, P.M.; Weiss, D.S;.Organic Photoreceptorsfor Imaging Sistems, Marcel Dekker, New York, 1993

[55] Forrest, S. R.; Bradley, D. D. C.; Thompson, M. E.; "Measuring the efficiency of Organic Light Emitting Devices”. Advanced Materials, v. 15, p. 1043-1048, 2003.

[56] "Diffuse reclectors - Essencials of Reflections and Table of contents". Gigahertzoptik, p. 123. Site: http://www.gigahertz-optik.de/pdf/catalogue/Diffuse Reflectors.pdf em: 01/07/2008.

[57] "Cores e Sistemas de Cores". Apostila n 11 do Instituto de Ciências Matemáticas e de Computação e Estatística Gráfica. Site: http://www.dpi.ufv.br/disciplinas/inf390/files/pagin...i.icmc.sc.usp.br/documentacao/apostilas/ cg/ap11.html em: 01/05/2008.

[58] "Dominant wavelength and Purity". Technical note $n^{\circ}$ I103, site: www.delta.dk .

[59] DeLongchamp, D.: Hammond, P. T.: "Layer-by-Layer Assembly of PEDOT/Polyaniline Electrochromic devices". Advanced Materials, v. 13, p. 1455, 2001.

[60] Braga, G. S. et al.; "influence of deposition parameters on the morphology and electrical conductivity of PANI/PSS self-assembled filmes". Mat. Sci. Eng. C, v. 28, p. 555562, 2008.

[61] Santos, G. et al., "Organic light-emitting diodes with europium (III) emissive layers base don beta-diketonate complexes: The influence of the central ligand". Journal of Non-Crystallyne Solids, v. 354, p. 2897-2900, 2008 [doi:10.1016/j.jnoncrysol.2007.10.097]

[62] Deichmann, V. A. F.; Novo, J. B. M.; Cirpan, A., Karasz, F. E.; Ackcelrud, L.; "Photoand Electroluminescence bahevior of Eu3+ Ions in blends with poly(vinyl-carbazole)". J.

Braz. Chem. Soc., v. 0, p. 1-7, 2007.

[63] Santos, G.; Fonseca, J. F.; Andrade, A. M.; Braga, S. S.; Coelho, A. C.; Gonçalves, I. S.; Simões, W.; Pereira, L.; "Novel Europium beta-diketonate Complex in Organic Light 
Emitting Diode: Eu(BTA)3bipy[tris(1-(2-benzoyl)-3,3,3-trifluoroacetone))-bipyridine, Europium (III)]". ECS Transactions, n9, v. 1, p. 243-249, 2007.

[64] Kim, J.-S. et al.; "Exciplex emission and energy transfer in white light-emitting organic electroluminescent device". Synthetic Metals, v. 132, p. 285-288, 2003.

[65] Chen, Z.; Deng, Z.; Shi, Y.; Xu, Y.; Xiao, J.; Zhang, Y.; Wang, R.; "Electroluminescent devices based on rare-earth complex $\mathrm{TbY}(\mathrm{p}-\mathrm{MBA})_{6}(\mathrm{phen})_{2}$ ". Journal of Luminescence, v. 122-123, p. 671-673, 2007.

[66] K. Fujimto, J.-H. kim, K. Ohmori, A. Ono, S. Shiratori, Flexible multilayer electrode films consisted of polyaniline and polyelectrolyte by layer-by-layer self-assembly, Colloids and Surfaces A: Physicochemical and Engineering Aspects (2007), doi:10.1016/j.colsurfa.2007.05.046

[67] Dirani et al.; "Influence of polyaniline and phthalocyanine hole-transport layers on the electrical performance of light-emitting diodes using MEH-PPV as emissive material". Thin Solid Films, v. 516, p. 3184-3188, 2008.

[68] Santos, G. et al.; "Opto-electrical properties of single layer flexible electroluminescence device with ruthenium complex". Journal of Non-Crystalline Solids, .v 354, p. 2571-2574, 2008.

[69] David, G.; Walsh, P. J.; Gordon, K. C.; "Red Electroluminescence from transparent PVK-dye films based on on dipyrido[3,2-a:20,30-c]phenazine and $\operatorname{Re}(\mathrm{CO}) 3 \mathrm{Cl}$-dipyrido[3,2a:20,30-c]phenazine dyes". Chemical Physics Letters, v. 383, p. 292-296, 2004.

[70] Bian, Z.; Gao, D., Wang, K.; Jin, L.; Huang, C.; "Pure red electroluminescent devices using a novel europium (III) complex as emitting layer". Thin Solid Films, v. 460, p. 237241, 2004.

71 Ling, Q. D.; Cai, Q. J.; Kang, E. T.; Neoh, K. G.; Zhu, F. R.; Huang, W.; "Monochromatic light-emitting copolymers of $\mathrm{N}$-vinylcarbazole and Eu-complex 4-nivylcarbazole and their single layer high luminance PLEDs". Journal of Materials Chemistry, .v 14, p. 2741-2748, 2004.

[72] Santos, G. et al. "Electro-optical measurements, stability and physical charge behavior of rare-earth based organic light emitting diode". SPIE Digital Library, Organic Light Emitting Materials and Devices XI, v. 6655, p. 66551V-1 - 66551V-7, 2007.

[73] Zhang et al. "Synthesis and electroluminescent properties of a novel terbium complex". Synthetic Metal, v. 114, p. 321-323, 2000.

[74] Xin, H.; Li, F. Y.; Shi, M.; Bian, Z. Q., Huang, C. H.; "Efficient Electroluminescent from a New Terbium Complex". Journal of American Chemical Society, v. 125, p. 71667167, 2003. 
[75] Papadimitrakopoulos, F. et al.; "Light emitting diodes prepared from TerbiumImmobilized Polyurea Chelates". Journal of Macromolecular Science, .v A40, $n^{0} 12, p$. 1253-1262, 2003.

[76] Huang, L.; Tian, H.; Li, F.-Y.; Gao, D.-, Q.; Huang, Y.-, Y.; Huang, C.- H.; "Blue organic electroluminescent devices based on a dystyrylarylene derivade as emitting layer and a terbium complex as electron-transport layer". Journal of Luminescence, v. 97, p. 5559, 2002.

[77] Koppe, M., "Organic rare earth complexes in plymer matrices and light emitting diodes". Mol. Cryst. Liq. Cryst., v. 385, p. [221]/101 - [231]/231, 2002.

[78] Lee, C.-L.; Kang, N.-G.; Cho, Y.-S.; Lee, J.-S.; Kim, J.-J.; "Polymer electroluminescent device: comparison of phosphorescent dye doped and coordinated systems". Optical Materials, v. 21, 119-123, 2002.

[79] Miyamoto, Y.; Uekawa, M.; Ikeda, H.; Kaifu, K.; "Electroluminescent properties of a Eu-complex doped in phosphorescent materials". Journal of Luminescence, v. 81, p. 159164, 1999.

[80] Lin, Q.; Shi, C. Y.; Liang, Y. J.; Zheng, Y. X., Wang, S. B.; Zhang, H. J.; "Green electroluminescence generate from the thin film based on a soluble lanthanide complex!. Synthetic Metals, v. 114, p. 373-375, 2000.

[81] Amaral, T. P. e tal., "Estudo das propriedades de compósitos de polianilina e resinas epoxídica”. Polímeros. Ciência e Tecnologia, v. 11, n³, p. 149-157, 2001.

[82] "Luz e Cor - Sistemas Gráficos/Computação gráfica e interfaces". Faculdade de Engenharia da Universidade do Porto. Acesso em: http://paginas.fe.up.pt/ aas/pub/Aulas/CGI/Slides/07 Cor.pdf em: 01/04/2008.

[83] Pingsheng, H. et al. "Fabrication and characterization og Langgmuir-Blodgett films based on rare earth beta-diketonate complexes". Thin Solids Films, v. 468, p. 268-272, 2004.

[84] Jernigan, J.C.; Surridge, N.A.; Zvanut, M.E.; Silver, M.; Murray, R.W.; J. Phys. Chem.,v. 93, p. 4620, 1989.

[85] Gordon, K. C.; Walsh, P. J.; McGale; E. M.; "Electroluminescence from PVK-based polymer blends with metal complex dyes". Current Applied Physics, v. 4, p. 331-334, 2004. [86] Liang, C. J.; Wong, T. C.; Hung, L. S.; Lee, S. T.; Hong, Z. R.; Li, W. L.; "Selfquenching of excited europium ions in $\mathrm{Eu}(\mathrm{DBM}) 3$ bath-based organic electroluminescent devices”. Journal of Physics D: Applied Physics, v. 34, p. L61-L64, 2001. 
[87] Lundin, N. J.; Blackman, A. G.; Gordon, K. C.; Officer, D. L.; "Synthesis and Characterization of a Multicomponent Rhenium(I) Complex for Application as an OLED Dopant". Angenwandte Chemie International Edition, .v 45, p. 2582-2584, 2006. 